GLENDA MARIA COLIM

ESTUDO DOS FATORES QUE AFETAM A TRANSFERÊNCIA DE CARGA EM JUNTAS DE PAVIMENTOS DE CONCRETO SIMPLES 
GLENDA MARIA COLIM

Engenheira Civil, Universidade Estadual de Goiás

\section{ESTUDO DOS FATORES QUE AFETAM A TRANSFERÊNCIA DE CARGA EM JUNTAS DE PAVIMENTOS DE CONCRETO SIMPLES}

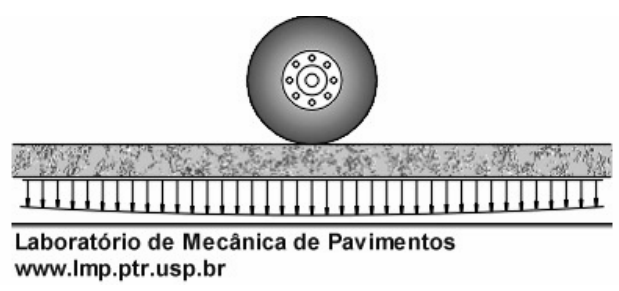

Dissertação apresentada à Escola Politécnica da Universidade de São Paulo para a obtenção do título de Mestre em Engenharia

Área de Concentração:

Engenharia de Transportes

Orientador:

José Tadeu Balbo 


\section{FICHA CATALOGRÁFICA}

\section{Colim, Glenda Maria}

Estudo dos fatores que afetam a transferência de carga em juntas de pavimentos de concreto simples / G.M. Colim. -- São Paulo, 2009.

$155 \mathrm{p}$.

Dissertação (Mestrado) - Escola Politécnica da Universidade de São Paulo. Departamento de Engenharia de Transportes.

1. Pavimentação de concreto 2. Juntas estruturais I. Universidade de São Paulo. Escola Politécnica. Departamento de Engenharia de Transportes II. t. 


\section{DEDICATÓRIA}

Dedico este trabalho a meus familiares e amigos. 


\section{AGRADECIMENTOS}

Ao professor Dr. José Tadeu Balbo, de quem tive todo o apoio e orientação para a realização deste trabalho. Pela sua atenção e paciência em me ensinar.

Ao professor Dr. Lev Khazanovich, professor visitante na USP em 2006, da Universidade de Minnesota e autor do programa ISLAB2000, pela sua colaboração na essência geral deste trabalho, ou seja, implantação do programa e treinamento nos processos de retroanálises.

Aos professores Dr. Antônio Figueiredo e Dr. Libânio Miranda Pinheiro pela participação na banca examinadora do exame de qualificação, por suas observações e sugestões no aprimoramento do meu projeto.

Ao Conselho Nacional de Desenvolvimento Científico e Tecnológico, CNPq, pela bolsa cedida e aproveitada em meus estudos durante os 24 meses de trabalho.

À DYNATEST por ter cedido o equipamento de FWD para a realização dos testes.

À minha amiga Taís Sachet, pela sua alegria contagiante e sua força em enfrentar obstáculos, me incentivando a ser mais forte em momentos de fraqueza e desânimo.

A todos os meus colegas de curso, em especial Afonso Virgillis, Daniela Bonina, Eduardo Mallmann e John Paul pelo apoio e a amizade criada.

Enfim, à minha família por todo o apoio, incentivo, compreensão e carinho. 


\section{EPÍGRAFE}

"O sucesso nunca é permanente, o fracasso nunca é total. Mas o que vale é a coragem de lutar... e vencedor é aquele que acredita em si próprio, em sua capacidade de superar obstáculos..." hoje posso dizer que venci mais um obstáculo.

Aos meus pais, Carlos Eduardo Colim e Maria Eterna do Prado, responsáveis pela minha formação moral e social. Aos meus tios José Francisco Cunha e Maura Colin Cunha por me acolherem com muito amor e me ensinarem valores que eu desconhecia. A todos vocês fica meu eterno amor e gratidão. 


\section{RESUMO}

Este trabalho de pesquisa foi realizado na busca de melhor entendimento do comportamento estrutural de pavimentos de concreto no que tange a transferência de carga em juntas, de quais os fatores que influenciam essa transferência de esforços nas juntas e a determinação, em caráter preliminar, de como as condições climáticas vigentes na área tropical dos estudos afeta o fenômeno. Para a realização dos experimentos foi empregada a pista experimental USP/FAPESP, construída em 1999, e até então não empregada para a determinação dos efeitos de transferência de cargas em juntas com e sem barra de transferência de carga. Paralelamente, para retroanalisar os parâmetros de transferência de carga, foram necessárias a avaliação e a análise estrutural de respostas a carregamentos dinâmicos das placas de concreto da pista experimental, possibilitando a determinação de diversos parâmetros em jogo, em especial, do módulo de elasticidade de concretos e do módulo de reação do subleito. Os estudos permitiram determinar que a ausência de barras de transferência de cargas em juntas transversais torna menos eficiente tal transferência além de apresentar nesse caso forte dependência da temperatura do concreto. Em juntas com barras de transferência de carga, para qualquer época do ano, a transferência de cargas é sempre igual ou superior a 90\%, aproximadamente, independentemente da geometria das placas. Não existindo tais dispositivos o valor da transferência de cargas variou de 60 a 75\%. Não foram observadas dependências importantes quanto a diferentes níveis de carregamento durante os testes, bem como para espessuras de placas de concreto, em placas com barras de transferência. Observou-se, também, embora em escala inferior ao que se narra na literatura passada, que o módulo de reação do subleito para carga de borda é maior que aquele para carga de centro. As faixas de valores de módulos de elasticidade para concretos de placas e para concretos compactados com rolo em sub-bases coincidiram com as faixas de valores encontrados em laboratório com medidas efetuadas na época da construção dos pavimentos. O processo de retroanálise com o programa ISLAB2000 mostrou-se um recurso valioso para a parametrização dos pavimentos de concreto estudados. 


\begin{abstract}
This research was proposed aiming an in deep study of the mechanism of load transfer across concrete pavement joints including the analysis of which factors influence such load transfers with special regards to the climate factors as concrete temperature. The concrete pavements under study were built in 1999 as a research supported by FAPESP, whose experimental sections has not been used before for such a goal. Backcalculation techniques were employed to analyze deflection data collected with FWD tests over the slabs and it was possible to define values for the test sections materials parameters like concrete modulus of elasticity and the modulus of subgrade reaction. Tests detected loss of load transfer efficiency on the dependence of concrete temperature for non dowelled joints. For dowelled joints, whatever the season of the year or period of the day, joint load transfer efficiency was at least 90\% approximately. However, without dowels, efficiency ranged from 60 to $75 \%$. No expressive dependence on the load level was observed during tests, as well as on the slab thicknesses, for cases of dowelled joints. It was observed the increase in the value of the modulus of subgrade reaction when loads were applied in joint position, although not so expressive as sometimes described in the literature. Ranges for concrete and rolled compacted concrete modulus of elasticity resulted similar to former values got from the construction period in laboratory. Therefore, backcalculation procedures using ISLAB2000 software is understood as a valuable tool for concrete slab characterization.
\end{abstract}




\section{LISTA DE FIGURAS}

Figura 1.1 Juntas transversais serradas em pavimentos de Concreto de Cimento Portland (CCP), em corte

Figura 1.2 Juntas de expansão

Figura 1.3 Esquema de junta transversal com barra de transferência de carga 24

Figura 1.4 Esquema de juntas longitudinais e transversais 25

Figura 1.5 (Esquerda) sem transferência de carga; (Direita) total transferência de carga 25

Figura 1.6 Deflexões nas placas carregada e descarregada 26

Figura 2.1 Perda de transferência de carga durante ensaios com placas em laboratório (fonte: FLEURY; GUIMARÃES, 2006)

Figura 2.2 Temperatura versus movimento das placas (adaptado de BODOCSI et al., 1993) 38

Figura 2.3 Abertura da junta versus mudança de temperatura no pavimento de concreto (KHAZANOVICH; GOTLIF, 2003) 39

Figura 2.4 Abertura da junta em diferentes tipos de pavimentos, em um mesmo dia adaptado de: KHAZANOVICH; GOTLIF, 2003) 40

Figura 2.5 LTE versus abertura da junta (KHAZANOVICH e GOTLIF, 2003) 41

Figura 2.6 Influência da abertura da junta no LTE (adaptado de: NISHIZAWA et al., 1989)

Figura 2.7 Exemplo de movimento de junta (adaptado de: LEE; STOFFELS, 2001)

Figura 2.8 Exemplo de congelamento de junta (adaptado de: LEE; STOFFELS, 2001) 
Figura 2.9 Esquema do empenamento da placa durante o dia e à noite. (Buch et al., 2004)

Figura 2.10 Esquema da placa sem empenamento (BUCH et al., 2004) 46

Figura 2.11 Distribuição de temperatura no pavimento (adaptado de: BUCH et al., 2004)

Figura 2.12 Posição do carregamento na placa de CCP (vista de topo) 50

Figura 2.13 Colocação de barras (SNYDER, 2007) 55

Figura 2.14 Pavimentadora inserindo barras de transferência de carga na execução do pavimento de concreto 55

Figura 2.15 Distribuição dos esforços nas BT em junta transversal 56

Figura 2.16 Modelos mecanicistas de LTE versus AGG 61

Figura 2.17 - Eficiência de junta moldada versus carga aplicada. Fonte: Tertuliano, 2005 64

Figura 2.18 - Eficiência de junta serrada versus carga aplicada (TERTULIANO, 2005) 65

Figura 2.19 LTE em função da carga aplicada em junta serrada utilizando como mecanismo de transferência de carga barras circulares e quadradas. (RODRIGUES, 2008) 66

Figura 2.20 LTE em função da carga aplicada em junta serrada utilizando como mecanismo de transferência de carga prato e discos metálicos. (RODRIGUES, 2008)

Figura 2.21 Exemplo de variação do LTE ao longo de um dia (Adaptado de: SHAHIN, 1985) 67

Figura 2.22 Fatores de correção de LTE segundo Shahin (1985) 68

Figura 2.23 Fluxograma de procedimentos usados para determinação do k, do LTE e do índice de vazios. (Adaptado de: SHAHIN, 1985) 69

Figura 2.24 Relação entre abertura da junta e espessura da placa de concreto (adaptado de: ZOLLINGER, 2007) 70 
Figura 3.1 Seções em planta da pista experimental (sem escala) 76

Figura 3.2 Seções em corte da pista experimental (sem escala) 76

Figura 3.3 Vista da pista experimental da USP 77

Figura 3.4 Fissuras transversais na superfície da pista experimental 77

Figura 3.5 Esquema da situação atual da pista experimental da EPUSP (julho de 2006) 78

Figura 3.6 Fissura na placa A3 da pista experimental 78

Figura 3.7 Falling Weight Deflectometer 79

Figura 3.8 FWD na pista experimental da USP 80

Figura 3.9 Bacias de deflexões com testes com FWD na pista experimental da USP 80

Figura 3.10 Testes com FWD na pista experimental USP/FAPESP, em julho de 2006 81

Figura 3.11 Posições das cargas em cada placa de concreto da pista experimental da USP 82

Figura 3.12 Posição do prato na junta da placa de concreto 83

Figura 3.13 Posicionamento de cada sensor na placa de concreto, pelo FWD 84

Figura 3.14 Posicionamento do prato de aplicação de carga na placa de concreto .84

Figura 3.15 Tela para entrada de dados sobre geometria das placas e discretização da malha 88

Figura 3.16 Tela para entrada de dados sobre as propriedades das camadas (placa e base) 88

Figura 3.17 Tela para entrada de dados sobre a fundação 89

Figura 3.18 Tela para entrada de dados sobre o carregamento aplicado 89 
Figura 3.19 Informações sobre transferência de cargas em juntas 89

Figura 3.20 Tela principal com problema montado para rodada 90

Figura 3.21 Exemplo de bacias de deflexões 100

Figura 3.22 Fluxograma dos procedimentos deste estudo 101

Figura 4.1 Bacias de deflexões nos centros das placas das seções A e B da pista experimental USP/FAPESP 104

Figura 4.2 Bacias de deflexões nos centros das placas das seções A e D da pista experimental USP/FAPESP 104

Figura 4.3 Bacias de deflexões nos centros das placas das seções B e C da pista experimental USP/FAPESP 105

Figura 4.4 Bacias de deflexões nas juntas das seções A e B da pista experimental USP/FAPESP 109

Figura 4.5 Bacias de deflexões nas juntas das seções B e C da pista experimental USP/FAPESP

Figura 4.6 Bacias de deflexões nas juntas das seções A e D da pista experimental USP/FAPESP

Figura 4.7 Variações entre deflexões na junta E3 sem BT 111

Figura 4.8 Valores de módulo de reação retroanalisados (centro das placas) ...... 118

Figura 4.9 Valores de kb nos testes realizados em julho/2006 121

Figura 4.10 Valores de kb nos testes realizados em janeiro/2007 122

Figura 411 Valores de LTE nas juntas, durante o inverno de 2006 125

Figura 4.12 Valores de LTE nas juntas, durante o verão de 2007 126

Figura 4.13 Transferência de carga de manhã e à tarde no inverno de 2006 em placas com tipos de bases diferentes 127

Figura 4.14 Curvas extraídas da equação de Buch relacionando o grau de transferência de carga com o valor de AGG 128 
Figura 4.15 Comparações entre LTE, com os três diferentes níveis de carga ...... 130 Figura 4.16 Comparação entre LTE medido e retroanalisado em juntas com BT . 132 Figura 4.17 Comparação entre LTE medido e retroanalisado em juntas com BT . 133 Figura 4.18 Comparação entre LTE medido e retroanalisado em juntas sem BT . 134 Figura 4.19 Valores de $k_{\text {borda }}$ retroanalisado versus $L T E_{\text {medido }}$ 141

Figura 4.20 Valores de $\mathrm{k}_{\text {borda }}$ versus $\mathrm{k}_{\text {centro }}$ 142 


\section{LISTA DE TABELAS}

Tabela 2.1 Movimentos das juntas serradas transversais (BODOCSI et al., 1993) . 16

Tabela 2.2 Dimensões das barras de transferência de carga (adaptado de: RODRIGUES; CASSARO, 1998) 35

Tabela 3.1 Características das seções experimentais em pavimento de concreto na USP 54

Tabela 3.2 Diferencial térmico em cada placa de pavimento de concreto na pista experimental

Tabela 3.3 Diferenciais térmicos nos anos de 2006 e 2007 64

Tabela 3.4 Retroanálise de E e k, e valores de deflexões no centro da placa A2 (E tentativo $=40.000 \mathrm{MPa})$

Tabela 3.5 Retroanálise de E e k, e valores de deflexões no centro da placa A2 (E tentativo $=42.500 \mathrm{MPa})$

Tabela 3.6 Retroanálise de E e k, e valores de deflexões no centro da placa A2 (E tentativo $=45.000 \mathrm{MPa})$

Tabela 3.7 Retroanálise de E e k, e valores de deflexões no centro da placa A2 (E tentativo $=47.500 \mathrm{MPa})$

Tabela 3.8 Retroanálise de E e k, e valores de deflexões no centro da placa A2 (E tentativo $=9.000 \mathrm{MPa})$

Tabela 3.9 Retroanálise de E e k, e valores de deflexões no centro da placa A2 (E tentativo $=52.500 \mathrm{MPa}$ )

Tabela 3.10 Retroanálise de $E$ e k, e valores de deflexões no centro da placa A2 (E tentativo $=55.000 \mathrm{MPa}$ ) 
Tabela 3.11 Retroanálise de E e k, e valores de deflexões no centro da placa A2 (E tentativo $=57.500 \mathrm{MPa})$

Tabela 3.12 Retroanálise de E e k, e valores de deflexões no centro da placa A2 (E tentativo $=60.000 \mathrm{MPa})$

Tabela 3.13 Retroanálise de E e k, e valores de deflexões no centro da placa A2 (E tentativo $=62.500 \mathrm{MPa})$ 75

Tabela 3.14 Retroanálise de E e k, e valores de deflexões no centro da placa A2 (E tentativo $=65.000 \mathrm{MPa})$ 75

Tabela 3.15 Retroanálise de E e k, e valores de deflexões no centro da placa A2 (E tentativo $=67.500 \mathrm{MPa})$ 76

Tabela 3.16 Retroanálise de E e k, e valores de deflexões no centro da placa A2 (E tentativo $=70.000 \mathrm{MPa})$ 76

Tabela 3.17 Retroanálise de E e k, e valores de deflexões no centro da placa A2 . 78

Tabela 3.18 Retroanálise de E e k, e valores de deflexões no centro da placa A2 . 78 Tabela 3.19 Retroanálise de E e k, e valores de deflexões no centro da placa A2 . 79 Tabela 4.1 Valores de deflexões no centro da placa de concreto, com três níveis de carga

Tabela 4.2 Deflexões medidas pelo FWD pela manhã no inverno (2006) 84

Tabela 4.3 Deflexões medidas pelo FWD no período da tarde no inverno (2006) .. 85 Tabela 4.4 Deflexões medidas pelo FWD no período da tarde no verão (2007) ..... 86 Tabela 4.5 Deflexões medidas pelo FWD no período da noite no verão (2007) ...... 87 Tabela 4.6 Resultados de E e k pelo critério de Hall (1991) na seção A 90 
Tabela 4.8 Resultados de E e k pelo critério de Hall (1991) na seção C 91

Tabela 4.9 Resultados de E e k pelo critério de Hall (1991) na seção D 92

Tabela 4.10 Resultados de E e k pelo critério de Hall (1991) na seção E 92

Tabela 4.11 Resumo dos resultados de E e k pelo critério de Hall (1991) 94

Tabela 4.12 Resumo dos valores de E e k retroanalisados 95

Tabela 4.13 Valores de LTE e kb (de borda) nos testes realizados em julho/2006 ... 98

Tabela 4.14 Valores de LTE e $k_{b}$ (de borda) nos testes realizados em março/2007.. 99

Tabela 4.15 Resultados de LTE (em \%) a partir dos testes com diferentes níveis de carga 102

Tabela 4.16 Resultados do LTE em 2006 e 2007 103

Tabela 4.17 Valores retroanalisados e medidos de LTE 108

Tabela 4.18 - Resumo de valores de LTE retroanalisados e medidos em campo 110

Tabela 4.19 - Média dos valores de LTE retroanalisados e medidos em campo, em juntas com BT 111

Tabela 4.20 - Média dos valores de LTE retroanalisados e medidos em campo em juntas sem BT 112

Tabela 4.21 Dosagem do concreto de cimento Portland da pista experimental .... 114

Tabela 4.22 Dosagem do CCR da pista experimental 114

Tabela 4.23 Módulo de elasticidade em tração na flexão do CCP na pista experimental 115 
Tabela 4.24 Módulo de elasticidade em compressão de amostras aos 28 dias do CCR empregado na pista experimental

Tabela 4.25 Valores de módulos de elasticidade obtidos em laboratório 116

Tabela 4.26 Módulos de elasticidade retroanalisados para o CCR 117

Tabela 4.27 Resultados de retroanálises de módulo de reação do subleito no centro da placa e na borda, em todos os testes realizados 118

Tabela 4.28 Limites mínimos e máximos arredondados de k de centro e de borda 119 


\section{LISTA DE ABREVIATURAS E SIGLAS}

AASHTO American Association of State Highway and Transportation Officials

ACPA American Concrete Pavement Association

$\mathrm{ACl} \quad$ American Concrete Institute

AGG Aggregate Interlock

BGTC Brita Graduada Tratada com Cimento

BGS Brita Graduada Simples

BT Barra de Transferência de Carga

CCP Concreto de Cimento Portland

CCR Concreto Compactado com Rolo

CNPq Conselho Nacional de Desenvolvimento Científico e Tecnológico

EPUSP Escola Politécnica da Universidade de São Paulo

FAPESP Fundação de Amparo à Pesquisa do Estado de São Paulo

FWD Falling Weight Deflectometer

FHWA Federal Highway Administration

GFRP Glass Fiber Reinforced Polymer

JPCP Jointed Plain Concrete Pavement 


$\begin{array}{ll}\text { LTE } & \text { Load Transfer Efficiency } \\ \text { LTPP } & \text { Long Term Pavement Performance } \\ \text { LVDT } & \text { Linear Variable Differential Transformer } \\ \text { MEF } & \text { Método dos Elementos Finitos } \\ \text { NHCRP } & \text { National Highway Cooperative Research Program } \\ \text { PCA } & \text { Portland Cement Association } \\ \text { PMSP } & \text { Prefeitura Municipal de São Paulo } \\ \text { SMP } & \text { Seasonal Monitoring Program } \\ \text { TRB } & \text { Transportation Research Board } \\ \text { TRR } & \text { Transportation Research Record } \\ \text { USP } & \text { Universidade de São Paulo }\end{array}$




\section{LISTA DE SÍMBOLOS}

Coeficiente de expansão térmica do concreto

$\delta_{1} \quad$ Deflexão na placa carregada

$\delta_{2} \quad$ Deflexão na placa descarregada

$\delta_{T} \quad$ Movimento Horizontal

$\Delta T \quad$ Variação de Temperatura

$v \quad$ Coeficiente de Poisson

$\sigma \quad$ Tensão de tração na flexão

A Fator de correção do LTE, em relação à deflexão na junta

AREA Área da bacia de deflexões

AGG Módulo em cisalhamento entre faces verticais

a Raio do prato de aplicação de carga

b Diâmetro da barra de transferência de carga

$d_{0} \quad$ Deflexão sob a carga aplicada

$d_{30} \quad$ Deflexão a $300 \mathrm{~mm}$ do centro da carga aplicada

$d_{65} \quad$ Deflexão a $650 \mathrm{~mm}$ do centro da carga aplicada

$d_{90} \quad$ Deflexão a $900 \mathrm{~mm}$ do centro da carga aplicada

$D T+\quad$ Diferencial térmico máximo positivo 
Módulo de elasticidade do concreto

F

Fator de correção do LTE, em relação à temperatura

$H_{f} \quad$ Umidade no fundo da placa de concreto

$h \quad$ Espessura da placa

$k$

Módulo de reação do subleito

$I$

Momento de inércia da seção transversal da barra de transferência

$\ell \quad$ Raio de rigidez relativa

L Comprimento da placa

$P \quad$ Esforço ou carga atuante

$x$

Espaçamento entre barras de transferência de carga 


\section{SUMÁRIO}

1 INTRODUÇÃO

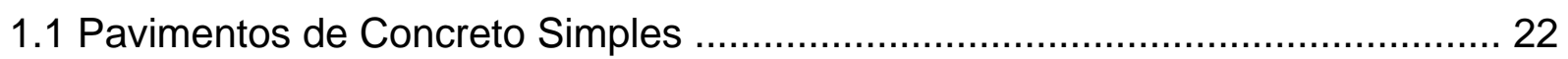

1.2 Tipos de Juntas em Pavimentos de Concreto ................................................ 23

1.3 Transferência de Carga em Juntas ............................................................. 25

1.4 Motivação e Justificativas para o Estudo ...................................................... 27

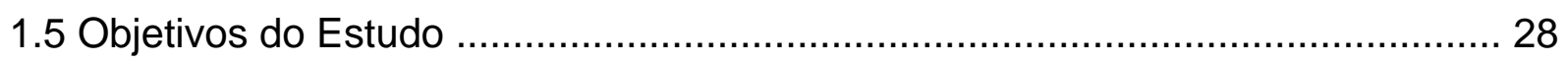

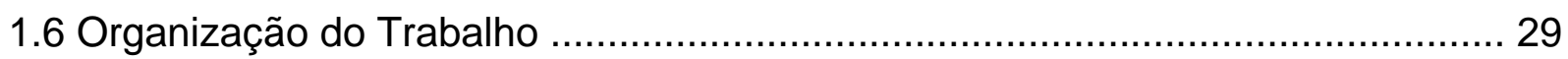

2 PRINCIPAIS ASPECTOS RELATIVOS À TRANSFERÊNCIA DE CARGA EM

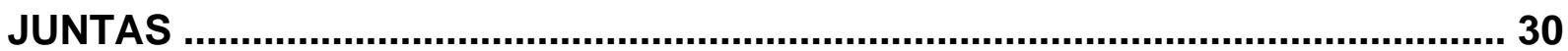

2.1 Evoluções nos Conceitos de Juntas em Pavimentos de concreto Simples ........ 30

2.2 Abertura de Juntas por Efeitos da Temperatura ............................................ 36

2.3 Efeitos da Temperatura na Transferência de Carga ........................................ 45

2.4 Formulações de Esforços na Transferência de Carga ......................................... 49

2.4.1 Tipos de Barras de Transferência e sua Disposição em Juntas ..................... 52

2.4.2 Esforços nas Barras de Transferência .......................................................... 55

2.4.3 Transferência de Carga por Intertravamento de Agregados .......................... 58

2.4.4 Modelos Mecanicistas de LTE com Intertravamento de Agregados ................ 60

2.5 Medidas de Transferência de Cargas em Juntas ............................................. 62

2.6 Variações Diárias da Transferência de Cargas em Juntas ................................ 66

2.7 Efeitos da Fundação na Abertura de Juntas ................................................... 69

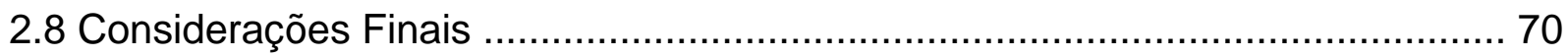

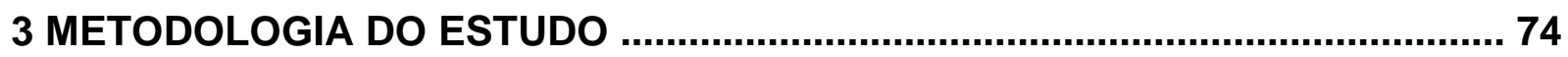

3.1 Objetivos e Metodologia para Medição do LTE ……………………………...... 74

3.2 Descrição da Pista Experimental USP/FAPESP.................................................. 75

3.3 Procedimentos de Avaliação de Deflexões em Pista ........................................ 79

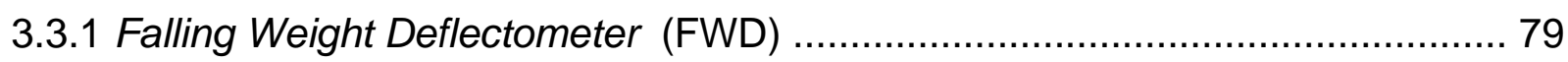

3.3.2 Medidas de Deflexões com Carga no Centro da Placa .................................. 81

3.3.3 Medidas de Deflexões com Carga na Junta da Placa ................................... 83

3.4 Estimativa de Parâmetros Estruturais antes da Retroanálise ............................ 85 
3.5 Procedimentos de Retroanálise das Bacias de Deflexões

3.5.1 O Programa ISLAB2000

3.5.2 Procedimento de Retroanálise das Bacias de Deflexões de Centro de Placas 90

4 ANÁLISE DE RESULTADOS DE TRANSFERÊNCIA DE CARGA EM JUNTAS 102

4.1 Medidas de Deflexões 102

4.1.1 Medidas de Deflexões com Carga no Centro da Placa 102

4.1.2 Medidas de Deflexões com Carga na Junta da Placa 105

4.2 Estimativas dos Parâmetros Estruturais (E e k) 111

4.3 Retroanálises do Módulo de Elasticidade do Concreto (E) e do Módulo de Reação do Subleito (k) no Centro da Placa 115

4.4 Retroanálises dos Valores de Eficiência de Transferência de Carga (LTE) e de Módulo de Reação do Subleito na Borda da Placa 119

4.5 Transferência de Carga em Juntas por Medidas Diretas 122

4.6 LTE medido versus LTE retroanalisado 131

4.7 Análise dos Valores de Módulo de Elasticidade do Concreto .135

4.8 Análise dos Valores de Módulo de Reação de Subleito (kb) na Borda e no Centro da Placa (k) 


\section{INTRODUÇÃO}

\subsection{Pavimentos de Concreto Simples}

Segundo Balbo (1989) os pavimentos de concreto simples consistem em placas de concreto, finitas em comprimento e largura, justapostas, apoiadas sobre bases e subleitos, empregadas em vias urbanas ou rurais. Essas placas são construídas in loco ou pré-moldadas. Em ambos os casos, existem juntas longitudinais e transversais.

No caso de placas pré-moldadas, as juntas estão preestabelecidas conforme as dimensões das placas. Já quando o concreto é moldado in loco, as juntas são construídas conforme posicionamento e dimensões estabelecidas em projeto. Assim, nesse caso, as juntas são necessárias principalmente devido à retração (de secagem) que ocorre no concreto durante seu período inicial de cura.

Esse procedimento é realizado com o objetivo de induzir as fissuras de retração exatamente na posição em que as juntas são serradas, caso contrário essas fissuras de retração ocorreriam de maneira desordenada, resultando em placas com dimensões irregulares entre si. Nessas juntas podem estar presentes dispositivos de transferência de carga, constituídos por barras de aço, cuja função é exatamente transferir carga de uma placa para outra.

No caso da ausência de tais dispositivos, há também transferência de carga por meio do intertravamento dos agregados nas faces verticais das fissuras abaixo das juntas (Figura 1.1). Em ambos os casos, a transferência de carga nessas juntas é bastante favorável para prevenir o escalonamento entre placas na posição das juntas (PCA, 2008). 


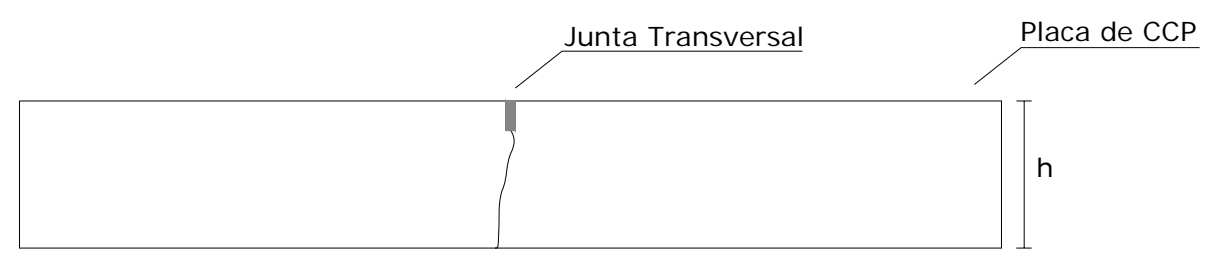

Figura 1.1 Juntas transversais serradas em pavimentos de Concreto de Cimento Portland (CCP), em corte.

\subsection{Tipos de Juntas em Pavimentos de Concreto}

Os tipos mais importantes de juntas nos pavimentos de concreto são: de expansão; de contração; e de construção. As juntas de expansão, modernamente, são usadas no encontro entre as placas do pavimento de concreto e alguma outra estrutura, como pontes e viadutos, ou no encontro de um pavimento novo com um antigo, permitindo que o pavimento trabalhe sem a influência das outras estruturas existentes (Figura 1.2).

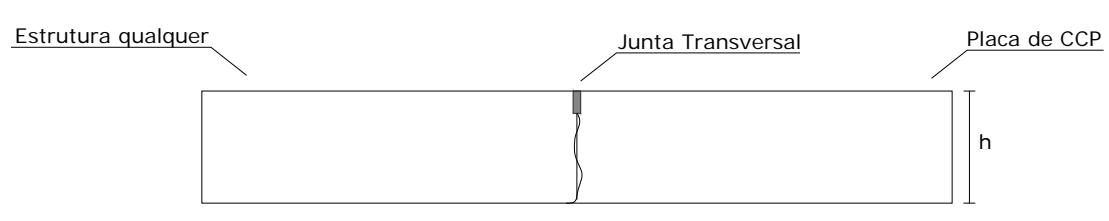

Figura 1.2 Juntas de expansão.

As juntas de expansão são bastante úteis em áreas de transição para separar segmentos de pavimentação de objetos relativamente imóveis. Essas juntas podem ter abertura atingindo valores de $25,4 \mathrm{~mm}$, sendo que o material para enchimento deve ser bastante flexível, permitindo até $50 \%$ de compressão, além de não sofrer contração, não ser absorvente, reativo ou expansivo. Sendo assim, o material de preenchimento se torna uma junta de vedação pré-moldada (LEE et al, 2001). As barras de transferência de carga (BT) devem ser evitadas em juntas de expansão nas quais diferentes movimentos horizontais podem ocorrer, podendo tais barras danificar o concreto. 
A experiência demonstrou que o uso de juntas de expansão não é obrigatório, exceto no caso em que uma placa de concreto é colocada ao lado de uma estrutura que não é submetida à mesma temperatura e umidade. No passado, o emprego de juntas de expansão transversais se dava para aliviar forças de compressão no pavimento, limitando a ocorrência de blowups (alçamento de placas por compressão de uma contra outra). Contudo, as juntas de expansão possuem uma tal abertura que não permitem o intertravamento entre agregados, resultando em placas que trabalham isoladamente.

As juntas de expansão, embora sejam juntas construtivas, têm suas posições predeterminadas no projeto de execução. Quando as juntas de construção são executadas em posições não definidas a priori, necessariamente ao final de um dia de concretagem, em geral possuem dispositivos de transferência de carga (BT), sendo ausente o material de enchimento nessa junta; além disso, há um intertravamento de agregados nas faces dessas juntas, que melhoram a transferência de cargas. Essas juntas perfazem as tarefas de juntas de contração (retração) embora não sirvam para controlar, naquele local, fissuras de retração.

As juntas de contração (Figura 1.3), conforme mencionado anteriormente, controlam a posição das fissuras de retração; são executadas transversalmente e longitudinalmente (Figura 1.4), definindo a geometria das placas de concreto. Tal geometria é também determinante das respostas estruturais dos pavimentos às cargas e às variações ambientais.

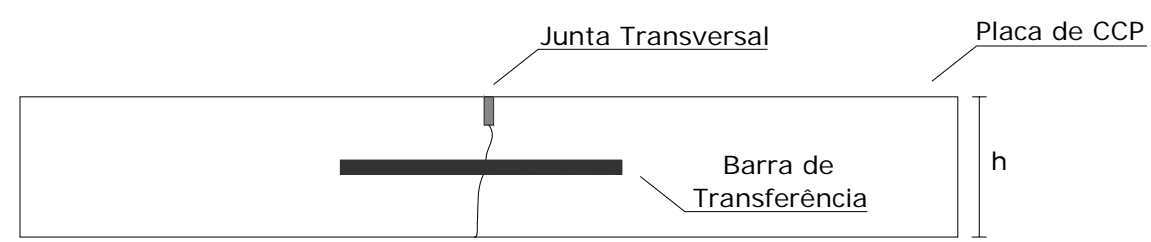

Figura 1.3 - Esquema de junta transversal com barra de transferência de carga. 
Longitudinal

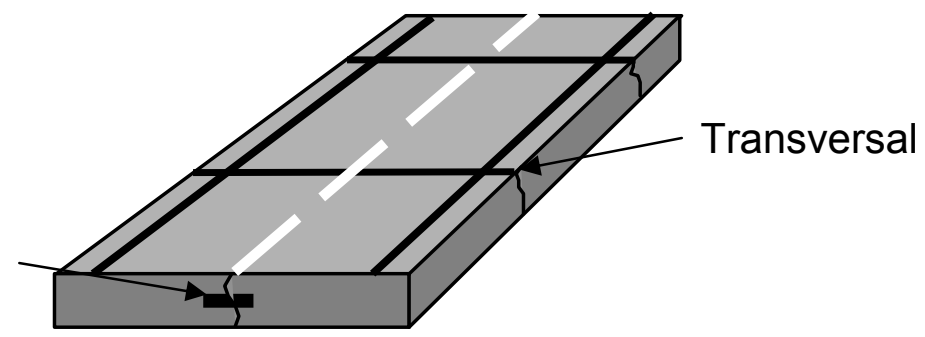

Figura 1.4 - Esquema de juntas longitudinais e transversais.

\subsection{Transferência de Carga em Juntas}

O conceito de transferência de carga consiste na idéia de que tensões e deflexões em uma placa de pavimento carregada são dissipadas para outra placa através da junta transversal. A transferência de carga depende de vários fatores estruturais tais como a temperatura, a reação de suporte do subleito e o tipo de junta. A idade do pavimento de concreto, a umidade, a magnitude e repetição de carga também influem na eficiência da junta de transferir carga de uma placa a outra adjacente.

Quando se tem uma carga na proximidade da borda, existe uma deformação da placa de concreto do pavimento proporcional à magnitude da carga, à espessura da placa, ao módulo de elasticidade dos materiais envolvidos e às condições de suporte da placa. A Figura 1.5 representa possíveis mecanismos de respostas aos carregamentos aplicados em pavimentos de concreto simples. Em ambos os casos a carga é aplicada nas proximidades de uma junta transversal; no primeiro caso ocorre um deslocamento vertical na placa carregada, enquanto não se manifestam deslocamentos na placa adjacente; portanto, a transferência de cargas entre as placas nessa junta é nula. Já no segundo caso, ambas as placas deslocam-se de modo idêntico; assim sendo a transferência de cargas entre as placas se torna completa.
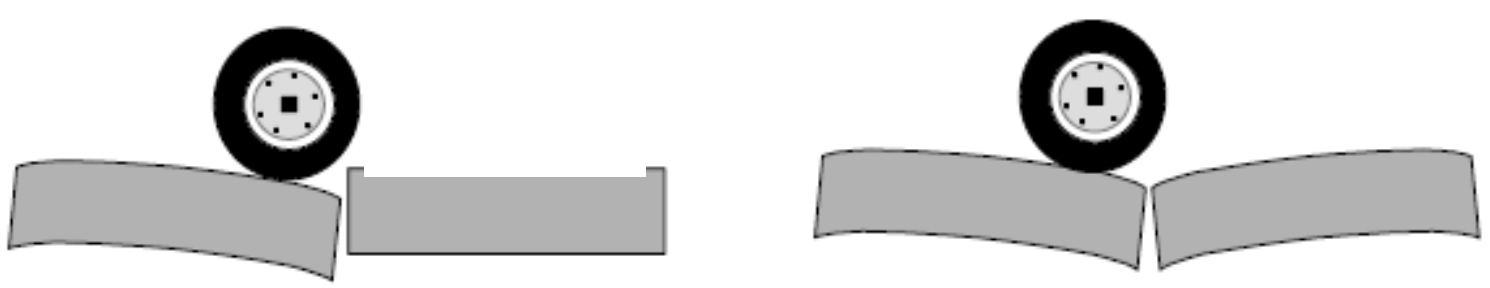

Figura 1.5 (Esquerda) sem transferência de carga; (Direita) total transferência de carga. 
A eficiência de transferência de carga (Load Transfer Efficiency) - LTE - nas juntas e nas fissuras das placas de concreto afeta a resposta estrutural e o desempenho dos pavimentos. Quando a carga do tráfego é aplicada próxima à junta transversal do pavimento de concreto, ocorrem deflexões em ambas as placas, pois parte da carga aplicada é transferida para a placa sucessiva onde não há carregamento externo. Conseqüentemente, as deflexões e tensões na placa carregada podem ser apreciavelmente menores se ambas as placas dividirem a tarefa de dissipar os esforços aplicados por cargas externas (mesmo ambientais). A redução de tensões e deformações é dependente desse mecanismo de transferência de cargas.

A porcentagem de transferência de carga ou LTE é determinada por meio de testes com aplicação de carga adjacente à junta, sendo medidas a deflexão sob a carga aplicada e a deflexão na placa sem carregamento (SHAHIN, 1985), à mesma distância da junta (deflexões em simetria). O valor do LTE é determinado com base na relação entre a deflexão na placa carregada $\left(\delta_{1}\right)$ e a deflexão na placa sem o carregamento $\left(\delta_{2}\right)$, conforme representadas na Figura 1.6 e matematicamente descritas pela equação [1.1] conforme se segue:

$$
L T E=\frac{\delta_{2}}{\delta_{1}} \times 100[\%]
$$

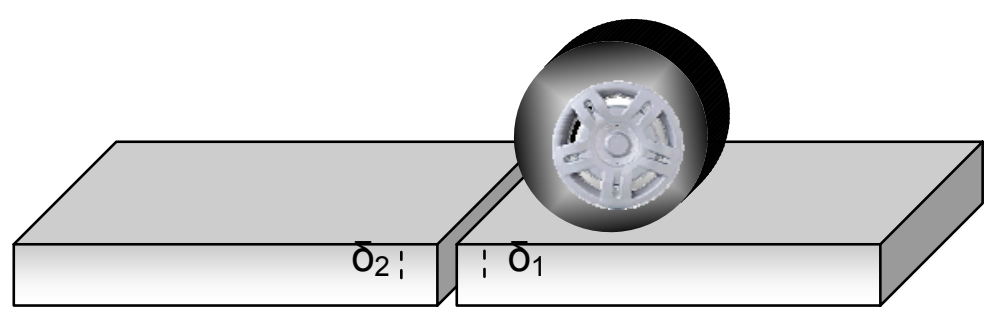

Figura 1.6 Deflexões nas placas carregada e descarregada.

Nota-se que, na realidade, avalia-se uma eficiência de transferência de deslocamentos verticais nas bordas de duas placas sucessivas. Caso a junta tenha uma baixa eficiência de transferir carga, as deflexões na placa sem o carregamento são menores do que as deflexões na placa carregada e, portanto, o valor do LTE 
aproxima-se de zero. Se a junta tiver uma boa eficiência de transferência de carga, as deflexões em ambas as placas (carregada e descarregada) serão aproximadamente idênticas e o valor de LTE aproximar-se-á de 100\%. A American Concrete Pavement Associatio (ACPA, 1989) recomenda que a junta seja considerada adequada se for $75 \%$ efetiva ou mais.

\subsection{Motivações e Justificativas para o Estudo}

Sabe-se que o concreto expande ou contrai em função das condições climáticas, conforme os períodos do dia e as estações do ano. Esses efeitos causam movimentos horizontais nas placas provocando aberturas e fechamentos nas juntas de contração e de expansão. Segundo Shahin (1985), para calcular tensões nas placas de concreto, o que se faz na fase de projeto, é essencial a determinação do LTE em juntas transversais. Assim sendo, durante os projetos, é indispensável o conhecimento prévio de padrões de transferência de carga nas juntas de pavimentos de concreto simples.

Métodos de dimensionamento de pavimentos de concreto simples, como aqueles da Prefeitura do Município de São Paulo (PMSP, 2004) e da Portland Cement Association (PCA, 1984), bastante conhecidos no país, não consideram explicitamente o valor do LTE e muito menos suas variações sazonais. Assim, valores de tensões determinadas no projeto podem se distanciar da realidade de campo, onde o LTE varia conforme condições climáticas às quais os pavimentos ficam expostos.

Em não existindo estudos dessa natureza em clima tropical úmido é fundamental que alguma pesquisa seja realizada para estabelecer padrões de transferência de carga em juntas transversais de pavimentos de concreto simples. Trabalhos nessa direção possibilitariam atualização dos métodos de dimensionamento para consideração das variações de LTE ao longo do horizonte de projeto. 


\subsection{Objetivos do Estudo}

O trabalho de pesquisa foi realizado na busca de um maior conhecimento de como se dá a transferência de carga em juntas de pavimentos de concreto (seus padrões) e quais os fatores que influenciam nessa transferência de esforços. Para tanto, o estudo estabeleceu os seguintes objetivos:

- Medidas de deflexões, com Falling Weight Deflectometer (FWD), sobre placas de concreto de pavimentos, com aplicação de cargas próximas às juntas transversais de contração, para determinação de valores de LTE;

- Conduzir tais medidas de deflexões em diferentes condições climáticas, inverno e verão, manhã, tarde e anoitecer; tais experimentos foram restritos devido à difícil disponibilidade do equipamento pertencente a uma empresa de engenharia;

- Comparar resultados de LTE obtidos em diferentes períodos do dia e em diferentes estações climáticas do ano (a mais fria e a mais quente, na cidade de São Paulo);

- Determinação dos parâmetros estruturais dos pavimentos de concretos simples analisados: módulo de elasticidade do concreto, módulo de reação do subleito e do valor LTE, para todas as placas e juntas do universo de testes realizados. Tal determinação foi realizada utilizando retroanálises de bacias de deflexões FWD com o programa de elementos finitos para placas de concreto simples ISLAB 2000 (Khazanovich et al., 2001).

Para a realização dos experimentos foi empregada a pista experimental USP/FAPESP, construída em 1999 sob a coordenação do Laboratório de Mecânica de Pavimentos da EPUSP, até então não empregada para a determinação dos efeitos de transferência de cargas em juntas com e sem barra de transferência de carga.

Paralelamente, para retroanalisar o parâmetro de transferência de carga, foi necessária a análise estrutural de respostas a carregamentos dinâmicos das placas de concreto dessa pista experimental. As retroanálises foram possíveis dado o 
perfeito conhecimento das dimensões e tipos de materiais utilizados na construção dos pavimentos.

\subsection{Organização do Trabalho}

O trabalho está organizado em cinco capítulos, iniciando pela introdução onde são definidos os objetivos e a estrutura da pesquisa. O segundo capítulo apresenta a revisão bibliográfica acerca do estudo proposto; desde os tipos de juntas de pavimentos de CCP aos modelos de rigidez do sistema estrutural, passando pelos diferenciais térmicos encontrados nas placas de concreto. $O$ terceiro capítulo engloba as características da pista experimental utilizada para este estudo e a metodologia de avaliação empregada. O quarto capítulo é composto por resultados, análise e discussões dos testes realizados nos anos de 2006 e 2007, confrontandoos com os resultados encontrados na literatura. No quinto capítulo são apresentadas as conclusões e as recomendações para estudos futuros sobre o tema. 


\section{PRINCIPAIS ASPECTOS RELATIVOS À TRANSFERÊNCIA DE CARGAS EM JUNTAS}

\subsection{Evoluções nos Conceitos de Juntas em Pavimentos de Concreto Simples}

O primeiro pavimento de Concreto de Cimento Portland nos Estados Unidos foi construído em 1891 em Bellafontaine, Ohio. Alguns registros apontavam que as juntas nas placas de concreto eram uma questão antes de conveniência do que de acomodação nos movimentos do concreto e da placa. Já no século XX a crença era de que a expansão do concreto deveria ser controlada, e os engenheiros então começaram a pensar em um mecanismo na placa para permitir tal expansão. Mais tarde foi descoberto que as placas se contraiam devido à secagem do concreto. Desde então, se deu mais atenção à contração das placas e preocupou-se menos com a expansão do concreto. (ACPA, 1989).

Em 1920, várias agências começaram a experimentar dispositivos de transferência de carga em juntas transversais. Isto foi motivado pelo crescimento do tráfego e a evolução da pavimentação. O primeiro uso de barras de transferência de carga foi em 1918, num pavimento em Newport News, na Virgínia. (ACPA, 1989).

De acordo com Friberg (1938) as juntas transversais possuíam abertura entre 6,5 e $25 \mathrm{~mm}$, e as barras de transferência de carga deveriam ser de aço simples com seção circular de diâmetro de $3 / 4$ ou 7/8 de polegadas (19 ou $22 \mathrm{~mm}$ ) e o comprimento, $600 \mathrm{~mm}$ na maioria das rodovias. Elas deveriam ser espaçadas de 300 a $500 \mathrm{~mm}$ entre si, sendo que um dos lados da barra seria engraxado a fim de apresentar menor resistência possível à movimentação do pavimento (não aderir ao concreto).

Alterações importantes aconteceram durante várias décadas, em relação ao comprimento da placa, aos mecanismos de transferência de carga e técnicas de projeto. Por volta do ano de 1930, muitos pavimentos de concreto de cimento Portland (CCP) continham uma malha de aço nas placas e uma combinação de juntas de contração e de expansão. (ACPA, 1989). Assim, as juntas de contração e 
expansão eram espaçadas em 9 e 27 m, respectivamente. No entanto, a execução dos pavimentos apresentava deficiências de qualidade. As juntas de expansão fechavam enquanto as juntas de contração abriam e assim eram preenchidas por materiais rígidos, acarretando sérios esborcinamentos e blowups (levantamento da junta transversal com quebra e esmagamento do concreto nas proximidades).

Durante a $2^{\mathrm{a}}$ Guerra Mundial, com a carência de aço no mercado, os pavimentos de concreto simples se tornaram uma alternativa atraente. As juntas de expansão tinham espaçamento entre 32 e $37 \mathrm{~m}$ e as juntas de contração, 4,5 a 6 m. Como, em tese, as juntas de expansão fechariam (com o aumento de temperatura) e as de contração abririam (com a diminuição da temperatura), o desempenho do pavimento era insatisfatório pela perda de transferência de carga nessas juntas quando abrissem (KHAZANOVICH, 2007).

Em 1947, a Universidade de Illinois realizou testes em muitos dispositivos para a transferência de cargas, inclusive as barras de transferência (KHAZANOVICH, 2007). Enquanto muitas pesquisas em uso de barra de transferência foram conduzidas ao longo dos anos, uma importante verificação de ordem prática foi alcançada por Teller e Cashell (1958): eles indicavam, embora empiricamente, que o diâmetro da barra deveria ter 1/8 da espessura da placa de concreto do pavimento.

Blowups e spallings (destacamento do concreto definindo pequenos painéis soltos com extremidades coincidentes com a posição da armadura transversal e longitudinal) eram problemas em pavimentos com armaduras. Por volta de 1980, em muitos estados americanos e em outros países foi adotado o pavimento de concreto simples com BT (Barra de Transferência) com juntas de contração de 4,5 a 6,0 metros. Devido a falhas relacionadas à degradação por oxidação de barras de transferência e de armaduras, muitas agências desenvolveram especificações para resistência à corrosão de armadura (ACPA, 1989).

Após a $2^{\mathrm{a}}$ Guerra Mundial, os projetos de pavimentos de CCP se desenvolveram em duas direções: (1) placas sem BT com espaçamento curto e separadas por juntas de contração, porém sem juntas de expansão; (2) em pavimentos de concreto armado 
com o espaçamento de juntas de expansão de 15 a 30 metros (KHAZANOVICH, 2007).

No início da década de 1990 expandiu-se a prática da construção de pavimentos de concreto simples com juntas e barras de transferência de carga espaçadas de 3,5 a 6,0 metros, dependendo da espessura das placas, ou de pavimentos armados e com juntas espaçadas entre si não mais que 9 metros.

De 1973 a 1995, agências de transportes de 53 estados e províncias dos Estados Unidos e Canadá pesquisaram sobre a prática de construção de juntas de contração em pavimentos de CCP. Baseada na análise dos dados fornecidos pelas pesquisas, as seguintes observações foram feitas (KHAZANOVICH, 2007):

- "50 estados e províncias usavam juntas de contração em pavimentos planos e armados desde 1960;

- A maioria das agências em 1995 usou o mesmo espaçamento entre as juntas que em 1973;

- 5 estados usaram espaçamento entre as juntas de 4,50 metros, enquanto 9 estados preferiram intervalos de 6,0 metros;

- O espaçamento entre as juntas variou entre 4,5 e 6,0 metros em 19 estados e 11 destes 19 estados usaram o mesmo espaçamento;

- Entre 1973 e 1995, o número de estados e províncias que usavam barras de transferência de carga em JPCP (do inglês, Joint Plain Concrete Pavement Juntas de Pavimento de Concreto Simples) aumentou de 42 a 46, dentro dos 53 estados pesquisados;

- 24 das 42 agências de transporte interrogadas aumentaram o diâmetro das barras de transferência;

- Apenas 4 estados utilizaram a regra de que o diâmetro da barra deve ter $1 / 8$ da espessura da placa;

- Em 1973, o comprimento das barras de transferência variou entre 300 e 600 $\mathrm{mm}$, enquanto que a maioria dos estados usou barras de $450 \mathrm{~mm}$ de comprimento;

- As barras foram espaçadas a cada $300 \mathrm{~mm}$ em todos os estados, exceto na Carolina do Sul, que utilizou espaçamento de 350 mm, e em Utah, 1.210 mm; 
- O Departamento de Transportes de Utah se diferenciou dos outros estados, utilizando 16 mm de diâmetro e 760 mm de comprimento."

No Brasil, Fleury e Guimarães (2006) construíram em laboratório nove placas de concreto simples com $105 \mathrm{~mm}$ de espessura sobre uma camada de $130 \mathrm{~mm}$ de borracha para simular uma base elástica e uniforme, com a finalidade de estudar mecanismos de transferência de carga em juntas de pavimentos de concreto. As placas tinham $2,2 \times 0,6 \mathrm{~m}$, sendo serradas transversalmente na metade do comprimento; seis delas continham barras de transferência de carga de 12,5 ou 16 $\mathrm{mm}$ de diâmetro posicionadas a meia altura das placas e espaçadas $200 \mathrm{~mm}$ entre elas. Os carregamentos eram estáticos com valor de carga de $300 \mathrm{kN}$. Com o objetivo de medir deslocamentos verticais na junta, foram empregados quatro deflectômetros digitais, sendo dois do lado carregado da barra e dois do lado sem carregamento, próximos à junta. $\mathrm{O}$ ensaio chegaria ao seu final quando ocorresse a separação das placas, ou o fechamento da junta ou a perda de eficiência de transferência de cargas em juntas.

Os autores verificaram que todas as placas com juntas serradas de contração fissuraram durante sua cura, e observaram também que placas sem BT resistem menos, em termos de fissuração, às cargas aplicadas, "o que pode ser atribuído à falta de mecanismos para transferir esforços". A bem da verdade, não é a ausência de mecanismos por completo que afeta o desempenho da junta, mesmo porque há transferência de cargas por meio de intertravamento de agregados nas faces das juntas de contração. O que provavelmente ocorreu foi que em juntas com a presença de BT houve transferência de carga mais eficiente durante os testes o que levou a ocorrência de fissuras mais tardias.

Os resultados sobre a eficiência de transferência de carga, conforme apresentados na Figura 2.1, mostram que na junta sem BT, quando o aumento da abertura da junta (com aumento de carga) ocorreu queda brusca no LTE enquanto que, nas juntas com BT essa perda de LTE ocorria lentamente com o aumento da abertura da junta. Ainda, o estudo indicou que placas com BT de $16 \mathrm{~mm}$ de diâmetro resistiram a maiores cargas antes da separação da junta que as placas com barras de 12,5 mm. 


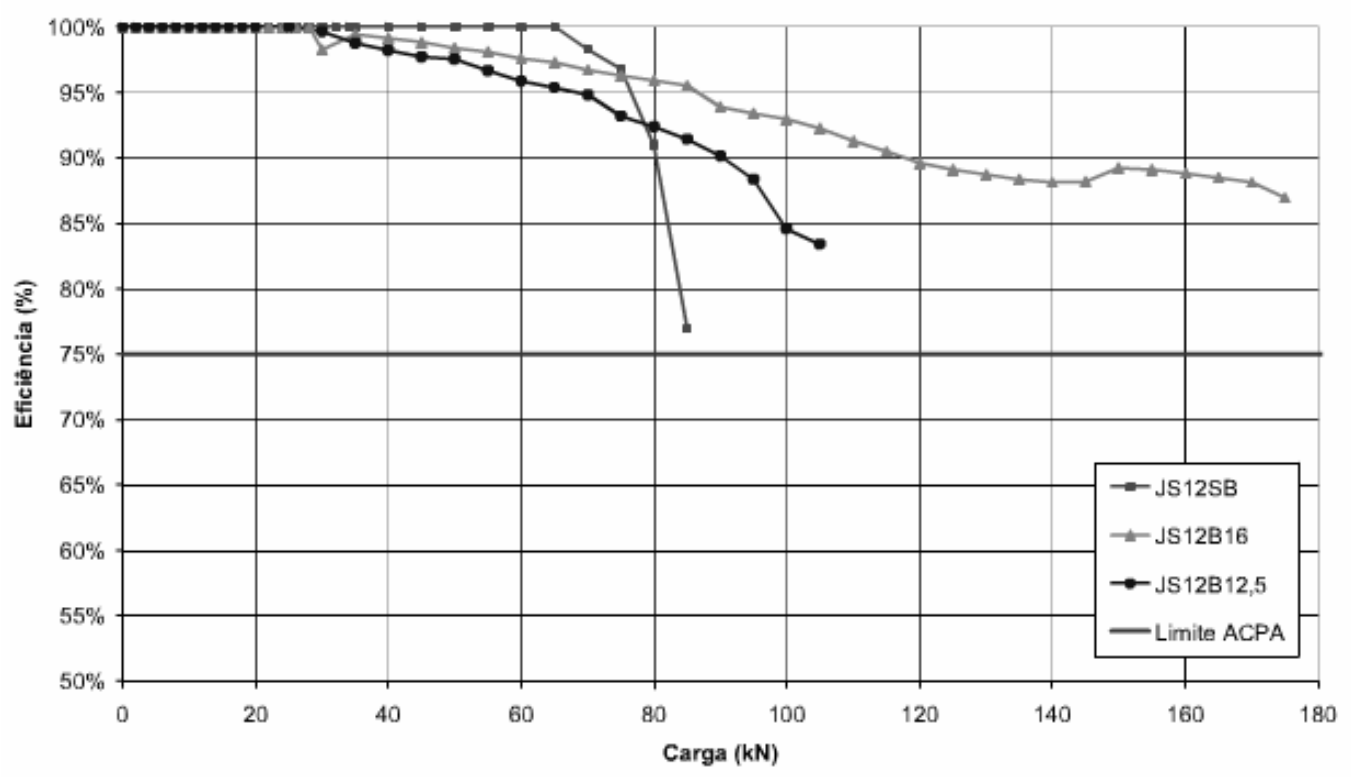

Figura 2.1 Perda de transferência de carga durante ensaios com placas em laboratório (FLEURY; GUIMARÃES, 2006).

O estudo mais recente de juntas em pavimentos de concreto no Brasil foi realizado por Rodrigues et al. (2007). Os autores realizaram ensaios em laboratório para estudar o comportamento estrutural de juntas transversais, variando a seção da barra de transferência (circular de $12 \mathrm{~mm}$ de diâmetro ou quadrada de lado $10 \mathrm{~mm}$ ), a espessura das placas de concreto $(120$ e $160 \mathrm{~mm}$ ) e o tipo de carregamento, além de testarem um novo dispositivo de transferência que consistiu em placas de aço quadradas com diâmetros de 115 e 163 mm.

Como resultados, observaram que para placas de concreto mais delgadas $(120 \mathrm{~mm})$ as barras circulares tinham um desempenho melhor do que as barras quadradas. Já para placas de concreto com $160 \mathrm{~mm}$ ocorreu o contrário: as barras quadradas proporcionaram melhor desempenho. Também, observaram que o uso de BT em pavimentos de concreto tornam a transferência de carga significativamente maior do que no caso de ausência de dispositivo de transferência de carga.

Os pavimentos de concreto são geralmente concebidos de modo a garantir a continuidade nas juntas, isto é, dotando-as de mecanismos de transferência eficientes, permitindo que o dimensionamento seja feito considerando a carga atuando longe das bordas transversais. Os mecanismos mais comuns são as barras 
de transferência empregadas tanto nas juntas transversais de contração, de construção e de expansão, raramente empregadas hoje em dia, exceto nos casos mencionados no Capítulo 1. Como em muitos pavimentos de concreto não ocorre obrigatoriamente fluxo direcional de veículos como nas rodovias (é o caso de pavimentos em aeroportos), as barras transferência de carga podem ser empregadas em juntas longitudinais também.

Segundo Khazanovich (2007), "as juntas transversais são executadas para aliviar as tensões internas no concreto causadas por retração de secagem, temperatura e gradientes de umidade na massa fresca do concreto, bem como restrições de atrito entre o concreto e a camada de base subjacente. Essas tensões podem conduzir ao surgimento de fissuras não controladas nas placas... O desempenho de muitos pavimentos de concreto com juntas não foi, historicamente, interpretado por sua capacidade estrutural, mas preferencialmente pelo seu sistema de juntas... Valores medíocres de eficiência de transferência de carga, conduzem à ocorrência de fissuras longitudinais e de canto, além de expressivo escalonamento nas juntas. Esses defeitos podem levar à presença de irregularidade e pobres condições de rolamento".

Segundo Zollinger e Barenberg (1989) o escalonamento de juntas ocorre devido ao depósito de material erodido pela ação de água livre sob as placas nas proximidades das juntas, causando um alçamento de uma das placas ${ }^{1}$. Este processo, conjuntamente com a erosão, origina o bombeamento de finos, concomitantemente com o deslocamento diferencial das placas quando a carga deixa uma placa e aproxima-se de outra.

Existem vários fatores que afetam a qualidade na transferência de carga em juntas (ZOLLINGER e BARENBERG, 1989), tais como a abertura das juntas - ligada

\footnotetext{
${ }^{1}$ De acordo com José Tadeu Balbo, em janeiro de 2009 - Comunicação pessoal - não é necessário um alçamento para causar o escalonamento; o simples afundamento de uma das placas contíguas, na proximidade das juntas ou em sua área completa, causa este escalonamento. Outros fatores, como a pavimentação de placas sobre solos compressíveis, estão também associados ao surgimento deste tipo de defeito em juntas de pavimentos de concreto.
} 
diretamente ao intertravamento de agregados -, o suporte oferecido pelas camadas inferiores e a presença de dispositivos de transferência de carga.

Quanto aos efeitos do módulo de reação do subleito nas placas de concreto, modelos analíticos como aquele de Westergaard (1926) e numéricos, como aquele de Balbo (1989), ambos empregando o conceito de fundação de Winkler, mostraram que o efeito de variações desse parâmetro nas tensões em placas de concreto é muito pequeno. Contudo, trabalhos como de Spangler (1942) mostram com clareza que há diferenças entre este conceito de reação do subleito quando uma carga é aplicada na borda ou no centro de uma placa. A aplicação de modernos programas de elementos finitos, por outro lado, requer o emprego de um elemento de equilíbrio do sistema, de reação da fundação a forças aplicadas, e o parâmetro mais comumente empregado é o valor do módulo de reação do subleito (k).

\subsection{Abertura de Juntas por Efeitos da Temperatura}

Os movimentos horizontais em placas de pavimentos de concreto simples ocorrem em função de variações da temperatura no concreto causando sua expansão. Esses movimentos resultam em abertura e fechamento das juntas durante a vida de serviço do pavimento. Quando ocorrem aberturas nas juntas transversais, as faces verticais da fissura se encontram mais afastadas entre si, o que resulta em menor transferência de carga por intertravamento de agregados; isto faz com que as tensões nas placas aumentem. Portanto, as respostas estruturais às cargas são diferentes em função da abertura existente nas juntas.

Em projetos de juntas em pavimentos de concreto simples, as mudanças de temperatura devem ser levadas em conta como se fossem cargas adicionais aos pavimentos; assim é necessária a previsão de movimentos horizontais nas placas de concreto que ocorrerão ao longo de sua utilização. Diversos autores, dentre os quais Bodocsi et al. (1993a), empregam a convencional equação [2.1] para determinação do alongamento ou encurtamento dos materiais em função da variação de temperatura a que são submetidos: 


$$
\delta_{T}=\alpha_{C} \times \Delta T \times L
$$

sendo $\delta_{\mathrm{T}}$ o movimento horizontal induzido pela variação da temperatura no concreto, $\alpha$ o coeficiente de expansão térmica do concreto variando de 6 a $14 \times 10^{-5} /{ }^{\circ} \mathrm{C}$ (FURNAS, 2000), $\Delta T$ a variação de temperatura sofrida e $L$ o comprimento da placa (maior dimensão).

Para entender o efeito das diferentes características do pavimento de concreto em relação a abertura de juntas, doze seções-teste foram construídas em Chillicothe, Ohio, com vários comprimentos de placas, tipos de bases, tipos de barras de transferência de carga e modos de serragem das juntas. O pavimento possuía duas faixas de 3,6 $\mathrm{m}$ de largura e espessura de $230 \mathrm{~mm}$ da placa de CCP. Para as bases foram utilizados tanto materiais granulares quanto estabilizados com cimento.

As medidas de movimentos horizontais foram realizadas por meio de sensores LVDT (Linear Variable Differential Transformer) durante um período de dezesseis meses. Na tabela 2.1 são apresentados alguns dos resultados daquela pesquisa.

Tabela 2.1 Movimentos das juntas serradas transversais (BODOCSI et al., 1993a).

\begin{tabular}{|c|c|c|c|c|c|}
\hline \multirow[b]{2}{*}{ Seção } & \multirow{2}{*}{$\begin{array}{c}\text { Comprimento } \\
\text { (m) }\end{array}$} & \multirow{2}{*}{$\begin{array}{c}\text { Tipo de } \\
\text { base }\end{array}$} & \multicolumn{3}{|c|}{ Movimento medido $(\mathrm{mm})$} \\
\hline & & & $\begin{array}{c}\text { Máximo } \\
\text { Fechamento }\end{array}$ & $\begin{array}{l}\text { Máxima } \\
\text { Abertura }\end{array}$ & $\begin{array}{l}\text { Média ao longo } \\
\text { do experimento }\end{array}$ \\
\hline 3 & 6,4 & Estabilizada & 2,26 & 1,98 & 0,37 \\
\hline 4 & 12,2 & Estabilizada & 1,98 & 1,90 & 0,34 \\
\hline 6 & 6,4 & Granular & 2,13 & 1,92 & 0,28 \\
\hline 7 & 12,2 & Granular & 1,99 & 2,02 & 0,40 \\
\hline 9 & 12,2 & Granular & 2,05 & 2,10 & 0,34 \\
\hline 10 & 6,4 & Granular & 2,00 & 2,18 & 0,52 \\
\hline
\end{tabular}

Neste estudo observou-se que o máximo movimento ocorreu nos meses em que a temperatura variou amplamente entre o dia e a noite. Também verificou que é a temperatura a meia altura da placa que melhor se relaciona com seu movimento horizontal e não temperaturas no topo ou no fundo das placas. Bodocsi et al. (1993) relacionaram a temperatura no concreto com os deslocamentos horizontais nas placas, conforme exemplo apresentado na Figura 2.2, na qual os movimentos 
positivos são referentes ao fechamento das juntas e os movimentos negativos representam a abertura das juntas. Os resultados cobrem o período de 27 de setembro a 11 de outubro de 1990 (experimento em Chillicothe, Ohio).

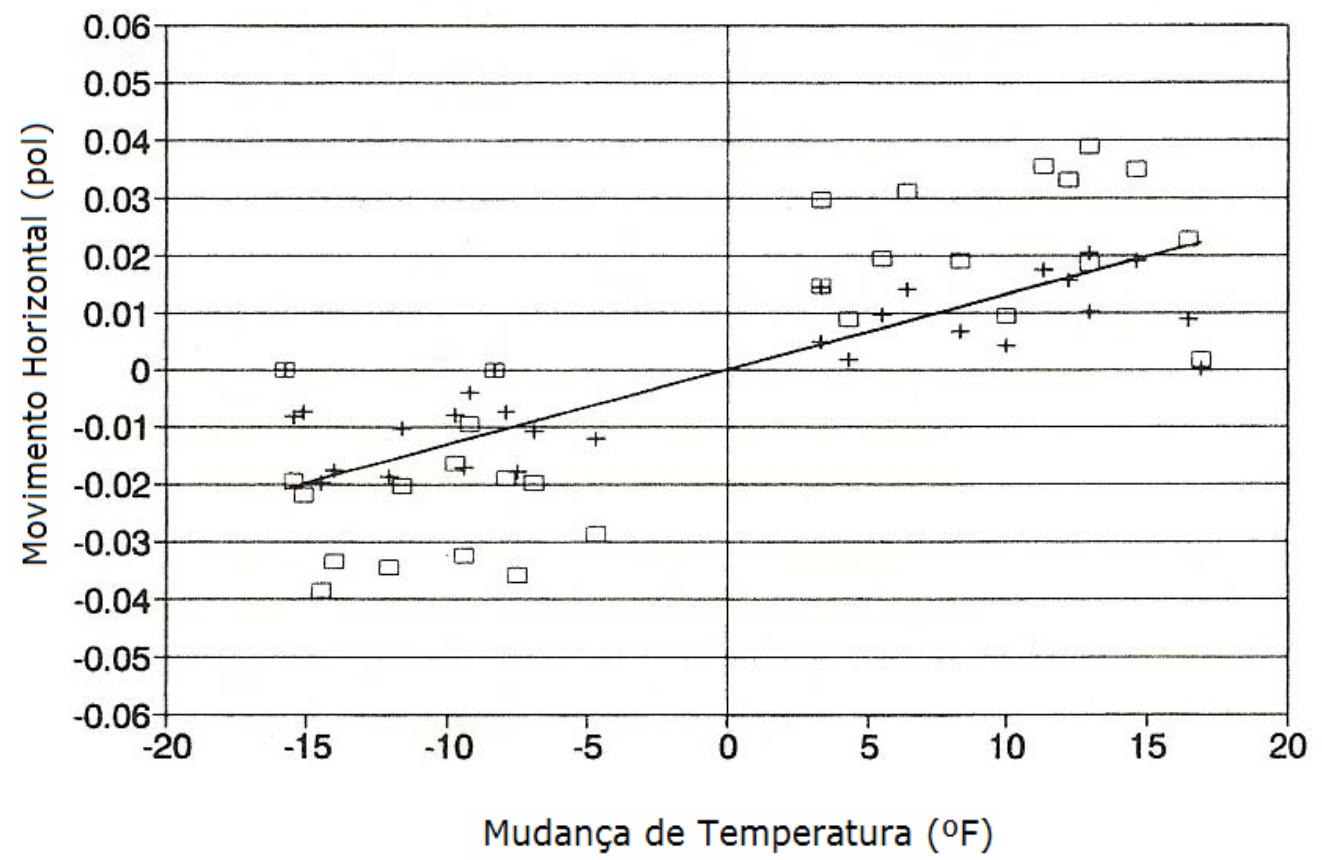

Figura 2.2 - Temperatura versus movimento das placas (adaptado de: BODOCSI et al.,1993).

De acordo com a figura 2.2, obtida de uma correlação da equação 2.1, quanto maior a temperatura, menor a abertura da junta, e quando contrário, maior a abertura horizontal da junta. O estudo mostrou que o máximo movimento (abertura) ocorre em meses mais frios. Isto é um indicativo que o LTE em baixas temperaturas é menor devido à contração do concreto.

Neste estudo verificou-se que o tipo de base, fosse ela granular ou estabilizada com cimento, não afetou a abertura da junta. Isto é indicativo de que o emprego de bases como CCR (concreto compactado com rolo) ou BGTC (brita graduada tratada com cimento) não restringiria o movimento das placas de modo diferente de BGS (brita graduada simples) ou outras bases granulares. Valores apoiando essa conclusão foram apresentados na Tabela 2.1 .

Bodocsi et al. (1993b) usaram no experimento dois tipos de barras de transferência de cargas em juntas transversais: convencionais de aço com sua metade engraxada 
e barras de aço revestidas com plástico (para controle de corrosão), ambas circulares. O estudo mostrou que o uso dos dispositivos mencionados não afetou o movimento horizontal das placas, portando, não alterou o LTE.

Khazanovich e Gotlif (2003) estudaram dados a partir de inúmeras seções de rodovias dentro do programa do National Highway Cooperative Pavement Research (NHCPR), incluindo medidas de aberturas de juntas em diferentes horas do dia e estações do ano. Na Figura 2.3 são apresentados resultados sobre abertura de juntas para várias estações climáticas, em uma mesma seção de controle. Para essas análises, sempre foi definida uma temperatura de referência pela manhã, sendo calculada pela média da temperatura entre o topo, o meio e o fundo da placa, em torno da qual a junta abre ou fecha, sendo tais valores medidos com instrumentação em pista. Observa-se que com o aumento da temperatura do concreto há fechamento das juntas; há tendência de juntas se abrirem e se fecharem de forma semelhante (valores absolutos) para as mesmas variações absolutas de temperatura. Os autores observaram que a abertura máxima, para todos os dados de medidas, não ultrapassou $2 \mathrm{~mm}$ consideradas todas as seções de rodovias.

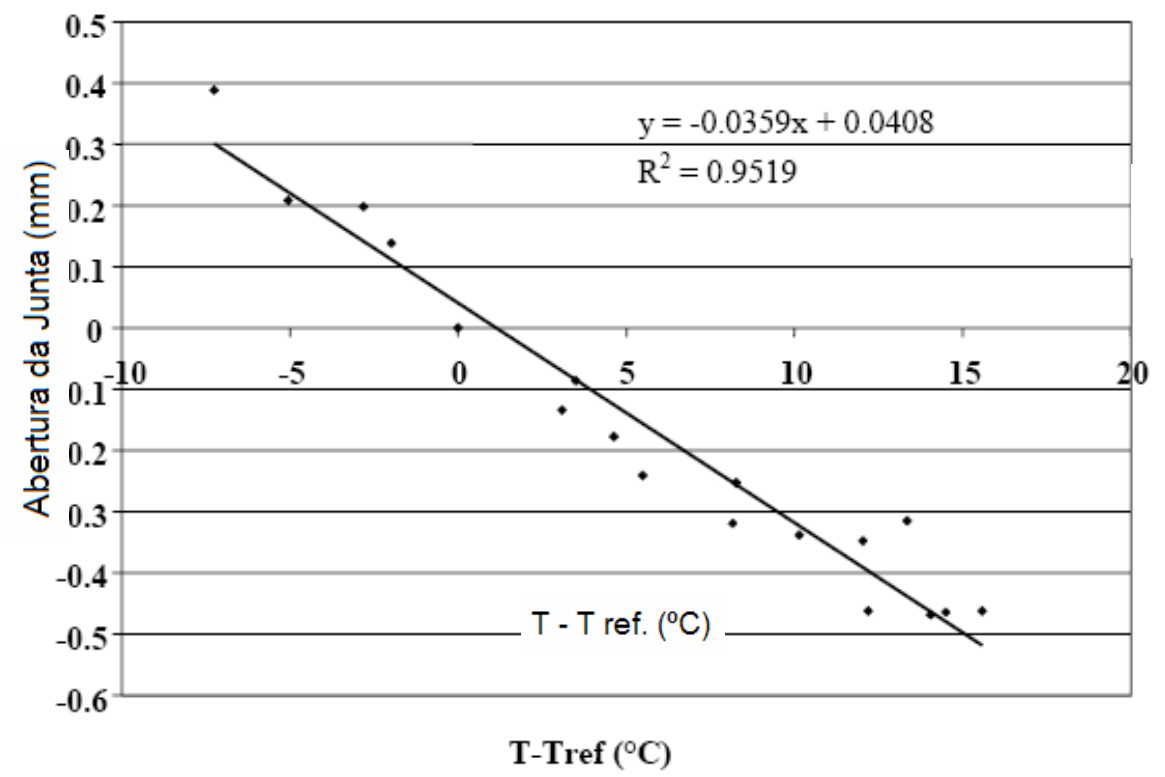

Figura 2.3 - Abertura da junta versus mudança de temperatura no pavimento de concreto (adaptado de: KHAZANOVICH; GOTLIF, 2003). 
Analisando a Figura 2.4, não há diferenças significativas na abertura da junta entre placas de pavimentos de concreto simples com BT e pavimentos de concreto armado (este último possuindo malha de aço que reduziria a abertura da junta, melhorando a transferência de carga por ela). Nota-se apenas que as aberturas das juntas em placas sem BT são menores que em placas com BT.

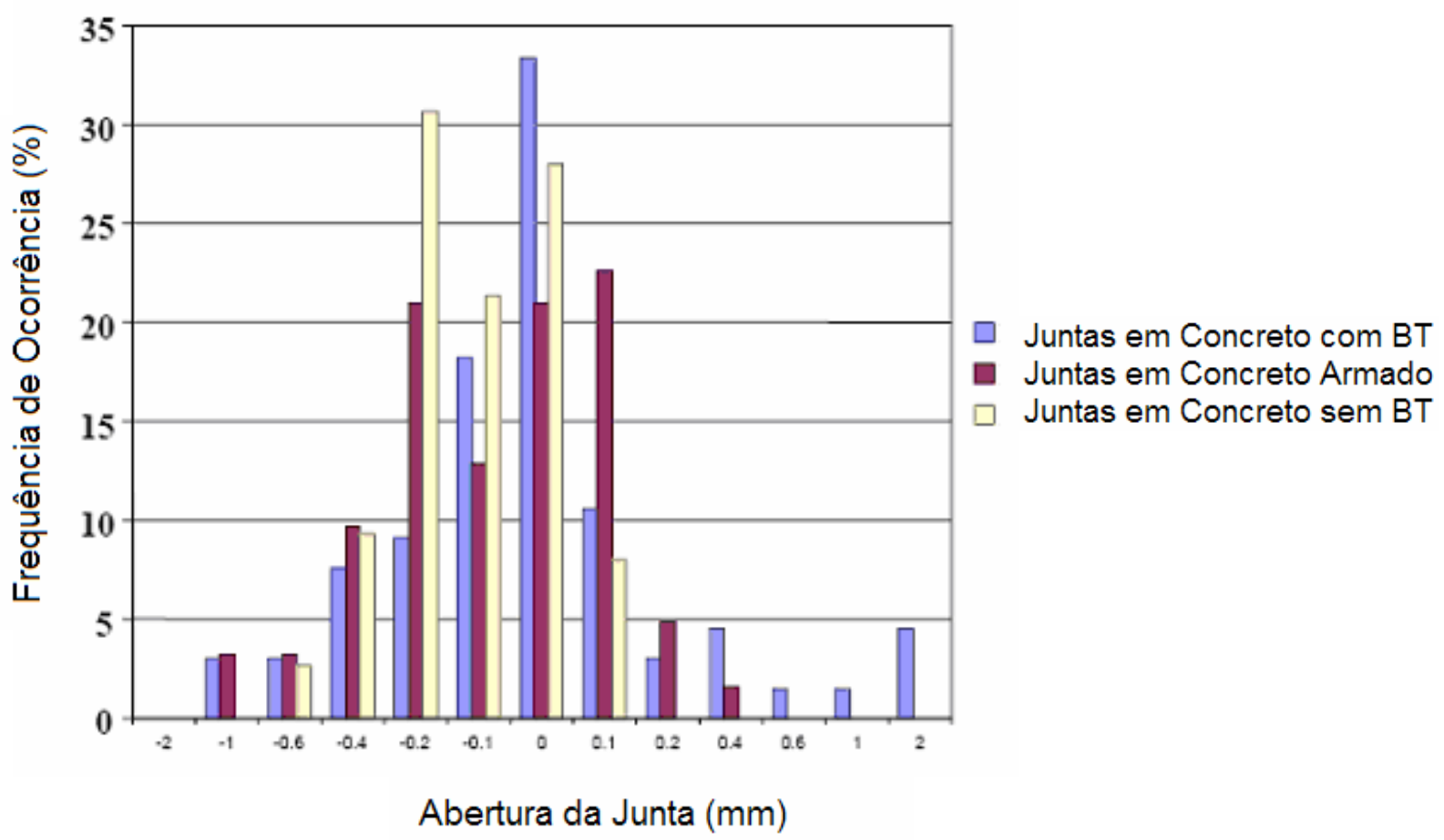

Figura 2.4 - Abertura da junta em diferentes tipos de pavimentos, em um mesmo dia (adaptado de: KHAZANOVICH; GOTLIF, 2003).

Khazanovich e Gotlif (2003) também correlacionaram o LTE com valores de abertura de juntas, conforme exemplo apresentado para uma seção particular de testes na Figura 2.5. Relatam os autores terem verificado, com surpresa, que apenas em duas seções houve boa correlação numérica entre os dois parâmetros; entretanto, esse não foi o padrão geral de resultados, sendo que na maioria dos casos não houve correlação significativa. Atribuíram a tais resultados as seguintes hipóteses: erro de ensaio com FWD ou com instrumentação (LVDT); empenamento da placa não determinado para o estudo, sugerindo maiores investigações. Contudo, segundo Zollinger e Barenberg (1989), a eficiência de transferência de carga é drasticamente reduzida com o aumento da abertura da junta. Por esta razão, a abertura da junta deve ser a menor possível. 


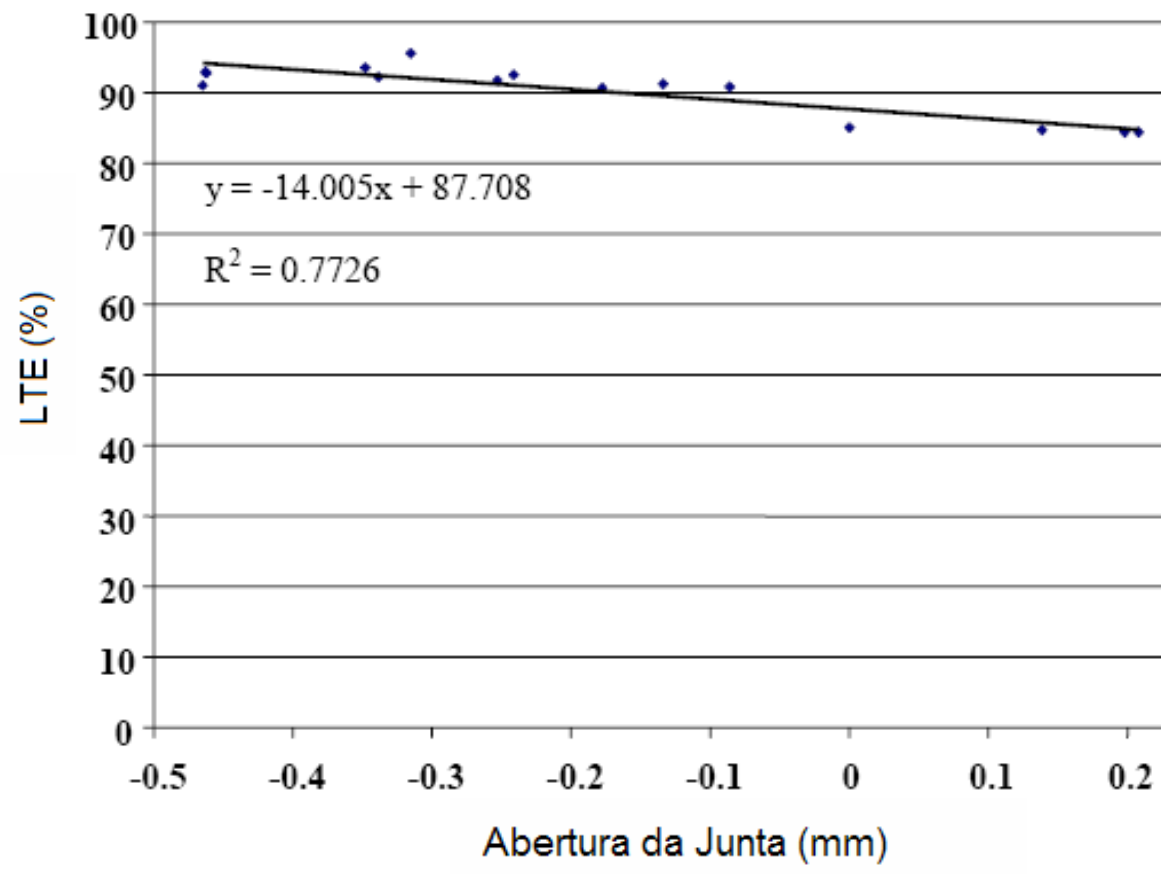

Figura 2.5 - LTE versus abertura da junta (Adaptado de: KHAZANOVICH; GOTLIF, 2003).

Para Vandenbossche (2007), a LTE em juntas sem BT pode diminuir em mais 50\% quando a abertura for maior que 0,9 mm. Edwards et al. (1989, apud VANDENBOSSCHE, 2007) realizou testes com FWD cujos resultados de LTE resultaram em 50\% pela manhã e $90 \%$ à tarde. Greer (1990, apud VANDENBOSSCHE, 2007) também obteve resultados indicando mudança de 16 para $84 \%$ os valores de LTE em placas sem BT, conforme alterações de temperatura entre semanas de inverno e verão. Essas alterações não foram significativas quando houve dispositivo de transferência de carga (BT) na junta da placa de concreto simples.

Nishizawa et al. (1989) desenvolveram um modelo relacional entre LTE e a abertura da junta (w) para pavimentos com e sem BT, que são apresentados por meio da Figura 2.6. Observaram os autores que, no caso de presença de BT, novamente a abertura possui pouca interferência no valor de LTE quando comparada ao caso de pavimentos de concreto sem BT. Com BT o valor de LTE diminui em função da abertura da junta, tendendo à estabilização na casa de $80 \%$. Ainda, na Figura 2.6 é apresentada uma regressão linear dos pontos fornecidos no trabalho de Nishizawa et al. (1989) quando se verifica que, para placas sem BT o valor de LTE cai 
bruscamente na medida em que a junta se abre, tendendo a zero para uma abertura em torno de $4 \mathrm{~mm}$.

Imaginando uma junta com $0 \mathrm{~mm}$ de abertura, LTE próximo de $100 \%$ é esperado segundo o modelo descrito. Se o valor se estabiliza em $80 \%$ para placas com BT, pode-se dizer que o intertravamento entre agregados seria responsável no máximo por $20 \%$ da transferência de carga. Isto nos permite concluir que a BT é um elemento de imensa importância na redução das deflexões nas juntas, e portanto, diminui as tensões nesses locais.

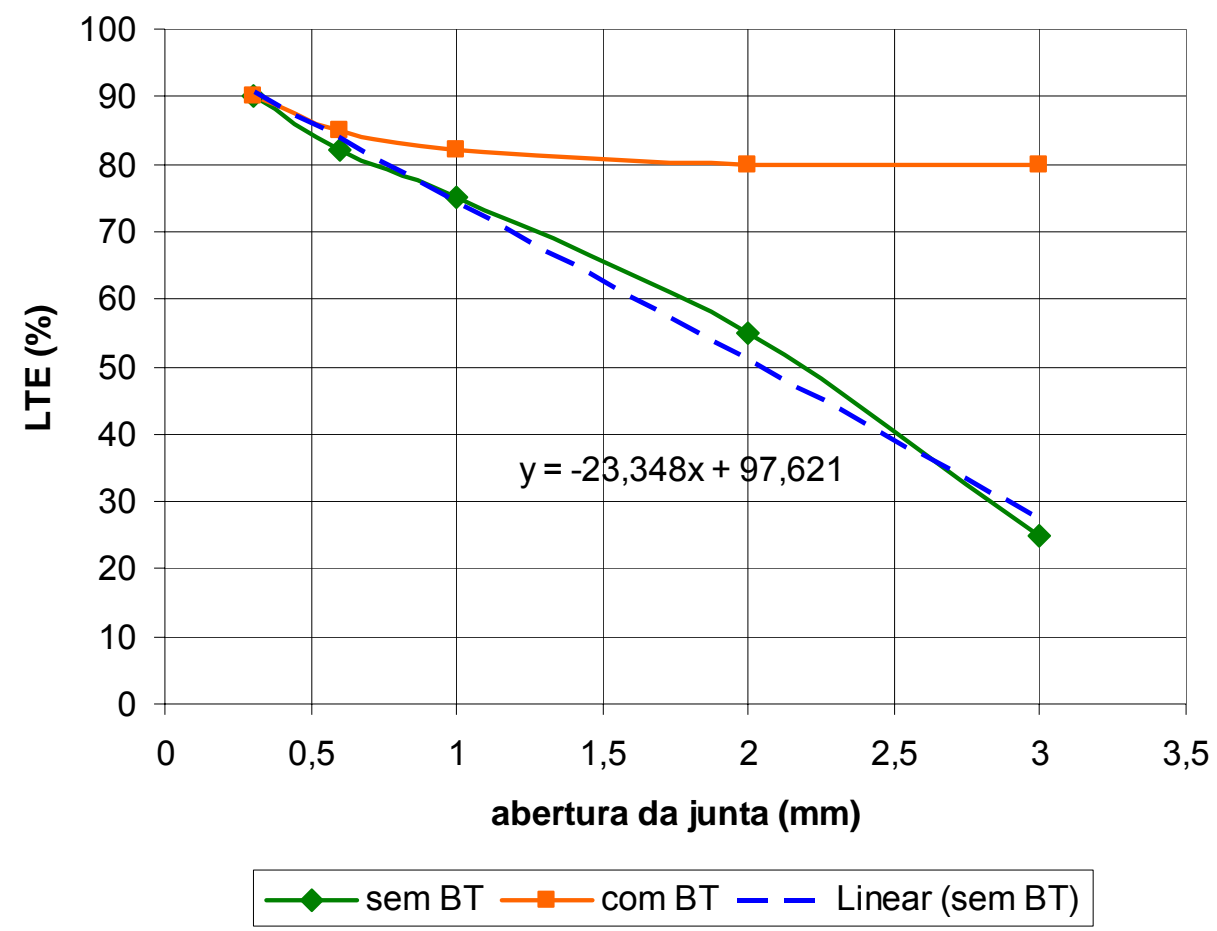

Figura 2.6 Influência da abertura da junta no LTE (adaptado de: NISHIZAWA et al., 1989).

Colley e Humphrey (1966), ambos da PCA, realizaram análises em campo e em laboratório por meio de pesquisas a fim de avaliar a eficiência e durabilidade da transferência de carga devido ao entrosamento de agregados. Nesta pesquisa foram consideradas a abertura da junta, a resistência da fundação, a grandeza da carga e a espessura da placa.

O equipamento utilizado possuía uma caixa contendo subleito compactado de argila siltosa, dois tipos de base - areia grossa e material tratado com cimento - com 150 
$\mathrm{mm}$ de espessura e as placas de concreto de 1,22 m x 5,49 m, com espessuras 180 e $230 \mathrm{~mm}$, tendo uma junta transversal no centro. Dois tipos de agregados foram empregados nos concretos: tipo seixo rolado com partículas quase completamente arredondadas e pedra britada com partículas angulares. Contava com um sistema para controlar a abertura da junta e um aparelho para aplicação de cargas repetidas.

Em relação à abertura das juntas, que pode variar de 0,5 a 2,0 mm, segundo os autores, os estudos apresentaram resultados para placas sobre base de pedregulho. Nestas placas, quanto maior a abertura da junta, menor sua eficiência de transferir carga. Já a durabilidade diminui com o aumento da abertura da junta. Notou-se também que para uma mesma durabilidade a abertura de junta é maior em placas mais espessas $(230 \mathrm{~mm})$ do que em placas delgadas $(180 \mathrm{~mm})$; no entanto há uma tendência em aumentar a diferença de aberturas quando o índice de durabilidade do pavimento diminui.

Foram realizados ensaios de campo e de laboratório e os resultados comparados. Os valores de eficiência de transferência de carga no laboratório eram consideravelmente inferiores aos de campo. Isto ocorre devido à influência de variações climáticas diárias das aberturas das juntas. O ganho em eficiência de transferência de carga acompanha o ciclo de abertura e fechamento das juntas de pavimentos de concreto em serviço.

Este processo de abertura e fechamento das juntas pode ser definido como movimento horizontal das placas de concreto simples, e por se conhecer este movimento horizontal das placas é que se opta pela selagem das juntas serradas.

A selagem de juntas é realizada para prevenir a infiltração de água da superfície pela junta até o solo e a entrada de materiais incompressíveis dentro dela. Do mesmo modo, reduz a umidade relacionada a distúrbios como bombeamento de finos, fissuras devido ao enfraquecimento do solo e rompimento do concreto em pedaços.

Lee e Stoffels (2001) realizaram um estudo com 16 seções-teste de pavimentos de concreto simples diferentes, distribuídas geograficamente nos EUA e Canadá e 
monitoradas pelo programa LTPP (Long Term Pavement Performance) SMP, visualizando a relação entre o movimento da junta com a mudança de temperatura. Um exemplo desta relação é apresentado na Figura 2.7. Quando não há movimentação na junta em relação a temperatura (Figura 2.8), trata-se de junta congelada (do inglês, joint freezing).

Segundo estes autores, não há variação significante da abertura da junta ao longo da espessura do pavimento. Poblete et al. (1988) determinou que a máxima diferença entre abertura da junta no topo da placa e no fundo encontrada em um pavimento chileno foi de 0,15 mm, em pavimentos sem BT Pittman (1996) observou que a largura da abertura da junta na superfície era estatisticamente igual no fundo da fissura. Portanto, as medidas de abertura de junta obtidas na superfície da placa de concreto são representativas, não havendo alterações de largura ao longo da profundidade do pavimento.

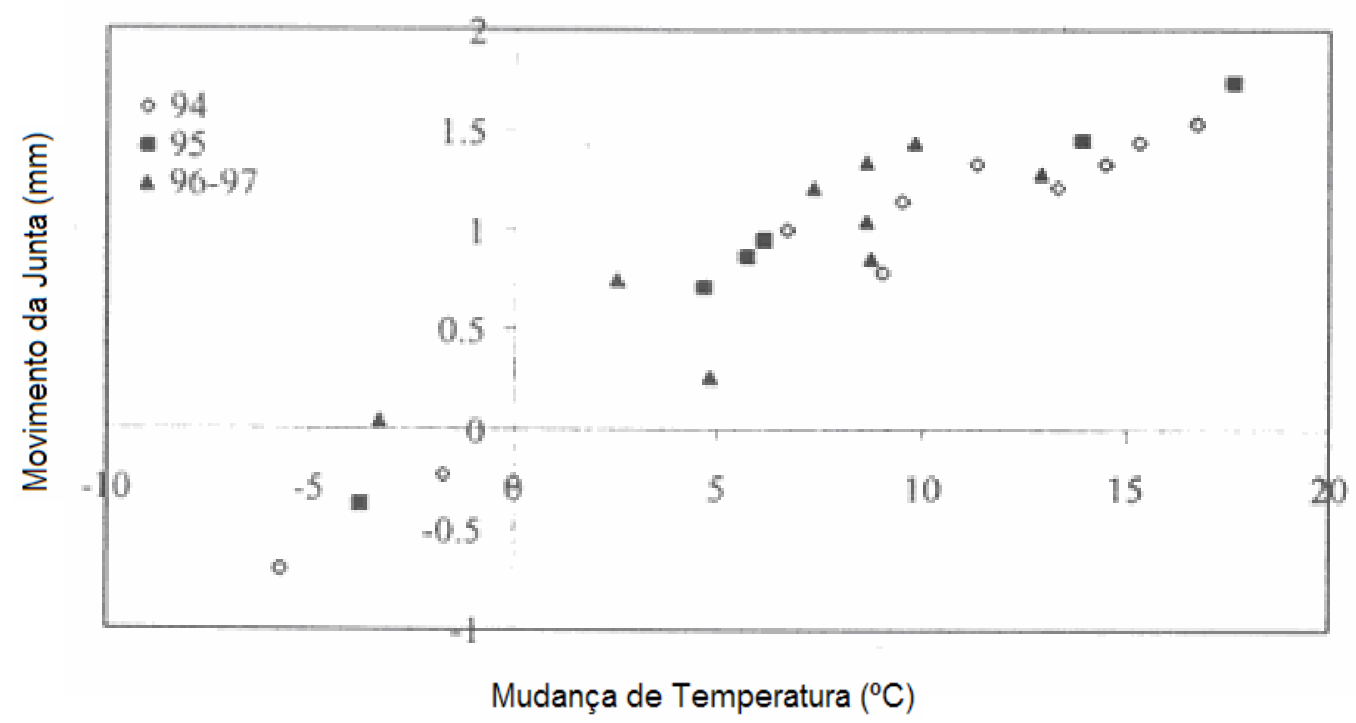

Figura 2.7 Exemplo de movimento de junta (adaptado de: LEE; STOFFELS, 2001). 


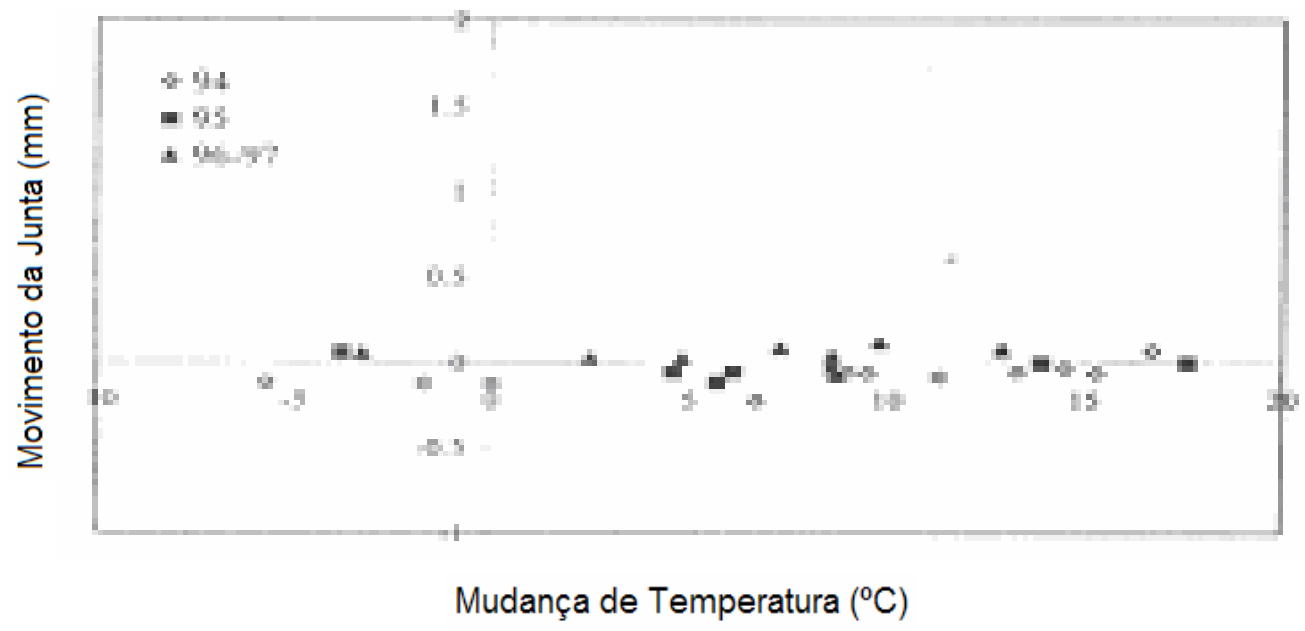

Figura 2.8 Exemplo de congelamento de junta (adaptado de: LEE; STOFFELS, 2001).

\subsection{Efeitos da Temperatura na Transferência de Carga}

Segundo Huang (1993), durante o dia, quando a temperatura no topo da placa de concreto é maior que a temperatura no fundo, fenômeno conhecido por gradiente de temperatura positivo, seu topo tende a se expandir, enquanto o fundo tende a se contrair, ocasionando uma curvatura convexa. Já à noite, ocorre o contrário. Quando o topo da placa está mais frio que o fundo (gradiente de temperatura negativo), ele tende a se contrair e o fundo a se expandir, tornando a placa com curvatura côncava (Figura 2.9). Tal efeito é denominado empenamento térmico.
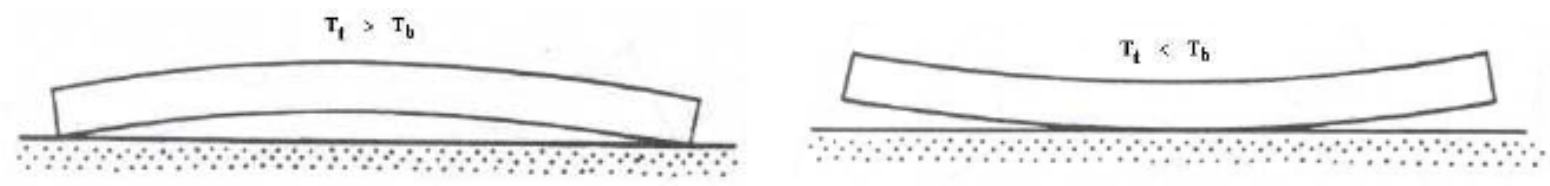

Figura 2.9 Esquema do empenamento da placa durante o dia e à noite. (BUCH et al., 2004).

O empenamento é restringido pela ação do peso próprio da placa, gerando tensões de compressão no topo e tração no fundo, no caso diurno, e tensões de tração no topo e de compressão no fundo da placa durante a noite. Segundo Huang (1993), os gradientes térmicos que ocorrem durante o dia são em geral o dobro daqueles que ocorrem durante a noite. Quando não há diferencial de temperatura, entre topo e 
fundo, o peso próprio faz com que a placa fique em total contato com a base, sem qualquer empenamento. (Figura 2.10).

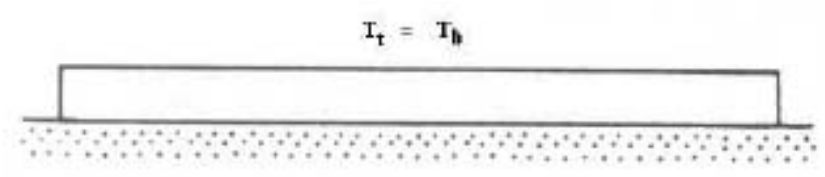

Figura 2.10 Esquema da placa sem empenamento (BUCH et al., 2004).

De acordo com Houben (1994), gradientes térmicos negativos ( $t_{\text {fundo }}>t_{\text {topo }}$ ) abaixo de $-0,03^{\circ} \mathrm{C} / \mathrm{mm}$ ocasionam perda de suporte ao longo da borda da placa de concreto, enquanto que gradientes térmicos positivos acima de $0,03^{\circ} \mathrm{C} / \mathrm{mm}$ ocasionam perda de suporte na área central da placa de concreto. Wu e Tia (1989) acreditavam que os danos causados pela carga de roda em uma placa de concreto não plenamente apoiada, devido a seu empenamento, podiam ser substancialmente maiores que aqueles causados quando a placa encontrava-se em contato pleno. O desprezo dos efeitos térmicos em um projeto pode resultar em um subdimensionamento do pavimento. Um exemplo de variação não linear de temperatura ao longo da profundidade da placa é apresentado na Figura 2.11.

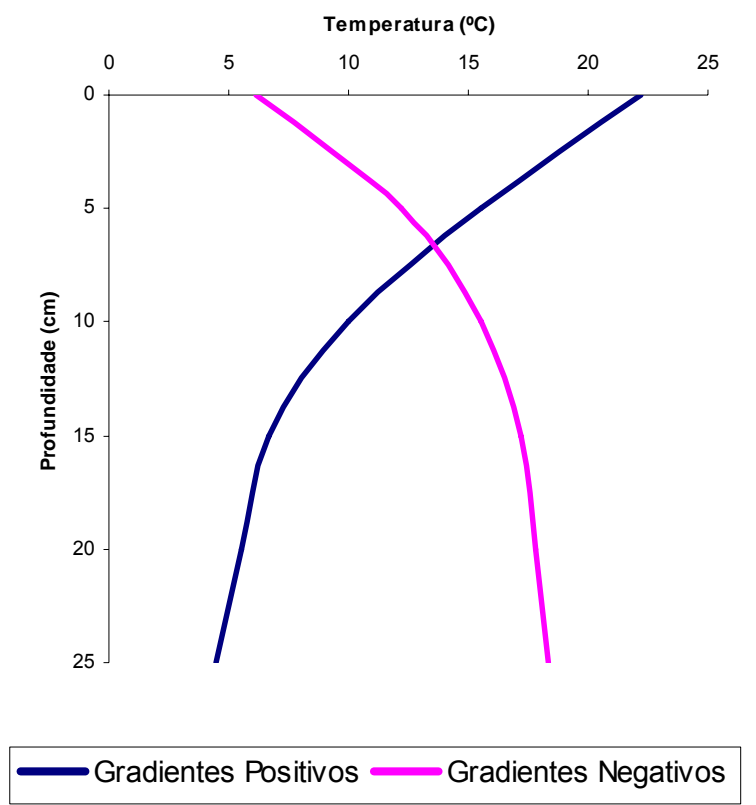

Figura 2.11 Distribuição de temperatura no pavimento (adaptado de: $\mathrm{BUCH}$ et al., 2004). 
Balbo e Severi (2002) apresentaram relações empíricas para o cálculo do diferencial térmico máximo positivo $\left(\mathrm{DT}+\right.$, em $\left.{ }^{\circ} \mathrm{C}\right)$ em placas de concreto com base na temperatura máxima de topo $\left(\mathrm{T}_{\mathrm{T}, \mathrm{Max}}\right.$ em $\left.{ }^{\circ} \mathrm{C}\right)$, a espessura da placa $(\mathrm{h}$, em $\mathrm{mm}$ ) e a presença ou não de umidade no fundo da placa $\left(\mathrm{H}_{\mathrm{f}}\right.$, com valor 0 para ausência de umidade de fundo e valor 1 caso contrário), conforme as equações [2.2] e [2.3] que se seguem, respectivamente, para períodos de primavera/verão e outono/inverno, no clima tropical úmido:

$$
\begin{gathered}
D T+=-18,83+0,542 \cdot T_{T \cdot \text { máx }}+0,037 \cdot h+4,165 \cdot H_{f} \\
D T+=-6,543+0,509 \cdot T_{T . \text { máx }}+0,0013 \cdot h
\end{gathered}
$$

De acordo com estes modelos, os autores chegaram a conclusões de que a espessura da placa é um parâmetro mais relevante para a determinação do diferencial térmico em períodos mais quentes (primavera/verão) se comparados a períodos mais amenos (outono/inverno). Também pode ser inferido que a presença de umidade no fundo da placa é importante em estações úmidas. Com base na medida da temperatura de topo e conhecendo-se a espessura da placa de concreto, é possível determinar o valor do diferencial térmico máximo presente. Conhecido o diferencial térmico na placa determina-se a temperatura de fundo e, sucessivamente, a temperatura média na seção transversal. A zona constante em temperatura na seção transversal causa a contração ou a expansão da placa de concreto; os demais componentes causam o empenamento.

Jeong et al. (2006) observou que o empenamento da placa de concreto simples afetava a transferência de carga em placas com BT, quando não havia rigidez nas barras. A curvatura da superfície da placa causada por gradientes térmicos negativos resultaria em valores de LTE mais elevados.

Vandenbossche (2007) afirma que efeitos de mudanças uniformes de temperatura na placa de concreto simples ocorrem em decorrência de oscilações diárias e sazonais de temperatura. O aumento uniforme de temperatura em toda a placa faz com que a mesma sofra expansão, diminuindo assim a abertura das fissuras e 
juntas. Este processo resulta em um aumento tanto na rigidez da junta transversal sem BT quanto na transferência de carga pela junta. Aumentando a transferência de carga na junta, há diminuição nas deflexões na placa carregada e respectivo aumento nas deflexões que ocorrem na placa descarregada sucessiva. Já com a redução da temperatura, ocorre o contrário: com a contração da placa torna-se maior a abertura entre as juntas e fissuras. Com isso, há uma perda significativa de transferência de carga através dessas juntas, ainda mais se essa junta não tiver BT.

Westergaard em 1926 desenvolveu uma solução para o empenamento nas juntas das placas de concreto em pavimentos de CCP, e mais tarde, Bradbury (1938) ampliou seus estudos. Segundo estes autores, a natureza do empenamento de placas de concreto simples é governada pelo comprimento da placa e pela rigidez relativa do subleito $(\ell)$ dada pela equação [2.4].

$$
\ell=\sqrt{\frac{E \times h^{3}}{12 \times\left(1-v^{2}\right) \times k}}
$$

na qual $E$ é o módulo de elasticidade do concreto, $h$ a espessura da placa, $v$ o coeficiente de Poisson do concreto e k o módulo de reação do subleito.

Ainda Bradbury (1938) e Darter (1977), dentre muitos autores, verificaram que com o aumento da abertura da junta da placa de concreto havia um acréscimo nas tensões máximas da placa.

Há que se considerar que, quando o concreto é lançado e curado, suas propriedades ficam afetadas por essa temperatura de cura média inicial, quando ocorre seu enrijecimento. Durante a vida de serviço da estrutura de pavimento, essas placas irão expandir ou contrair em função de condições climáticas e da própria resistência ao movimento horizontal imposta pela ação de seu peso próprio sobre a superfície da base. No clima temperado, é possível que tal aspecto tenha uma influência apreciável e negativa, no comportamento de placas sem BT, uma vez que, por contração térmica, a abertura das juntas aumentaria, diminuindo bastante o entrosamento dos agregados, e, portanto, impondo até uma possível condição de não transferência de cargas entre placas sucessivas. A temperatura de referência 
dos pavimentos de concreto, para a qual não estão nem contraídos nem expandidos, é um fator limitante para a determinação de aberturas nas juntas e, portanto, para a determinação teórica da transferência de carga.

\subsection{Formulações de Esforços na Transferência de Carga}

Quando uma placa de concreto simples é submetida a uma carga de roda, isto ocasiona o desenvolvimento de tensões e a distribuição destas tensões sobre o subleito. No entanto, a resposta desta placa de concreto a esta carga é controlada pela rigidez da junta transversal ou da borda longitudinal.

A carga de roda posicionada na borda longitudinal da placa pode aumentar expressivamente a tensão na placa de concreto comparada com a mesma carga posicionada no interior (meio) da placa (BALBO, 1999). Por sua natureza, as juntas já enfraquecem todo o sistema de apoio do pavimento. Qualquer tipo de fissura na placa ou junta não selada, permite eventualmente que a água se infiltre nas camadas inferiores. Este fato pode facilitar a ocorrência de erosão na base, com uma conseqüente perda de apoio para a placa de concreto. O material de base ou subleito é deslocado por força da erosão, ocasionando vazios sob a placa, descalçando-a, aumentando as tensões no concreto, o que leva à fissuração do material.

Segundo Buch (1989) a transferência de cargas que ocorre através das juntas nas placas de pavimentos de concreto reduz o movimento vertical independente de placas contíguas, evitando patologias tais como os escalonamentos, esborcinamentos e bombeamento de finos nas juntas e fissuras adicionais.

A necessidade dos mecanismos de transferência de carga fica evidente diante das tensões que ocorrem devido à posição da carga em relação às juntas (Figura 2.12). A carga no interior da placa na posição 1 é aquela que resulta na menor solicitação do concreto enquanto que a carga localizada na borda longitudinal livre (posição 4) é a que resulta em maior solicitação na placa de concreto, quando as placas possuem barras de transferência de cargas como mecanismo de transferência. Quando não 
há dispositivos do tipo BT na junta transversal, que trabalharia exclusivamente por entrosamento de agregados, a posição de carga mais crítica torna-se aquela indicada pela posição 2 (BALBO, 1989).

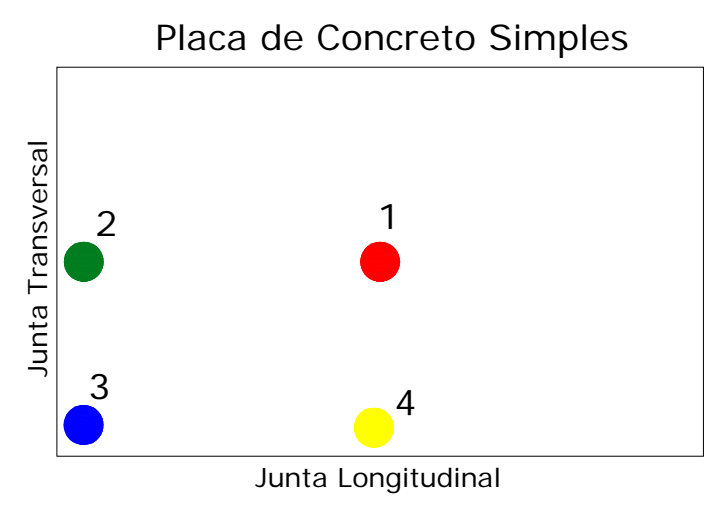

Figura 2.12 Posição do carregamento na placa de CCP (vista de topo).

Para efeitos comparativos, em placas com dispositivo de transferência de carga em juntas, pode-se dizer que se o momento fletor gerado pela carga na posição 2 for igual a 1, essa mesma carga produzirá na posição 1 um momento igual a 0,7 e na posição 4 um momento igual a 1,4 (RODRIGUES et al, 2006). Mais especificamente para placas sem BT, Balbo (1989) encontrou, por simulação numérica de diversas condições de carregamento, tensões de tração na flexão $35 \%$ superiores para cargas sobre juntas transversais em relação ao centro. Portanto, caso não sejam previstos mecanismos de transferência de carga nas juntas, de forma a garantir a resposta conjunta de placas sucessivas, o dimensionamento deveria ser efetuado pela posição de carga mais desfavorável, que nesse caso seria a posição 2.

Tanto que tais fatos são explicitamente considerados nos métodos da Portland Cement Association (PCA) para dimensionamento de pavimentos de concreto simples, nas versões PCA (1966) e PCA (1984). O primeiro método não considera a existência de BT nas placas de concreto e nem acostamento e a carga crítica encontra-se na borda transversal; portanto a tensão crítica de projeto é avaliada próxima a esta junta, empregando-se modelos originalmente desenvolvidos por Westergaard. No segundo (PCA, 1984), cujo cálculo de tensões é baseado em modelos desenvolvidos com base no método dos elementos finitos (utilizando o programa J-Slab), as placas possuem BT e a tensão crítica é calculada nas 
proximidades do centro da borda longitudinal; quando esta borda é livre as tensões são maiores que para o caso de borda conectada com acostamento de concreto, quando há transferência de carga nessa posição por intertravamento de agregados no mínimo ${ }^{2}$.

Fleury e Guimarães (2006) verificaram, embora com testes estáticos de capacidade de carga em juntas (em laboratório) que a presença de elementos de transferência de cargas tem como conseqüência a possibilidade do aumento da capacidade de carga para uma mesma espessura de placa; o que é de se considerar em projetos de pavimentos onde efeitos de repetições de cargas geradas por tráfego misto rodoviário não seja o fator mais limitante, como seriam os casos de pátios de estacionamento de aeronaves e de contêineres, para exemplificar.

Existem outros mecanismos de transferência de cargas em juntas de pavimentos de concreto simples que podem ser considerados, como o próprio entrosamento dos agregados, entretanto sua eficiência depende de uma abertura máxima de juntas inferior a $1 \mathrm{~mm}(\mathrm{ACl}, 1996)$, limitando o comprimento da placa em poucos metros. Como se sabe, quanto menor a abertura de uma junta de retração (ou contração) garantir-se-ia maior entrosamento dos agregados pela maior proximidade entre as faces verticais fissuradas do local.

Segundo Khazanovich e Gotlif (2003) o modelo mais largamente utilizado para a determinação da eficiência de transferência de carga em juntas (LTE) é aquele dado pela equação 1.1 apresentada no Capítulo 1 e reapresentada a seguir:

$$
L T E=\frac{\delta_{2}}{\delta_{1}} \times 100[\%]
$$

É possível também calcular o LTE em função das tensões de tração na flexão simétricas à uma junta (pela relação entre a tensão no lado descarregado pela tensão no lado carregado), empregando-se a equação [2.6]:

\footnotetext{
${ }^{2}$ Comunicação pessoal do professor José Tadeu Balbo em julho 2007.
} 


$$
L T E_{\sigma}=\frac{\sigma_{2}}{\sigma_{1}} \times 100[\%]
$$

A grande dificuldade de empregar a equação acima é obter tais tensões em campo, o que é feito por meio de instrumentação, determinando-se deformações, que custa caro e requer muito trabalho de coleta e interpretação dos resultados.

\subsubsection{Tipos de Barras de Transferência e sua Disposição em Juntas}

A transferência de carga, como foi dito anteriormente, é a capacidade da junta de um pavimento de concreto transferir carga de uma placa a outra adjacente, o que pode ser realizado ou por intertravamento de agregados ou por mecanismos de transferir cargas, como as barras de transferência, ou por ambos.

Para fornecer uma elevada e estável LTE, barras de transferência de carga devem estar presentes nas juntas transversais ao longo do pavimento de concreto simples. Quando as BT são utilizadas em pavimentos de concreto, as cargas próximas às juntas são distribuídas entre as duas placas adjacentes, reduzindo deflexões e tensões nessas áreas.

Como resultado, os pavimentos com barras de transferência nas juntas das placas desenvolvem pouco ou nenhum escalonamento, tornando a qualidade de rolamento consideravelmente melhor ao longo dos anos. Assim, o uso de barras de transferência de carga tornou-se essencial em projetos de pavimentos de concreto simples. Entretanto, as BT sofrem corrosão ao longo dos anos devido à umidade e ao emprego de sais de desgelo para remoção de neve na superfície, no caso de países em clima temperado.

Existem vários formatos e tipos de barras de transferência de carga metálicas utilizadas em juntas de pavimentos de concreto simples. As barras de seção retangular são pouco empregadas no Brasil, embora tenham larga utilização nos exterior. Outro tipo de dispositivo de transferência de carga são as placas em 
formato de diamante usadas juntamente com barras de seção retangular. Geralmente são empregadas em juntas de construção para restringir e transferir esforços permitindo a movimentação da placa de concreto tanto vertical quanto horizontal. Segundo Walker e Holland (1998), a capacidade de acomodação horizontal é essencial em pavimentos com juntas nas duas direções como em aeroportos, em que as juntas se encontram. Em concreto protendido, no qual o espaçamento entre as juntas é maior, esse tipo de mecanismo de transferência de carga se torna mais eficiente.

Walker e Holland (1998) fizeram uma comparação analítica entre barras de transferência de carga circular e placas formato diamante utilizando o MEF e cálculos comparativos. As únicas vantagens que os autores encontraram para a substituição de barras circulares por placas tipo diamante, sem perda de desempenho e eficiência de transferir carga de uma placa a outra, para espaçamentos de juntas de $300 \mathrm{~mm}$, foram que: ao utilizar placas tipo diamante para transferir carga em juntas, materiais compressíveis são facilmente aderidos ao lado destas placas de transferência acomodando melhor os deslocamentos horizontais paralelos na junta minimizando o tamanho e a quantidade de juntas de retração; e essas placas de transferência possuem maior custo/beneficio que as barras metálicas.

Eddie et al (2001) realizaram um trabalho substituindo barras de transferência de carga de aço por barras de polímero de resina de fibra de vidro, denominado GFRP (do inglês, Glass Fiber-Reinforced Polymer). Este estudo teve início quando as barras metálicas começaram a apresentar corrosão e com isto, o pavimento de concreto poderia se expandir e se danificar. O objetivo dos autores era avaliar o desempenho das juntas através da eficiência de transferência de carga (LTE).

Neste trabalho foram moldados em laboratório doze placas de concreto simples para comparar o desempenho dos dois tipos de dispositivo de transferência de carga. As placas possuíam dimensões 2440 × $610 \mathrm{~mm}$ e $254 \mathrm{~mm}$ de espessura. As barras foram locadas a $150 \mathrm{~mm}$ das bordas e $300 \mathrm{~mm}$ entre elas. Este experimento consistiu em três fases: na primeira, foram realizados ensaios com carga estática utilizando a base de matriz de molas metálicas; a segunda fase foi caracterizada por 
ensaios de carga também estática com as placas apoiadas em base granular; e na terceira fase as placas eram apoiadas em base granular, mas a carga era dinâmica.

A eficiência de transferência de carga nas juntas das placas ensaiadas na primeira fase, onde o carregamento foi de $100 \mathrm{kN}$, variou entre 86 e 100\%, tendo as barras de GFRP apresentando melhor desempenho. Já nas placas ensaiadas na segunda fase, onde estão apoiadas em base granular, até uma carga de $300 \mathrm{kN}$, a LTE se manteve entre 90 e $97 \%$. Os resultados mostraram que nesta fase também as barras de GFRP apresentaram melhor desempenho (Eddie et al, 2001).

Já na terceira fase, cujo ensaio compreendia carregamento dinâmico, foram aplicadas cargas com uma freqüência de $6 \mathrm{~Hz}$, variando a intensidade da carga de 20 a $130 \mathrm{kN}$, simulando desta forma a aproximação do veiculo e a passagem do mesmo sobre a junta. Em relação a eficiência de transferência de carga, as placas com BT metálicas obtiveram valores de 94 a $97 \%$ de LTE enquanto que as placas com barras tipo GFRP apresentaram valores de 80 a $90 \%$ de LTE em um milhão de ciclos.

Comparando-se os ensaios de Eddie et al (2001), tanto os de carga estática quanto o de cargas cíclicas, pode-se dizer que há a possibilidade de se substituir as barras metálicas por barras de polímero, porém o baixo módulo de elasticidade destas ultimas apresenta um limitador para o seu uso, ou seja, a tensão de suporte entre a barra e o concreto pode ser reduzida, diminuindo a transferência de carga na junta.

Malisch (2000) comenta que as barras circulares, por não suportarem bem as movimentações horizontais, podem causar fissuras nas placas de concreto simples devido ao empenamento restringido, o que as barras de seção retangular suportam com maior facilidade tais movimentos.

O modo como devem ser inseridas as BT é apresentado na figura 2.13. O equipamento de pavimentação em concreto pode também ter uma função de inserir as barras durante a concretagem. (Figura 2.14) 


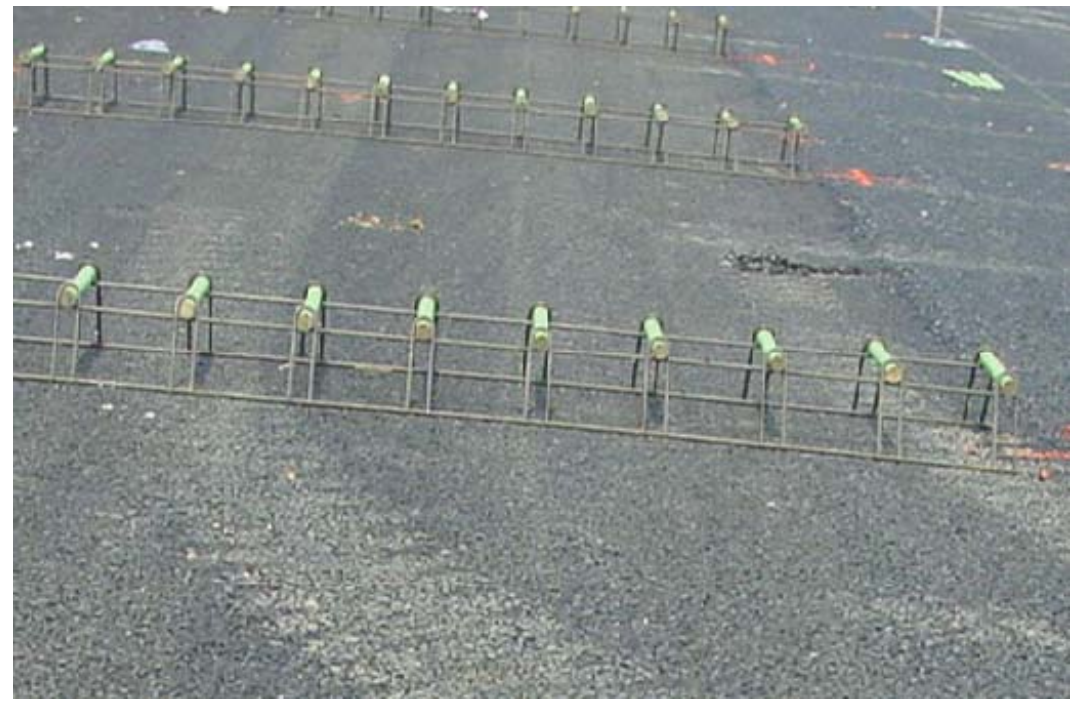

Figura 2.13 - Colocação de barras circulares metálicas (SNYDER, 2007).

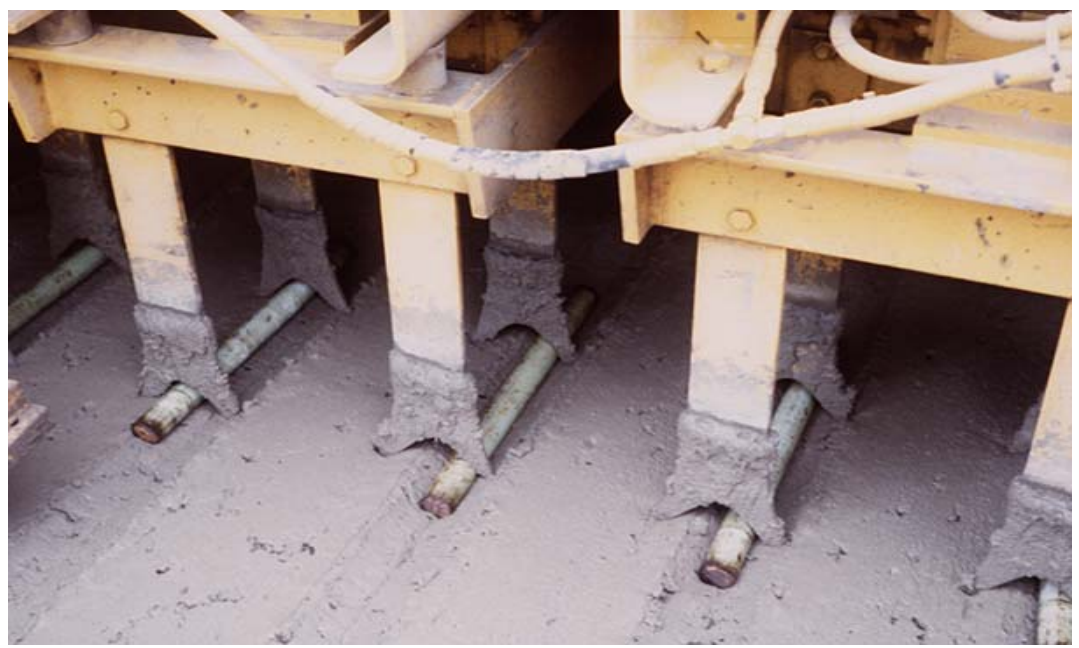

Figura 2.14 - Pavimentadora inserindo barras de transferência de carga na execução do pavimento de concreto. (SNYDER, 2007)

\subsubsection{Esforços nas Barras de Transferência}

As barras de transferência de carga circulares têm seu desempenho condicionado por dois parâmetros principais: o espaçamento e o diâmetro das barras. Secundariamente, é função também da abertura da junta (YODER e WITCZAK, 1975). Na prática é comum, para a locação de BT, o emprego do espaçamento fixo (geralmente $300 \mathrm{~mm}$ ) e diâmetro conforme a espessura do pavimento, conforme indicados na Tabela 2.2. 
Tabela 2.2 Dimensões típicas das barras de transferência de carga (adaptado de: RODRIGUES e CASSARO, 1998).

\begin{tabular}{cccc}
\hline $\begin{array}{c}\text { Espessura da } \\
\text { Placa }(\mathbf{m m})\end{array}$ & $\begin{array}{c}\text { Diâmetro da } \\
\text { Barra }(\mathbf{m m})\end{array}$ & $\begin{array}{c}\text { Comprimento da } \\
\text { Barra }(\mathbf{m m})\end{array}$ & Espaçamento (mm) \\
\hline 125 & 16 & 400 & 300 \\
150 & 20 & 400 & 300 \\
200 & 25 & 460 & 300 \\
$>200$ & 32 & 460 & 300 \\
\hline
\end{tabular}

Friberg (1938) apresentou soluções analíticas para o dimensionamento de barras de transferência de cargas em juntas de pavimentos de concreto simples. Para finalidades práticas, a influência da carga se dá até uma distância igual a 1,8 vezes o raio de rigidez relativo da placa de concreto dado pela equação 2.4 , apresentada anteriormente neste capítulo.

Na Figura 2.15 são representados os esforços aplicados nas barras, na forma de diagrama de distribuição de forças, quando a carga está posicionada próxima à junta com barras de transferência. Considerando uma junta com 100\% de eficiência de transferência de carga, o esforço atuante $\left(P_{a}\right)$ na barra mais solicitada, situada imediatamente abaixo da carga ( $P$, em kgf), é dado pela equação 2.7 , e quando a barra se situa próxima a uma borda livre, o esforço atuante nesta barra corresponde à equação 2.8 .

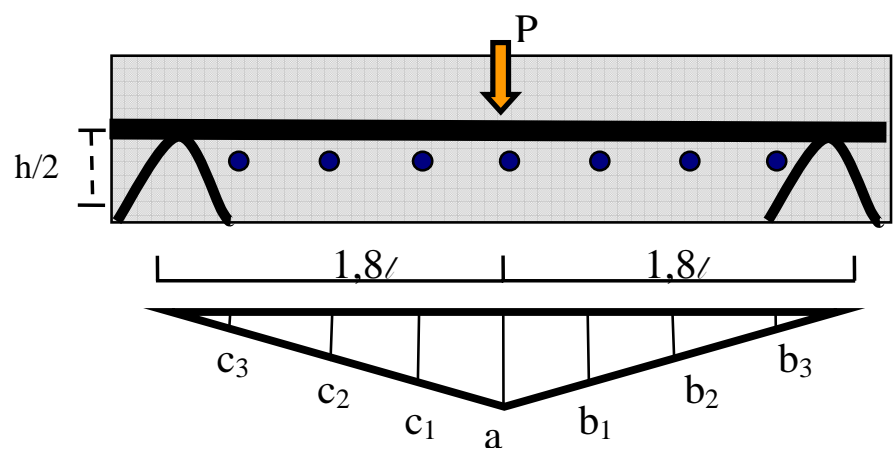

Figura 2.15 Distribuição dos esforços nas BT em junta transversal.

Sendo a igual a $1 \mathrm{e} \mathrm{b} 1=\mathrm{c} 1, \mathrm{~b} 2=\mathrm{c} 2, \ldots \mathrm{bn}=\mathrm{cn}$, tendo $b_{n}=1-\left(\frac{n \times x}{1,8 \ell}\right)$, e $\mathrm{x}$ é o espaçamento entre as barras e $\ell$ é o raio de rigidez relativa (equação [2.4]). 


$$
\begin{aligned}
& P_{a}=\frac{0,5 \times P}{\left[1+2 \times\left(b_{1}+b_{2}+\ldots+b_{n}\right)\right]} \\
& P_{a}=\frac{0,5 \times P}{\left[1+\left(b_{1}+b_{2}+\ldots+b_{n}\right)\right]}
\end{aligned}
$$

Sendo assim, a análise das duas expressões permite perceber que a barra mais solicitada estará sempre próxima a uma borda livre. Um modelo proposto por Friberg (1938) admite que a placa de concreto seja absolutamente rígida e, portanto, o subleito acaba não recebendo esforços, o que, na realidade, não ocorre; logo, as cargas nas barras avaliadas acabam sendo maiores do que o calculado.

A rigidez relativa desta barra engastada no concreto é dada pela equação [2.9], em que o k é o módulo de reação do subleito, b é o diâmetro da barra de transferência de carga circular, E é o módulo de elasticidade do material que constitui a BT e I o momento de inércia da seção transversal da barra.

$$
\beta=\sqrt[4]{\frac{k \times b}{4 \times E \times I}}
$$

Então, para avaliar a influência do raio de rigidez relativa na força aplicada nas barras de transferência, pode-se comparar, por exemplo, uma carga $P$ aplicada em uma junta, exatamente no alinhamento de uma BT. A tendência natural é que essa força se distribua com maior intensidade na barra em seu alinhamento, enquanto as barras adjacentes recebem menores esforços, proporcionais à distância em que se encontram do centro de aplicação de cargas. (OLIVEIRA, 2000). 


\subsubsection{Transferência de Carga por Intertravamento de Agregados}

Segundo Khazanovich e Gotlif (2003) a transferência de cargas se dá por meio de barras de transferência, do intertravamento de agregados, pela base e pelo subleito. Pereira et al. (2006) mostraram inclusive grande capacidade de transferência de carga de bases asfálticas para whitetoppings. O intertravamento de agregados ocorre nas faces fissuradas abaixo da junta serrada (de contração), sendo que, como visto anteriormente, a abertura dessa fissura afeta de forma significativa a transferência de cargas.

Bian et al (2007) afirma que durante os primeiros anos da vida útil do pavimento de concreto simples e sob uma temperatura alta, o intertravamento de agregados proporciona alta transferência de carga; porém tal transferência pode variar durante todo o ano, devido a mudanças climáticas. Quando a temperatura é baixa, a abertura da junta aumenta e o contato entre as faces abaixo da fissura se distancia, tendo um intertravamento de agregados reduzido. Repetições de carga de roda podem desgastar as faces das juntas, diminuindo assim o intertravamento de agregados ao longo dos anos de uso dos pavimentos.

Como foi dito anteriormente, as juntas transversais são executadas para orientar as fissuras de retração por secagem nos pavimentos de concreto. Este espaçamento pode ser determinado pela presença ou não de armadura, pela temperatura do concreto e pelas propriedades dos agregados (interfere no coeficiente de expansão térmica do concreto), além de considerados os principais aspectos de projeto que são as magnitudes das cargas e o empenamento térmico combinados.

Buch (1989) estudou o mecanismo de transferência de cargas por meio do intertravamento de agregados nas faces fissuradas por retração induzidas por serragem nas juntas. A textura dessas faces bem como seu afastamento interferem diretamente nessa transferência de carga nas juntas das placas de concreto simples. No trabalho é proposto modelo numérico, apresentado na seqüência, relacionando o valor de LTE (em \%) e parâmetros ligados à natureza estrutural do sistema de pavimento de concreto, que são seu raio de rigidez relativa do sistema placa e subleito $(\ell)$ e o módulo de reação do subleito $(k)$, além de um parâmetro que 
caracteriza o módulo em cisalhamento entre as faces homólogas verticais na junta serrada na placa de concreto; esse último parâmetro é denominado por AGG (Aggregate Interlock), tendo sido tal modelo gerado pelo método dos elementos finitos (programa ILLISLAB) calibrado com resultados de experimentos em laboratório, de acordo com a equação [2.10].

$$
L T E=\frac{1}{0,011+0,0733 \times e^{\left(-0,862 \times \frac{A G G}{k \times \ell}\right)}}
$$

Observa-se, assim, que a espessura da placa e a rigidez do sistema de apoio interferem diretamente na transferência de carga. Entretanto, para Buch (1989) a ausência de BT torna este mecanismo de transferência de carga ineficiente.

Segundo Colley e Humphrey (1966), em seus ensaios, o único mecanismo de transferência de carga neste experimento seria por entrosamento de agregados. As aberturas das juntas foram medidas através de pinos de referência e extensômetro tipo Whittemore. As deflexões foram medidas com deflectômetros de precisão de 0,025 mm para cargas estáticas e com extensômetros elétricos para as cargas dinâmicas.

Outro fator estudado por Colley e Humphrey (1966) foi a influência da forma do agregado sobre a eficiência de transferência de carga nas juntas das placas de concreto. Os agregados graúdos utilizados foram: seixo rolado com valor de abrasão Los Angeles de 28; e pedra britada com resistência ao desgaste Los Angeles de 24. Verificou-se que a eficiência da junta aumentou com o aumento da angulosidade do agregado graúdo.

Com esse trabalho, os autores concluíram que o entrosamento de agregados pode ser um mecanismo eficiente de transferência de carga, e o comportamento da junta é influenciado por sua abertura, resistência da fundação, intensidade da carga, espessura da placa de concreto e forma do agregado. Cada uma destas variáveis, juntamente com o ambiente, deve ser considerada no projeto. 


\subsubsection{Modelos Mecanicistas de LTE com Intertravamento de Agregados}

Um modelo para o mecanismo de transferência de carga era um problema sério. Vários autores estudaram e desenvolveram modelos de elementos finitos a fim de entenderem melhor o processo de transferência de carga nas juntas. Algumas hipóteses foram obtidas destes estudos, como:

- Antes do carregamento, as placas de concreto são planas e em pleno contato com a base (subleito);

- As juntas de pavimentos de concreto se propagam pela camada de base, e não ocorre transferência de carga pela base;

- O subleito segue o modelo de Winkler, que propunha que não há transmissão de esforços para o subleito, ou seja, não há transferência de carga pelo subleito;

- As juntas de pavimento de concreto simples possuem LTE uniforme ao longo de sua espessura. A transferência de carga completa em juntas sem BT ocorre por meio de intertravamento de agregados, ao passo que em juntas com BT, a transferência se dá pelas barras de transferência.

A relação desenvolvida por loannides e Korovesis $(1990$, 1992) formam uma base para a retroanálise da rigidez de juntas por intertravamento de agregados em placas sem BT ou da rigidez da barra em juntas com BT, onde o LTE é conhecido.

Crovetti (1994) propôs uma relação entre LTE e AGG, conforme é apresentado na equação [2.11] seguinte:

$$
L T E=\frac{100 \%}{1+1,2 \times\left(\frac{A G G_{T O T}}{k \times \ell}\right)^{-0,849}}
$$


O modelo de Zollinger et al (1999) baseado nesta relação é conforme a equação [2.12]:

$$
L T E=\frac{100 \%}{1+10\left[\frac{0,214+0,183 \times \frac{a}{\ell}-\log \left(\frac{A G G_{T O T}}{k \times \ell}\right)}{1,18}\right]}
$$

Considerando espessura da placa de concreto (h) igual a $200 \mathrm{~mm}$, um módulo de elasticidade $(E)$ de $30.000 \mathrm{~N} / \mathrm{mm}^{2}$, um módulo de reação do subleito $(k) 0,05$ $\mathrm{MPa} / \mathrm{mm}, \mu=0,15$ e o raio do prato de aplicação de carga de $150 \mathrm{~mm}$, e os modelos de Crovetti, Zollinger, loannides e Buch (equação 2.10) resultaram em um gráfico apresentado na Figura 2.16.

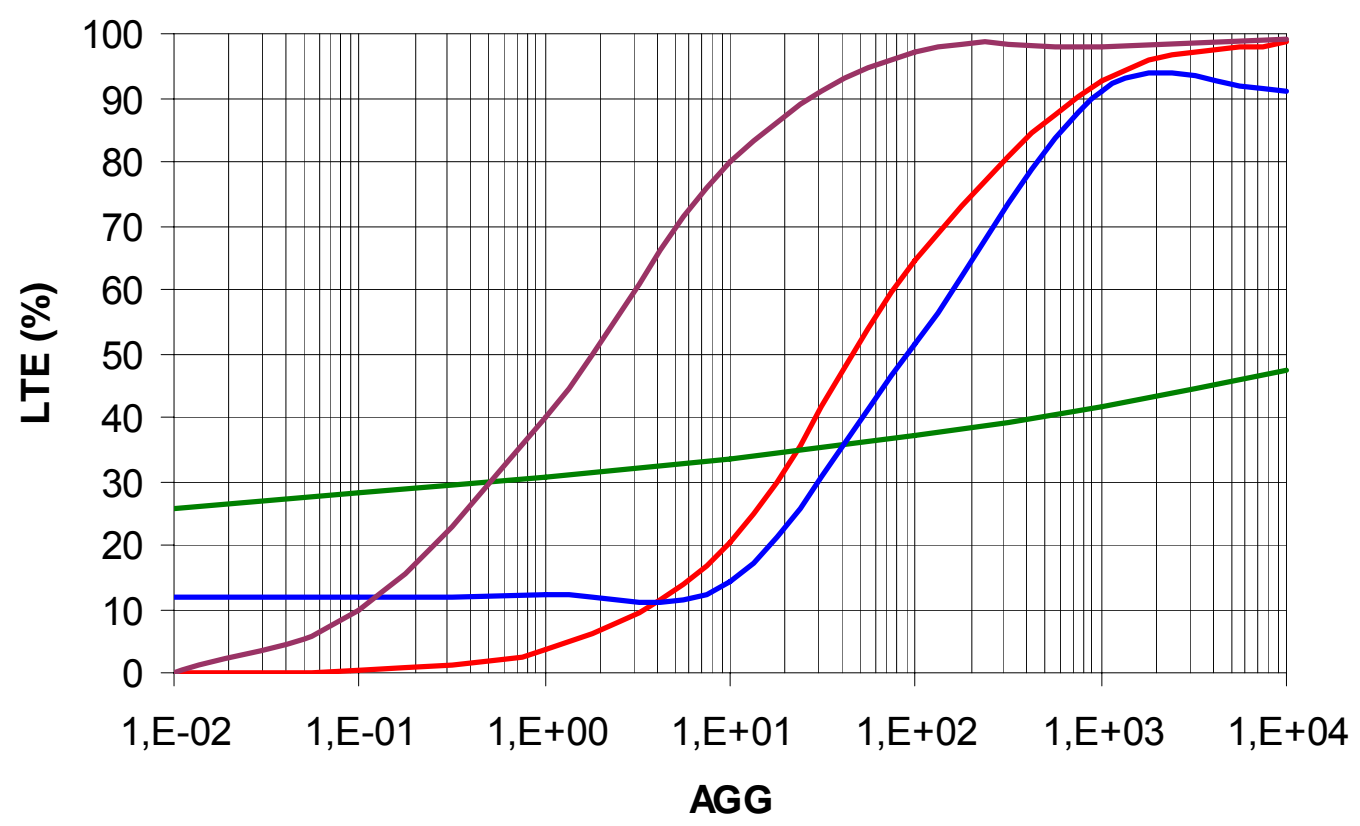

\section{CROVETTI —ZOLLINGER —BUCH — IOANNIDES}

Figura 2.16 - Modelos mecanicistas de LTE versus AGG. 


\subsection{Medidas de Transferência de Cargas em Juntas}

Algumas medidas de transferência de carga em juntas de pavimentos de concreto simples são apresentadas neste item a fim de se comparar resultados práticos de testes de aplicações de carga tanto em campo quanto em laboratório.

Para uma investigação da influência da resistência do solo de fundação na eficiência e durabilidade de transferência de carga, Colley e Humphrey (1966) utilizaram três tipos de subleito em seu estudo: argila, pedregulho e uma sub-base tratada com cimento. Com uma abertura de 0,89 mm e sobre subleito de argila, comparando-se duas placas de espessuras diferentes (180 e $280 \mathrm{~mm}$ ), a eficiência de transferência de carga foi de $5 \%$ para a mais delgada e $29 \%$ para a placa mais espessa. É evidente que a rigidez da placa mais espessa contribuiu para a resistência do pavimento sobre esse tipo de subleito. Sobre uma base granular, a eficiência saltou para $9 \%$ e $50 \%$, respectivamente. E aumentou ainda mais sobre base tratada com cimento. E quanto maior a abertura das juntas, menor a eficiência de transferir carga.

Quanto à grandeza da carga, os ensaios realizados com cargas repetidas de 20, 30 e $40 \mathrm{kN}$, após 500.000 repetições de carga, determinaram eficiência de 96, 68 e $39 \%$, respectivamente. Depois de 1.000 .000 de ciclos, estes valores passaram a ser 98, 65 e 9\%. Estes dados indicam que a eficiência decresce quando a grandeza da carga aumenta. Na placa ensaiada com carga de $2 \mathrm{t}$ foram adicionadas 1.000 .000 de aplicações, não se verificou nenhuma variação de eficiência. (COLLEY; HUMPHREY, 1966).

Vandenbossche (2007) estudou o desempenho da junta utilizando a divisão da deflexão obtida sob a carga aplicada a $152 \mathrm{~mm}$ de distância da junta $\left(\delta_{1}\right)$ pela deflexão medida a 152 mm de distância da mesma junta, porém no lado da placa descarregado $\left(\delta_{2}\right)$, conforme já foi apresentado na equação 2.4. A eficiência de transferência de carga pode ser corrigida para a curvatura da placa usando deflexões coletadas na placa do meio de um conjunto de placas sucessivas. Sendo assim, o LTE é multiplicado pela deflexão medida sob a placa do meio $\left(\delta_{M}\right)$ dividido 
pela deflexão $305 \mathrm{~mm}$ para o centro da carga aplicada $\left(\delta_{\mathrm{M} 12}\right)$, conforme equações 2.13 e 2.14. O fator de correção (A) explica o fato de que as deflexões estão sendo medidas $152 \mathrm{~mm}$ distantes da junta e não diretamente na junta. Khazanovich e Gotlif (2003) propunham que os efeitos da curvatura (flexão) da placa mínimos aceitos no caso da rigidez da placa muito baixa, ou seja, o raio de rigidez relativa $(\ell)$ seria menor que $750 \mathrm{~mm}$. Nos estudos de Vandenbossche, o raio de rigidez relativa variou entre $1,45 \mathrm{~m}$ e $0,81 \mathrm{~m}$. Devido a grande variação de $\ell$ nas seções teste do estudo em questão, o fator de correção para a curvatura foi usado no cálculo de LTE.

$$
\begin{gathered}
A=\frac{\delta_{M}}{\delta_{M 12}} \\
L T E_{\text {corrigido }}=L T E_{\delta} \times A \times 100 \%
\end{gathered}
$$

Vandenbossche (2007) acrescenta ainda que uma eficiência de transferência de carga em placas de pavimento de concreto simples novo sem BT nas juntas pode variar entre 70 e 100\%. E o LTE em pavimentos novos com BT variam entre 80 e $100 \%$. Os dados de LTPP mostram que o LTE em pavimentos de concreto simples em serviço nos EUA e no Canadá variam entre si menos que $20 \%$. Um LTE menor que $70 \%$ é considerado inaceitável.

A Federal Highway Administration (FHWA, 1990) recomenda que uma restauração seja desenvolvida para prevenir futuros danos no pavimento, caso ocorra uma das condições a seguir: escalonamento na junta ou fissuras de $3 \mathrm{~mm}$ ou mais; LTE menor que 70\%; diferença entre a deflexão na placa carregada e na placa descarregada maior que $0,25 \mathrm{~mm}$; e acúmulo de escalonamento nas juntas e fissuras acima de $525 \mathrm{~mm} / \mathrm{km}$ de extensão.

Tertuliano (2005) desenvolveu uma pesquisa para avaliar os mecanismos de transferência de esforços cisalhantes (verticais), comparando os valores obtidos experimentalmente com recomendações de cálculo e verificando a influência da presença ou não de barras de transferência de carga. Em seus ensaios com 
carregamento estático avaliaram-se oito placas de concreto cujas dimensões foram 1.100 x $600 \mathrm{~mm}$, variando: a presença ou não de BT, a espessura da placa de concreto (80 ou $120 \mathrm{~mm}$ ), largura da abertura da junta (6 ou $30 \mathrm{~mm}$ ) e tipo de junta (serrada ou moldada).

Os resultados deste experimento mostraram que as juntas com BT com abertura de $30 \mathrm{~mm}$ na série moldada apresentaram valores decrescentes de eficiência de transferência de carga na medida em que se aumenta o carregamento, estabilizando este caimento após a carga de 40 kN, conforme é apresentado na Figura 2.17. Notase que para juntas com abertura de $6 \mathrm{~mm}$, após este nível de carregamento, o LTE continua diminuindo. Já as juntas serradas mantiveram um LTE de aproximadamente $100 \%$ até a fissuração da junta. Após este processo, a eficiência de transferência de carga nas juntas com BT inicia uma descida se estabilizando na faixa de $90 \%$, enquanto que nas juntas sem BT, há uma queda brusca de LTE. (Figura 2.18).

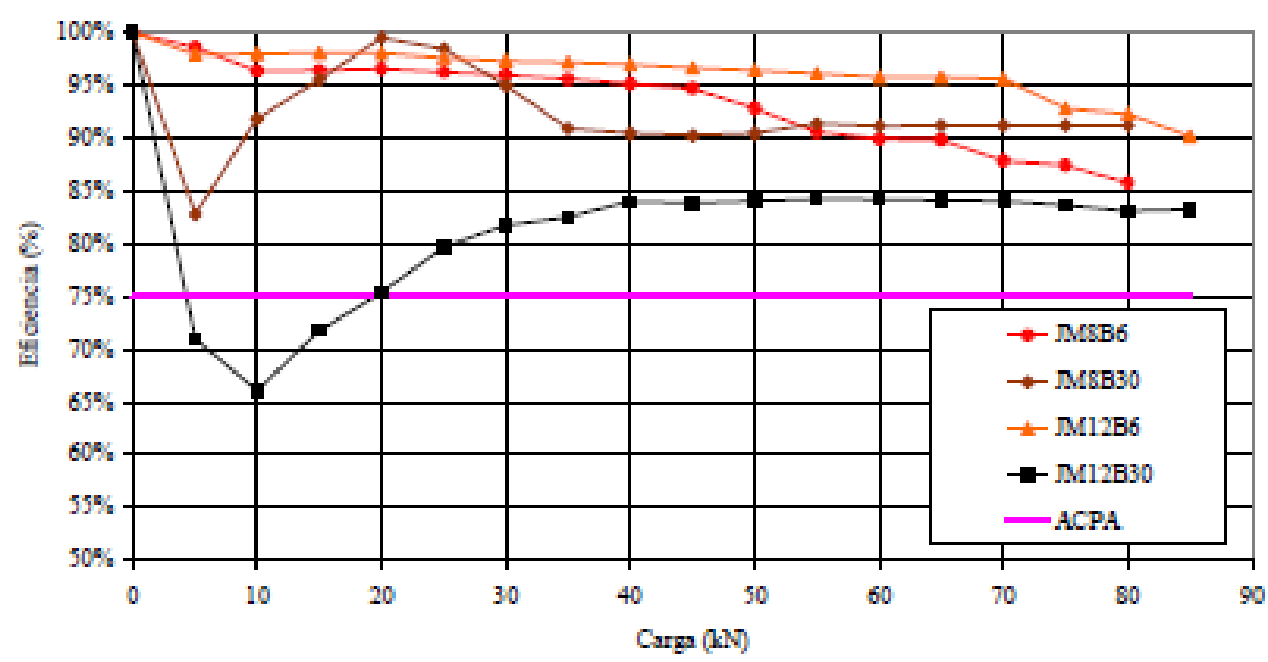

Figura 2.17 - Eficiência de junta moldada versus carga aplicada. (TERTULIANO, 2005). 


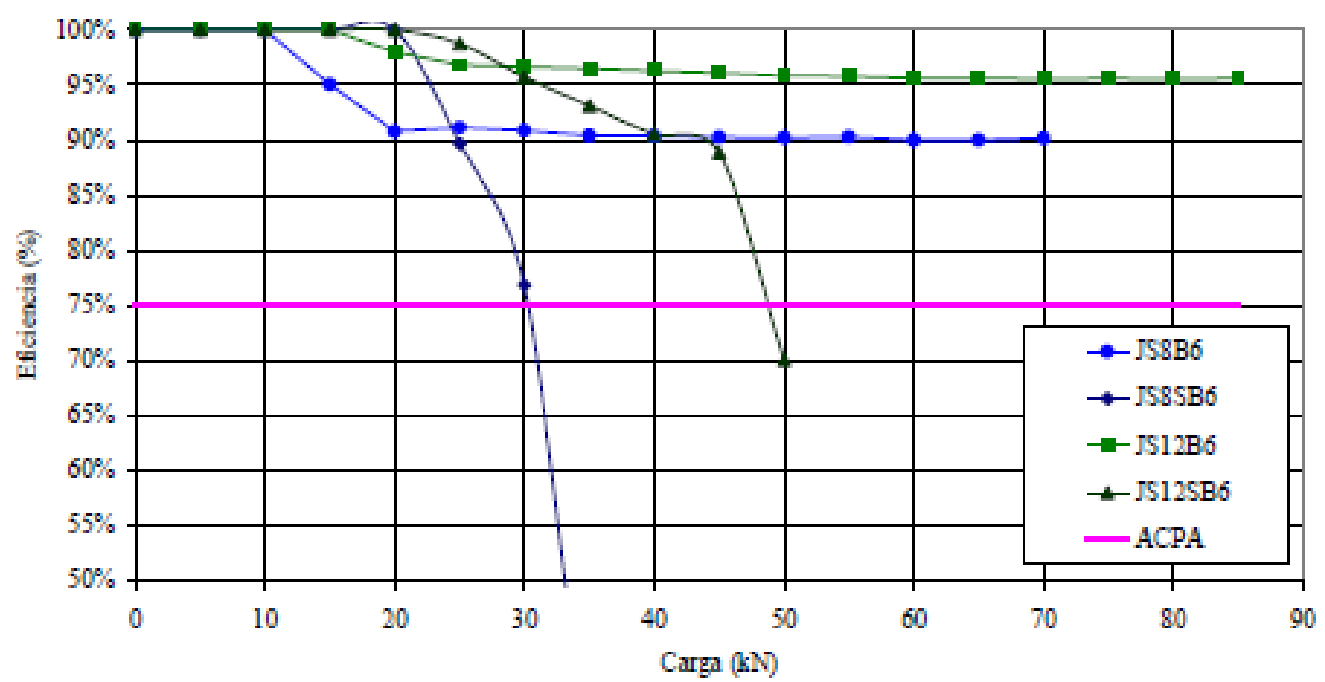

Figura 2.18 - Eficiência de junta serrada versus carga aplicada (TERTULIANO, 2005).

Para as duas séries de juntas, moldada e serrada, as placas de $120 \mathrm{~mm}$ de espessura apresentaram maiores valores de LTE. Entretanto, a placa com junta serrada e com presença de BT seria a melhor opção em termos de eficiência e desempenho do pavimento. Porém as placas sem BT obtiveram um resultado satisfatório quando o nível de carregamento é baixo, até a fissuração da junta. Todos os resultados deste experimento foram acima do limite sugeridos pela ACPA $(75 \%)$.

O estudo mais recente de comportamento de juntas transversais em placas de concreto simples foi realizado por Rodrigues (2008) em que se experimentaram placas de concreto em laboratório com dimensões 2200 × 600 mm, com espessuras de 120 e 160 mm, utilizando como dispositivos de transferência de carga BT circular e quadrada, placa e disco, e as juntas seriam ou serradas ou moldadas.

Os resultados obtidos neste experimento mostraram que utilizando as barras de transferência de carga, tanto a circular quanto a quadrada, a LTE diminui à medida que a carga aumenta, o que difere do mecanismo de transferência utilizando em especial o disco, em que a transferência de carga na junta serrada diminui após elevado nível de carregamento. Entre as placas e o disco metálicos, o ultimo teve um maior desempenho do que a placa metálica em relação à transferência de carga, conforme Figuras 2.19 e 2,20. 


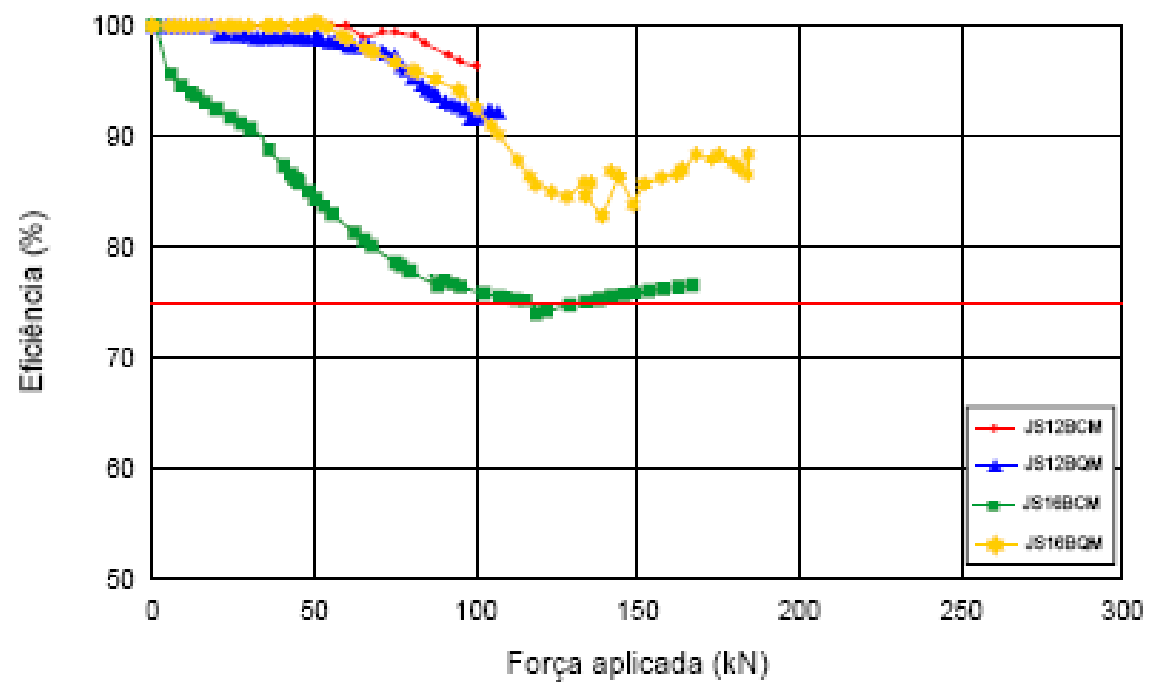

Figura 2.19 LTE em função da carga aplicada em junta serrada utilizando como mecanismo de transferência de carga barras circulares e quadradas. (RODRGIGUES, 2008).

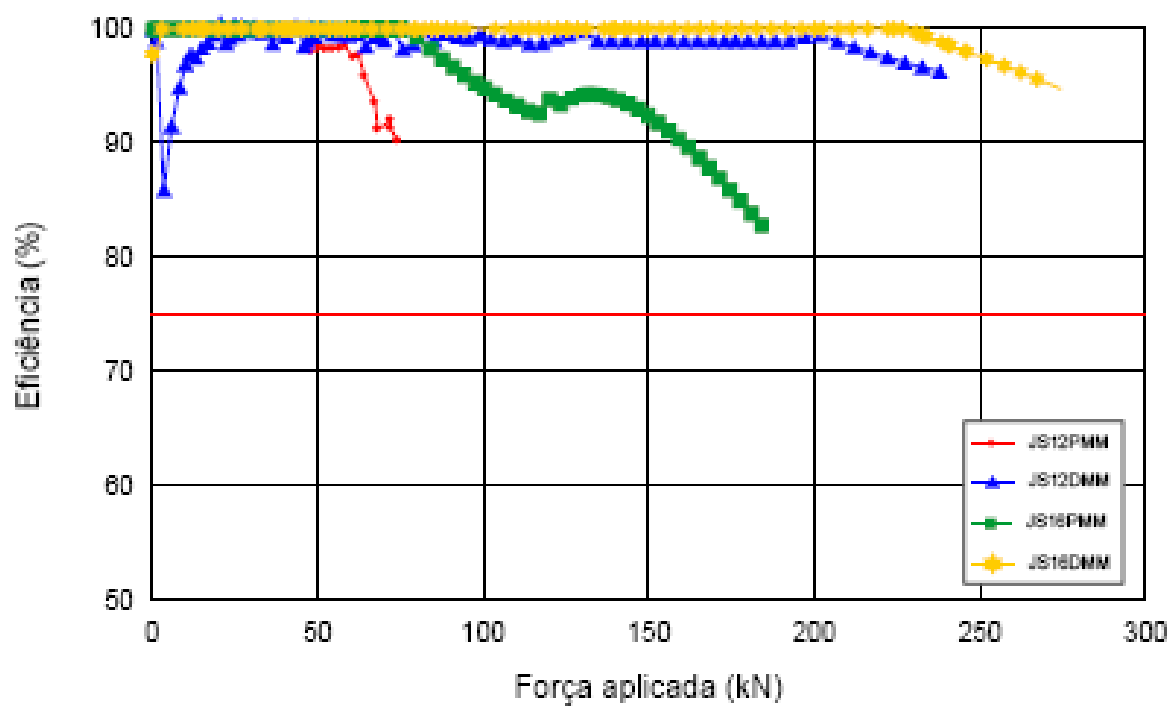

Figura 2.20 LTE em função da carga aplicada em junta serrada utilizando como mecanismo de transferência de carga prato e discos metálicos. (RODRGIGUES, 2008)

\subsection{Variações Diárias da Transferência de Cargas em Juntas}

Shahin (1985) propõe que a transferência de carga em juntas seja corrigida conforme a temperatura ou horário, pois os valores de LTE que ocorrem no início da manhã são menores que aqueles verificados no fim do dia devido à expansão do concreto no período. Na Figura 2.21 medidas reais para um dia, em diversos horários, permitem observar que, pela manhã das $8 \mathrm{~h}$ às $11 \mathrm{~h}$ ocorreu pouca variação 
no LTE que variou de 45 a $50 \%$. Após esse período e até às 14 h há um aumento linear e crescente para $60 \%$. Por fim, a partir das 14 h não há alteração de LTE.

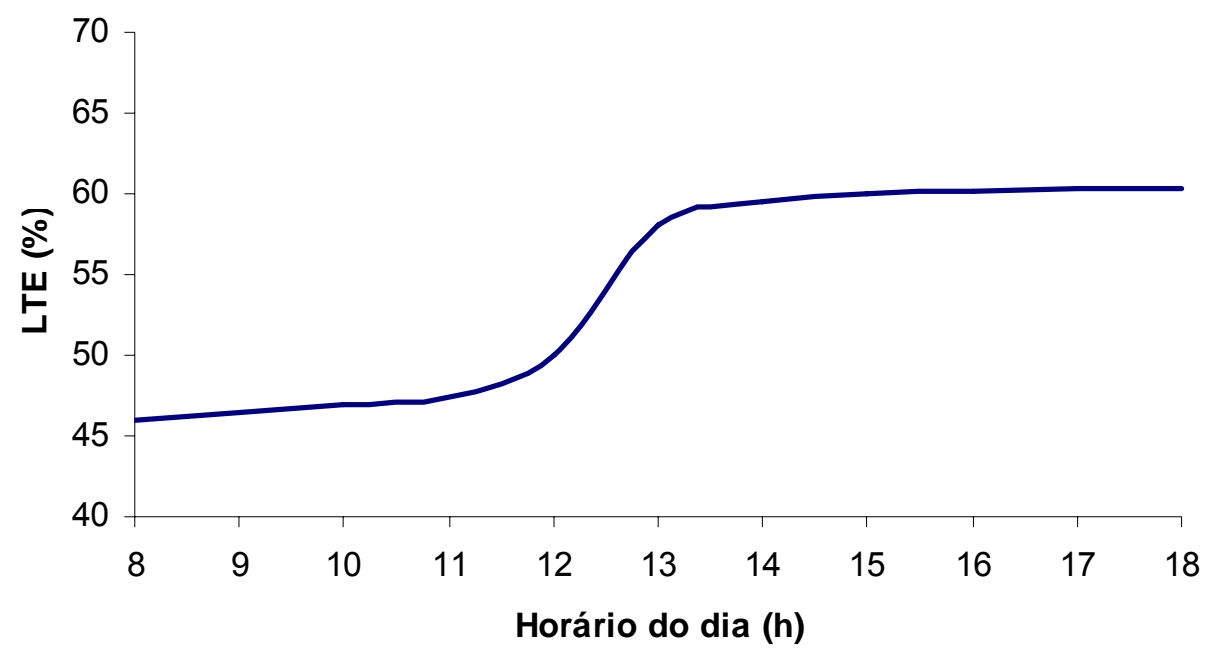

Figura 2.21 Exemplo de variação do LTE ao longo de um dia (Adaptado de: SHAHIN, 1985).

Para que seja realizada esta correção no valor do LTE (conhecido apenas um valor de LTE se torna possível a determinação de LTE para qualquer outro horário do dia), Shahin (1985) propõe a utilização da seguinte equação com o fator de correção (F):

$$
L T E_{\text {corrigido }}=L T E_{\text {medido }} \times(1+F)
$$

Tal fator de correção é dado graficamente para determinados períodos de medidas no pavimento, conforme Figura 2.21. O modelo apresentado indica decréscimo de $F$ entre $8 \mathrm{~h}$ e $14 \mathrm{~h}$, sendo que após esse período $\mathrm{F}$ é nulo, para o horário de referência de 14h. A determinação de LTE para o horário de 14h é realizada pela equação 2.15 com base na medida de LTE para um horário qualquer se determinando o fator de correção para o esse horário de medida (Figura 2.22). Novamente, pela Figura 2.21 se verifica que após $14 \mathrm{~h}$ o LTE não se altera. Esses estudos foram realizados em pavimentos de aeroportos.

Shahin (1985) complementa suas análises com simulações em computador de cargas aplicadas no canto de uma placa de concreto, determinando valores de LTE 
em função do módulo de reação do subleito $(k)$ e das deflexões máximas sobre a placa. Observou-se em tal estudo que para um mesmo valor de deflexão, quanto menor o valor de k maior a transferência de carga (maior LTE).

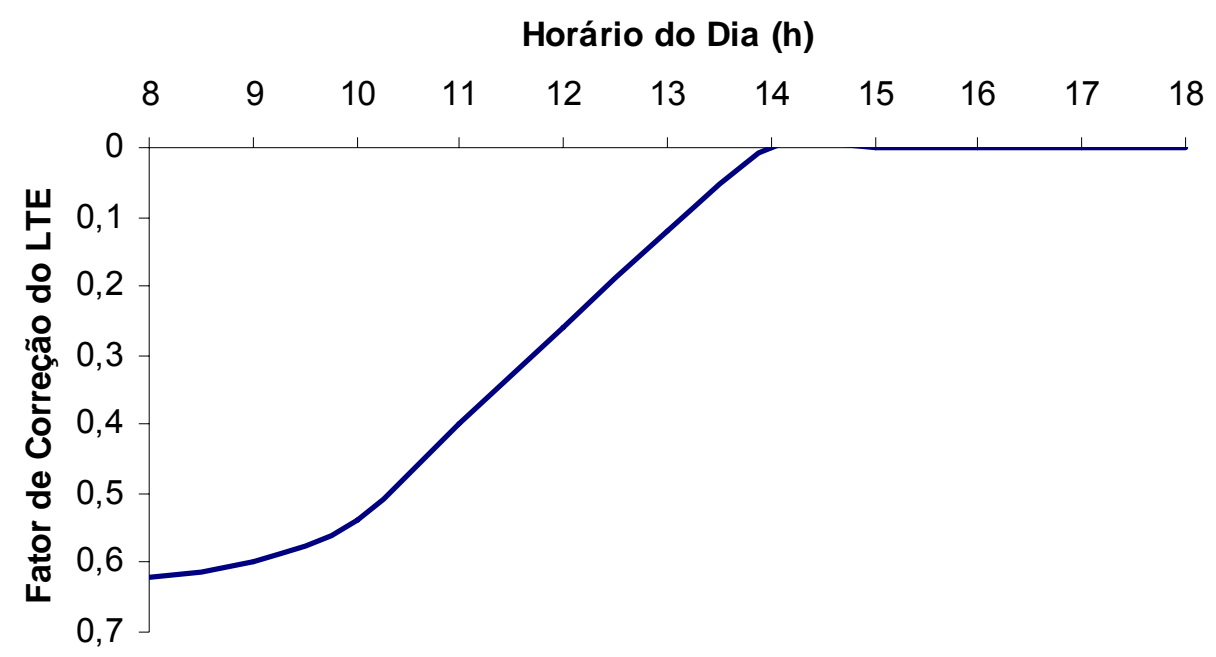

Figura 2.22 Fatores de correção de LTE segundo Shahin (1985).

Shahin (1985) ainda apresenta um fluxograma de procedimentos usados para determinação do módulo de reação do subleito (k), da transferência de carga (LTE) e da localização de vazios, que não vêm ao caso neste estudo. (Figura 2.23)

Khazanovich e Gotlif (2003) afirmam, em estudo sobre dados de seções de controle do LTPP do National Highway Cooperative Research Program (NHCRP), que quase todas as seções analisadas apresentavam LTE dependente da variação da temperatura durante o dia, em diferentes regiões com climas diferentes nos EUA. Trabalhando com as médias de valores de LTE para seções com BT foi encontrado um coeficiente de variação em torno de 10\%, sendo que, para juntas sem BT o coeficiente de variação da média diária superava em certos casos $40 \%$.

Concluem que o horário do dia afeta muito a transferência de carga na junta e que esse efeito é decorrente da movimentação das juntas. Para finalidades de projeto aconselham, com base nas análises realizadas, que as medidas de deflexões para determinação de LTE sejam realizadas logo pela manhã ou durante o inverno nos 
EUA, quando praticamente não ocorre movimentação das placas e a contração é máxima.

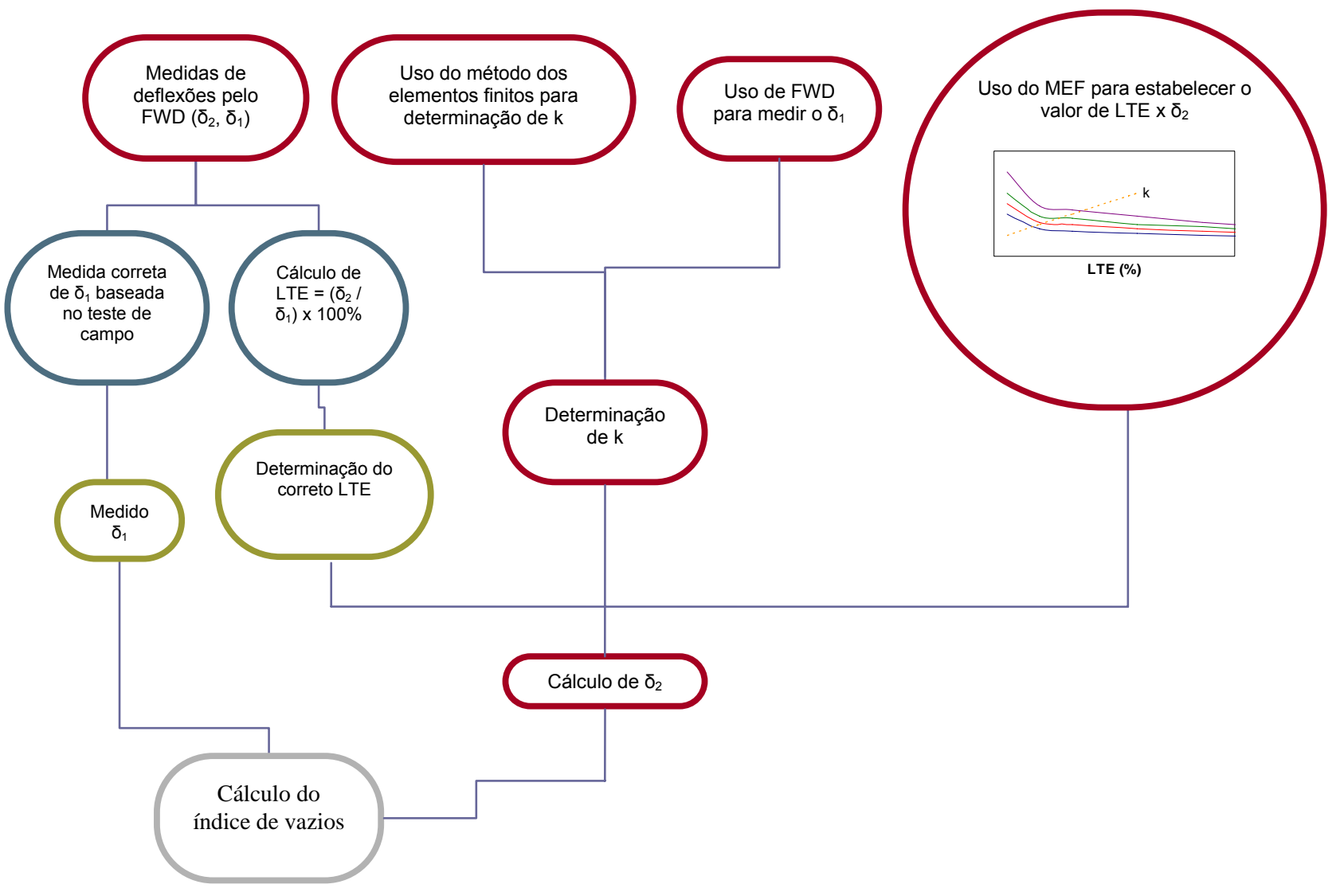

Figura 2.23 Fluxograma de procedimentos usados para determinação do k, do LTE e do índice de vazios. (Adaptado de: SHAHIN, 1985)

\subsection{Efeitos da Fundação na Abertura de Juntas}

Zollinger (2007) apresentou resultados de um experimento em pavimentos de concreto simples com diferentes espessuras de placas de concreto (de 200 a 360 $\mathrm{mm}$ ), a fim de analisar a abertura da junta na placa de concreto em função do módulo de reação do subleito. Estes resultados são apresentados na Figura 2.24, em que é nítida a percepção de que quanto menor o módulo de reação do subleito (k) maior a abertura da junta, e quanto maior a espessura da placa de concreto, para um mesmo k, maior a abertura da junta. 


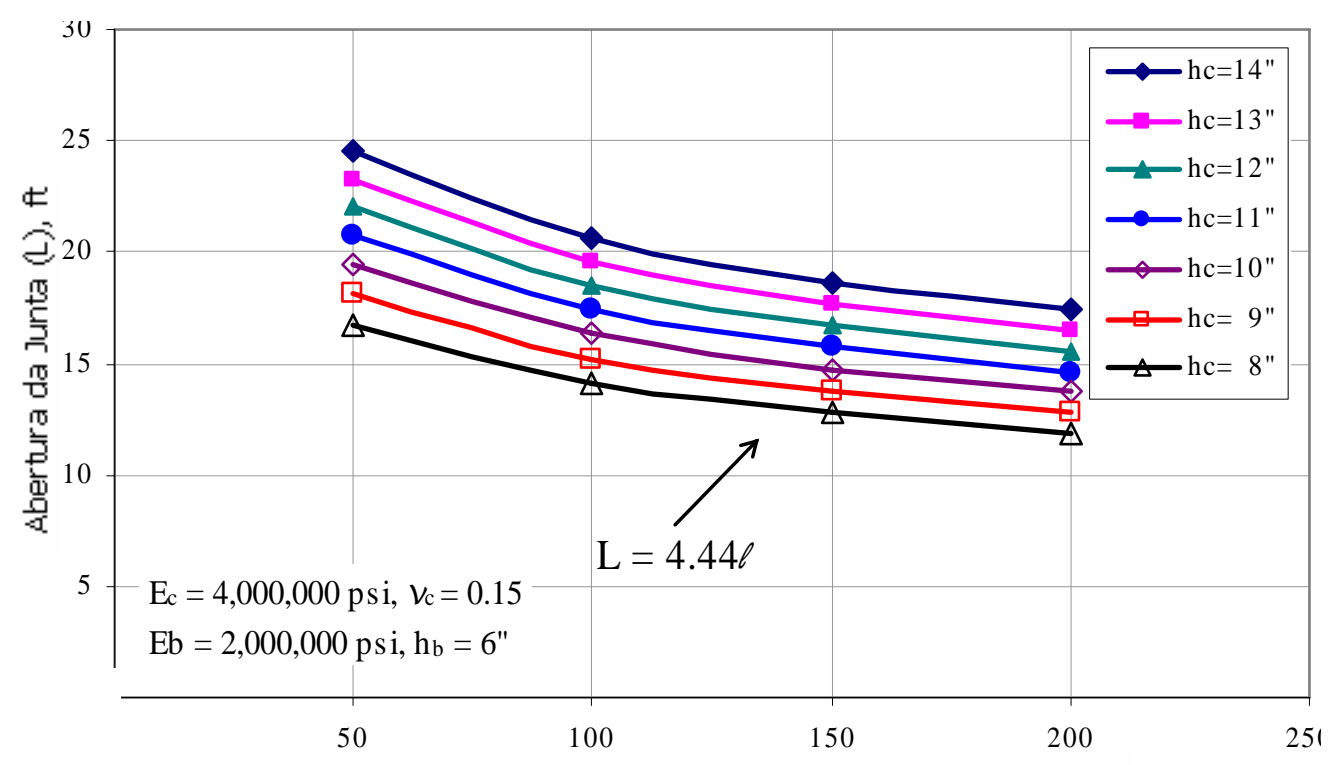

Módulo de Reaçăo do Subleito (b) em poi

Figura 2.24 Relação entre abertura da junta e espessura da placa de concreto (adaptado de: ZOLLINGER, 2007).

\subsection{Considerações Finais}

De acordo com a revisão bibliográfica, o LTE é um parâmetro complexo que depende de vários fatores como a presença ou não de barras de transferência, o tipo da base, a espessura da placa, reação da fundação, a posição e o nível da carga na junta, e a temperatura do concreto. Os estudos anteriores permitem consolidar conhecimentos e experiências conforme as que se seguem:

- Nos primórdios da construção dos pavimentos de concreto as juntas de contração eram locadas de 9 em 9 metros e as juntas de expansão de 27 em 27 metros. Mais tarde, as juntas de expansão ganharam um intervalo entre 32 e 37 metros e as juntas de contração já eram executadas de 4,5 a 6 metros;

- Atualmente, juntas de expansão são empregadas somente em encontro com estruturas rígidas;

- O diâmetro da barra deveria ter a medida de 1/8 da espessura da placa de concreto simples;

- As juntas com BT com dimensões maiores resistem a cargas mais elevadas; 
- As barras de transferência de carga podem ser empregadas em juntas longitudinais, onde o fluxo de veículos não é direcional, no caso de pavimentos aeroportuários;

- Na ausência de mecanismos de transferência de carga, esta é desenvolvida por intertravamento de agregados, ligado diretamente à maior ou menor abertura da junta;

- Quanto mais fechada é a junta transversal, maior o contato entre as faces das placas, facilitando a transferência de carga;

- O fator temperatura é muito importante para a eficiência de transferência de cargas. Pois, quanto menor a temperatura maior a abertura da junta e assim menor a transferência de carga nas juntas caso estas não possuam BT. E quanto maior a temperatura, mais fechada é a junta transversal;

- A abertura da junta não é afetada pelo tipo de base utilizado no pavimento que tanto pode ser estabilizada com cimento quanto granular. Entretanto, a LTE é bruscamente reduzida com o aumento da abertura da junta;

- Em juntas sem BT, e quando a abertura é maior que 0,9 mm, a LTE reduz em $50 \%$ seu valor. E quando esta abertura chega a $4 \mathrm{~mm}$, a LTE é quase nula;

- Testes em juntas sem BT resultaram em valores de LTE de $50 \%$ pela manhã e de $90 \%$ no período da tarde. Outros testes verificaram as seguintes mudanças no LTE devido ao aumento da temperatura: de 16 para $84 \%$. Quando há BT, não há diferença significativa com mudanças de temperatura;

- O intertravamento de agregados é responsável por no máximo $20 \%$ da transferência de carga;

- Com o aumento da abertura da junta, a durabilidade do pavimento cai;

- Comparando-se experimentos de campo e de laboratório, os resultados de LTE de laboratório são consideravelmente inferiores aos de campo, devido às diferenças de experimentos no que tange a temperatura do concreto;

- Ao longo da espessura não há variação de abertura de junta. Foi observado apenas em um caso (no Chile) de pavimento sem BT que a diferença máxima de abertura de junta entre topo e fundo foi de $0,15 \mathrm{~mm}$;

- O empenamento da placa afeta a transferência de carga nas juntas; gradientes térmicos negativos resultam em um LTE mais elevado; 
- Em juntas sem BT, com o aumento da transferência de carga, diminuem-se as deflexões na placa carregada e aumentam-se as deflexões na placa descarregada. Reduzindo-se a temperatura, a transferência de carga diminui e ocorre o contrário com as deflexões;

- Com o aumento da abertura da junta há um aumento nas tensões máximas da placa. Uma carga de roda posicionada na borda longitudinal pode aumentar a tensão na placa em $50 \%$ e a tensão no subleito em até $150 \%$, se comparada à posição do centro da placa; em outros estudos, a tensão na placa com carga posicionada na borda aumentou $35 \%$ em relação ao centro da mesma;

- Para que haja eficiente transferência de carga por intertravamento de agregados é necessário que a abertura da junta não ultrapasse $1 \mathrm{~mm}$, e o comprimento da placa deve ser limitado a poucos metros;

- A transferência de carga por meio de intertravamento de agregados é afetada diretamente pela abertura da junta, espessura da placa e pela rigidez do sistema de apoio. E indiretamente pela intensidade da carga e angulosidade do agregado utilizado no concreto.

- Quanto maior o nível de carregamento, em ensaio com cargas cíclicas, menor a LTE;

- Em pavimentos de concreto novos sem BT, a LTE pode variar entre 70 e $100 \%$. E pavimentos novos com BT, essa variação é de 80 a 100\%. Um LTE menor que $70 \%$ é considerado inaceitável para alguns autores.

- Medidas de LTE em extensa pesquisa de campo em pavimentos nos EUA e no Canadá apresentaram variação de menos de $20 \%$ entre si;

- O pavimento pode ser considerado com mau desempenho estrutural ou danificado quando: a junta estiver com abertura maior que $3 \mathrm{~mm}$; o LTE for menor que $70 \%$; a diferença entre as deflexões na placa carregada e na placa descarregada for maior que $0,25 \mathrm{~mm}$;

- Comparando-se placas com juntas serradas e moldadas, ambas com BT, as primeiras se mostraram mais eficientes e com melhor desempenho;

- Em juntas com dispositivos de transferência de carga tipo barra circular e quadrada, o valor de LTE diminui à medida que se aumenta a carga aplicada. Quando se utiliza discos metálicos para transferir carga nas juntas, após um 
elevado nível de carregamento, a transferência de carga tende a se estabilizar.

- Em estudos realizados para placas sem BT, valores de LTE pela manhã, entre os horários de 8 as $11 \mathrm{~h}$, variaram de 45 a 50\%. Deste ultimo horário até as $14 \mathrm{~h}$, houve um aumento para $60 \%$, e depois disto, não houve alteração de LTE; portanto, no período da tarde, no pico máximo de temperatura, o aumento foi de $20 \%$ para juntas sem BT;

- Alguns estudiosos trabalharam com médias de valores de LTE, encontrando coeficiente de variação em torno de $10 \%$ para juntas com BT e $40 \%$ para juntas sem BT;

- Quanto maior a espessura da placa, maior a abertura da junta e assim, menor a reação do subleito na junta ou borda;

- Em estudos sobre transferência de carga em juntas sem BT, em placas de concreto sobre subleito de argila, com uma abertura de 0,89 $\mathrm{mm}$, valores de LTE resultaram em 5\% para placas com $180 \mathrm{~mm}$ e $29 \%$ para placas com 280 $\mathrm{mm}$. Já sobre subleito de base granular, estes valores foram de 9\% e 50\%, respectivamente. Sobre base tratada com cimento, houve aumento maior ainda. 


\section{METODOLOGIA DO ESTUDO}

\subsection{Objetivos e Metodologia para Medição do LTE}

Para se medir a eficiência de transferência de carga nas juntas de pavimentos de concreto é necessário conhecer todas as características do pavimento em si, como espessura, largura e comprimento, tipo de base, serragem de juntas, enfim, seu processo de execução e construção. Por isso foi utilizada para este estudo a pista experimental da USP/FAPESP, executada pelo Laboratório de Mecânica de Pavimentos. Os testes se dariam durante o inverno e verão e compreenderiam diferentes períodos do dia (manhã, tarde e noite).

O LTE foi medido de duas maneiras: diretamente, conforme a equação descrita na revisão bibliográfica utilizando as deflexões medidas em campo pelo FWD; e por retroanálise, processo de determinação de parâmetros estruturais utilizando programa computacional, e por meio de aproximação de bacias de deflexões teóricas e as medidas em campo chegava-se então a um valor de LTE.

Por se tratar de um pavimento de concreto já construído, deveriam ser definidos parâmetros reais (em campo) ainda desconhecidos como o módulo de elasticidade do concreto $(E)$, o módulo de reação do subleito $(k)$ e o próprio LTE. Então foi adotado que as medidas de deflexões se realizassem nos centros das placas nas seções experimentais para que os parâmetros $E$ e $k$ fossem determinados, por retroanálise, por aproximação das bacias de deflexões medida e teórica.

Neste estudo foram utilizadas duas ferramentas de pesquisa: o Falling Weight Deflectometer (FWD) para medidas de deflexões e o programa ISLAB2000 que simula as condições de carregamento interativamente para a retroanálise de parâmetros, além de um termômetro infravermelho para a medição da temperatura de topo da superfície do pavimento de concreto sem contato algum. 


\subsection{Descrição da Pista Experimental USP/FAPESP}

A metodologia do estudo em questão tem caráter técnico-científico e, além de se valer da pesquisa bibliográfica, usando uma série de procedimentos já anteriormente bem estabelecidos como meio de avaliação dos efeitos climáticos nas juntas de pavimentos de concreto simples, decorrentes de testes de FWD sobre a pista experimental da Escola Politécnica da Universidade de São Paulo (EPUSP).

A pista experimental da EPUSP, financiada pela Fundação de Amparo à Pesquisa do Estado de São Paulo (FAPESP), teve seu início de construção em maio de 1999, tendo sido concluída em outubro do mesmo ano. Maiores detalhes sobre a construção e o concreto empregado na Pista Experimental FAPESP/EPUSP podem ser encontrados em Balbo et al. (2000).

O pavimento experimental em concreto simples na USP é composto por cinco seções de teste divididas em três placas de concreto para cada seção, conforme apresentado na Tabela 3.1. As Figuras 3.1 e 3.2 ilustram a pista experimental em planta e em corte, respectivamente. Na Figura 3.3 é apresentada uma visão da área construída no ano de 2006.

Tabela 3.1 Características das seções experimentais em pavimento de concreto na USP.

\begin{tabular}{|c|c|c|c|c|c|c|}
\hline Seção & Placa & $\begin{array}{c}\text { Comprimento } \\
\text { (m) }\end{array}$ & $\begin{array}{c}\text { Espessura } \\
\text { da placa } \\
\text { (mm) }\end{array}$ & $\begin{array}{c}\text { Tipo de } \\
\text { Base }\end{array}$ & $\begin{array}{c}\text { Espessura } \\
\text { da base } \\
(\mathrm{mm})\end{array}$ & $\begin{array}{c}\text { Barras de Transferência } \\
\text { de carga }(\phi=32 \mathrm{~mm} ; \\
\text { c }=400 \mathrm{~mm})\end{array}$ \\
\hline \multirow{3}{*}{$A$} & A1 & 4,00 & 150 & BGS & 200 & \multirow{3}{*}{ Em ambas as juntas } \\
\hline & $\mathrm{A} 2$ & 5,50 & 150 & BGS & 200 & \\
\hline & A3 & 7,50 & 150 & BGS & 200 & \\
\hline \multirow{3}{*}{ B } & B1 & 4,00 & 150 & CCR & 200 & \multirow{3}{*}{ Em ambas as juntas } \\
\hline & $\mathrm{B} 2$ & 5,50 & 150 & CCR & 200 & \\
\hline & B3 & 7,50 & 150 & CCR & 200 & \\
\hline \multirow{3}{*}{ C } & C1 & 4,00 & 250 & CCR & 100 & \multirow{3}{*}{ Em ambas as juntas } \\
\hline & $\mathrm{C} 2$ & 5,50 & 250 & CCR & 100 & \\
\hline & C3 & 7,50 & 250 & CCR & 100 & \\
\hline \multirow{3}{*}{$\mathrm{D}$} & D1 & 4,00 & 250 & BGS & 100 & \multirow{3}{*}{ Em ambas as juntas } \\
\hline & D2 & 5,50 & 250 & BGS & 100 & \\
\hline & D3 & 7,50 & 250 & BGS & 100 & \\
\hline \multirow{3}{*}{$E$} & E1 & 5,50 & 250 & BGS & 100 & \multirow{3}{*}{$\begin{array}{c}\text { Apenas entre as placas E1 } \\
\text { e E2 }\end{array}$} \\
\hline & E2 & 5,50 & 250 & BGS & 100 & \\
\hline & E3 & 5,50 & 250 & BGS & 100 & \\
\hline
\end{tabular}




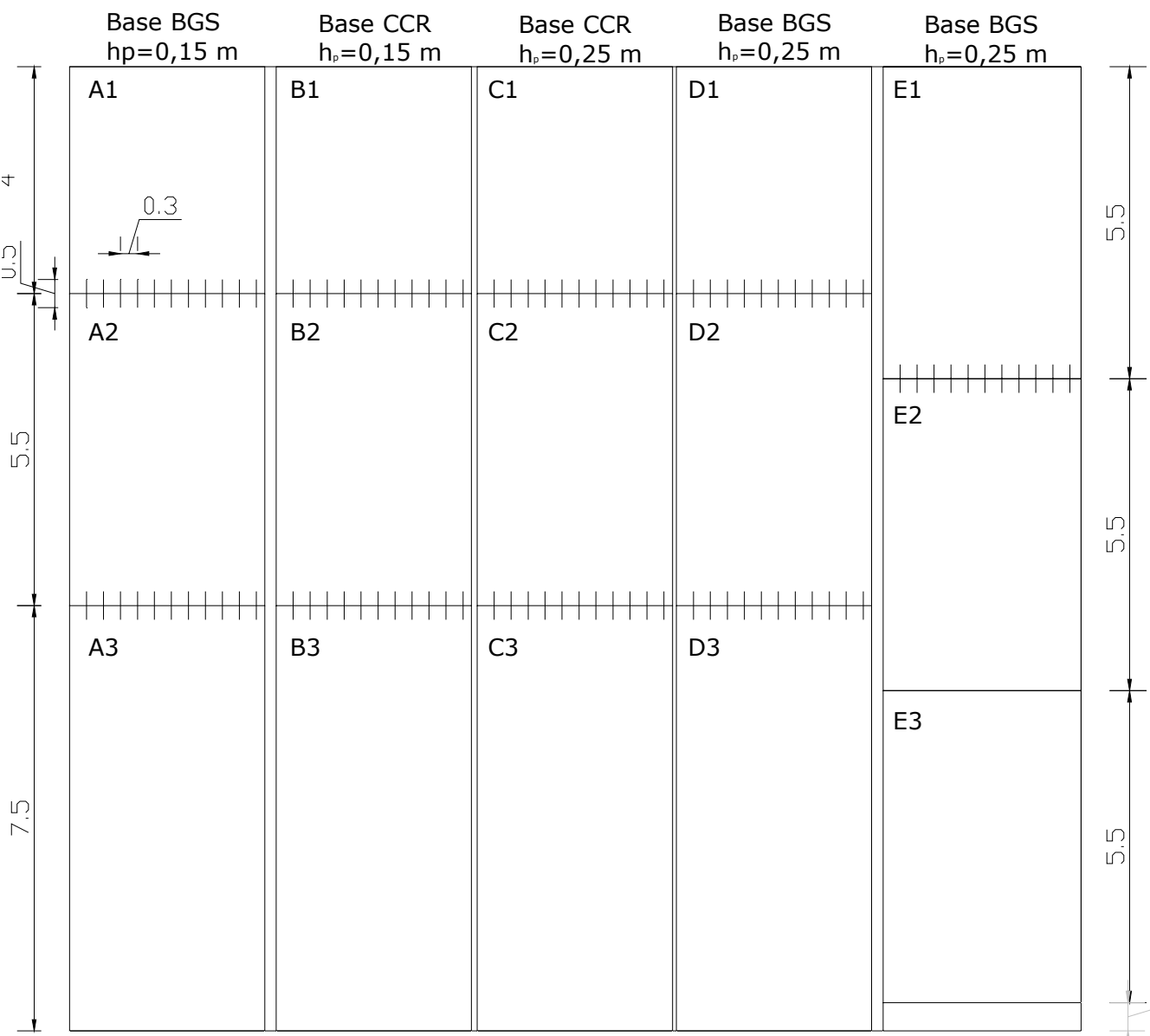

Figura 3.1 Seções em planta da pista experimental (sem escala).

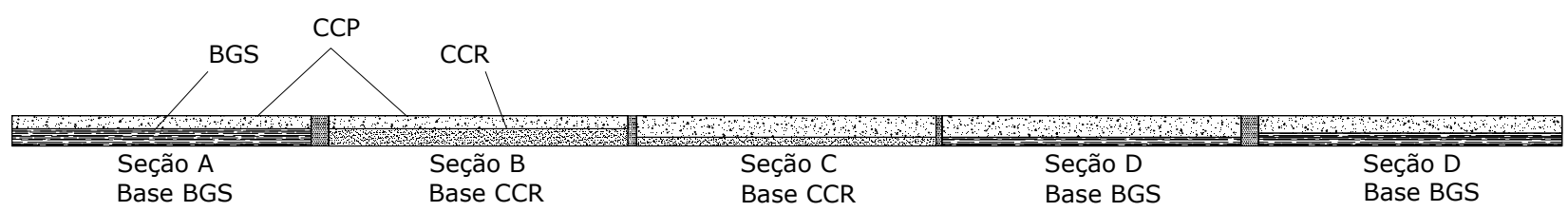

Figura 3.2 Seções em corte da pista experimental (sem escala). 


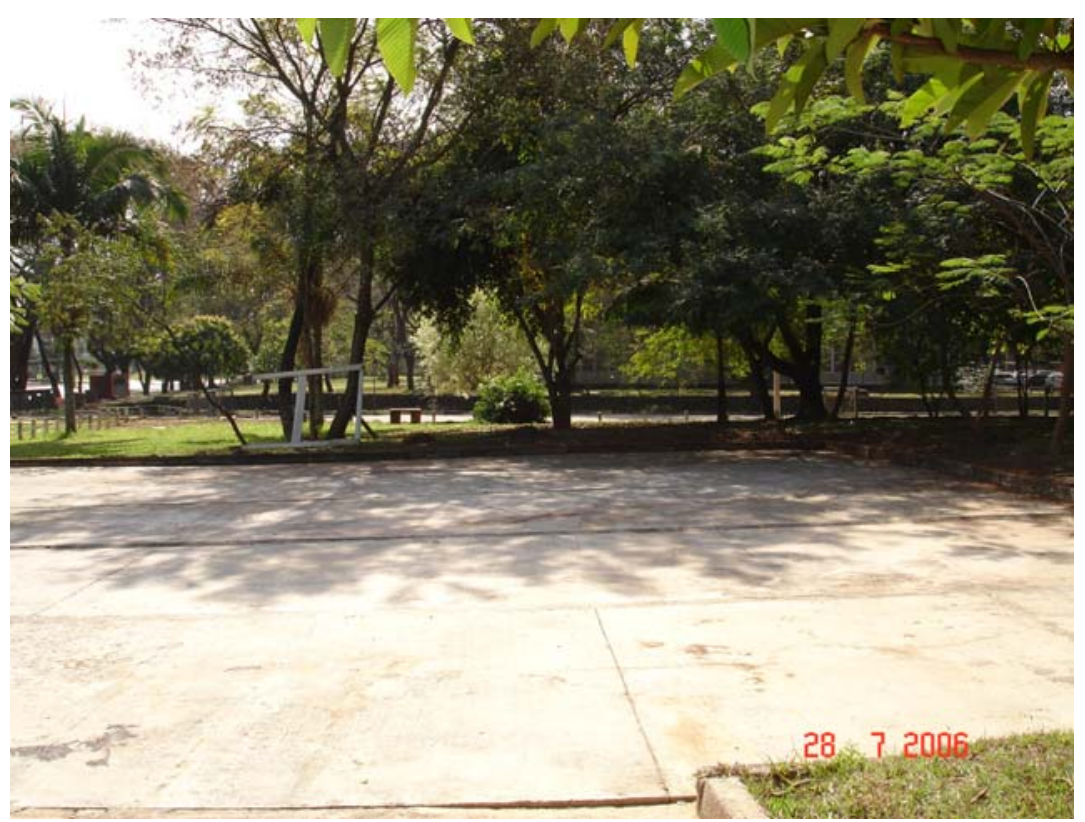

Figura 3.3 Vista da pista experimental da USP.

Atualmente (em julho de 2006), a pista experimental da EPUSP encontra-se com algumas fissuras transversais em uma das placas (seção $A$, placa A3) e outras fissuras que, acredita-se, ou foram causadas por retração plástica após o lançamento do concreto (seção C, placas C1 e C3 - última seção construída na época), ou estão em processo de ocorrência de reação álcali-agregado, conforme apresentado nas Figuras 3.4 e 3.5. Não foi realizado procedimento de aplicação de carga pelo FWD na placa A3 devido à fissura que lá se encontra.
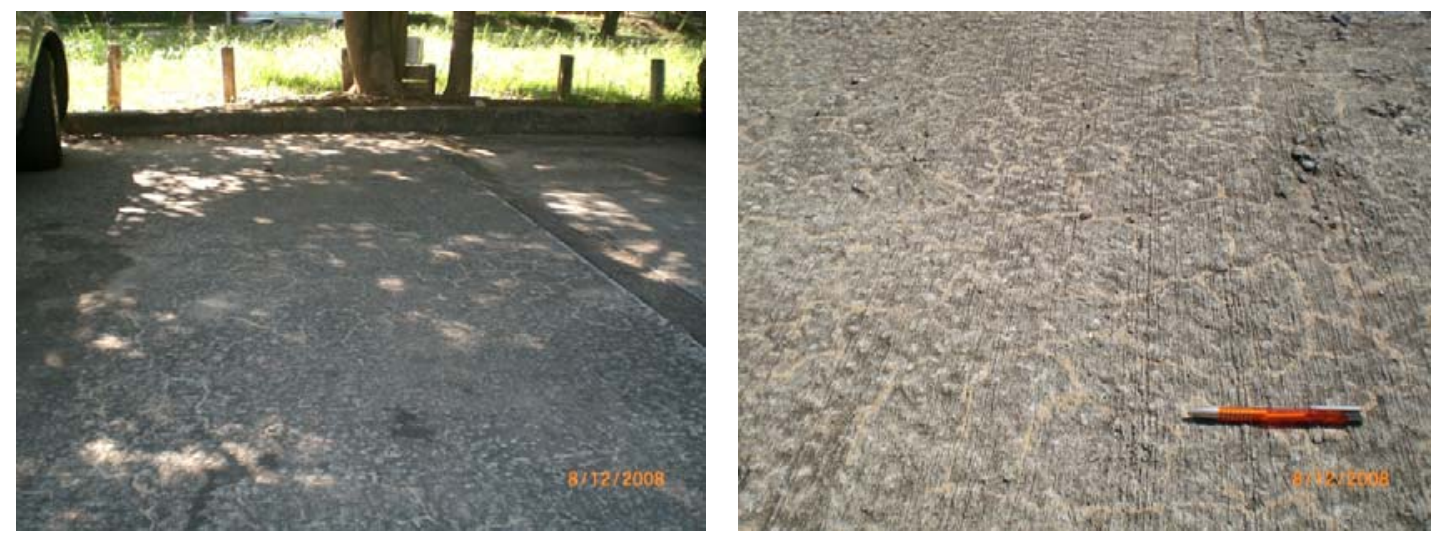

Figura 3.4 Fissuras transversais na superfície da pista experimental. 


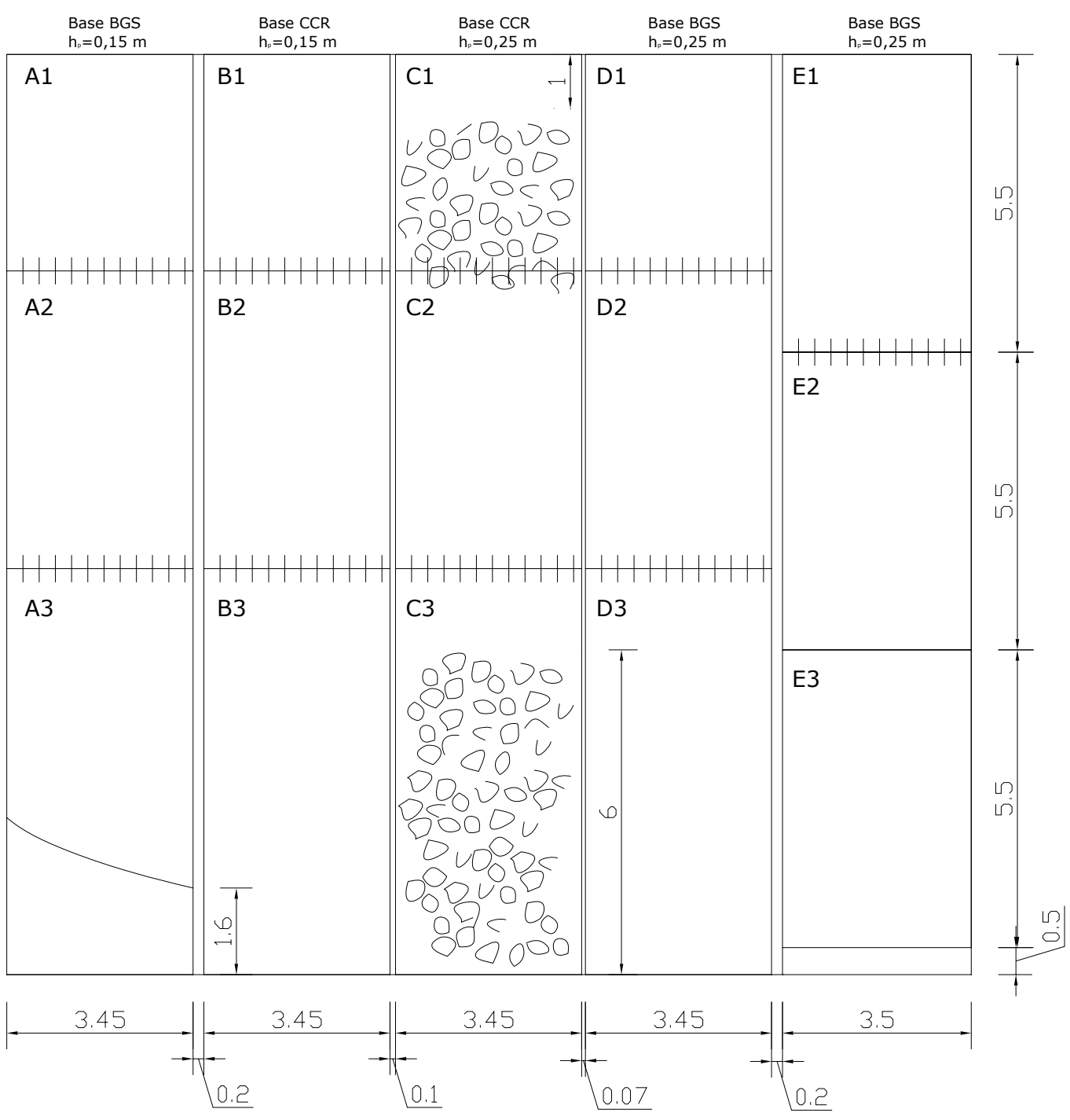

Figura 3.5 Esquema da situação atual da pista experimental da EPUSP (julho de 2006).

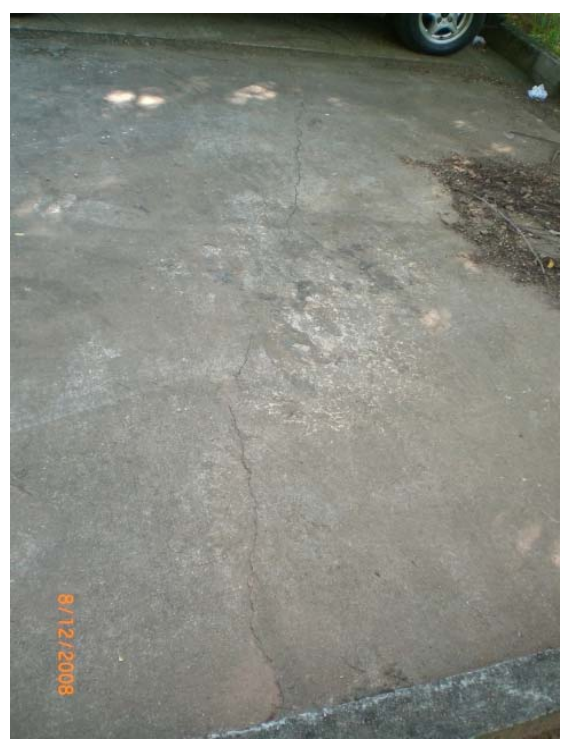

Figura 3.6 Fissura na placa A3 da pista experimental. 


\subsection{Procedimentos de Avaliação de Deflexões em Pista}

\subsubsection{Falling Weight Deflectometer (FWD)}

O Falling Weight Deflectometer (FWD) é um equipamento de ensaio não destrutivo onde uma carga de impacto é aplicada na superfície do pavimento e sensores captam, em distâncias preestabelecidas a partir do ponto de aplicação de carga (0, 20, 30, 45, 65, 90 e 120mm), as ondas de acelerações verticais que ocorrem na superfície (onda de deslocamento), que são duplamente integradas para a determinação das deflexões (deslocamentos verticais) sofridas no pavimento. (Figura 3.7)

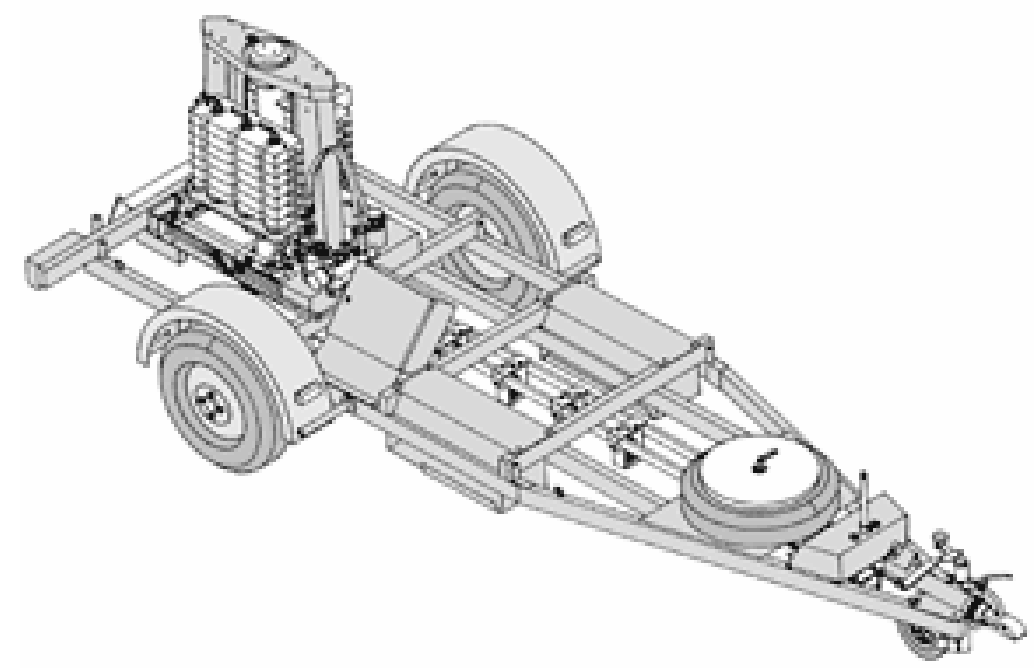

Figura 3.7 Falling Weight Deflectometer.

O equipamento é movido por um veículo motorizado que o reboca, sendo operado por uma só pessoa e aplicável a todos tipos de pavimentos, desde estradas de terra até robustos pavimentos em aeroportos (Figura 3.8). É considerado um equipamento de alta precisão e excelente repetibilidade (BALBO, 2007). Os dados gerados combinados com a espessura das camadas do pavimento são usados na determinação dos módulos de elasticidade das camadas empregando-se processo de retroanálise de bacias de deflexões. Com esta informação é possível também a determinação do módulo de reação do subleito e até estimativas da vida remanescente, bem como se estabelecer as necessidades de recuperação ou manutenção do pavimento em estudo. 
No trabalho em questão, foi utilizado um equipamento que em seu sistema é permitido a aquisição automática de deflexões recuperáveis por meio de sete sensores, sendo o diâmetro do placa de aplicação de carga de $300 \mathrm{~mm}$.

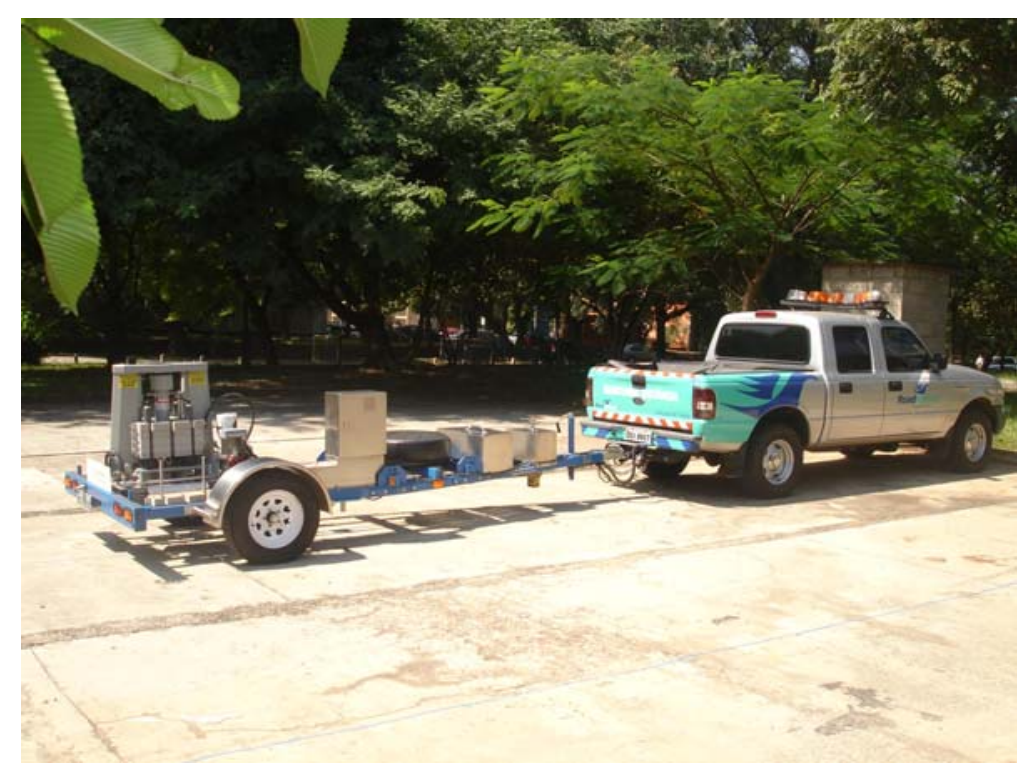

Figura 3.8 FWD na pista experimental da USP.

Para confiar em tal precisão que o equipamento apresentava, foram realizados, antes de mais nada, 20 aplicações de carga em um mesmo ponto de apoio e medidas as deflexões. Conclui-se que aquele equipamento realmente possuía tal precisão de resultados, de acordo com a Figura 3.9.

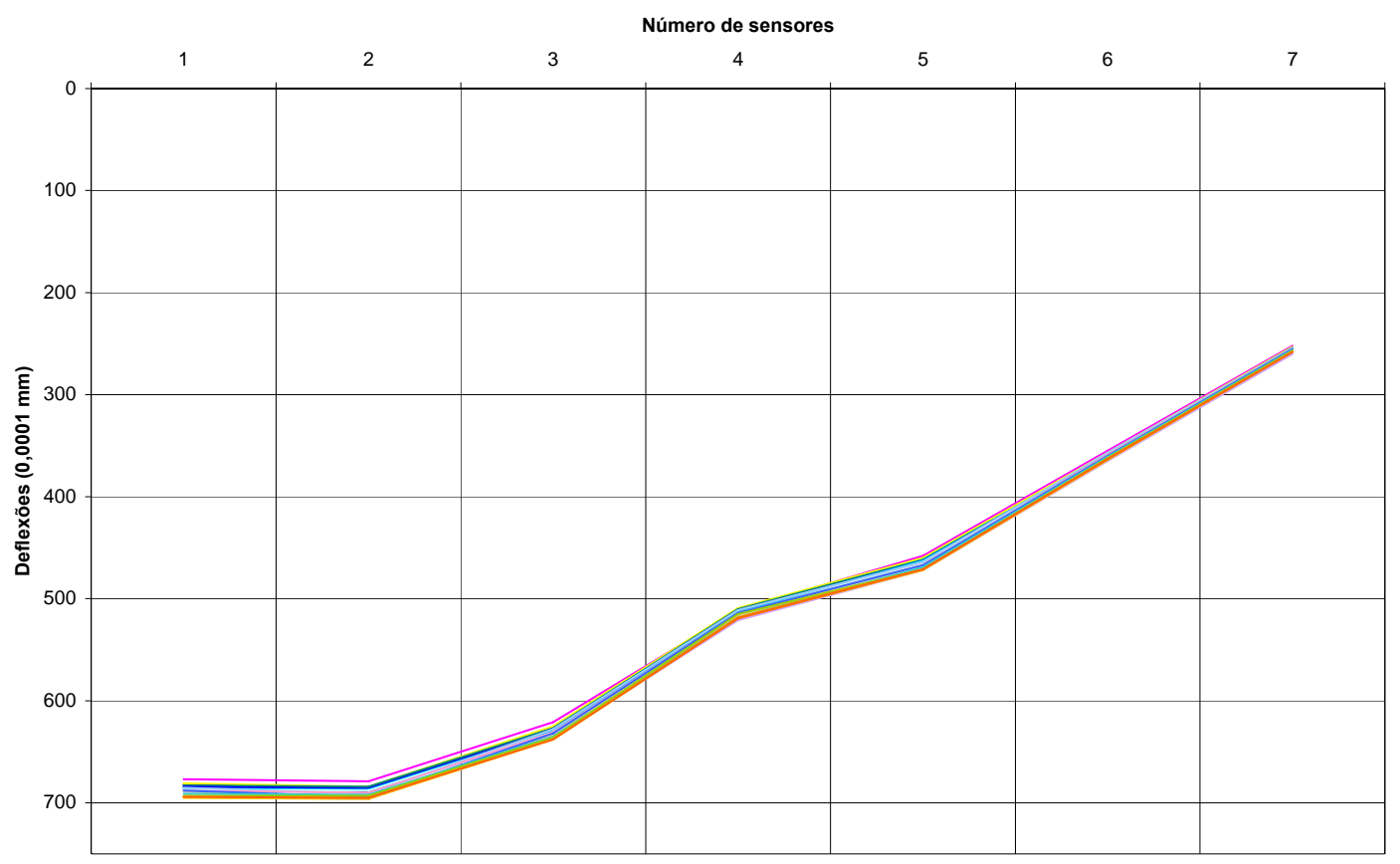

Figura 3.9 Bacias de deflexões de testes com FWD na pista experimental da USP. 


\subsubsection{Medidas de Deflexões com Carga no Centro da Placa}

Em julho de 2006 foram realizados testes com FWD (Figura 3.10) quando a placa circular de aplicação de carga foi posicionada no centro da placa de concreto a fim de se obter resultados de módulo de elasticidade e módulo de reação do subleito do pavimento de concreto estudado, conforme mencionado anteriormente. Cada sensor do FWD resultou em uma deflexão para uma determinada pressão, também registrada no teste em pista. Foram realizados dois testes em cada centro de placa de concreto e as posições de cada ponto são indicadas na Figura 3.11.
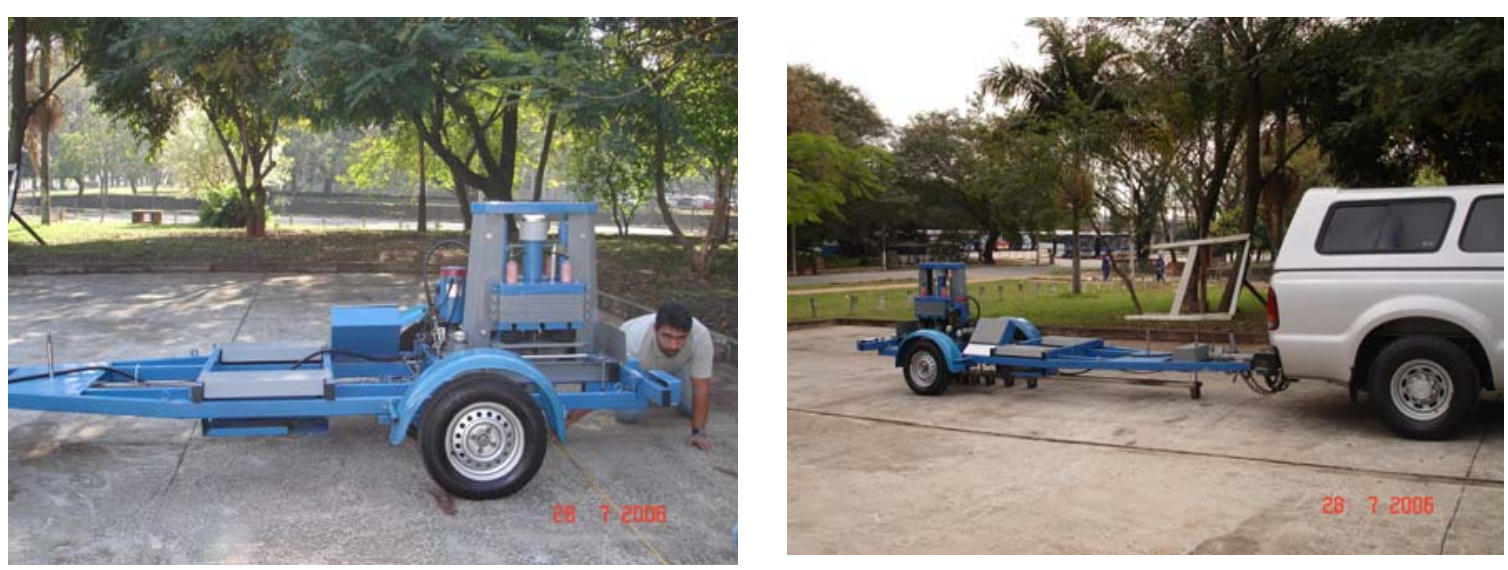

Figura 3.10 Testes com FWD na pista experimental USP/FAPESP, em julho de 2006.

As aplicações de cargas no centro de placas foram realizadas no dia 28 de julho de 2006 em apenas no período da manhã visto que as temperaturas ambientais não afetam o módulo de elasticidade do concreto de cimento Portland, parâmetro a ser determinado pelo procedimento de retroanálise de bacias de deflexões (que será melhor detalhado adiante). Com a medida de temperatura de topo no horário e local da aplicação de carga determina-se o diferencial térmico (Tabela 3.2) descrito na revisão bibliográfica e na equação 2.3 . 


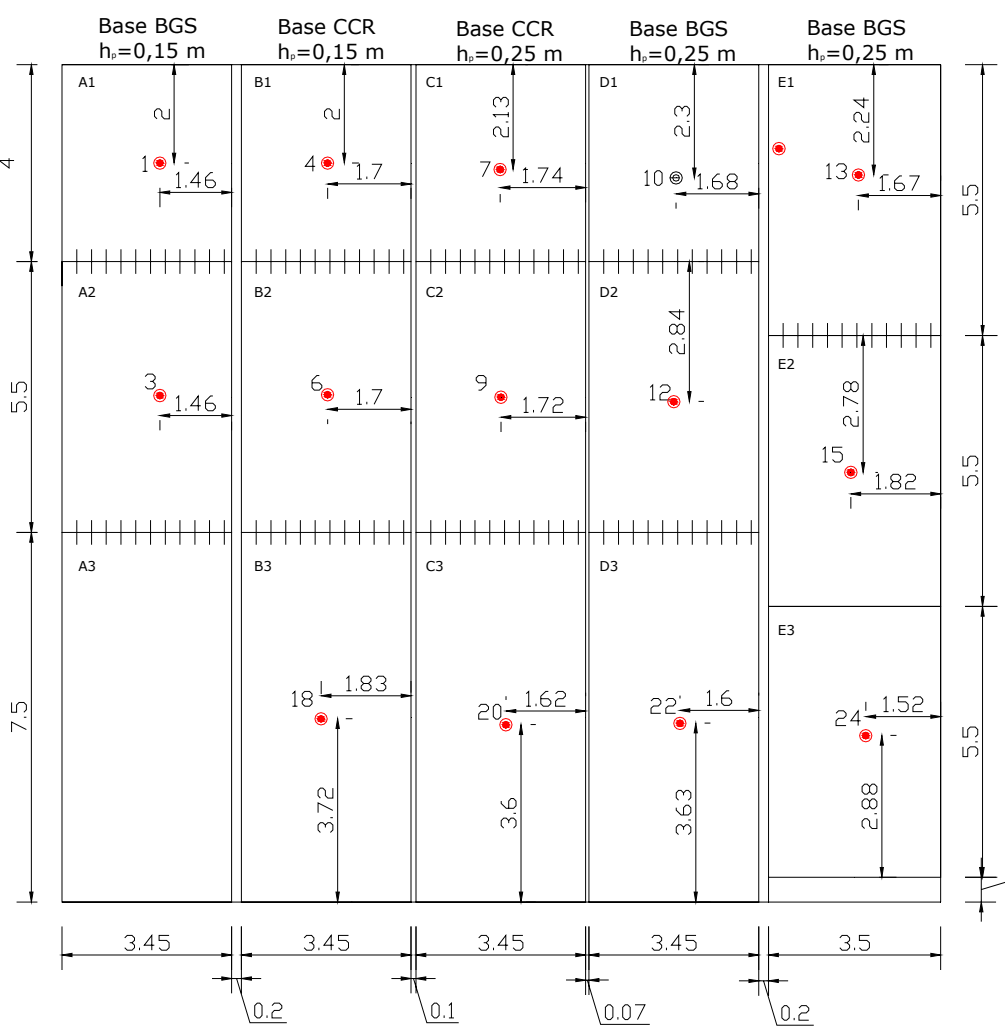

Figura 3.11 Posições das cargas em cada placa de concreto da pista experimental

Tabela 3.2 Diferencial térmico em cada placa de pavimento de concreto da pista experimental.

\begin{tabular}{|c|c|c|c|c|c|c|}
\hline Seção & $\begin{array}{c}\text { Espessura } \\
\text { CCP }(\mathbf{c m})\end{array}$ & $\begin{array}{l}\text { Posição } \\
\text { FWD }\end{array}$ & Horário & $\begin{array}{c}\text { Temperatura } \\
\left({ }^{\circ} \mathrm{C}\right)\end{array}$ & $\begin{array}{c}\text { Diferencial } \\
\text { Térmico }(\Delta \mathrm{T} \\
\left.{ }^{\circ} \mathrm{C}\right)\end{array}$ & $\begin{array}{l}\text { Média } \\
\left({ }^{\circ} \mathrm{C}\right)\end{array}$ \\
\hline \multirow{2}{*}{ A } & \multirow{2}{*}{15} & 1 & $9 \mathrm{~h} 25$ & 20,0 & 3,7 & \multirow{2}{*}{3,9} \\
\hline & & 3 & 9h45 & 21,0 & 4,2 & \\
\hline \multirow{3}{*}{ B } & \multirow{3}{*}{15} & 4 & $9 \mathrm{~h} 50$ & 19,5 & 3,4 & \multirow{3}{*}{4,0} \\
\hline & & 6 & 9h57 & 19,0 & 3,2 & \\
\hline & & 18 & 10h31 & 23,5 & 5,4 & \\
\hline \multirow{3}{*}{ C } & \multirow{3}{*}{25} & 7 & $10 \mathrm{~h} 00$ & 20,0 & 3,7 & \multirow{3}{*}{4,2} \\
\hline & & 9 & $10 \mathrm{h06}$ & 21,0 & 4,2 & \\
\hline & & 20 & 10h40 & 22,0 & 4,7 & \\
\hline \multirow{3}{*}{ D } & \multirow{3}{*}{25} & 10 & 10h08 & 22,5 & 5,0 & \multirow{3}{*}{5,3} \\
\hline & & 12 & 10h12 & 23,0 & 5,2 & \\
\hline & & 22 & $10 \mathrm{~h} 50$ & 24,0 & 5,7 & \\
\hline \multirow{3}{*}{ E } & \multirow{3}{*}{25} & 13 & 10h16 & 28,0 & 7,8 & \multirow{3}{*}{6,8} \\
\hline & & 15 & $10 \mathrm{~h} 25$ & 25,0 & 6,2 & \\
\hline & & 24 & $11 \mathrm{~h} 03$ & 25,5 & 6,5 & \\
\hline
\end{tabular}

As aplicações de carga sobre o pavimento de concreto foram realizadas com três níveis de carga para avaliar-se o efeito do carregamento no módulo de elasticidade e também foram aplicadas duas vezes cada carga, apenas para confirmação de valores. 


\subsubsection{Medidas de Deflexões com Carga na Junta da Placa}

No inverno de 2006 e no verão de 2007, durante os testes, a placa de aplicação de carga do FWD foi posicionada próxima da junta transversal, em sua posição mais central na borda transversal, sendo o primeiro sensor posicionado na própria placa de carregamento; os demais sensores estavam posicionados na outra placa (do lado oposto da junta transversal). Este procedimento de medida permite a determinação da deflexão sob a carga em uma placa, a $150 \mathrm{~mm}$ da junta transversal e também a deflexão do lado oposto (onde não há carga) a 150 mm da mesma junta (Figura 3.12); são, portanto deflexões eqüidistantes das juntas. Para cada ponto de teste foram aplicadas sucessivamente três diferentes cargas de impacto (aproximadamente 47, 74 e 84 kN), com duas aplicações para cada uma delas.
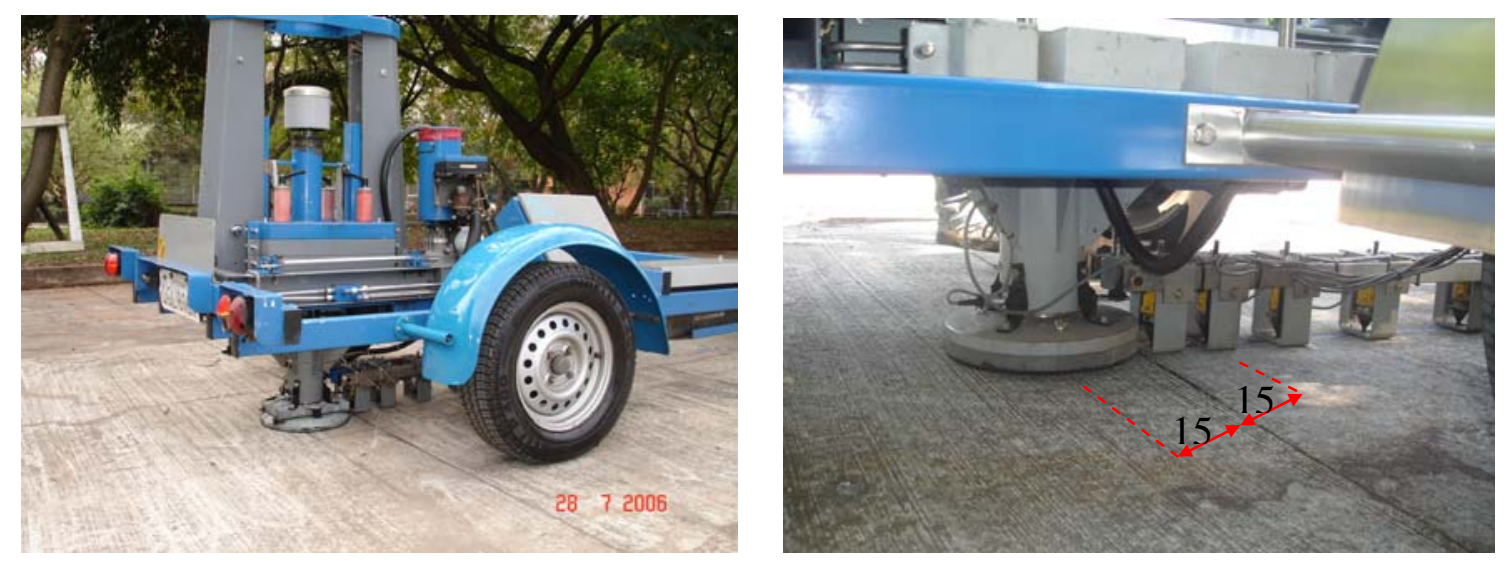

Figura 3.12 Posição do prato na junta da placa de concreto.

Assim, com base em medidas dessa natureza é possível, conforme exposto no Capítulo 2, a determinação do valor LTE. Na Figura 3.14 é apresentado o posicionamento de cada uma das cargas aplicadas em juntas da pista experimental, e na Figura 3.13, as distâncias dos sensores ao centro do prato de aplicação. Os testes foram realizados durante o inverno de 2006 (julho) na manhã e à tarde, e também no verão de 2007 (março), nos períodos da tarde e da noite. Os horários dos testes, as temperaturas na superfície das placas (medidas com infra-vermelho) e os diferenciais térmicos (DT) calculados (segundo as equações 2.2 e 2.3) são apresentados na Tabela 3.3. 


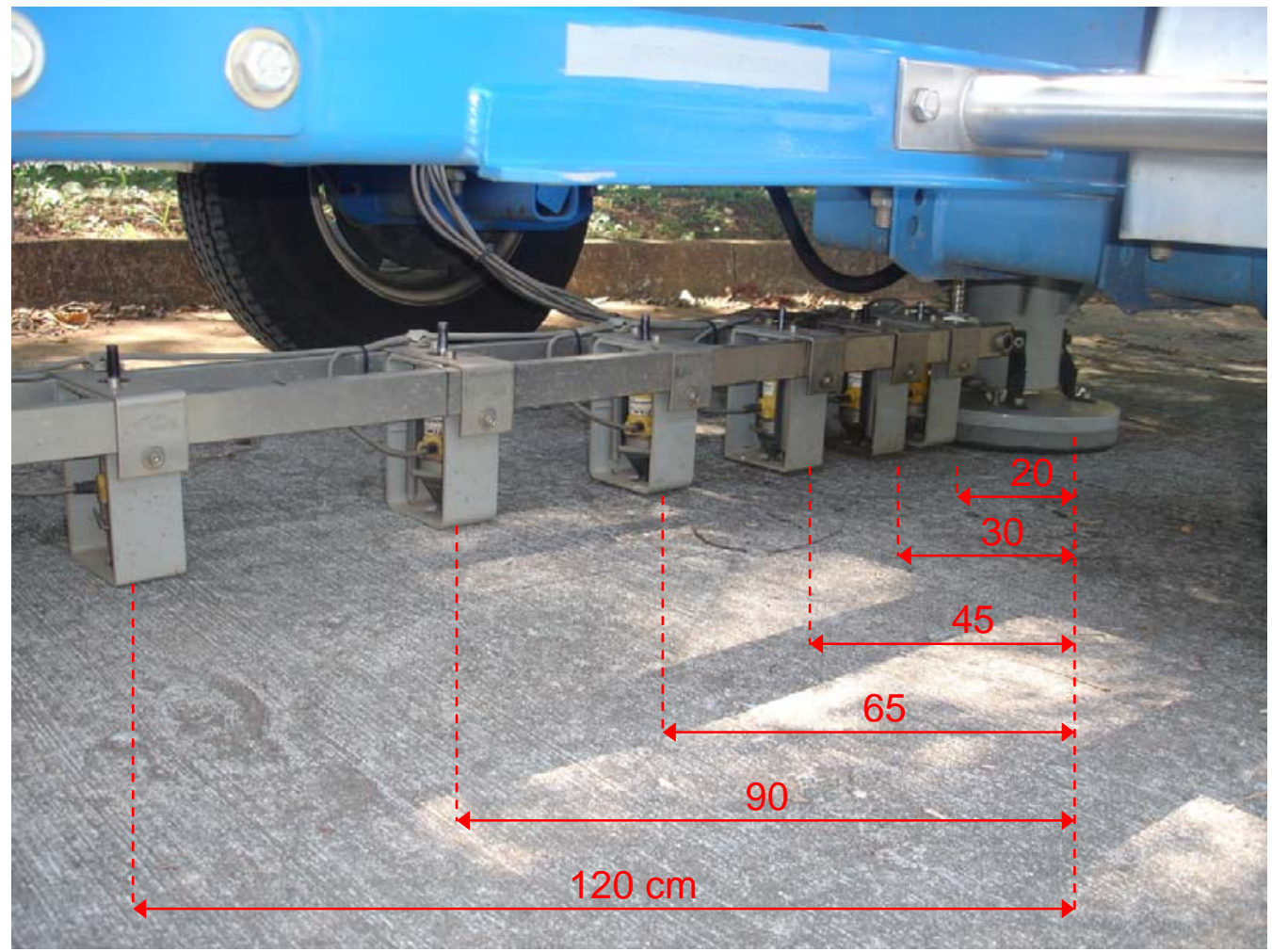

Figura 3.13 Posicionamento de cada sensor na placa de concreto, pelo FWD.

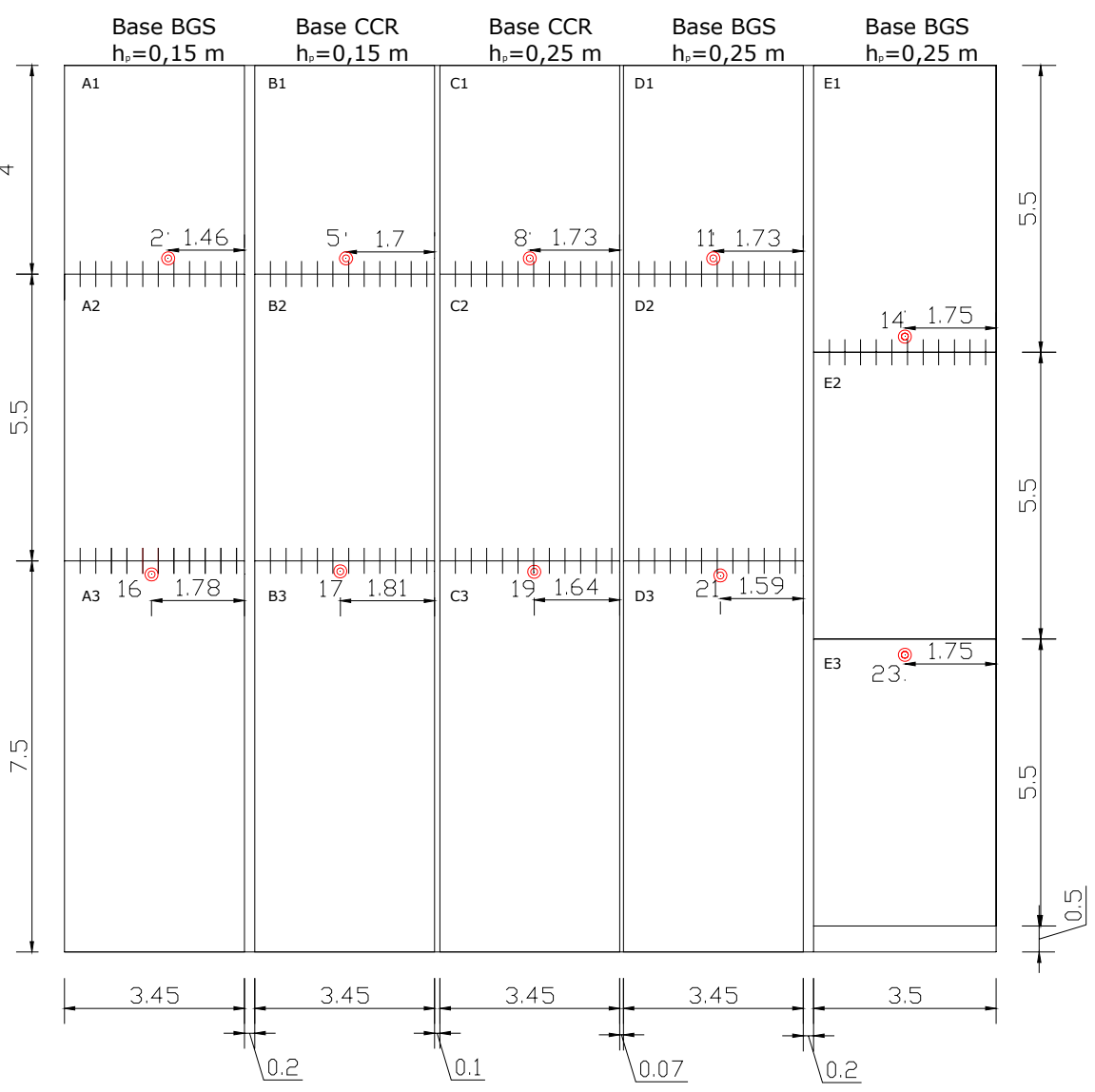

Figura 3.14 - Posicionamento do prato de aplicação de carga na placa de concreto. 
Tabela 3.3 Diferenciais térmicos nos anos de 2006 e 2007.

\begin{tabular}{|c|c|c|c|c|c|c|c|c|c|c|c|c|c|}
\hline \multirow{3}{*}{ Seção } & \multirow{3}{*}{ Posição } & \multicolumn{6}{|c|}{ Inverno - 28/07/2006 } & \multicolumn{6}{|c|}{ Verão - 26/03/2007 } \\
\hline & & \multicolumn{3}{|c|}{ Manhã } & \multicolumn{3}{|c|}{ Tarde } & \multicolumn{3}{|c|}{ Tarde } & \multicolumn{3}{|c|}{ Noite } \\
\hline & & Horário & $\begin{array}{l}T_{\text {topo }} \\
\left({ }^{\circ} \mathrm{C}\right)\end{array}$ & $\begin{array}{l}\text { DT } \\
\left({ }^{\circ} \mathrm{C}\right)\end{array}$ & Horário & $\begin{array}{l}\mathrm{T}_{\text {topo }} \\
\left({ }^{\circ} \mathrm{C}\right)\end{array}$ & $\begin{array}{c}\text { DT } \\
\left({ }^{\circ} \mathrm{C}\right)\end{array}$ & Horário & $\begin{array}{l}\mathrm{T}_{\text {topo }} \\
\left({ }^{\circ} \mathrm{C}\right)\end{array}$ & $\begin{array}{l}\text { DT } \\
\left({ }^{\circ} \mathrm{C}\right)\end{array}$ & Horário & $\begin{array}{l}\mathrm{T}_{\text {topo }} \\
\left({ }^{\circ} \mathrm{C}\right)\end{array}$ & $\begin{array}{c}\text { DT } \\
\left({ }^{\circ} \mathrm{C}\right)\end{array}$ \\
\hline \multirow{2}{*}{ A } & 2 & $9 \mathrm{~h} 32$ & 20,0 & 3,8 & $13 \mathrm{~h} 35$ & 27,0 & 7,4 & $12 \mathrm{~h} 30$ & 25,0 & 0,3 & 19h35 & 25,5 & 0,5 \\
\hline & 16 & $10 \mathrm{~h} 27$ & 24,0 & 5,9 & $14 \mathrm{~h} 05$ & 34,0 & 11,0 & $13 \mathrm{~h} 02$ & 26,0 & 0,8 & $18 \mathrm{~h} 47$ & 28,0 & 1,9 \\
\hline \multirow{2}{*}{ B } & 5 & $9 h 54$ & 19,5 & 3,6 & $13 \mathrm{~h} 47$ & 26,0 & 6,9 & $12 \mathrm{~h} 35$ & 24,5 & 0,0 & $18 \mathrm{~h} 20$ & 28,5 & 2,2 \\
\hline & 17 & $10 \mathrm{~h} 36$ & 24,0 & 5,9 & $14 \mathrm{~h} 09$ & 34,0 & 11,0 & $13 \mathrm{~h} 12$ & 31,0 & 3,5 & $18 \mathrm{~h} 52$ & 26,5 & 1,1 \\
\hline \multirow[b]{2}{*}{$c$} & 8 & 10h02 & 20,0 & 4,0 & $13 \mathrm{~h} 50$ & 32,0 & 10,1 & $12 \mathrm{~h} 42$ & 41,0 & 12,6 & $18 \mathrm{~h} 30$ & 32,0 & 7,8 \\
\hline & 19 & $10 \mathrm{~h} 46$ & 22,5 & 5,2 & $14 \mathrm{~h} 12$ & 29,0 & 8,6 & $13 \mathrm{~h} 20$ & 38,5 & 11,3 & $19 \mathrm{~h} 00$ & 28,0 & 5,6 \\
\hline & 11 & $10 \mathrm{~h} 10$ & 23,0 & 5,5 & $13 \mathrm{~h} 58$ & 34,0 & 11,1 & $12 \mathrm{~h} 50$ & 43,0 & 13,7 & $18 \mathrm{~h} 34$ & 32,5 & 8,0 \\
\hline & 21 & 10h55 & 24,0 & 6,0 & $14 \mathrm{~h} 14$ & 31,0 & 9,6 & $13 \mathrm{~h} 30$ & 44,5 & 14,5 & $19 \mathrm{~h} 04$ & 30,5 & 7,0 \\
\hline & 14 & $10 \mathrm{~h} 20$ & 27,0 & 7,5 & $14 \mathrm{~h} 00$ & 34,0 & 11,1 & $12 \mathrm{~h} 56$ & 45,0 & 14,8 & 18h42 & 33,0 & 8,3 \\
\hline & 23 & $11 \mathrm{~h} 00$ & 25,0 & 6,5 & $14 \mathrm{~h} 16$ & 35,0 & 11,6 & $13 \mathrm{~h} 40$ & 46,0 & 15,4 & $19 \mathrm{~h} 12$ & 30,5 & 7,0 \\
\hline
\end{tabular}

\subsection{Estimativa de Parâmetros Estruturais antes da Retroanálise}

Antes de se iniciarem as retroanálises de parâmetros estruturais das placas de concreto utilizando as deflexões resultantes dos testes com FWD e o programa de elementos finitos há necessidade de uma estimativa prévia dos valores de módulo de elasticidade do concreto e do módulo de reação do subleito para se ter valores mais abalizados de partida ("sementes"). Esta estimativa pode ser realizada empregando-se o critério proposto por Hall (1991). Embora não se conheça o raio de rigidez relativa da placa a priori, há a possibilidade de encontrar valores precisos utilizando o tipo de estimativa proposto por Hall (1991).

A bacia de deflexões medida em campo é parametrizada por meio de uma estimativa de sua área (denominada por $A R E A$ ), baseado nas medidas individuais de deflexões de uma bacia na placa de CCP. Este parâmetro é definido conforme a equação [3.1]:

$$
A R E A=6 \times\left[1+2 \times\left(\frac{d_{30}}{d_{0}}\right)+2 \times\left(\frac{d_{65}}{d_{0}}\right)+\left(\frac{d_{90}}{d_{0}}\right)\right]
$$


As deflexões $d_{0}, d_{30}, d_{65}$ e $d_{90}$ são dadas em polegadas. Com o valor de AREA, estima-se a rigidez relativa por meio da equação [3.2]:

$$
\ell_{k}=\left[\frac{\ln \left(\frac{36-A R E A}{1812,279133}\right)}{-2,559340}\right]^{4,387009}
$$

Segundo Crovetti (1997), pode-se encontrar o valor de k a partir da seguinte equação [3.3] (de Westergaard):

$$
k=\frac{P}{8 \times d_{0} \times \ell_{k}^{2}} \times\left\{1+\left(\frac{1}{2 \pi}\right) \times\left[\ln \left(\frac{a}{2 \ell_{k}}\right)+\gamma-1,25\right] \times\left(\frac{a}{\ell_{k}}\right)^{2}\right\}
$$

Sendo $k$ o módulo de reação do subleito (em libras por polegada cúbica), $P$ a carga aplicada (em libras-força), $d_{0}$ a deflexão máxima no centro da placa (em polegadas), $\ell_{k}$ o raio de rigidez relativa determinado pela equação 3.2 (em polegadas) e a o raio da carga circular aplicada pelo FWD (em polegadas).

Conhecidos os valores do raio de rigidez relativa e do módulo de reação do subleito, o valor do módulo de elasticidade da placa de concreto (E) é calculado pela equação [3.4] de Westergaard:

$$
E=\frac{12 \times k \times \ell_{k}\left(1-v^{2}\right)}{h^{3}}
$$

onde vé o coeficiente de Poisson e $h$ a espessura da placa de concreto. 


\subsection{Procedimentos de Retroanálise das Bacias de Deflexões}

\subsubsection{O Programa ISLAB2000}

A interpretação das deformadas foi realizada no Laboratório de Mecânica de Pavimentos da EPUSP com uso de um software específico denominado programa ISLAB2000 que permite simulações numéricas por elementos finitos das provas de carga, ensejando a avaliação do módulo de elasticidade do concreto e do módulo de reação do subleito para as condições reais de campo por retroanálise.

Este software foi desenvolvido pelo ERES - Divisão de Associados de Pesquisa Aplicada (ARA) - juntamente com apoio do Departamento de Transportes de Michigan e Departamento de Transportes de Minnesota. O programa de análise de elementos finitos foi desenvolvido especificamente para analisar sistemas de pavimentos de concreto simples. O programa é uma extensão melhorada do ILLISLAB, um programa de elementos finitos para análise de pavimentos rígidos desenvolvido na Universidade de Illinois sob direção do Prof. Dr. Ernest Barenberg. O programa passou por diversas revisões e modificações. As últimas modificações foram o ILSL2, desenvolvida na Universidade de Illinois, e a versão revisada do ILL2 desenvolvida pela empresa ERES (KHAZANOVICH, 1994; KHAZANOVICH et al, 2000). Estes dois programas contêm muitas características avançadas que o distinguem de outros programas de pavimentação que são baseados na Teoria de Placas. O ILSLAB2000 mantém a maioria dos conceitos e aproximações incorporadas no ILSL2.

O programa ISLAB2000 pode ser usado eficientemente para analisar pavimentos que contenham uma, duas ou três camadas (placa de concreto, base e sub-base estabilizada ou subleito), com rigidez uniforme ou variável, com juntas transversais e longitudinais (até em acostamentos), com diversos carregamentos de tráfego e níveis de transferência de carga nas juntas transversais e longitudinais.

O primeiro passo para uso do programa foi informar as propriedades geométricas e elásticas das placas de concreto na seção experimental. Isto requer o preenchimento de uma série de dados em diversas janelas conforme apresentadas 
nas Figuras de 3.15 a 3.20. Quando a base é cimentada é tratada como uma placa subjacente; em caso de base granular é tratada como parte integrante do subleito.

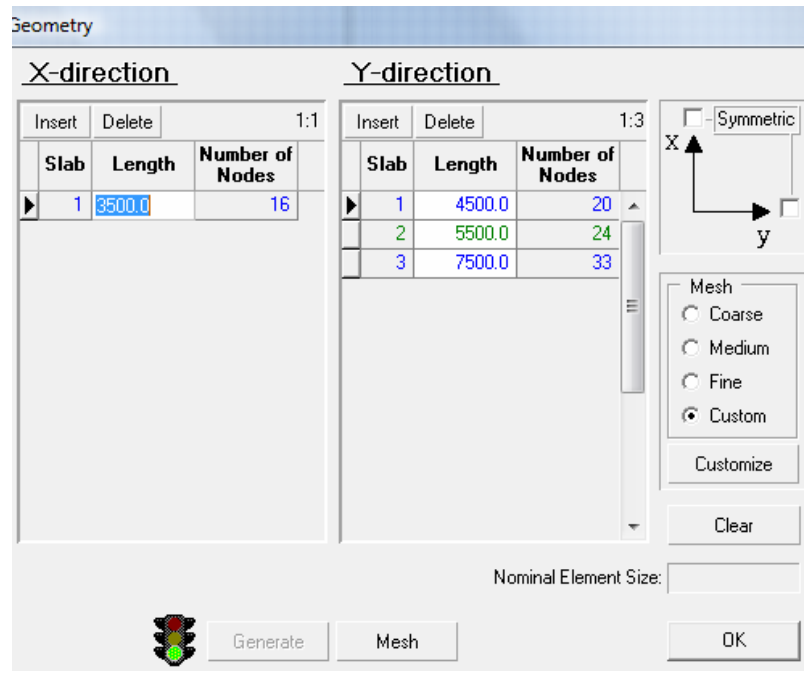

Figura 3.15 Tela para entrada de dados sobre geometria das placas e discretização da malha.

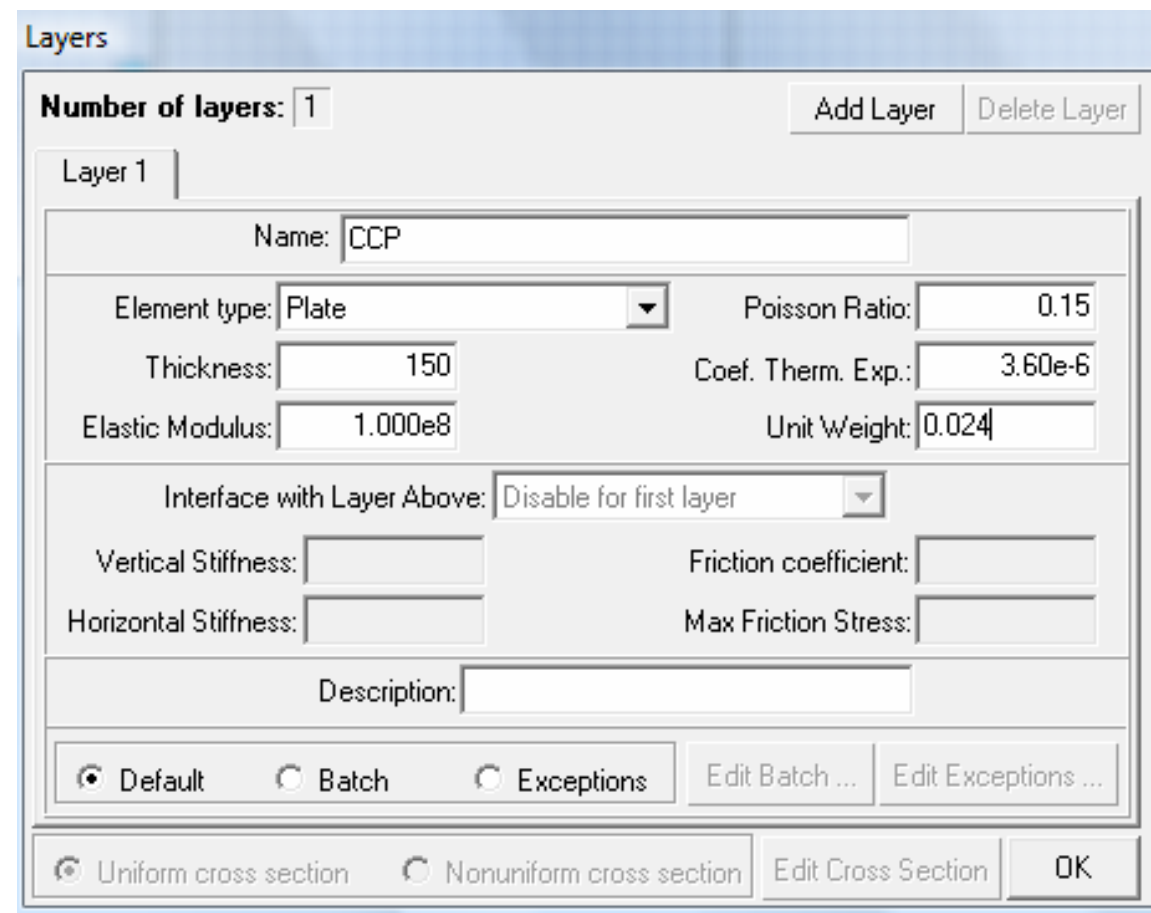

Figura 3.16 Tela para entrada de dados sobre as propriedades das camadas (placa e base). 


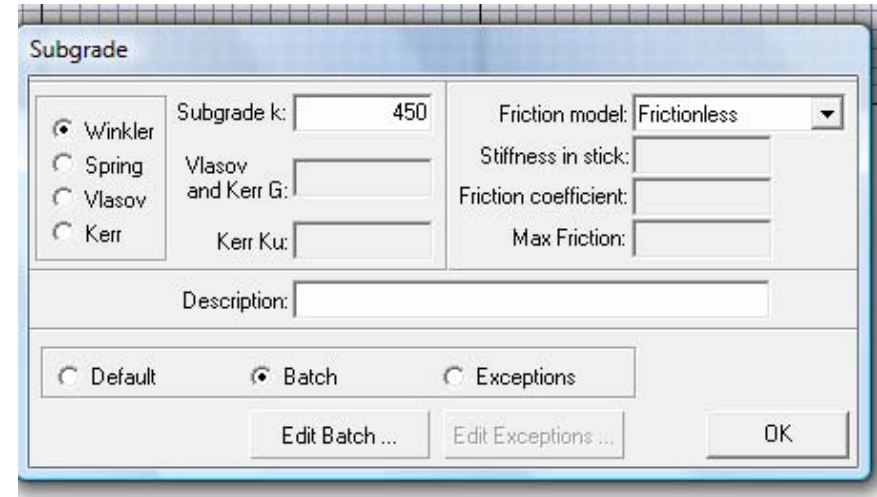

Figura 3.17 Tela para entrada de dados sobre a fundação.

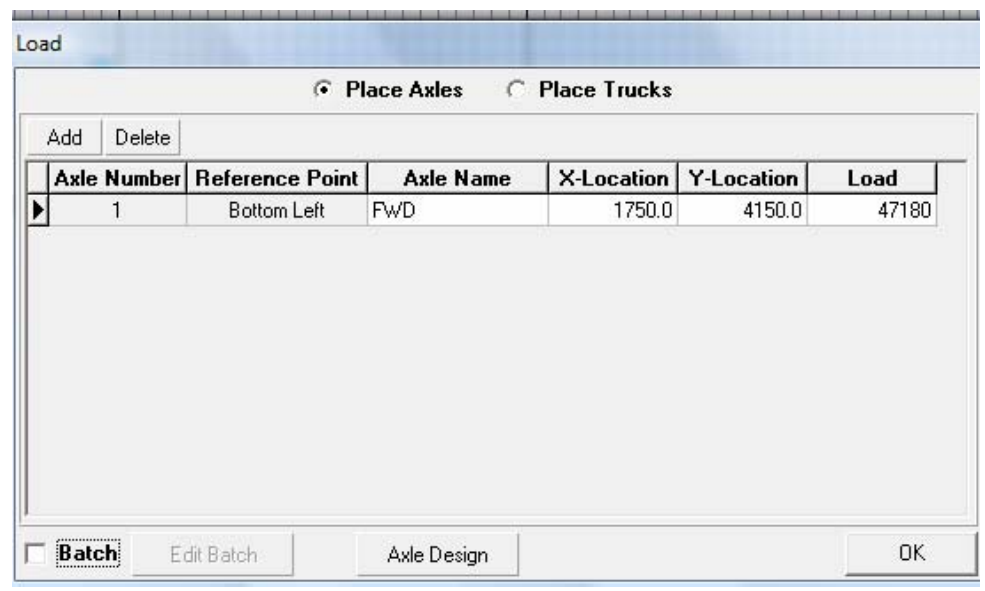

Figura 3.18 Tela para entrada de dados sobre o carregamento aplicado.

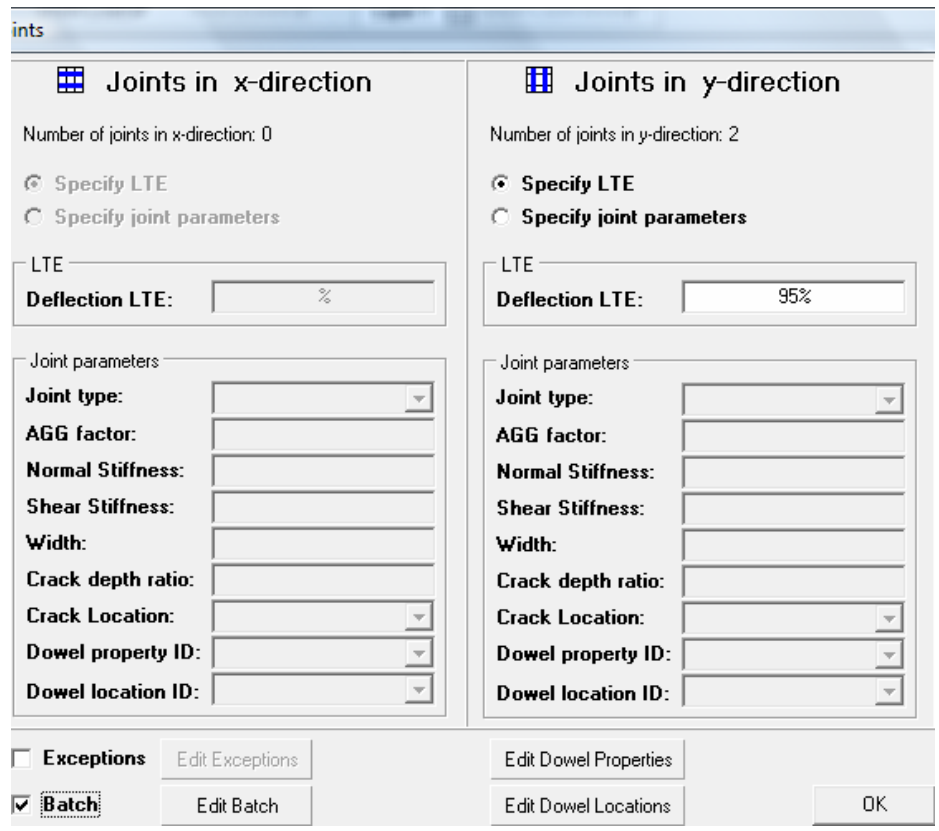

Figura 3.19 Informações sobre transferência de cargas em juntas. 


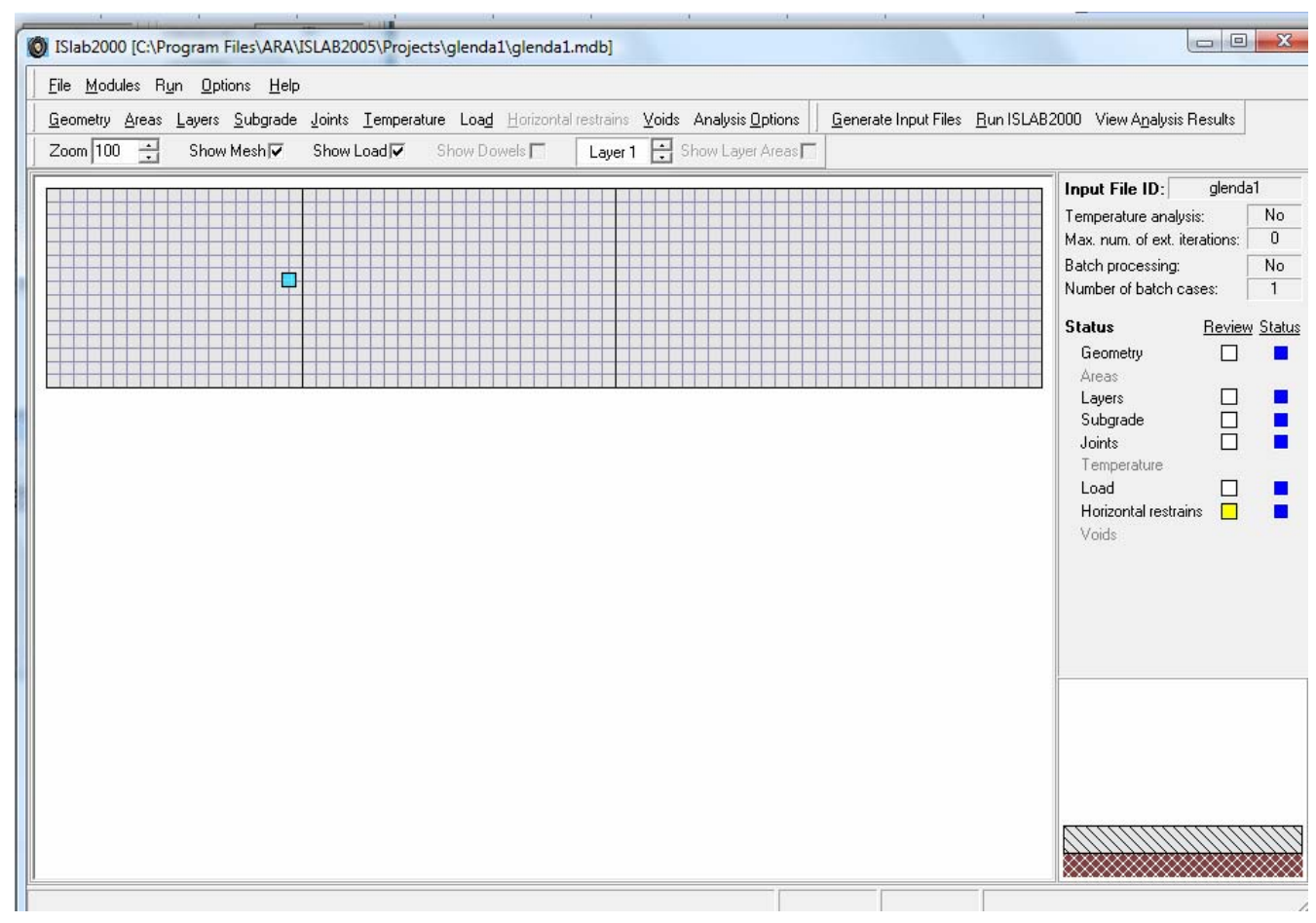

Figura 3.20 Tela principal com problema montado para rodada.

Para a realização de simulações com o programa ISLAB2000 foi utilizado o modo de simulação "em lotes" (batch), com apoio de uma planilha de entrada de dados do Microsoft Excel especialmente preparada; ela permitia que o programa ISLAB acessasse tal planilha para procurar as informações de cada uma das 27.786 simulações realizadas para a retroanálise de parâmetros estruturais dos pavimentos de concreto estudados (14.826 para carga de centro e 12.960 para carga na junta da placa).

\subsubsection{Procedimento de Retroanálise das Bacias de Deflexões de Centro de Placas}

Após a estimativa de valores dos parâmetros E e k pelo critério de Hall (1991), foram fixados como extremos de uma faixa de variação para as tentativas de retroanálise, para tais parâmetros, um valor redondo abaixo da menor estimativa e outro valor redondo acima da maior estimativa para o parâmetro em questão. Dentro dessas faixas para as combinações de parâmetros foram realizadas várias simulações, incrementando-se os valores e combinando-os, com o objetivo de se simular bacias 
de deflexões e compará-las com as bacias medidas em campo. O exemplo abaixo apresentado exemplifica o modo como foram encontrados os valores retroanalisados de E e k.

O exemplo emprega uma aplicação de carga no centro da placa A2. As características deste pavimento são:

- Espessura da placa de concreto: $150 \mathrm{~mm}$;

- Espessura da base de BGS: 200 mm;

- Carga aplicada pelo FWD: 74,36 KN;

- Posição do FWD na placa de concreto: 3 (ver Figura 3.11);

Estabelecidos os valores tentativos de $\mathrm{E}$ e $\mathrm{k}$ a partir de seus valores estimativos, foram realizadas exaustivas simulações do programa ISLAB2000, para todas as combinações possíveis, conforme apresentadas em exemplo nas Tabelas 3.4 a 3.16. A primeira simulação nesta placa com este carregamento englobou valores de E variando entre 40.000 e $70.000 \mathrm{MPA}$, a cada $2.500 \mathrm{MPa}$, totalizando em 13 valores a serem retroanalisados, combinando-os com os valores de $k$, que variaram entre 30 e $80 \mathrm{MPa} / \mathrm{m}$, a cada $5 \mathrm{MPa} / \mathrm{m}$, resultando em 11 valores diferentes.

Tabela 3.4 Retroanálise de E e k, e valores de deflexões no centro da placa A2

$\left(\mathrm{E}_{\text {tentativo }}=40.000 \mathrm{MPa}\right)$.

\begin{tabular}{|c|c|c|c|c|c|c|c|c|}
\hline \multirow{2}{*}{$\begin{array}{c}\text { Modulo de } \\
\text { elasticidade } \\
\text { E (MPa) }\end{array}$} & \multirow{2}{*}{$\begin{array}{c}\text { Reação do } \\
\text { Subleito k } \\
\text { (MPa/m) }\end{array}$} & \multicolumn{7}{|c|}{ Deflexão - Sensores ( $\mathrm{mm})$} \\
\hline & & 0 & 20 & 30 & 45 & 65 & 90 & 120 \\
\hline 51.455 & 31,59 & 0,0363 & 0,0348 & 0,0332 & 0,0308 & 0,0271 & 0,0228 & 0,0183 \\
\hline 48.757 & 33,63 & 0,0357 & 0,0340 & 0,0323 & 0,0302 & 0,0264 & 0,0222 & 0,0177 \\
\hline \multirow[t]{6}{*}{$\begin{array}{c}E_{\text {tentativo }} \\
\text { (MPa) }\end{array}$} & $\begin{array}{c}k_{\text {tentativo }} \\
(\mathrm{MPa} / \mathrm{m})\end{array}$ & & & & & & & \\
\hline & 30,00 & 0,0532 & 0,0510 & 0,0488 & 0,0448 & 0,0390 & 0,0316 & 0,0234 \\
\hline & 35,00 & 0,0487 & 0,0466 & 0,0445 & 0,0406 & 0,0350 & 0,0280 & 0,0203 \\
\hline & 40,00 & 0,0452 & 0,0431 & 0,0410 & 0,0373 & 0,0319 & 0,0252 & 0,0180 \\
\hline & 45,00 & 0,0423 & 0,0403 & 0,0382 & 0,0346 & 0,0293 & 0,0229 & 0,0161 \\
\hline & 50,00 & 0,0399 & 0,0379 & 0,0359 & 0,0323 & 0,0272 & 0,0211 & 0,0146 \\
\hline \multirow[t]{6}{*}{40.000} & 55,00 & 0,0379 & 0,0359 & 0,0339 & 0,0304 & 0,0255 & 0,0195 & 0,0133 \\
\hline & 60,00 & 0,0361 & 0,0342 & 0,0322 & 0,0288 & 0,0239 & 0,0182 & 0,0122 \\
\hline & 65,00 & 0,0346 & 0,0327 & 0,0307 & 0,0274 & 0,0226 & 0,0170 & 0,0113 \\
\hline & 70,00 & 0,0332 & 0,0313 & 0,0294 & 0,0261 & 0,0215 & 0,0160 & 0,0105 \\
\hline & 75,00 & 0,0320 & 0,0301 & 0,0283 & 0,0250 & 0,0204 & 0,0151 & 0,0098 \\
\hline & 80,00 & 0,0309 & 0,0291 & 0,0272 & 0,0240 & 0,0195 & 0,0143 & 0,0092 \\
\hline
\end{tabular}


Tabela 3.5 Retroanálise de $\mathrm{E}$ e k, e valores de deflexões no centro da placa A2

$\left(E_{\text {tentativo }}=42.500 \mathrm{MPa}\right)$.

\begin{tabular}{|c|c|c|c|c|c|c|c|c|}
\hline \multirow{2}{*}{$\begin{array}{c}\text { Modulo de } \\
\text { elasticidade } \\
\text { E (MPa) }\end{array}$} & \multirow{2}{*}{$\begin{array}{c}\text { Reação do } \\
\text { Subleito k } \\
\text { (MPa/m) }\end{array}$} & \multicolumn{7}{|c|}{ Deflexão - Sensores ( $\mathrm{mm}$ ) } \\
\hline & & 0 & 20 & 30 & 45 & 65 & 90 & 120 \\
\hline 51.455 & 31,59 & 0,0363 & 0,0348 & 0,0332 & 0,0308 & 0,0271 & 0,0228 & 0,0183 \\
\hline 48.757 & 33,63 & 0,0357 & 0,0340 & 0,0323 & 0,0302 & 0,0264 & 0,0222 & 0,0177 \\
\hline \multirow[t]{6}{*}{$\begin{array}{c}E_{\text {tentativo }} \\
\text { (MPa) }\end{array}$} & $\begin{array}{c}K_{\text {tentativo }} \\
(\mathrm{MPa} / \mathrm{m})\end{array}$ & & & & & & & \\
\hline & 30,00 & 0,0518 & 0,0498 & 0,0477 & 0,0439 & 0,0383 & 0,0312 & 0,0232 \\
\hline & 35,00 & 0,0474 & 0,0454 & 0,0434 & 0,0397 & 0,0344 & 0,0276 & 0,0202 \\
\hline & 40,00 & 0,0440 & 0,0420 & 0,0400 & 0,0365 & 0,0313 & 0,0249 & 0,0179 \\
\hline & 45,00 & 0,0412 & 0,0393 & 0,0373 & 0,0338 & 0,0288 & 0,0226 & 0,0161 \\
\hline & 50,00 & 0,0389 & 0,0370 & 0,0350 & 0,0316 & 0,0268 & 0,0208 & 0,0146 \\
\hline \multirow[t]{6}{*}{42.500} & 55,00 & 0,0369 & 0,0350 & 0,0331 & 0,0298 & 0,0250 & 0,0193 & 0,0133 \\
\hline & 60,00 & 0,0352 & 0,0333 & 0,0314 & 0,0282 & 0,0235 & 0,0180 & 0,0122 \\
\hline & 65,00 & 0,0337 & 0,0318 & 0,0300 & 0,0268 & 0,0222 & 0,0168 & 0,0113 \\
\hline & 70,00 & 0,0323 & 0,0305 & 0,0287 & 0,0255 & 0,0211 & 0,0158 & 0,0105 \\
\hline & 75,00 & 0,0312 & 0,0294 & 0,0276 & 0,0244 & 0,0201 & 0,0149 & 0,0098 \\
\hline & 80,00 & 0,0301 & 0,0283 & 0,0265 & 0,0235 & 0,0192 & 0,0141 & 0,0092 \\
\hline
\end{tabular}

Tabela 3.6 Retroanálise de E e k, e valores de deflexões no centro da placa A2

$\left(E_{\text {tentativo }}=45.000 \mathrm{MPa}\right)$.

\begin{tabular}{c|ccccccccc}
\hline $\begin{array}{c}\text { Modulo de } \\
\text { elasticidade } \\
\boldsymbol{E}(\mathbf{M P a})\end{array}$ & $\begin{array}{c}\text { Reação do } \\
\text { Subleito } \boldsymbol{k} \\
\mathbf{( M P a / m )}\end{array}$ & $\mathbf{0}$ & $\mathbf{2 0}$ & $\mathbf{3 0}$ & $\mathbf{4 5}$ & $\mathbf{6 5}$ & $\mathbf{9 0}$ & $\mathbf{1 2 0}$ \\
51.455 & 31,59 & 0,0363 & 0,0348 & 0,0332 & 0,0308 & 0,0271 & 0,0228 & 0,0183 \\
48.757 & 33,63 & 0,0357 & 0,0340 & 0,0323 & 0,0302 & 0,0264 & 0,0222 & 0,0177 \\
$\boldsymbol{E}_{\text {tentativo }}$ & $\begin{array}{c}\boldsymbol{K}_{\text {tentativo }} \\
\mathbf{( M P a )}\end{array}$ & & & & & & & & \\
& $\mathbf{M P a} / \boldsymbol{m})$ & & & & & & & \\
& 30,00 & 0,0506 & 0,0486 & 0,0466 & 0,0430 & 0,0376 & 0,0308 & 0,0231 \\
& 35,00 & 0,0463 & 0,0444 & 0,0424 & 0,0389 & 0,0338 & 0,0273 & 0,0201 \\
& 40,00 & 0,0429 & 0,0410 & 0,0391 & 0,0357 & 0,0308 & 0,0246 & 0,0178 \\
& 45,00 & 0,0402 & 0,0383 & 0,0365 & 0,0331 & 0,0283 & 0,0224 & 0,0160 \\
& 50,00 & 0,0379 & 0,0361 & 0,0342 & 0,0310 & 0,0263 & 0,0206 & 0,0145 \\
45.000 & 55,00 & 0,0359 & 0,0342 & 0,0324 & 0,0292 & 0,0246 & 0,0191 & 0,0133 \\
& 60,00 & 0,0343 & 0,0325 & 0,0307 & 0,0276 & 0,0231 & 0,0178 & 0,0122 \\
& 65,00 & 0,0328 & 0,0311 & 0,0293 & 0,0262 & 0,0219 & 0,0166 & 0,0113 \\
& 70,00 & 0,0315 & 0,0298 & 0,0280 & 0,0250 & 0,0207 & 0,0157 & 0,0105 \\
& 75,00 & 0,0303 & 0,0286 & 0,0269 & 0,0239 & 0,0197 & 0,0148 & 0,0098 \\
& 80,00 & 0,0293 & 0,0276 & 0,0259 & 0,0230 & 0,0189 & 0,0140 & 0,0092 \\
\hline
\end{tabular}


Tabela 3.7 Retroanálise de E e k, e valores de deflexões no centro da placa A2 $\left(\mathrm{E}_{\text {tentativo }}=47.500 \mathrm{MPa}\right)$.

\begin{tabular}{|c|c|c|c|c|c|c|c|c|}
\hline \multirow{2}{*}{$\begin{array}{c}\text { Modulo de } \\
\text { elasticidade } \\
\text { E (MPa) }\end{array}$} & \multirow{2}{*}{$\begin{array}{c}\text { Reação do } \\
\text { Subleito k } \\
\text { (MPa/m) }\end{array}$} & \multicolumn{7}{|c|}{ Deflexão - Sensores ( $\mathrm{mm})$} \\
\hline & & 0 & 20 & 30 & 45 & 65 & 90 & 120 \\
\hline 51.455 & 31,59 & 0,0363 & 0,0348 & 0,0332 & 0,0308 & 0,0271 & 0,0228 & 0,0183 \\
\hline 48.757 & 33,63 & 0,0357 & 0,0340 & 0,0323 & 0,0302 & 0,0264 & 0,0222 & 0,0177 \\
\hline \multirow[t]{6}{*}{$\begin{array}{c}E_{\text {tentativo }} \\
(M P a)\end{array}$} & $\begin{array}{c}k_{\text {tentativo }} \\
(\mathrm{MPa} / \mathrm{m})\end{array}$ & & & & & & & \\
\hline & 30,00 & 0,0494 & 0,0476 & 0,0457 & 0,0422 & 0,0370 & 0,0304 & 0,0229 \\
\hline & 35,00 & 0,0452 & 0,0434 & 0,0416 & 0,0382 & 0,0332 & 0,0270 & 0,0200 \\
\hline & 40,00 & 0,0419 & 0,0401 & 0,0383 & 0,0351 & 0,0303 & 0,0243 & 0,0177 \\
\hline & 45,00 & 0,0392 & 0,0375 & 0,0357 & 0,0325 & 0,0279 & 0,0221 & 0,0159 \\
\hline & 50,00 & 0,0370 & 0,0353 & 0,0335 & 0,0304 & 0,0259 & 0,0204 & 0,0144 \\
\hline \multirow{6}{*}{47.500} & 55,00 & 0,0351 & 0,0334 & 0,0317 & 0,0286 & 0,0242 & 0,0189 & 0,0132 \\
\hline & 60,00 & 0,0334 & 0,0318 & 0,0301 & 0,0271 & 0,0228 & 0,0176 & 0,0122 \\
\hline & 65,00 & 0,0320 & 0,0303 & 0,0287 & 0,0257 & 0,0215 & 0,0165 & 0,0113 \\
\hline & 70,00 & 0,0307 & 0,0291 & 0,0274 & 0,0245 & 0,0204 & 0,0155 & 0,0105 \\
\hline & 75,00 & 0,0296 & 0,0280 & 0,0263 & 0,0235 & 0,0194 & 0,0147 & 0,0098 \\
\hline & 80,00 & 0,0286 & 0,0270 & 0,0253 & 0,0225 & 0,0186 & 0,0139 & 0,0092 \\
\hline
\end{tabular}

Tabela 3.8 Retroanálise de E e k, e valores de deflexões no centro da placa A2 $\left(\mathrm{E}_{\text {tentativo }}=50.000 \mathrm{MPa}\right)$.

\begin{tabular}{|c|c|c|c|c|c|c|c|c|}
\hline \multirow{2}{*}{$\begin{array}{c}\text { Modulo de } \\
\text { elasticidade } \\
\text { E (MPa) }\end{array}$} & \multirow{2}{*}{$\begin{array}{c}\text { Reação do } \\
\text { Subleito k } \\
\text { (MPa/m) }\end{array}$} & \multicolumn{7}{|c|}{ Deflexão - Sensores ( $\mathrm{mm}$ ) } \\
\hline & & 0 & 20 & 30 & 45 & 65 & 90 & 120 \\
\hline 51.455 & 31,59 & 0,0363 & 0,0348 & 0,0332 & 0,0308 & 0,0271 & 0,0228 & 0,0183 \\
\hline 48.757 & 33,63 & 0,0357 & 0,0340 & 0,0323 & 0,0302 & 0,0264 & 0,0222 & 0,0177 \\
\hline \multirow[t]{6}{*}{$\begin{array}{c}E_{\text {tentativo }} \\
(\mathrm{MPa})\end{array}$} & $\begin{array}{c}k_{\text {tentativo }} \\
(\mathrm{MPa} / \mathrm{m})\end{array}$ & & & & & & & \\
\hline & 30,00 & 0,0484 & 0,0466 & 0,0448 & 0,0415 & 0,0365 & 0,0301 & 0,0228 \\
\hline & 35,00 & 0,0443 & 0,0425 & 0,0407 & 0,0375 & 0,0327 & 0,0267 & 0,0199 \\
\hline & 40,00 & 0,0410 & 0,0393 & 0,0375 & 0,0344 & 0,0298 & 0,0240 & 0,0176 \\
\hline & 45,00 & 0,0384 & 0,0367 & 0,0350 & 0,0319 & 0,0275 & 0,0219 & 0,0159 \\
\hline & 50,00 & 0,0362 & 0,0345 & 0,0328 & 0,0298 & 0,0255 & 0,0201 & 0,0144 \\
\hline \multirow{6}{*}{50.000} & 55,00 & 0,0343 & 0,0327 & 0,0310 & 0,0281 & 0,0238 & 0,0187 & 0,0132 \\
\hline & 60,00 & 0,0327 & 0,0311 & 0,0294 & 0,0266 & 0,0224 & 0,0174 & 0,0121 \\
\hline & 65,00 & 0,0313 & 0,0297 & 0,0281 & 0,0252 & 0,0212 & 0,0163 & 0,0112 \\
\hline & 70,00 & 0,0300 & 0,0284 & 0,0269 & 0,0241 & 0,0201 & 0,0154 & 0,0105 \\
\hline & 75,00 & 0,0289 & 0,0274 & 0,0258 & 0,0230 & 0,0192 & 0,0145 & 0,0098 \\
\hline & 80,00 & 0,0279 & 0,0264 & 0,0248 & 0,0221 & 0,0183 & 0,0138 & 0,0092 \\
\hline
\end{tabular}


Tabela 3.9 Retroanálise de E e k, e valores de deflexões no centro da placa A2

$\left(E_{\text {tentativo }}=52.500 \mathrm{MPa}\right)$.

\begin{tabular}{|c|c|c|c|c|c|c|c|c|}
\hline \multirow{2}{*}{$\begin{array}{c}\text { Modulo de } \\
\text { elasticidade } \\
\text { E (MPa) }\end{array}$} & \multirow{2}{*}{$\begin{array}{c}\text { Reação do } \\
\text { Subleito k } \\
\text { (MPa/m) }\end{array}$} & \multicolumn{7}{|c|}{ Deflexão - Sensores ( $\mathrm{mm}$ ) } \\
\hline & & 0 & 20 & 30 & 45 & 65 & 90 & 120 \\
\hline 51.455 & 31,59 & 0,0363 & 0,0348 & 0,0332 & 0,0308 & 0,0271 & 0,0228 & 0,0183 \\
\hline 48.757 & 33,63 & 0,0357 & 0,0340 & 0,0323 & 0,0302 & 0,0264 & 0,0222 & 0,0177 \\
\hline \multirow[t]{6}{*}{$\begin{array}{c}E_{\text {tentativo }} \\
\text { (MPa) }\end{array}$} & $\begin{array}{c}K_{\text {tentativo }} \\
(\mathrm{MPa} / \mathrm{m})\end{array}$ & & & & & & & \\
\hline & 30,00 & 0,0474 & 0,0457 & 0,0440 & 0,0408 & 0,0360 & 0,0297 & 0,0226 \\
\hline & 35,00 & 0,0434 & 0,0417 & 0,0400 & 0,0369 & 0,0323 & 0,0264 & 0,0198 \\
\hline & 40,00 & 0,0401 & 0,0385 & 0,0368 & 0,0338 & 0,0294 & 0,0238 & 0,0176 \\
\hline & 45,00 & 0,0375 & 0,0359 & 0,0343 & 0,0314 & 0,0271 & 0,0217 & 0,0158 \\
\hline & 50,00 & 0,0354 & 0,0338 & 0,0322 & 0,0293 & 0,0251 & 0,0199 & 0,0143 \\
\hline \multirow[t]{6}{*}{52.500} & 55,00 & 0,0335 & 0,0320 & 0,0304 & 0,0276 & 0,0235 & 0,0185 & 0,0131 \\
\hline & 60,00 & 0,0320 & 0,0304 & 0,0289 & 0,0261 & 0,0221 & 0,0172 & 0,0121 \\
\hline & 65,00 & 0,0306 & 0,0291 & 0,0275 & 0,0248 & 0,0209 & 0,0162 & 0,0112 \\
\hline & 70,00 & 0,0294 & 0,0279 & 0,0263 & 0,0237 & 0,0198 & 0,0152 & 0,0105 \\
\hline & 75,00 & 0,0283 & 0,0268 & 0,0253 & 0,0226 & 0,0189 & 0,0144 & 0,0098 \\
\hline & 80,00 & 0,0273 & 0,0258 & 0,0243 & 0,0217 & 0,0180 & 0,0137 & 0,0092 \\
\hline
\end{tabular}

Tabela 3.10 Retroanálise de E e k, e valores de deflexões no centro da placa A2

$\left(E_{\text {tentativo }}=55.000 \mathrm{MPa}\right)$.

\begin{tabular}{|c|c|c|c|c|c|c|c|c|}
\hline \multirow{2}{*}{$\begin{array}{c}\text { Modulo de } \\
\text { elasticidade } E \\
\text { (MPa) }\end{array}$} & \multirow{2}{*}{$\begin{array}{c}\text { Reação do } \\
\text { Subleito k } \\
\text { (MPa/m) }\end{array}$} & \multicolumn{7}{|c|}{ Deflexão - Sensores ( $\mathrm{mm})$} \\
\hline & & 0 & 20 & 30 & 45 & 65 & 90 & 120 \\
\hline 51.455 & 31,59 & 0,0363 & 0,0348 & 0,0332 & 0,0308 & 0,0271 & 0,0228 & 0,0183 \\
\hline 48.757 & 33,63 & 0,0357 & 0,0340 & 0,0323 & 0,0302 & 0,0264 & 0,0222 & 0,0177 \\
\hline $\begin{array}{c}E_{\text {tentativo }} \\
(\mathrm{MPa})\end{array}$ & $\begin{array}{c}k_{\text {tentativo }} \\
(\mathrm{MPa} / \mathrm{m})\end{array}$ & & & & & & & \\
\hline \multirow{11}{*}{55.000} & 30,00 & 0,0465 & 0,0449 & 0,0432 & 0,0401 & 0,0355 & 0,0294 & 0,0225 \\
\hline & 35,00 & 0,0425 & 0,0409 & 0,0393 & 0,0363 & 0,0318 & 0,0261 & 0,0197 \\
\hline & 40,00 & 0,0394 & 0,0378 & 0,0362 & 0,0333 & 0,0290 & 0,0235 & 0,0175 \\
\hline & 45,00 & 0,0368 & 0,0353 & 0,0337 & 0,0308 & 0,0267 & 0,0215 & 0,0157 \\
\hline & 50,00 & 0,0347 & 0,0331 & 0,0316 & 0,0288 & 0,0248 & 0,0197 & 0,0143 \\
\hline & 55,00 & 0,0329 & 0,0314 & 0,0298 & 0,0271 & 0,0232 & 0,0183 & 0,0131 \\
\hline & 60,00 & 0,0313 & 0,0298 & 0,0283 & 0,0257 & 0,0218 & 0,0171 & 0,0121 \\
\hline & 65,00 & 0,0300 & 0,0285 & 0,0270 & 0,0244 & 0,0206 & 0,0160 & 0,0112 \\
\hline & 70,00 & 0,0288 & 0,0273 & 0,0258 & 0,0233 & 0,0196 & 0,0151 & 0,0104 \\
\hline & 75,00 & 0,0277 & 0,0263 & 0,0248 & 0,0223 & 0,0186 & 0,0143 & 0,0098 \\
\hline & 80,00 & 0,0267 & 0,0253 & 0,0239 & 0,0214 & 0,0178 & 0,0135 & 0,0092 \\
\hline
\end{tabular}


Tabela 3.11 Retroanálise de E e k, e valores de deflexões no centro da placa A2

$\left(\mathrm{E}_{\text {tentativo }}=57.500 \mathrm{MPa}\right)$.

\begin{tabular}{c|ccccccccc}
\hline $\begin{array}{c}\text { Modulo de } \\
\text { elasticidade } \\
\boldsymbol{E}(\mathbf{M P a})\end{array}$ & $\begin{array}{c}\text { Reação do } \\
\text { Subleito } \boldsymbol{k} \\
\mathbf{( M P a / m )}\end{array}$ & $\mathbf{0}$ & $\mathbf{2 0}$ & $\mathbf{3 0}$ & $\mathbf{4 5}$ & $\mathbf{6 5}$ & $\mathbf{9 0}$ & $\mathbf{1 2 0}$ \\
51.455 & 31,59 & 0,0363 & 0,0348 & 0,0332 & 0,0308 & 0,0271 & 0,0228 & 0,0183 \\
48.757 & 33,63 & 0,0357 & 0,0340 & 0,0323 & 0,0302 & 0,0264 & 0,0222 & 0,0177 \\
$\boldsymbol{E}_{\text {tentativo }}$ & $\begin{array}{c}\boldsymbol{k} \text { tentativo } \\
\mathbf{M P a})\end{array}$ & & & & & & & & \\
& $\mathbf{M P a} / \boldsymbol{m})$ & & & & & & & \\
& 30,00 & 0,0457 & 0,0441 & 0,0425 & 0,0395 & 0,0350 & 0,0291 & 0,0224 \\
& 35,00 & 0,0417 & 0,0402 & 0,0386 & 0,0357 & 0,0314 & 0,0259 & 0,0196 \\
& 40,00 & 0,0386 & 0,0371 & 0,0356 & 0,0328 & 0,0286 & 0,0233 & 0,0174 \\
& 45,00 & 0,0361 & 0,0346 & 0,0331 & 0,0304 & 0,0263 & 0,0213 & 0,0156 \\
& 50,00 & 0,0340 & 0,0325 & 0,0310 & 0,0284 & 0,0245 & 0,0196 & 0,0142 \\
57.500 & 55,00 & 0,0322 & 0,0308 & 0,0293 & 0,0267 & 0,0229 & 0,0181 & 0,0130 \\
& 60,00 & 0,0307 & 0,0293 & 0,0278 & 0,0252 & 0,0215 & 0,0169 & 0,0120 \\
& 65,00 & 0,0294 & 0,0280 & 0,0265 & 0,0240 & 0,0203 & 0,0159 & 0,0112 \\
& 70,00 & 0,0282 & 0,0268 & 0,0254 & 0,0229 & 0,0193 & 0,0150 & 0,0104 \\
& 75,00 & 0,0271 & 0,0258 & 0,0244 & 0,0219 & 0,0184 & 0,0142 & 0,0097 \\
& 80,00 & 0,0262 & 0,0248 & 0,0234 & 0,0210 & 0,0176 & 0,0134 & 0,0092 \\
\hline
\end{tabular}

Tabela 3.12 Retroanálise de E e k, e valores de deflexões no centro da placa A2

$\left(E_{\text {tentativo }}=60.000 \mathrm{MPa}\right)$.

\begin{tabular}{|c|c|c|c|c|c|c|c|c|}
\hline \multirow{2}{*}{$\begin{array}{c}\text { Modulo de } \\
\text { elasticidade } \\
\text { E (MPa) }\end{array}$} & \multirow{2}{*}{$\begin{array}{c}\text { Reação do } \\
\text { Subleito } k \\
\text { (MPa/m) }\end{array}$} & \multicolumn{7}{|c|}{ Deflexão - Sensores ( $\mathrm{mm}$ ) } \\
\hline & & 0 & 20 & 30 & 45 & 65 & 90 & 120 \\
\hline 51.455 & 31,59 & 0,0363 & 0,0348 & 0,0332 & 0,0308 & 0,0271 & 0,0228 & 0,0183 \\
\hline 48.757 & 33,63 & 0,0357 & 0,0340 & 0,0323 & 0,0302 & 0,0264 & 0,0222 & 0,0177 \\
\hline \multirow[t]{6}{*}{$\begin{array}{c}E_{\text {tentativo }} \\
(\mathrm{MPa})\end{array}$} & $\begin{array}{c}k_{\text {tentativo }} \\
(\mathrm{MPa} / \mathrm{m})\end{array}$ & & & & & & & \\
\hline & 30,00 & 0,0449 & 0,0434 & 0,0418 & 0,0389 & 0,0346 & 0,0289 & 0,0222 \\
\hline & 35,00 & 0,0410 & 0,0395 & 0,0380 & 0,0352 & 0,0310 & 0,0256 & 0,0194 \\
\hline & 40,00 & 0,0379 & 0,0365 & 0,0350 & 0,0323 & 0,0282 & 0,0231 & 0,0173 \\
\hline & 45,00 & 0,0354 & 0,0340 & 0,0325 & 0,0299 & 0,0260 & 0,0211 & 0,0156 \\
\hline & 50,00 & 0,0334 & 0,0320 & 0,0305 & 0,0279 & 0,0241 & 0,0194 & 0,0142 \\
\hline \multirow[t]{6}{*}{60.000} & 55,00 & 0,0316 & 0,0302 & 0,0288 & 0,0263 & 0,0226 & 0,0180 & 0,0130 \\
\hline & 60,00 & 0,0301 & 0,0287 & 0,0274 & 0,0249 & 0,0212 & 0,0168 & $0,012 C$ \\
\hline & 65,00 & 0,0288 & 0,0275 & 0,0261 & 0,0236 & 0,0201 & 0,0158 & 0,0111 \\
\hline & 70,00 & 0,0277 & 0,0263 & 0,0249 & 0,0225 & 0,0191 & 0,0148 & 0,0104 \\
\hline & 75,00 & 0,0266 & 0,0253 & 0,0239 & 0,0216 & 0,0182 & 0,0140 & 0,0097 \\
\hline & 80,00 & 0,0257 & 0,0244 & 0,0230 & 0,0207 & 0,0174 & 0,0133 & 0,0091 \\
\hline
\end{tabular}


Tabela 3.13 Retroanálise de E e k, e valores de deflexões no centro da placa A2

$\left(E_{\text {tentativo }}=62.500 \mathrm{MPa}\right)$.

\begin{tabular}{|c|c|c|c|c|c|c|c|c|}
\hline \multirow{2}{*}{$\begin{array}{c}\text { Modulo de } \\
\text { elasticidade } \\
\text { E (MPa) }\end{array}$} & \multirow{2}{*}{$\begin{array}{c}\text { Reação do } \\
\text { Subleito k } \\
\text { (MPa/m) }\end{array}$} & \multicolumn{7}{|c|}{ Deflexão - Sensores ( $\mathrm{mm})$} \\
\hline & & 0 & 20 & 30 & 45 & 65 & 90 & 120 \\
\hline 51.455 & 31,59 & 0,0363 & 0,0348 & 0,0332 & 0,0308 & 0,0271 & 0,0228 & 0,0183 \\
\hline 48.757 & 33,63 & 0,0357 & 0,0340 & 0,0323 & 0,0302 & 0,0264 & 0,0222 & 0,0177 \\
\hline \multirow[t]{6}{*}{$\begin{array}{c}E_{\text {tentativo }} \\
(M P a)\end{array}$} & $\begin{array}{c}k_{\text {tentativo }} \\
(\mathrm{MPa} / \mathrm{m})\end{array}$ & & & & & & & \\
\hline & 30,00 & 0,0442 & 0,0427 & 0,0412 & 0,0384 & 0,0341 & 0,0286 & 0,0221 \\
\hline & 35,00 & 0,0403 & 0,0389 & 0,0374 & 0,0347 & 0,0306 & 0,0254 & 0,0193 \\
\hline & 40,00 & 0,0373 & 0,0359 & 0,0344 & 0,0318 & 0,0279 & 0,0229 & 0,0172 \\
\hline & 45,00 & 0,0348 & 0,0334 & 0,0320 & 0,0295 & 0,0257 & 0,0209 & 0,0155 \\
\hline & 50,00 & 0,0328 & 0,0314 & 0,0300 & 0,0275 & 0,0239 & 0,0192 & 0,0141 \\
\hline \multirow[t]{6}{*}{62.500} & 55,00 & 0,0311 & 0,0297 & 0,0284 & 0,0259 & 0,0223 & 0,0178 & 0,0129 \\
\hline & 60,00 & 0,0296 & 0,0283 & 0,0269 & 0,0245 & 0,0210 & 0,0166 & 0,0120 \\
\hline & 65,00 & 0,0283 & 0,0270 & 0,0256 & 0,0233 & 0,0198 & 0,0156 & 0,0111 \\
\hline & 70,00 & 0,0272 & 0,0259 & 0,0245 & 0,0222 & 0,0188 & 0,0147 & 0,0104 \\
\hline & 75,00 & 0,0261 & 0,0248 & 0,0235 & 0,0212 & 0,0179 & 0,0139 & 0,0097 \\
\hline & 80,00 & 0,0252 & 0,0239 & 0,0227 & 0,0204 & 0,0171 & 0,0132 & 0,0091 \\
\hline
\end{tabular}

Tabela 3.14 Retroanálise de E e k, e valores de deflexões no centro da placa A2 $\left(E_{\text {tentativo }}=65.000 \mathrm{MPa}\right)$.

\begin{tabular}{|c|c|c|c|c|c|c|c|c|}
\hline \multirow{2}{*}{$\begin{array}{c}\text { Modulo de } \\
\text { elasticidade } \\
\text { E (MPa) }\end{array}$} & \multirow{2}{*}{$\begin{array}{c}\text { Reação do } \\
\text { Subleito k } \\
\text { (MPa/m) }\end{array}$} & \multicolumn{7}{|c|}{ Deflexão - Sensores ( $\mathrm{mm})$} \\
\hline & & 0 & 20 & 30 & 45 & 65 & 90 & 120 \\
\hline 51.455 & 31,59 & 0,0363 & 0,0348 & 0,0332 & 0,0308 & 0,0271 & 0,0228 & 0,0183 \\
\hline 48.757 & 33,63 & 0,0357 & 0,0340 & 0,0323 & 0,0302 & 0,0264 & 0,0222 & 0,0177 \\
\hline \multirow[t]{6}{*}{$\begin{array}{c}E_{\text {tentativo }} \\
(M P a)\end{array}$} & $\begin{array}{c}k_{\text {tentativo }} \\
(\mathrm{MPa} / \mathrm{m})\end{array}$ & & & & & & & \\
\hline & 30,00 & 0,0435 & 0,0421 & 0,0406 & 0,0379 & 0,0337 & 0,0283 & 0,0220 \\
\hline & 35,00 & 0,0397 & 0,0383 & 0,0368 & 0,0342 & 0,0303 & 0,0251 & 0,0192 \\
\hline & 40,00 & 0,0367 & 0,0353 & 0,0339 & 0,0314 & 0,0276 & 0,0227 & 0,0171 \\
\hline & 45,00 & 0,0343 & 0,0329 & 0,0315 & 0,0291 & 0,0254 & 0,0207 & 0,0154 \\
\hline & 50,00 & 0,0322 & 0,0309 & 0,0296 & 0,0272 & 0,0236 & 0,0191 & 0,0141 \\
\hline \multirow[t]{6}{*}{65.000} & 55,00 & 0,0305 & 0,0292 & 0,0279 & 0,0255 & 0,0221 & 0,0177 & 0,0129 \\
\hline & 60,00 & 0,0291 & 0,0278 & 0,0265 & 0,0242 & 0,0207 & 0,0165 & 0,0119 \\
\hline & 65,00 & 0,0278 & 0,0265 & 0,0252 & 0,0229 & 0,0196 & 0,0155 & 0,0111 \\
\hline & 70,00 & 0,0267 & 0,0254 & 0,0242 & 0,0219 & 0,0186 & 0,0146 & 0,0103 \\
\hline & 75,00 & 0,0257 & 0,0244 & 0,0232 & 0,0209 & 0,0177 & 0,0138 & 0,0097 \\
\hline & 80,00 & 0,0248 & 0,0236 & 0,0223 & 0,0201 & 0,0170 & 0,0131 & 0,0091 \\
\hline
\end{tabular}


Tabela 3.15 Retroanálise de E e k, e valores de deflexões no centro da placa A2

$\left(\mathrm{E}_{\text {tentativo }}=67.500 \mathrm{MPa}\right)$.

\begin{tabular}{|c|c|c|c|c|c|c|c|c|}
\hline \multirow{2}{*}{$\begin{array}{c}\text { Modulo de } \\
\text { elasticidade } \\
\text { E (MPa) }\end{array}$} & \multirow{2}{*}{$\begin{array}{c}\text { Reação do } \\
\text { Subleito k } \\
\text { (MPa/m) }\end{array}$} & \multicolumn{7}{|c|}{ Deflexão - Sensores ( $\mathrm{mm})$} \\
\hline & & 0 & 20 & 30 & 45 & 65 & 90 & 120 \\
\hline 51.455 & 31,59 & 0,0363 & 0,0348 & 0,0332 & 0,0308 & 0,0271 & 0,0228 & 0,0183 \\
\hline 48.757 & 33,63 & 0,0357 & 0,0340 & 0,0323 & 0,0302 & 0,0264 & 0,0222 & 0,0177 \\
\hline \multirow[t]{6}{*}{$\begin{array}{c}E_{\text {tentativo }} \\
(M P a)\end{array}$} & $\begin{array}{c}k_{\text {tentativo }} \\
(\mathrm{MPa} / \mathrm{m})\end{array}$ & & & & & & & \\
\hline & 30,00 & 0,0428 & 0,0415 & 0,0400 & 0,0374 & 0,0334 & 0,0281 & 0,0219 \\
\hline & 35,00 & 0,0391 & 0,0377 & 0,0363 & 0,0338 & 0,0299 & 0,0249 & 0,0192 \\
\hline & 40,00 & 0,0361 & 0,0348 & 0,0334 & 0,0310 & 0,0273 & 0,0225 & 0,0171 \\
\hline & 45,00 & 0,0337 & 0,0324 & 0,0311 & 0,0287 & 0,0251 & 0,0205 & 0,0154 \\
\hline & 50,00 & 0,0317 & 0,0305 & 0,0291 & 0,0268 & 0,0233 & 0,0189 & 0,0140 \\
\hline \multirow[t]{6}{*}{67.500} & 55,00 & 0,0301 & 0,0288 & 0,0275 & 0,0252 & 0,0218 & 0,0175 & 0,0129 \\
\hline & 60,00 & 0,0286 & 0,0274 & 0,0261 & 0,0238 & 0,0205 & 0,0164 & 0,0119 \\
\hline & 65,00 & 0,0274 & 0,0261 & 0,0249 & 0,0226 & 0,0194 & 0,0154 & 0,0110 \\
\hline & 70,00 & 0,0262 & 0,0250 & 0,0238 & 0,0216 & 0,0184 & 0,0145 & 0,0103 \\
\hline & 75,00 & 0,0253 & 0,0240 & 0,0228 & 0,0207 & 0,0175 & 0,0137 & 0,0097 \\
\hline & 80,00 & 0,0244 & 0,0232 & 0,0220 & 0,0198 & 0,0168 & 0,0130 & 0,0091 \\
\hline
\end{tabular}

Tabela 3.16 Retroanálise de E e k, e valores de deflexões no centro da placa A2

$\left(\mathrm{E}_{\text {tentativo }}=70.000 \mathrm{MPa}\right)$.

\begin{tabular}{|c|c|c|c|c|c|c|c|c|}
\hline \multirow{2}{*}{$\begin{array}{c}\text { Modulo de } \\
\text { elasticidade } \\
\text { E (MPa) }\end{array}$} & \multirow{2}{*}{$\begin{array}{c}\text { Reação do } \\
\text { Subleito k } \\
\text { (MPa/m) }\end{array}$} & \multicolumn{7}{|c|}{ Deflexão - Sensores ( $\mathrm{mm}$ ) } \\
\hline & & 0 & 20 & 30 & 45 & 65 & 90 & 120 \\
\hline 51.455 & 31,59 & 0,0363 & 0,0348 & 0,0332 & 0,0308 & 0,0271 & 0,0228 & 0,0183 \\
\hline 48.757 & 33,63 & 0,0357 & 0,0340 & 0,0323 & 0,0302 & 0,0264 & 0,0222 & 0,0177 \\
\hline \multirow[t]{6}{*}{$\begin{array}{c}E_{\text {tentativo }} \\
\text { (MPa) }\end{array}$} & $\begin{array}{c}K_{\text {tentativo }} \\
(\mathrm{MPa} / \mathrm{m})\end{array}$ & & & & & & & \\
\hline & 30,00 & 0,0422 & 0,0409 & 0,0395 & 0,0369 & 0,0330 & 0,0279 & 0,0218 \\
\hline & 35,00 & 0,0385 & 0,0372 & 0,0358 & 0,0334 & 0,0296 & 0,0247 & 0,0191 \\
\hline & 40,00 & 0,0356 & 0,0343 & 0,0330 & 0,0306 & 0,0270 & 0,0223 & 0,0170 \\
\hline & 45,00 & 0,0332 & 0,0319 & 0,0307 & 0,0283 & 0,0248 & 0,0204 & 0,0153 \\
\hline & 50,00 & 0,0312 & 0,0300 & 0,0287 & 0,0264 & 0,0231 & 0,0188 & 0,0139 \\
\hline \multirow[t]{6}{*}{70.000} & 55,00 & 0,0296 & 0,0284 & 0,0271 & 0,0249 & 0,0216 & 0,0174 & 0,0128 \\
\hline & 60,00 & 0,0282 & 0,0270 & 0,0257 & 0,0235 & 0,0203 & 0,0163 & 0,0118 \\
\hline & 65,00 & 0,0269 & 0,0257 & 0,0245 & 0,0223 & 0,0192 & 0,0153 & 0,0110 \\
\hline & 70,00 & 0,0258 & 0,0246 & 0,0234 & 0,0213 & 0,0182 & 0,0144 & 0,0103 \\
\hline & 75,00 & 0,0248 & 0,0237 & 0,0225 & 0,0204 & 0,0174 & 0,0136 & 0,0096 \\
\hline & 80,00 & 0,0240 & 0,0228 & 0,0216 & 0,0196 & 0,0166 & 0,0129 & 0,0091 \\
\hline
\end{tabular}


O critério de aproximação entre a bacia teórica e aquela medida em campo baseiase no cálculo do erro quadrático entre as deflexões das bacias em consideração. Tal erro é calculado pela equação [3.5]:

$$
E R R O=\left(\delta_{\text {medida }}-\delta_{\text {ISLAB }}\right)^{2}
$$

O menor erro quadrático indica as bacias que mais se aproximam entre si. 0 resultado para a primeira simulação acima descrita, conforme valores em destaque na Tabela 3.10, foi para E de 55.000 MPa e k de $45 \mathrm{MPa} / \mathrm{m}$.

Com base nos resultados acima, iniciou-se uma segunda série de simulações tomando-se a faixa de $\mathrm{E}$ entre 53.000 e $57.000 \mathrm{MPa}$, de 1.000 em $1.000 \mathrm{MPa}$, totalizando em 5 valores a serem retroanalisados, combinando-os com os novos valores de k que variaram entre 40 e $60 \mathrm{MPa} / \mathrm{m}$, de 5 em $5 \mathrm{MPa} / \mathrm{m}$. Os resultados dessa segunda série de simulações são apresentados na Tabela 3.17.

Como se verifica na Tabela 3.17, nesta segunda tentativa houve uma aproximação melhor entre as bacias teórica e medida, tendo como novos resultados parciais os valores: $\mathrm{E}=57.000 \mathrm{MPa}$ e $\mathrm{k}=45 \mathrm{MPa} / \mathrm{m}$.

Para a terceira série de simulações, fixou-se o valor de k (45 MPa/m) uma vez que não alterou entre a primeira e a segunda aproximação, variando-se agora apenas o valor do módulo de elasticidade, ainda não estimado com maior precisão, entre 56.800 e 57.400 MPa. Os resultados obtidos estão apresentados na Tabela 3.18. 
Tabela 3.17 Retroanálise de E e k, e valores de deflexões no centro da placa A2.

\begin{tabular}{|c|c|c|c|c|c|c|c|c|}
\hline \multirow{2}{*}{$\begin{array}{c}\text { Modulo de } \\
\text { elasticidade } \\
\text { E (MPa) }\end{array}$} & \multirow{2}{*}{$\begin{array}{c}\text { Reação do } \\
\text { Subleito k } \\
\text { (MPa/m) }\end{array}$} & \multicolumn{7}{|c|}{ Deflexão - Sensores ( $\mathrm{mm}$ ) } \\
\hline & & 0 & 20 & 30 & 45 & 65 & 90 & 120 \\
\hline 51.455 & 31,59 & 0,0363 & 0,0348 & 0,0332 & 0,0308 & 0,0271 & 0,0228 & 0,0183 \\
\hline 48.757 & 33,63 & 0,0357 & 0,0340 & 0,0323 & 0,0302 & 0,0264 & 0,0222 & 0,0177 \\
\hline \multirow[t]{3}{*}{$\begin{array}{c}E_{\text {tentativo }} \\
\text { (MPa) }\end{array}$} & $\begin{array}{c}K_{\text {tentativo }} \\
(\mathrm{MPa} / \mathrm{m})\end{array}$ & & & & & & & \\
\hline & 40,00 & 0,0400 & 0,0384 & 0,0367 & 0,0337 & 0,0293 & 0,0237 & 0,0175 \\
\hline & 45,00 & 0,0374 & 0,0358 & 0,0342 & 0,0313 & 0,0270 & 0,0216 & 0,0158 \\
\hline \multirow[t]{5}{*}{53.000} & 50,00 & 0,0352 & 0,0337 & 0,0321 & 0,0292 & 0,0251 & 0,0199 & 0,0143 \\
\hline & 55,00 & 0,0334 & 0,0319 & 0,0303 & 0,0275 & 0,0234 & 0,0185 & 0,0131 \\
\hline & 60,00 & 0,0318 & 0,0303 & 0,0288 & 0,0260 & 0,0220 & 0,0172 & 0,0121 \\
\hline & 40,00 & 0,0397 & 0,0381 & 0,0364 & 0,0335 & 0,0291 & 0,0236 & 0,0175 \\
\hline & 45,00 & 0,0371 & 0,0355 & 0,0339 & 0,0310 & 0,0268 & 0,0215 & 0,0157 \\
\hline \multirow[t]{5}{*}{54.000} & 50,00 & 0,0349 & 0,0334 & 0,0318 & 0,0290 & 0,0249 & 0,0198 & 0,0143 \\
\hline & 55,00 & 0,0331 & 0,0316 & 0,0301 & 0,0273 & 0,0233 & 0,0184 & 0,0131 \\
\hline & 60,00 & 0,0316 & 0,0301 & 0,0285 & 0,0258 & 0,0219 & 0,0172 & 0,0121 \\
\hline & 40,00 & 0,0394 & 0,0378 & 0,0362 & 0,0333 & 0,0290 & 0,0235 & 0,0175 \\
\hline & 45,00 & 0,0368 & 0,0353 & 0,0337 & 0,0308 & 0,0267 & 0,0215 & 0,0157 \\
\hline \multirow[t]{5}{*}{55.000} & 50,00 & 0,0347 & 0,0331 & 0,0316 & 0,0288 & 0,0248 & 0,0197 & 0,0143 \\
\hline & 55,00 & 0,0329 & 0,0314 & 0,0298 & 0,0271 & 0,0232 & 0,0183 & 0,0131 \\
\hline & 60,00 & 0,0313 & 0,0298 & 0,0283 & 0,0257 & 0,0218 & 0,0171 & 0,0121 \\
\hline & 40,00 & 0,0391 & 0,0375 & 0,0359 & 0,0331 & 0,0288 & 0,0234 & 0,0174 \\
\hline & 45,00 & 0,0365 & 0,0350 & 0,0334 & 0,0306 & 0,0265 & 0,0214 & 0,0157 \\
\hline \multirow[t]{5}{*}{56.000} & 50,00 & 0,0344 & 0,0329 & 0,0314 & 0,0286 & 0,0246 & 0,0197 & 0,0143 \\
\hline & 55,00 & 0,0326 & 0,0311 & 0,0296 & 0,0269 & 0,0231 & 0,0182 & 0,0131 \\
\hline & 60,00 & 0,0311 & 0,0296 & 0,0281 & 0,0255 & 0,0217 & 0,0170 & 0,0121 \\
\hline & 40,00 & 0,0388 & 0,0372 & 0,0357 & 0,0329 & 0,0287 & 0,0233 & 0,0174 \\
\hline & 45,00 & 0,0362 & 0,0347 & 0,0332 & 0,0304 & 0,0264 & 0,0213 & 0,0157 \\
\hline \multirow[t]{3}{*}{57.000} & 50,00 & 0,0341 & 0,0327 & 0,0312 & 0,0285 & 0,0245 & 0,0196 & 0,0142 \\
\hline & 55,00 & 0,0324 & 0,0309 & 0,0294 & 0,0268 & 0,0229 & 0,0182 & 0,0131 \\
\hline & 60,00 & 0,0308 & 0,0294 & 0,0279 & 0,0253 & 0,0216 & 0,0170 & 0,0120 \\
\hline
\end{tabular}

Tabela 3.18 Retroanálise de E e k, e valores de deflexões no centro da placa A2.

\begin{tabular}{|c|c|c|c|c|c|c|c|c|}
\hline \multirow{2}{*}{$\begin{array}{c}\text { Modulo de } \\
\text { elasticidade } \\
\text { E (MPa) }\end{array}$} & \multirow{2}{*}{$\begin{array}{c}\text { Reação do } \\
\text { Subleito k } \\
\text { (MPa/m) }\end{array}$} & \multicolumn{7}{|c|}{ Deflexão - Sensores ( $\mathrm{mm})$} \\
\hline & & 0 & 20 & 30 & 45 & 65 & 90 & 120 \\
\hline 51.455 & 31,59 & 0,0363 & 0,0348 & 0,0332 & 0,0308 & 0,0271 & 0,0228 & 0,0183 \\
\hline 48.757 & 33,63 & 0,0357 & 0,0340 & 0,0323 & 0,0302 & 0,0264 & 0,0222 & 0,0177 \\
\hline $\begin{array}{c}E_{\text {tentativo }} \\
(\mathrm{MPa})\end{array}$ & $\begin{array}{c}k_{\text {tentativo }} \\
(\mathrm{MPa} / \mathrm{m})\end{array}$ & & & & & & & \\
\hline 56.800 & 45,00 & 0,0363 & 0,0348 & 0,0332 & 0,0305 & 0,0264 & 0,0213 & 0,0157 \\
\hline 56.900 & 45,00 & 0,0363 & 0,0348 & 0,0332 & 0,0305 & 0,0264 & 0,0213 & 0,0157 \\
\hline 57.050 & 45,00 & 0,0362 & 0,0347 & 0,0332 & 0,0304 & 0,0264 & 0,0213 & 0,0157 \\
\hline 57.100 & 45,00 & 0,0362 & 0,0347 & 0,0332 & 0,0304 & 0,0264 & 0,0213 & 0,0157 \\
\hline 57.200 & 45,00 & 0,0362 & 0,0347 & 0,0332 & 0,0304 & 0,0264 & 0,0213 & 0,0157 \\
\hline 57.300 & 45,00 & 0,0362 & 0,0347 & 0,0331 & 0,0304 & 0,0264 & 0,0213 & 0,0157 \\
\hline 57.400 & 45,00 & 0,0361 & 0,0346 & 0,0331 & 0,0304 & 0,0263 & 0,0213 & 0,0156 \\
\hline
\end{tabular}


Como o resultado, o módulo de elasticidade nesta terceira tentativa foi de 57.200 $\mathrm{MPa}$; para a última série de simulações, variou-se E na faixa entre 57.150 e 57.250 $\mathrm{MPa}$. Os resultados finais são apresentados na Tabela 3.19. A melhor aproximação pelo erro quadrático foi de $E$ igual a $57.250 \mathrm{MPa}$ e $\mathrm{k}$ igual $45 \mathrm{MPa} / \mathrm{m}$, sendo que as bacias de deflexões retroanalisadas, teórica e de campo, são apresentadas na Figura 3.21.

Tabela 3.19 Retroanálise de E e k, e valores de deflexões no centro da placa A2.

\begin{tabular}{|c|c|c|c|c|c|c|c|c|}
\hline \multirow{2}{*}{$\begin{array}{c}\text { Modulo de } \\
\text { elasticidade } \\
\text { E (MPa) }\end{array}$} & \multirow{2}{*}{$\begin{array}{c}\text { Reação do } \\
\text { Subleito k } \\
\text { (MPa/m) }\end{array}$} & \multicolumn{7}{|c|}{ Deflexão - Sensores $(\mathrm{mm})$} \\
\hline & & 0 & 20 & 30 & 45 & 65 & 90 & 120 \\
\hline 51.455 & 31,59 & 0,0363 & 0,0348 & 0,0332 & 0,0308 & 0,0271 & 0,0228 & 0,0183 \\
\hline 48.757 & 33,63 & 0,0357 & 0,0340 & 0,0323 & 0,0302 & 0,0264 & 0,0222 & 0,0177 \\
\hline $\begin{array}{c}E_{\text {tentativo }} \\
\text { (MPa) }\end{array}$ & $\begin{array}{c}K_{\text {tentativo }} \\
(\mathrm{MPa} / \mathrm{m})\end{array}$ & & & & & & & \\
\hline 57.150 & 45,00 & 0,0362 & 0,0347 & 0,0332 & 0,0304 & 0,0264 & 0,0213 & 0,0157 \\
\hline 57.200 & 45,00 & 0,0362 & 0,0347 & 0,0332 & 0,0304 & 0,0264 & 0,0213 & 0,0157 \\
\hline 57.250 & 45,00 & 0,0362 & 0,0347 & 0,0331 & 0,0304 & 0,0264 & 0,0213 & 0,0157 \\
\hline
\end{tabular}

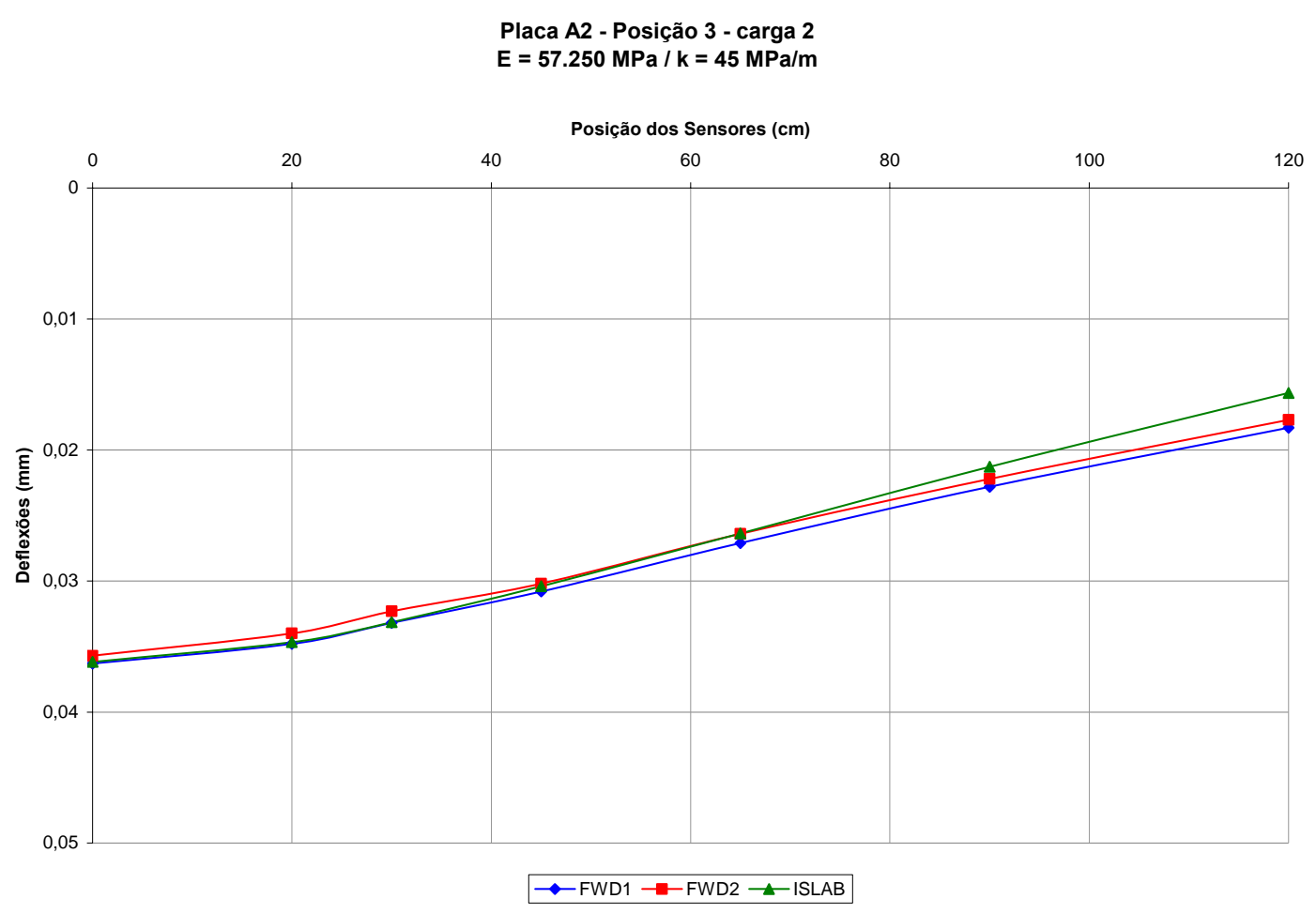

Figura 3.21 Exemplo de bacias de deflexões. 
Como foram aplicados duas vezes cada carregamento do FWD, e as deflexões obtidas bem parecidas, foi escolhida a curva que mais se aproximava de uma das bacias de deflexões. Em alguns poucos casos, em que o menor erro quadrático não era a bacia de deflexões que mais se aproximava das primeiras três deflexões, foi considerado, nestes casos, não o menor erro quadrático geral, mas a curva que mais se adequava as medidas de deflexões de campo, dentro dos melhores resultados quanto ao erro quadrático.

Tais procedimentos e critérios acima mencionados foram também empregados para o caso de retroanálises de bacias de deflexões medidas nas proximidades das juntas das placas de concreto. Acontece que para esses casos, os valores retroanalisados de módulo de elasticidade do concreto empregando-se as deflexões para carga aplicada no centro das placas, conforme descrito acima, foram tomados como referência final, restando ao fim do processo a determinação, por retroanálise, dos valores do módulo de reação do subleito nas bordas transversais $\left(k_{b}\right)$ e dos valores de eficiência de transferência de cargas em juntas (LTE). Na seqüência é apresentado o fluxograma dos procedimentos adotados para as retroanálises realizadas, onde ficam claras as seguintes dependências: (a) das retroanálises das cargas de centro nas estimativas iniciais de $\mathrm{E}$ e k; (b) das retroanálises das cargas nas juntas nas retroanálises das cargas no centro, para determinação de LTE e kb.

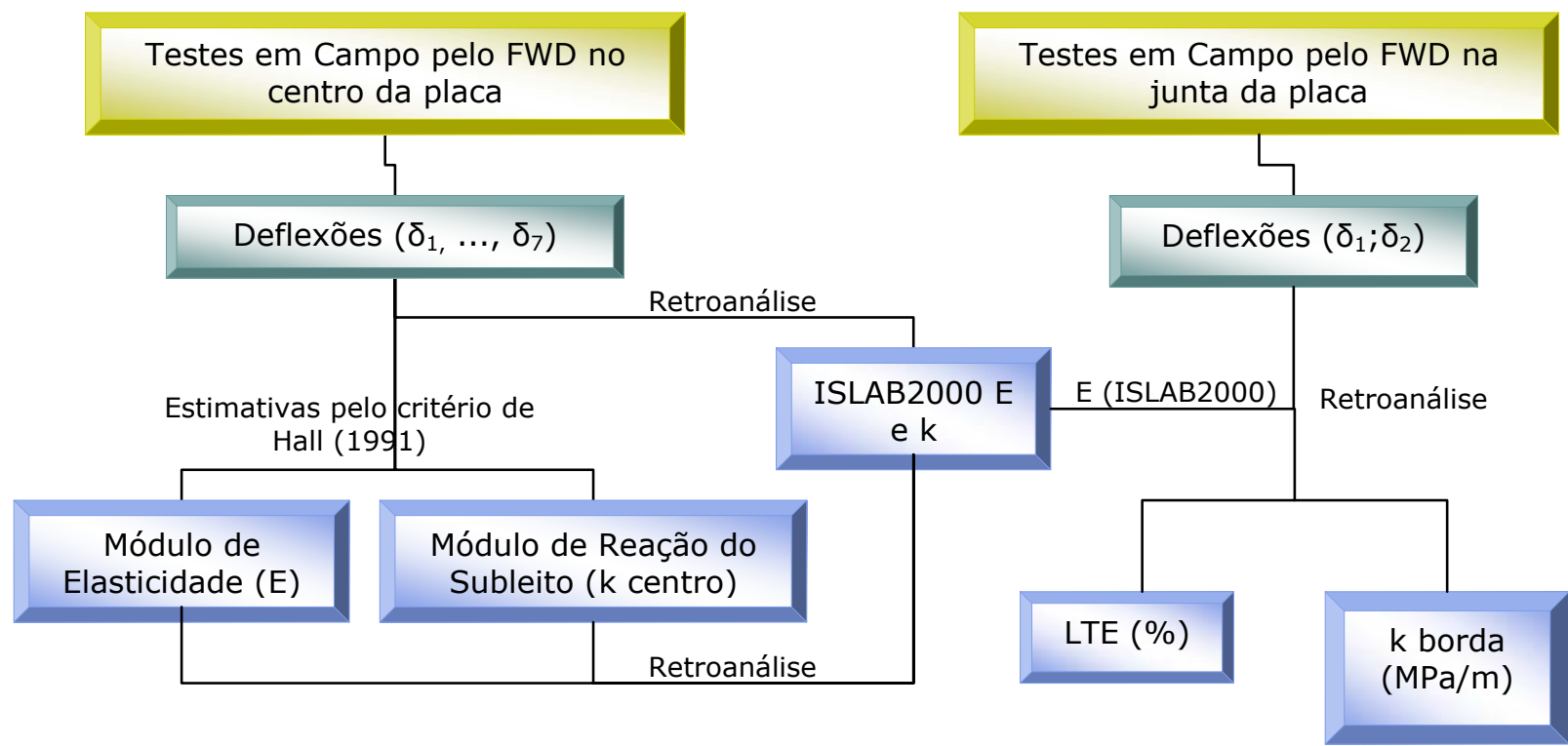

Figura 3.22 Fluxograma dos procedimentos deste estudo. 


\section{ANÁLISE DE RESULTADOS DE TRANSFERÊNCIA DE CARGA EM JUNTAS}

\subsection{Medidas de Deflexões}

\subsubsection{Medidas de Deflexões com Carga no Centro da Placa}

As deflexões determinadas pelo equipamento FWD nos centros das placas estão apresentadas na Tabela 4.1, sendo que nessa tabela "Afast. 0" significa que a deflexão indicada (medida) possui afastamento de $0 \mathrm{~mm}$ a partir do centro de aplicação de carga, enquanto que, por exemplo, "Afast. 120" indica afastamento de $1.200 \mathrm{~mm}$ do centro de aplicação de carga. Como já informado, deflexões nos centros das placas foram medidas apenas em 26 de julho de 2006 pela manhã. Para cada posição foram aplicados três diferentes níveis de carga e realizados dois ensaios para cada nível.

Para comparar os valores das medidas de deflexões no centro das placas de concreto a fim de avaliar a influência das características do pavimento construído como o tipo de base, a espessura da placa e seu comprimento, foram montados gráficos para deixar claro se existem fatores que afetam as medidas de deflexões e como atuam na placa de concreto simples.

A Figura 4.1, em que são apresentadas bacias de deflexões no centro de cada placa das seções A (posições 1 e 3) e B (posições 4, 6 e 18), permite concluir que as seções com o tipo de base BGS sofrem maiores deflexões (deslocamentos verticais) do que bases mais rígidas como o CCR. 
Tabela 4.1 Valores de deflexões no centro da placa de concreto, com três níveis de carga.

\begin{tabular}{|c|c|c|c|c|c|c|c|c|c|}
\hline \multirow[b]{2}{*}{ Seção } & \multirow[b]{2}{*}{ Posição } & \multirow[b]{2}{*}{ Carga } & \multicolumn{7}{|c|}{ Bacia de Deformação $\left(\times 10^{-4} \mathrm{~mm}\right)$} \\
\hline & & & $\begin{array}{c}\text { Afast. } \\
0\end{array}$ & $\begin{array}{l}\text { Afast. } \\
20\end{array}$ & $\begin{array}{c}\text { Afast. } \\
30\end{array}$ & $\begin{array}{c}\text { Afast. } \\
45\end{array}$ & $\begin{array}{c}\text { Afast. } \\
65\end{array}$ & $\begin{array}{c}\text { Afast. } \\
90\end{array}$ & $\begin{array}{c}\text { Afast. } \\
120\end{array}$ \\
\hline \multirow{7}{*}{ A } & \multirow{5}{*}{1} & $(K N)$ & Df1 & Df2 & Df3 & Df4 & Df5 & Df6 & Df7 \\
\hline & & 47,57 & 201 & 203 & 194 & 179 & 165 & 138 & 115 \\
\hline & & 74,22 & 310 & 306 & 292 & 270 & 244 & 208 & 171 \\
\hline & & 83,90 & 346 & 339 & 327 & 300 & 266 & 220 & 188 \\
\hline & & 47,50 & 226 & 220 & 206 & 191 & 167 & 138 & 114 \\
\hline & \multirow[t]{3}{*}{3} & 74,64 & 363 & 348 & 332 & 308 & 271 & 228 & 183 \\
\hline & & 84,19 & 402 & 384 & 367 & 340 & 299 & 249 & 203 \\
\hline \multirow{13}{*}{ B } & & 47,08 & 143 & 131 & 124 & 115 & 105 & 88 & 74 \\
\hline & \multirow[t]{3}{*}{4} & 74,22 & 213 & 195 & 177 & 166 & 144 & 119 & 101 \\
\hline & & 83,34 & 241 & 226 & 205 & 187 & 160 & 134 & 116 \\
\hline & & 46,51 & 106 & 101 & 94 & 75 & 93 & 68 & 61 \\
\hline & \multirow[t]{3}{*}{6} & 73,51 & 165 & 156 & 146 & 127 & 117 & 106 & 92 \\
\hline & & 83,13 & 186 & 174 & 164 & 145 & 129 & 118 & 103 \\
\hline & & 46,94 & 107 & 104 & 96 & 92 & 82 & 74 & 65 \\
\hline & \multirow[t]{3}{*}{18} & 74,15 & 171 & 162 & 152 & 144 & 131 & 116 & 99 \\
\hline & & 83,69 & 192 & 180 & 173 & 162 & 143 & 131 & 113 \\
\hline & & 46,58 & 94 & 95 & 88 & 82 & 74 & 66 & 60 \\
\hline & \multirow[t]{3}{*}{7} & 73,09 & 147 & 144 & 134 & 127 & 116 & 104 & 89 \\
\hline & & 82,35 & 165 & 162 & 151 & 142 & 130 & 116 & 100 \\
\hline & & 46,94 & 130 & 132 & 119 & 113 & 102 & 87 & 71 \\
\hline \multirow[t]{9}{*}{ C } & \multirow[t]{3}{*}{9} & 74,64 & 202 & 197 & 183 & 174 & 156 & 131 & 106 \\
\hline & & 84,05 & 224 & 220 & 201 & 192 & 172 & 146 & 116 \\
\hline & & 45,45 & 117 & 78 & 81 & 75 & 108 & 110 & 62 \\
\hline & \multirow[t]{3}{*}{20} & 72,59 & 179 & 121 & 115 & 115 & 166 & 107 & 93 \\
\hline & & 82,21 & 212 & 138 & 120 & 139 & 176 & 131 & 95 \\
\hline & & 46,37 & 116 & 113 & 106 & 102 & 94 & 84 & 72 \\
\hline & \multirow[t]{3}{*}{10} & 74,29 & 183 & 174 & 167 & 160 & 148 & 131 & 112 \\
\hline & & 83,62 & 205 & 194 & 186 & 177 & 161 & 144 & 125 \\
\hline & & 44,67 & 161 & 152 & 153 & 138 & 123 & 105 & 95 \\
\hline \multirow[t]{9}{*}{ D } & \multirow[t]{3}{*}{12} & 71,53 & 233 & 238 & 216 & 209 & 188 & 154 & 145 \\
\hline & & 80,79 & 265 & 260 & 220 & 232 & 208 & 169 & 131 \\
\hline & & 45,80 & 145 & 129 & 123 & 93 & 78 & 72 & 66 \\
\hline & \multirow[t]{3}{*}{22} & 73,30 & 223 & 195 & 179 & 152 & 129 & 112 & 97 \\
\hline & & 82,77 & 250 & 215 & 198 & 169 & 143 & 124 & 107 \\
\hline & & 45,17 & 117 & 110 & 110 & 101 & 89 & 79 & 63 \\
\hline & \multirow[t]{3}{*}{13} & 72,17 & 181 & 172 & 165 & 155 & 136 & 116 & 96 \\
\hline & & 81,85 & 201 & 191 & 180 & 170 & 150 & 128 & 104 \\
\hline & & 45,52 & 121 & 121 & 111 & 101 & 98 & 89 & 76 \\
\hline \multirow[t]{5}{*}{$E$} & \multirow[t]{3}{*}{15} & 72,31 & 190 & 184 & 171 & 157 & 151 & 137 & 113 \\
\hline & & 81,36 & 211 & 201 & 190 & 179 & 167 & 152 & 126 \\
\hline & & 45,52 & 102 & 102 & 97 & 95 & 85 & 79 & 68 \\
\hline & 24 & 73,02 & 158 & 160 & 152 & 148 & 134 & 121 & 103 \\
\hline & & 82,63 & 177 & 177 & 168 & 160 & 149 & 134 & 114 \\
\hline
\end{tabular}




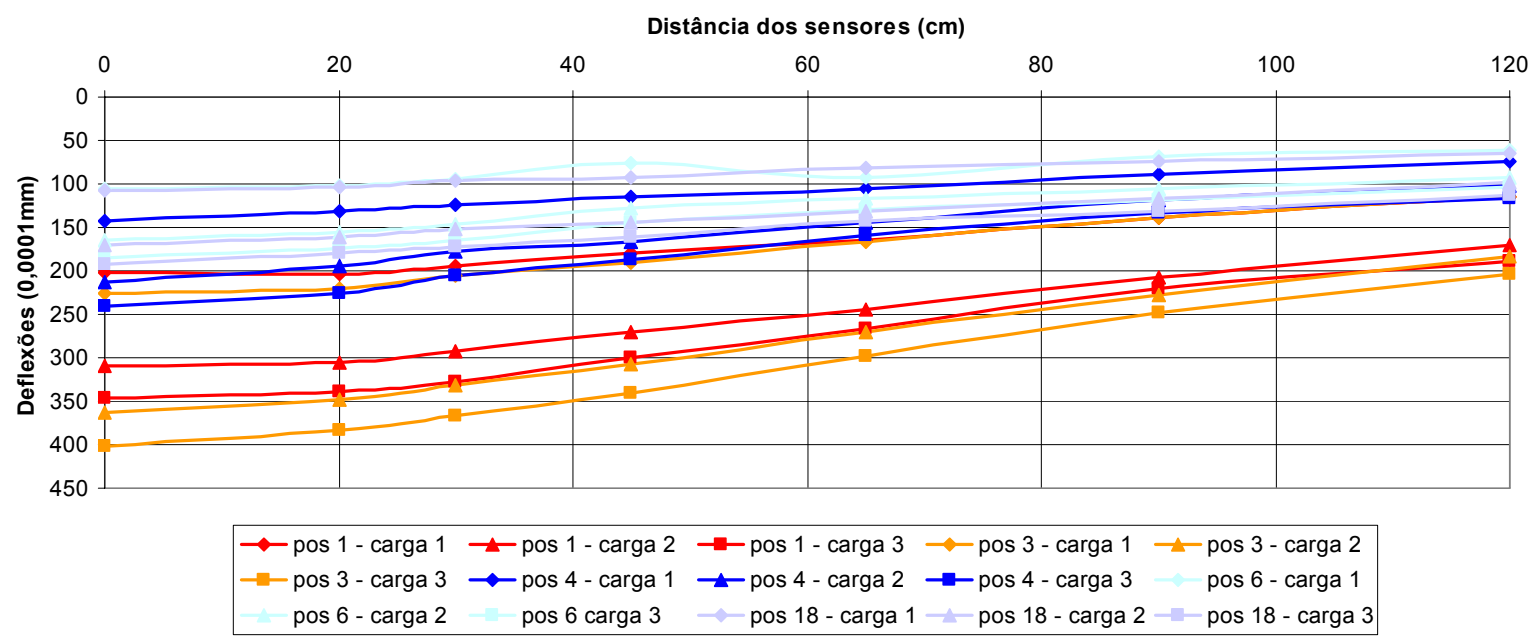

Figura 4.1 Bacias de deflexões nos centros das placas das seções A e B da pista experimental USP/FAPESP.

Ao comparar as medidas de deflexões de placas de concreto simples com o mesmo tipo de base, e diferentes espessuras (150 e $250 \mathrm{~mm}$ ), nota-se que placas mais esbeltas sofrem maiores deslocamentos verticais que as mais espessas, como no caso das seções A (posições 1 e 3 ) e D (posições 10, 12 e 22) da Figura 4.2. Nestes resultados de deflexões no centro da placa, não se obteve definição palpável entre as seções com o mesmo tipo de base rígida (CCR) e diferentes espessuras de placa de concreto (Figura 4.3).

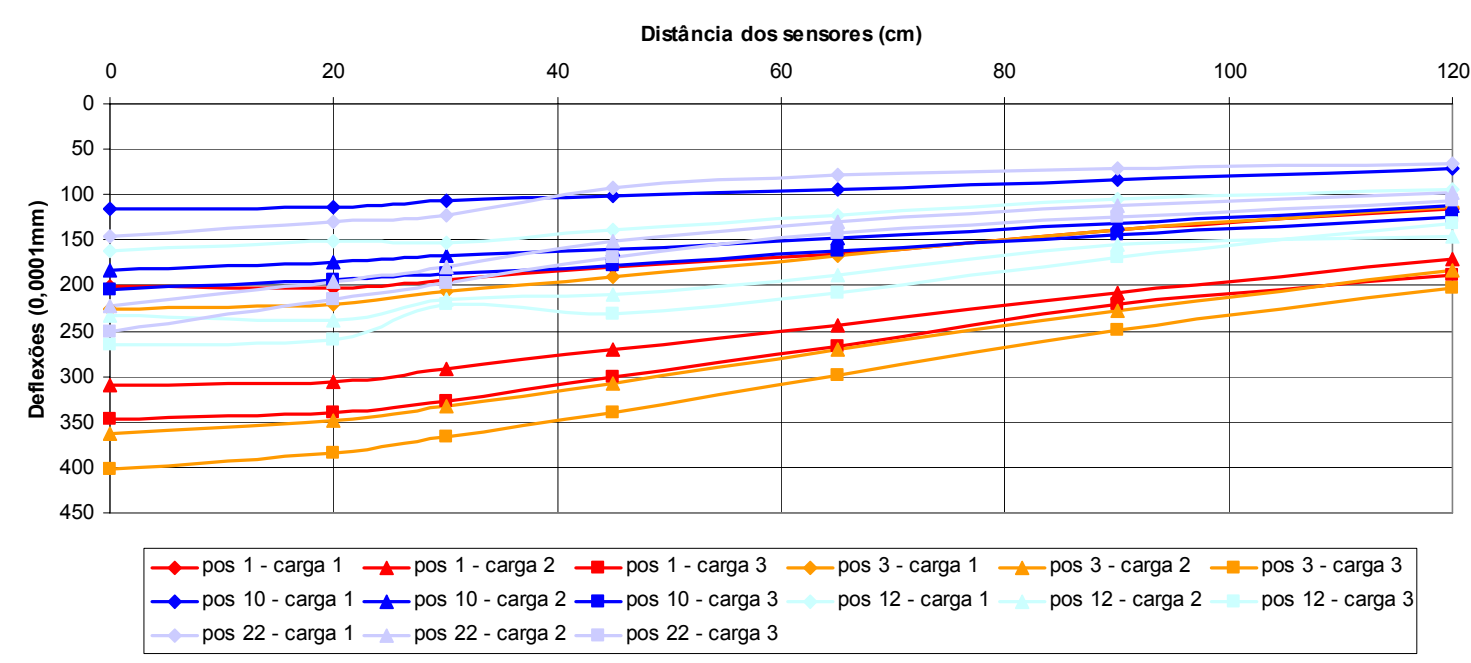

Figura 4.2 Bacias de deflexões nos centros das placas das seções A e D da pista experimental USP/FAPESP. 


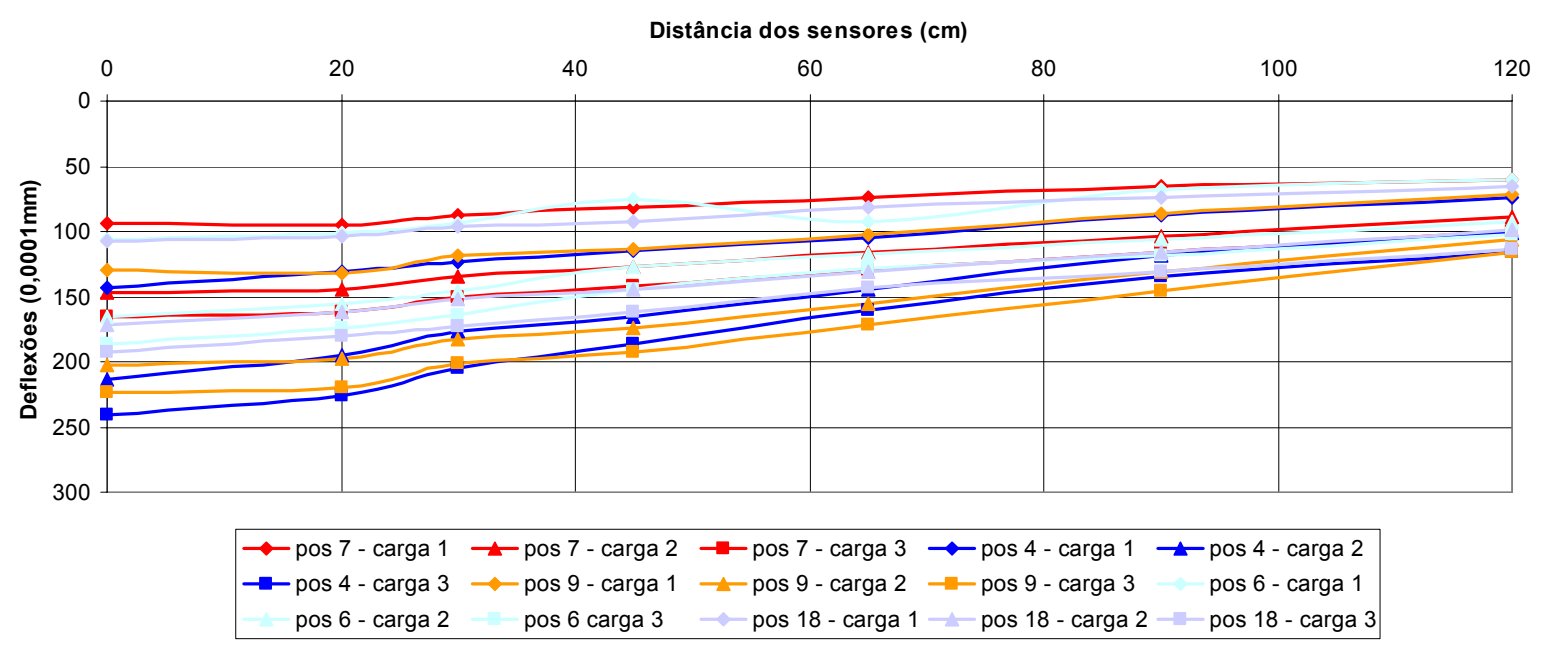

Figura 4.3 Bacias de deflexões nos centros das placas das seções $B$ e $C$ da pista experimental USP/FAPESP.

\subsubsection{Medidas de Deflexões com Carga na Junta da Placa}

As deflexões determinadas pelo equipamento FWD nas juntas das placas estão indicadas na tabela subseqüentes. A Tabela 4.2 apresenta dados de medidas de deflexões no período da manhã do dia 28 de julho de 2006. No mesmo dia, durante a tarde, foram realizados testes nas juntas e os valores de deflexões são indicados na Tabela 4.3.

Tabela 4.2 Deflexões medidas pelo FWD pela manhã no inverno (2006).

\begin{tabular}{|c|c|c|c|c|c|c|c|c|}
\hline \multirow[b]{2}{*}{ Posição } & \multirow[b]{2}{*}{ Carga } & \multicolumn{7}{|c|}{ Bacia de Deformação $\left(\times 10^{-4} \mathrm{~mm}\right)$} \\
\hline & & $\begin{array}{c}\text { Afast. } \\
0\end{array}$ & $\begin{array}{c}\text { Afast. } \\
20\end{array}$ & $\begin{array}{c}\text { Afast. } \\
30\end{array}$ & $\begin{array}{c}\text { Afast. } \\
45\end{array}$ & $\begin{array}{c}\text { Afast. } \\
65\end{array}$ & $\begin{array}{c}\text { Afast. } \\
90\end{array}$ & $\begin{array}{c}\text { Afast. } \\
120\end{array}$ \\
\hline & $(k N)$ & Df1 & Df2 & Df3 & Df4 & Df5 & Df6 & Df7 \\
\hline & 47,29 & 307 & 324 & 292 & 259 & 215 & 172 & 122 \\
\hline \multirow[t]{3}{*}{2} & 74,50 & 475 & 506 & 456 & 402 & 330 & 256 & 198 \\
\hline & 83,97 & 527 & 559 & 505 & 442 & 362 & 277 & 224 \\
\hline & 47,08 & 184 & 205 & 174 & 143 & 110 & 83 & 67 \\
\hline \multirow[t]{3}{*}{5} & 74,43 & 272 & 293 & 252 & 211 & 159 & 122 & 100 \\
\hline & 83,83 & 295 & 318 & 271 & 225 & 171 & 132 & 109 \\
\hline & 46,86 & 148 & 153 & 139 & 124 & 106 & 86 & 72 \\
\hline \multirow[t]{3}{*}{8} & 74,50 & 235 & 243 & 221 & 197 & 166 & 134 & 109 \\
\hline & 83,83 & 261 & 270 & 245 & 218 & 183 & 150 & 121 \\
\hline & 46,37 & 143 & 143 & 135 & 117 & 104 & 84 & 68 \\
\hline \multirow[t]{3}{*}{11} & 74,01 & 224 & 225 & 206 & 185 & 160 & 131 & 106 \\
\hline & 83,69 & 252 & 251 & 228 & 206 & 177 & 147 & 119 \\
\hline & 45,45 & 145 & 148 & 138 & 123 & 107 & 87 & 70 \\
\hline \multirow[t]{3}{*}{14} & 73,02 & 233 & 237 & 220 & 197 & 168 & 138 & 111 \\
\hline & 82,21 & 260 & 264 & 246 & 220 & 189 & 155 & 125 \\
\hline & 45,17 & 337 & 349 & 314 & 278 & 225 & 173 & 128 \\
\hline \multirow[t]{2}{*}{16} & 72,45 & 569 & 594 & 536 & 471 & 384 & 301 & 219 \\
\hline & 81,50 & 641 & 668 & 602 & 531 & 432 & 336 & 245 \\
\hline
\end{tabular}


Tabela 4.2 Deflexões medidas pelo FWD pela manhã no inverno (2006). continuação

\begin{tabular}{|c|c|c|c|c|c|c|c|c|}
\hline \multirow[b]{2}{*}{ Posição } & \multirow{2}{*}{ Carga } & \multicolumn{7}{|c|}{ Bacia de Deformação $\left(\times 10^{-4} \mathrm{~mm}\right)$} \\
\hline & & $\begin{array}{c}\text { Afast. } \\
0\end{array}$ & $\begin{array}{c}\text { Afast. } \\
20\end{array}$ & $\begin{array}{c}\text { Afast. } \\
30\end{array}$ & $\begin{array}{c}\text { Afast. } \\
45\end{array}$ & $\begin{array}{c}\text { Afast. } \\
65\end{array}$ & $\begin{array}{c}\text { Afast. } \\
90\end{array}$ & $\begin{array}{c}\text { Afast. } \\
120\end{array}$ \\
\hline & $(k N)$ & Df1 & $D f 2$ & Df3 & Df4 & Df5 & Df6 & Df7 \\
\hline \multirow{4}{*}{17} & 44,46 & 200 & 232 & 201 & 170 & 131 & 93 & 68 \\
\hline & 71,89 & 287 & 326 & 286 & 244 & 191 & 140 & 105 \\
\hline & 82,63 & 313 & 352 & 312 & 265 & 207 & 154 & 118 \\
\hline & 45,80 & 133 & 133 & 121 & 105 & 92 & 79 & 69 \\
\hline \multirow[t]{3}{*}{19} & 72,67 & 212 & 213 & 192 & 172 & 148 & 125 & 104 \\
\hline & 81,92 & 235 & 235 & 213 & 192 & 165 & 138 & 114 \\
\hline & 44,96 & 144 & 144 & 133 & 120 & 105 & 87 & 71 \\
\hline \multirow[t]{3}{*}{21} & 72,88 & 230 & 229 & 210 & 193 & 164 & 138 & 113 \\
\hline & 82,35 & 257 & 258 & 235 & 216 & 184 & 151 & 125 \\
\hline & 45,03 & 176 & 109 & 109 & 102 & 93 & 75 & 59 \\
\hline \multirow[t]{2}{*}{23} & 72,10 & 271 & 184 & 171 & 156 & 148 & 114 & 92 \\
\hline & 81,15 & 309 & 208 & 194 & 178 & 158 & 129 & 100 \\
\hline
\end{tabular}

Tabela 4.3 Deflexões medidas pelo FWD no período da tarde no inverno (2006).

\begin{tabular}{|c|c|c|c|c|c|c|c|c|}
\hline \multirow[b]{2}{*}{ Posição } & \multirow[b]{2}{*}{ Carga } & \multicolumn{7}{|c|}{ Bacia de Deformação $\left(\times 10^{-4} \mathrm{~mm}\right)$} \\
\hline & & $\begin{array}{c}\text { Afast. } \\
0\end{array}$ & $\begin{array}{c}\text { Afast. } \\
20\end{array}$ & $\begin{array}{c}\text { Afast. } \\
30\end{array}$ & $\begin{array}{c}\text { Afast. } \\
45\end{array}$ & $\begin{array}{c}\text { Afast. } \\
65\end{array}$ & $\begin{array}{c}\text { Afast. } \\
90\end{array}$ & $\begin{array}{c}\text { Afast } \\
120\end{array}$ \\
\hline & $(k g f)$ & Df1 & Df2 & Df3 & Df4 & Df5 & Df6 & Df7 \\
\hline \multirow{4}{*}{2} & 45,52 & 283 & 299 & 264 & 237 & 196 & 154 & 120 \\
\hline & 72,59 & 433 & 454 & 402 & 360 & 298 & 233 & 178 \\
\hline & 81,92 & 484 & 508 & 451 & 401 & 331 & 259 & 197 \\
\hline & 45,52 & 145 & 158 & 130 & 108 & 87 & 72 & 62 \\
\hline \multirow[t]{3}{*}{5} & 72,81 & 222 & 228 & 194 & 164 & 132 & 108 & 93 \\
\hline & 82,21 & 247 & 253 & 216 & 183 & 146 & 120 & 103 \\
\hline & 46,02 & 127 & 123 & 115 & 107 & 93 & 80 & 71 \\
\hline \multirow[t]{3}{*}{8} & 72,95 & 203 & 197 & 181 & 168 & 145 & 126 & 105 \\
\hline & 82,35 & 226 & 219 & 201 & 187 & 162 & 141 & 114 \\
\hline & 45,38 & 154 & 148 & 137 & 134 & 114 & 99 & 85 \\
\hline \multirow[t]{3}{*}{11} & 72,81 & 239 & 222 & 211 & 197 & 178 & 155 & 131 \\
\hline & 82,35 & 266 & 250 & 235 & 218 & 197 & 172 & 146 \\
\hline & 45,17 & 146 & 150 & 134 & 125 & 108 & 93 & 75 \\
\hline \multirow[t]{3}{*}{14} & 72,17 & 236 & 242 & 222 & 200 & 173 & 148 & 120 \\
\hline & 81,57 & 265 & 265 & 243 & 222 & 194 & 164 & 141 \\
\hline & 44,67 & 328 & 333 & 299 & 265 & 216 & 172 & 128 \\
\hline \multirow[t]{3}{*}{16} & 71,53 & 550 & 563 & 504 & 452 & 375 & 290 & 213 \\
\hline & 80,72 & 621 & 635 & 569 & 507 & 415 & 328 & 243 \\
\hline & 44,89 & 121 & 123 & 111 & 95 & 87 & 71 & 58 \\
\hline \multirow[t]{3}{*}{17} & 72,67 & 194 & 197 & 174 & 157 & 133 & 111 & 93 \\
\hline & 82,28 & 217 & 220 & 196 & 173 & 149 & 124 & 102 \\
\hline & 44,46 & 112 & 110 & 104 & 98 & 89 & 76 & 47 \\
\hline \multirow[t]{3}{*}{19} & 71,82 & 180 & 178 & 166 & 155 & 137 & 118 & 97 \\
\hline & 81,36 & 206 & 197 & 182 & 172 & 148 & 130 & 114 \\
\hline & 44,60 & 149 & 145 & 136 & 126 & 113 & 97 & 82 \\
\hline \multirow[t]{3}{*}{21} & 72,24 & 244 & 237 & 218 & 204 & 181 & 156 & 132 \\
\hline & 81,85 & 271 & 263 & 243 & 227 & 202 & 175 & 147 \\
\hline & 44,11 & 160 & 129 & 121 & 108 & 95 & 82 & 73 \\
\hline \multirow[t]{2}{*}{23} & 70,97 & 253 & 203 & 188 & 176 & 154 & 133 & 113 \\
\hline & 80,30 & 295 & 231 & 211 & 198 & 175 & 150 & 129 \\
\hline
\end{tabular}


É de se observar nos resultados uma clara tendência de diminuição das deflexões próximas das juntas no período mais quente (tarde), um primeiro indicador do efeito da temperatura, com expansão e melhor contato entre as placas, no comportamento estrutural dos pavimentos. Posteriormente, no dia 26 de março de 2007, os mesmos testes de aplicação de carga nas juntas das placas de concreto da pista experimental na USP foram realizados, nos períodos da tarde e ao anoitecer, respectivamente, cujos resultados são apresentados nas Tabelas 4.4 e 4.5 .

\begin{tabular}{|c|c|c|c|c|c|c|c|c|}
\hline \multirow[b]{2}{*}{ Posição } & \multirow{2}{*}{ Carga } & \multicolumn{7}{|c|}{ Bacia de Deformação (x10 $\left.{ }^{-4} \mathrm{~mm}\right)$} \\
\hline & & $\begin{array}{c}\text { Afast. } \\
0\end{array}$ & $\begin{array}{c}\text { Afast. } \\
20\end{array}$ & $\begin{array}{c}\text { Afast. } \\
30\end{array}$ & $\begin{array}{c}\text { Afast. } \\
45\end{array}$ & $\begin{array}{c}\text { Afast. } \\
65\end{array}$ & $\begin{array}{c}\text { Afast. } \\
90\end{array}$ & $\begin{array}{c}\text { Afast. } \\
120\end{array}$ \\
\hline & (kgf) & Df1 & Df2 & Df3 & Df4 & Df5 & Df6 & Df7 \\
\hline \multirow{4}{*}{2} & 48,91 & 379 & 390 & 359 & 287 & 270 & 210 & 150 \\
\hline & 64,75 & 494 & 507 & 465 & 376 & 348 & 272 & 194 \\
\hline & 88,07 & 644 & 661 & 605 & 493 & 447 & 347 & 247 \\
\hline & 51,81 & 137 & 139 & 121 & 90 & 83 & 70 & 59 \\
\hline \multirow[t]{3}{*}{5} & 68,21 & 179 & 178 & 156 & 117 & 109 & 91 & 77 \\
\hline & 90,12 & 229 & 229 & 199 & 150 & 138 & 115 & 97 \\
\hline & 51,53 & 123 & 125 & 117 & 94 & 93 & 77 & 64 \\
\hline \multirow[t]{3}{*}{8} & 67,01 & 162 & 164 & 153 & 123 & 123 & 104 & 85 \\
\hline & 89,91 & 217 & 218 & 203 & 167 & 161 & 135 & 110 \\
\hline & 50,54 & 156 & 149 & 142 & 122 & 119 & 103 & 87 \\
\hline \multirow[t]{3}{*}{11} & 67,15 & 203 & 195 & 186 & 154 & 155 & 136 & 116 \\
\hline & 89,42 & 266 & 255 & 243 & 201 & 202 & 177 & 150 \\
\hline & 51,46 & 179 & 177 & 166 & 139 & 136 & 118 & 98 \\
\hline \multirow[t]{3}{*}{14} & 67,01 & 237 & 235 & 221 & 183 & 182 & 157 & 131 \\
\hline & 88,64 & 315 & 313 & 294 & 247 & 243 & 210 & 175 \\
\hline & 51,60 & 367 & 375 & 343 & 274 & 251 & 196 & 136 \\
\hline \multirow[t]{3}{*}{16} & 66,73 & 486 & 504 & 469 & 372 & 338 & 261 & 187 \\
\hline & 86,66 & 646 & 683 & 621 & 501 & 455 & 351 & 252 \\
\hline & 50,47 & 145 & 141 & 127 & 98 & 94 & 77 & 63 \\
\hline \multirow[t]{3}{*}{17} & 67,22 & 191 & 188 & 169 & 127 & 125 & 102 & 85 \\
\hline & 89,84 & 249 & 245 & 220 & 171 & 161 & 132 & 108 \\
\hline & 51,74 & 123 & 110 & 103 & 86 & 85 & 74 & 61 \\
\hline \multirow[t]{3}{*}{19} & 66,52 & 165 & 150 & 141 & 116 & 116 & 100 & 85 \\
\hline & 89,70 & 214 & 198 & 186 & 152 & 153 & 131 & 109 \\
\hline & 52,52 & 169 & 167 & 161 & 141 & 130 & 117 & 97 \\
\hline \multirow[t]{3}{*}{21} & 67,22 & 223 & 220 & 209 & 171 & 172 & 150 & 123 \\
\hline & 88,85 & 290 & 279 & 265 & 225 & 223 & 192 & 161 \\
\hline & 51,18 & 196 & 130 & 123 & 104 & 103 & 90 & 76 \\
\hline \multirow[t]{2}{*}{23} & 66,87 & 258 & 181 & 172 & 142 & 145 & 127 & 107 \\
\hline & 86,31 & 277 & 237 & 226 & 191 & 189 & 164 & 140 \\
\hline
\end{tabular}


Tabela 4.5 Deflexões medidas pelo FWD no período da noite no verão (2007).

\begin{tabular}{|c|c|c|c|c|c|c|c|c|}
\hline \multirow[b]{2}{*}{ Posição } & \multirow[b]{2}{*}{ Carga } & \multicolumn{7}{|c|}{ Bacia de Deformação $\left(\times 10^{-4} \mathrm{~mm}\right)$} \\
\hline & & $\begin{array}{c}\text { Afast. } \\
0\end{array}$ & $\begin{array}{c}\text { Afast. } \\
20\end{array}$ & $\begin{array}{c}\text { Afast. } \\
30\end{array}$ & $\begin{array}{c}\text { Afast. } \\
45\end{array}$ & $\begin{array}{c}\text { Afast. } \\
65\end{array}$ & $\begin{array}{c}\text { Afast. } \\
90\end{array}$ & $\begin{array}{c}\text { Afast. } \\
120\end{array}$ \\
\hline & $(k g f)$ & Df1 & Df2 & Df3 & Df4 & Df5 & Df6 & Df7 \\
\hline \multirow{4}{*}{2} & 49,06 & 411 & 417 & 382 & 313 & 289 & 223 & 158 \\
\hline & 65,17 & 528 & 535 & 488 & 399 & 368 & 283 & 200 \\
\hline & 87,08 & 670 & 681 & 618 & 510 & 458 & 351 & 248 \\
\hline & 51,18 & 147 & 147 & 128 & 96 & 86 & 72 & 63 \\
\hline \multirow[t]{3}{*}{5} & 66,59 & 188 & 187 & 162 & 119 & 110 & 92 & 78 \\
\hline & 89,56 & 240 & 234 & 204 & 155 & 139 & 116 & 99 \\
\hline & 51,11 & 143 & 143 & 134 & 107 & 100 & 79 & 64 \\
\hline \multirow[t]{3}{*}{8} & 67,36 & 186 & 190 & 175 & 138 & 133 & 109 & 87 \\
\hline & 88,92 & 244 & 250 & 230 & 185 & 173 & 140 & 112 \\
\hline & 49,76 & 147 & 143 & 130 & 105 & 101 & 84 & 66 \\
\hline \multirow[t]{3}{*}{11} & 66,44 & 195 & 187 & 174 & 140 & 136 & 111 & 88 \\
\hline & 89,13 & 256 & 246 & 228 & 186 & 176 & 144 & 112 \\
\hline & 52,59 & 144 & 151 & 140 & 112 & 108 & 88 & 70 \\
\hline \multirow[t]{3}{*}{14} & 68,00 & 192 & 201 & 188 & 150 & 150 & 116 & 93 \\
\hline & 87,58 & 256 & 266 & 249 & 201 & 196 & 152 & 121 \\
\hline & 50,89 & 363 & 377 & 348 & 281 & 254 & 197 & 144 \\
\hline \multirow[t]{3}{*}{16} & 66,02 & 480 & 498 & 459 & 368 & 335 & 260 & 189 \\
\hline & 86,73 & 634 & 666 & 609 & 492 & 445 & 344 & 246 \\
\hline & 50,47 & 168 & 182 & 162 & 122 & 108 & 79 & 61 \\
\hline \multirow[t]{3}{*}{17} & 66,80 & 215 & 233 & 207 & 159 & 140 & 105 & 81 \\
\hline & 89,13 & 272 & 293 & 261 & 197 & 176 & 133 & 103 \\
\hline & 51,60 & 152 & 146 & 134 & 108 & 102 & 83 & 67 \\
\hline \multirow[t]{3}{*}{19} & 67,01 & 200 & 192 & 179 & 139 & 136 & 112 & 90 \\
\hline & 88,78 & 262 & 251 & 232 & 187 & 178 & 144 & 116 \\
\hline & 50,26 & 149 & 146 & 133 & 113 & 104 & 86 & 69 \\
\hline \multirow[t]{3}{*}{21} & 66,30 & 198 & 195 & 178 & 147 & 139 & 115 & 90 \\
\hline & 89,06 & 262 & 258 & 234 & 193 & 182 & 150 & 119 \\
\hline & 50,26 & 166 & 117 & 103 & 93 & 86 & 69 & 59 \\
\hline \multirow[t]{2}{*}{23} & 65,10 & 223 & 160 & 144 & 122 & 118 & 95 & 80 \\
\hline & 88,07 & 285 & 214 & 195 & 162 & 156 & 127 & 103 \\
\hline
\end{tabular}

Como se verifica a partir dos resultados acima há uma tendência de aumento da deflexão nas juntas na medida em que há esfriamento da placa de concreto ao anoitecer; os valores não são mais explicitamente favoráveis por completo a essa assertiva, pois as medidas foram realizadas às 18 horas, aproximadamente, ainda estando quente. Para comparar os valores das medidas de deflexões entre as placas a fim de avaliar a influência das características do pavimento de concreto construído como o tipo de base e a espessura da placa, além do comprimento da mesma, foram construídos gráficos para deixar claro se existem fatores que afetam as medidas de deflexões e como atuam na placa de concreto simples. 
Pela Figura 4.4, onde são apresentadas as bacias de deflexões das seções A (posições 2 e 16) e B (posições 5 e 17), observa-se que as deflexões da seção A, na ordem de carga mais pesada para a mais leve, em que o tipo de base é BGS, são maiores que as deflexões da seção $B$, onde o CCR foi utilizado como base. Este fato é esperado devido à maior rigidez da base CCR ocasionando menor deslocamento vertical (deformação vertical) na placa de concreto, e ocorre tanto durante o inverno quanto o verão, em todas as suposições estudadas.

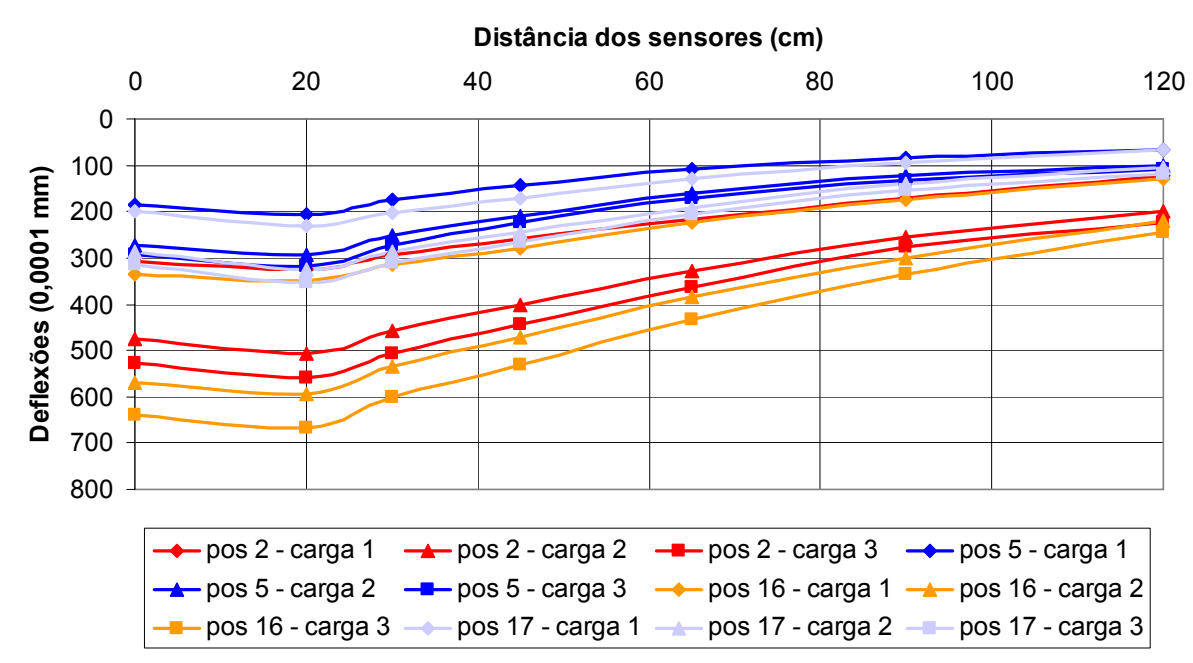

Figura 4.4 Bacias de deflexões nas juntas das seções A e B da pista experimental USP/FAPESP.

Outro fator influente de medidas de deflexões observado neste estudo foi a espessura da placa de concreto. Comparando-se as placas das seções B e C na Figura 4.5, em que a base é de CCR, e as espessuras das mesmas são de 150 e $250 \mathrm{~mm}$, respectivamente, nota-se que as deflexões da seção B (posições 5 e 17) são maiores que as da seção C (posições 8 e 19), podendo concluir que a placa mais esbelta sofre maiores deformações verticais que a placa mais espessa. $O$ mesmo ocorre com as seções $A$ e $D$ na Figura 4.6, cuja base nestas placas de concreto é BGS, com uma diferença: os valores das deflexões são maiores que os da Figura 4.5, fato confirmado pela Figura 4.4. 


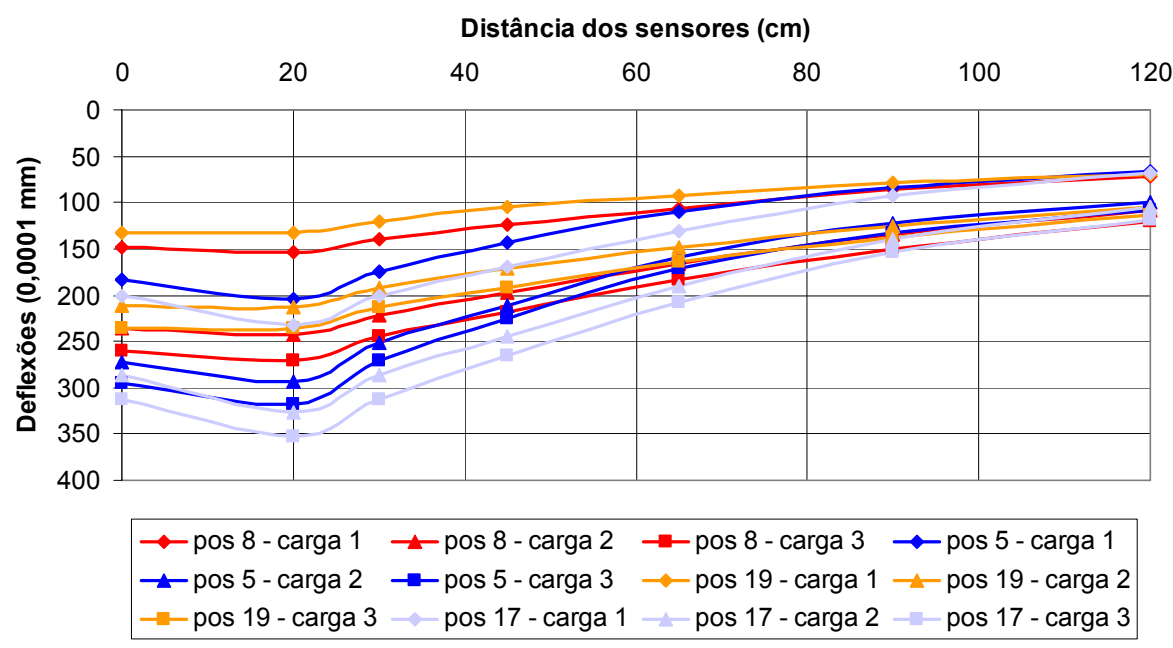

Figura 4.5 Bacias de deflexões nas juntas das seções $B$ e $C$ da pista experimental USP/FAPESP.

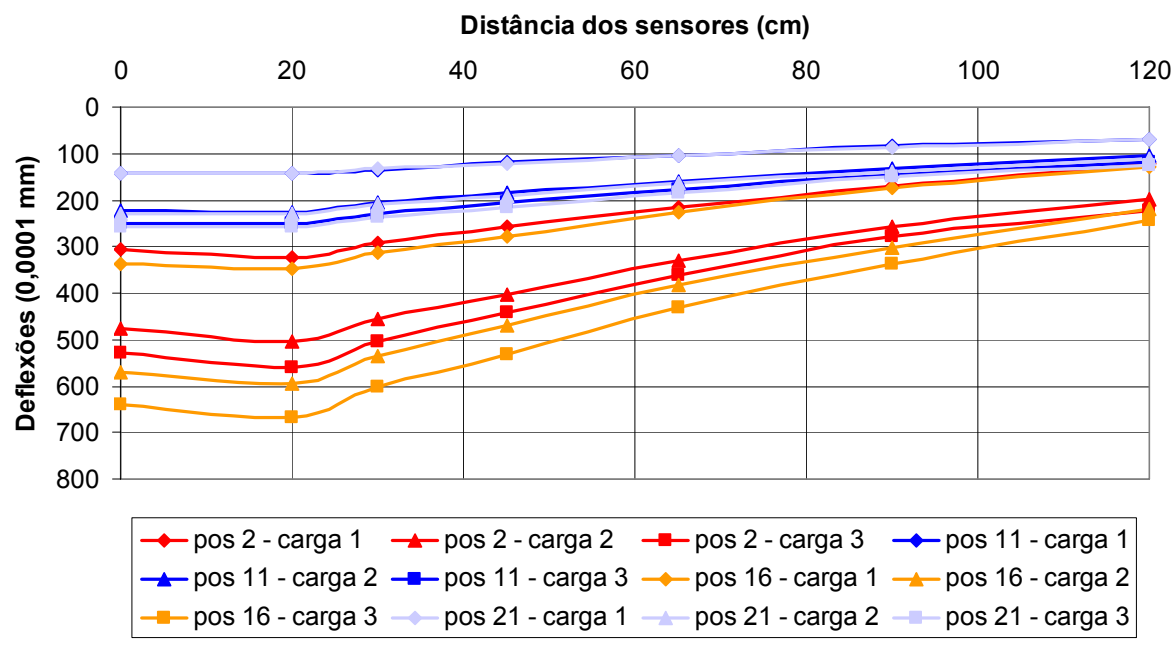

Figura 4.6 Bacias de deflexões nas juntas das seções A e D da pista experimental USP/FAPESP.

Segundo Vandenbossche (2007), ao aumentar a eficiência de transferência de carga em juntas sem dispositivos de transferência de carga, as deflexões sob a carga aplicada diminuem e consequentemente as deflexões à mesma distância da junta na placa descarregada aumentam. Este fenômeno é confirmado pelos dados de deflexões obtidos no presente estudo, no caso da junta E 23 e são apresentados na Figura 4.7. Desta forma, admite-se, então, como Nishizawa et al. (1989), que a barra de transferência é de extrema importância na redução das deflexões, pois é capaz de reduzir a deflexão sob a carga equiparando-as assim com a deflexão na placa descarregada. 


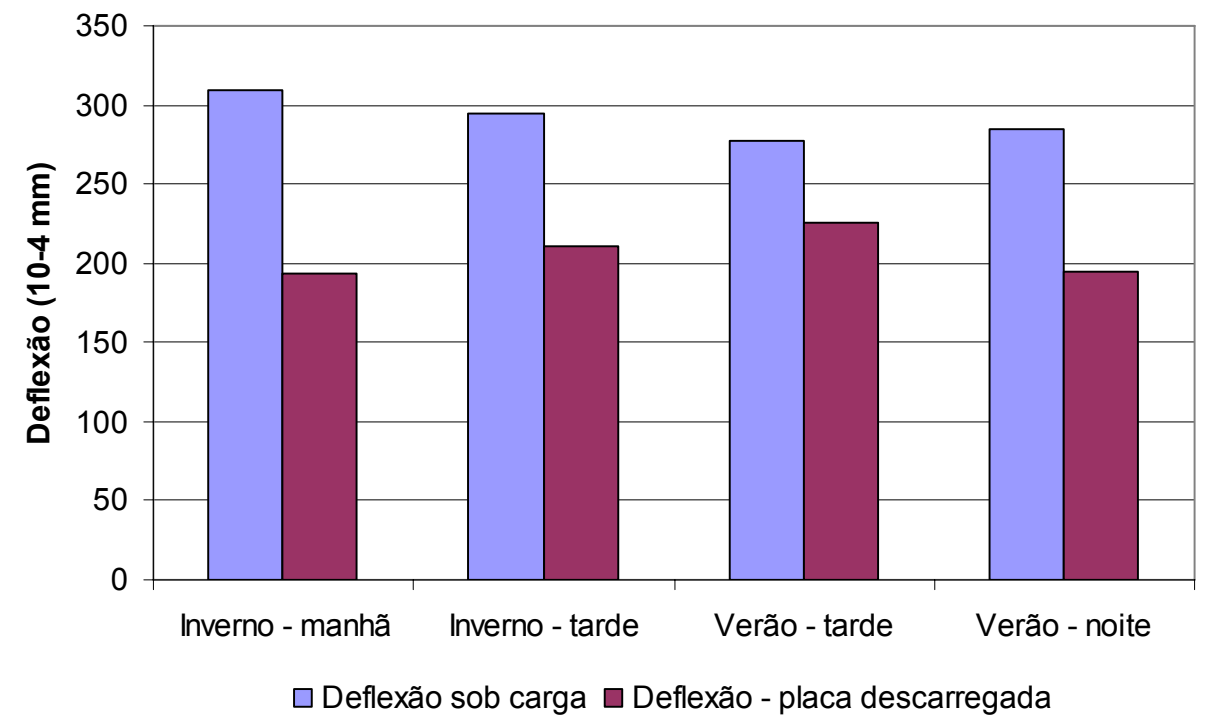

Figura 4.7 Variações entre deflexões na junta E3 sem BT.

\subsection{Estimativas dos Parâmetros Estruturais (E e k)}

Empregando-se o critério de estimativa de parâmetros estruturais para cargas aplicadas no centro de placas proposto por Hall (1991) e utilizando os valores de deflexões medidas em campo, foram obtidos os valores de módulo de reação do subleito $(k)$ e de módulo de elasticidade do concreto $(E)$ conforme indicados nas Tabelas 4.6 a 4.10 .

Tabela 4.6 Resultados de E e k pelo critério de Hall (1991) na seção A.

\begin{tabular}{|c|c|c|c|c|}
\hline \multirow[t]{2}{*}{ Placa } & \multirow[t]{2}{*}{ Posição } & Carga & $\begin{array}{c}\text { Módulo de Reação } \\
\text { do Subleito (k) }\end{array}$ & $\begin{array}{c}\text { Módulo de } \\
\text { Elasticidade do } \\
\text { CCP (E) }\end{array}$ \\
\hline & & $\mathrm{KN}$ & $\mathrm{MPa} / \mathrm{m}$ & $\mathrm{MPa}$ \\
\hline \multirow{10}{*}{ A } & \multirow{6}{*}{1} & \multirow{2}{*}{47} & 23,00 & 106.635 \\
\hline & & & 29,31 & 77.416 \\
\hline & & & 28,78 & 82.813 \\
\hline & & 74 & 31,30 & 73.296 \\
\hline & & \multirow{2}{*}{83} & 32,08 & 74.151 \\
\hline & & & 31,77 & 73.365 \\
\hline & \multirow{6}{*}{3} & \multirow{2}{*}{47} & 33,85 & 49.246 \\
\hline & & & 31,56 & 52.945 \\
\hline & & & 31,59 & 51.455 \\
\hline & & 74 & 33,63 & 48.757 \\
\hline $\mathrm{h}=15 \mathrm{~cm}$ & & \multirow{2}{*}{83} & 32,87 & 50.860 \\
\hline BGS & & & 34,42 & 48.073 \\
\hline
\end{tabular}


Tabela 4.7 Resultados de E e k pelo critério de Hall (1991) na seção B.

\begin{tabular}{|c|c|c|c|c|}
\hline \multirow[t]{8}{*}{ Placa } & \multirow[t]{2}{*}{ Posição } & Carga & $\begin{array}{l}\text { Módulo de Reação } \\
\text { do Subleito (k) }\end{array}$ & $\begin{array}{c}\text { Módulo de } \\
\text { Elasticidade do } \\
\text { CCP (E) }\end{array}$ \\
\hline & & KN & $\mathrm{MPa} / \mathrm{m}$ & $\mathrm{MPa}$ \\
\hline & \multirow{6}{*}{4} & \multirow{2}{*}{47} & 58,97 & 66.243 \\
\hline & & & 67,99 & 52.794 \\
\hline & & & 79,08 & 48.378 \\
\hline & & 74 & 77,86 & 45.957 \\
\hline & & & 77,65 & 48.872 \\
\hline & & & 79,45 & 47.226 \\
\hline \multirow{10}{*}{ B } & \multirow{6}{*}{6} & \multirow{2}{*}{47} & 49,52 & 164.412 \\
\hline & & & 58,77 & 128.689 \\
\hline & & & 78,76 & 91.403 \\
\hline & & 74 & 73,05 & 103.549 \\
\hline & & & 82,95 & 85.327 \\
\hline & & 83 & 79,31 & 92.576 \\
\hline & & 17 & 89,60 & 28.785 \\
\hline & & $4 r$ & 92,43 & 23.466 \\
\hline & 18 & & 93,49 & 29.777 \\
\hline & 10 & 74 & 95,19 & 27.406 \\
\hline$h=15 \mathrm{~cm}$ & & 02 & 96,51 & 28.412 \\
\hline CCR & & 83 & 97,08 & 27.672 \\
\hline
\end{tabular}

Tabela 4.8 Resultados de E e k pelo critério de Hall (1991) na seção C.

\begin{tabular}{|c|c|c|c|c|}
\hline \multirow[t]{8}{*}{ Placa } & \multirow[t]{2}{*}{ Posição } & Carga & $\begin{array}{c}\text { Módulo de Reação } \\
\text { do Subleito (k) }\end{array}$ & $\begin{array}{c}\text { Módulo de } \\
\text { Elasticidade do } \\
\text { CCP (E) }\end{array}$ \\
\hline & & KN & $\mathrm{MPa} / \mathrm{m}$ & $\mathrm{MPa}$ \\
\hline & \multirow{6}{*}{7} & \multirow{2}{*}{47} & 61,70 & 26.710 \\
\hline & & & 51,32 & 34.419 \\
\hline & & & 63,49 & 25.024 \\
\hline & & 74 & 61,11 & 27.387 \\
\hline & & \multirow{2}{*}{83} & 65,00 & 24.535 \\
\hline & & & 62,05 & 26.616 \\
\hline \multirow{10}{*}{ C } & \multirow{6}{*}{9} & \multirow{2}{*}{47} & 57,79 & 38.486 \\
\hline & & & 55,13 & 43.771 \\
\hline & & & 61,61 & 35.739 \\
\hline & & 74 & 60,03 & 37.446 \\
\hline & & & 61,82 & 35.891 \\
\hline & & 83 & 60,81 & 37.763 \\
\hline & & & 50,11 & 26.134 \\
\hline & & 47 & 50,56 & 27.324 \\
\hline & 20 & & 60,00 & 22.168 \\
\hline & & 74 & 63,32 & 20.874 \\
\hline $\mathrm{h}=25 \mathrm{~cm}$ & & 02 & 64,90 & 20.919 \\
\hline CCR & & 83 & 65,40 & 20.781 \\
\hline
\end{tabular}


Tabela 4.9 Resultados de E e k pelo critério de Hall (1991) na seção D.

\begin{tabular}{|c|c|c|c|c|}
\hline \multirow[t]{8}{*}{ Placa } & \multirow[t]{2}{*}{ Posição } & Carga & $\begin{array}{l}\text { Módulo de Reação } \\
\text { do Subleito (k) }\end{array}$ & $\begin{array}{c}\text { Módulo de } \\
\text { Elasticidade do } \\
\text { CCP (E) }\end{array}$ \\
\hline & & $\mathrm{KN}$ & $\mathrm{MPa} / \mathrm{m}$ & $\mathrm{MPa}$ \\
\hline & \multirow{6}{*}{10} & \multirow{2}{*}{47} & 47,38 & 24.096 \\
\hline & & & 48,32 & 23.411 \\
\hline & & & 52,94 & 21.959 \\
\hline & & 74 & 51,81 & 22.875 \\
\hline & & \multirow{2}{*}{83} & 55,37 & 21.421 \\
\hline & & & 55,64 & 21.273 \\
\hline \multirow{10}{*}{ D } & \multirow{6}{*}{12} & \multirow{2}{*}{47} & 43,76 & 31.512 \\
\hline & & & 69,31 & 15.746 \\
\hline & & & 79,03 & 15.536 \\
\hline & & 74 & 61,74 & 22.055 \\
\hline & & & 100,00 & 9.249 \\
\hline & & 83 & 54,06 & 27.091 \\
\hline & & & 41,09 & 31.716 \\
\hline & & $4 r$ & 39,90 & 32.939 \\
\hline & & & 47,04 & 27.444 \\
\hline & 22 & 74 & 45,90 & 28.258 \\
\hline $\mathrm{h}=25 \mathrm{~cm}$ & & & 48,10 & 27.476 \\
\hline BGS & & 83 & 46,28 & 29.187 \\
\hline
\end{tabular}

Tabela 4.10 Resultados de E e k pelo critério de Hall (1991) na seção E.

\begin{tabular}{|c|c|c|c|c|}
\hline \multirow[t]{8}{*}{ Placa } & \multirow[t]{2}{*}{ Posição } & Carga & $\begin{array}{c}\text { Módulo de Reação } \\
\text { do Subleito (k) }\end{array}$ & $\begin{array}{c}\text { Módulo de } \\
\text { Elasticidade do } \\
\text { CCP (E) }\end{array}$ \\
\hline & & KN & $\mathrm{MPa} / \mathrm{m}$ & $\mathrm{MPa}$ \\
\hline & \multirow{6}{*}{13} & \multirow{2}{*}{47} & 44,93 & 32.521 \\
\hline & & & 42,03 & 35.898 \\
\hline & & & 46,64 & 32.125 \\
\hline & & 74 & 42,93 & 36.571 \\
\hline & & \multirow{2}{*}{83} & 52,12 & 28.180 \\
\hline & & & 43,01 & 36.650 \\
\hline \multirow{10}{*}{ E } & \multirow{6}{*}{15} & \multirow{2}{*}{47} & 35,82 & 18.918 \\
\hline & & & 33,79 & 23.142 \\
\hline & & & 36,93 & 22.925 \\
\hline & & 74 & 38,64 & 20.945 \\
\hline & & & 51,67 & 14.358 \\
\hline & & & 38,53 & 22.199 \\
\hline & & 4 & 36,99 & 52.542 \\
\hline & & $4 t$ & 37,61 & 51.933 \\
\hline & 24 & & 35,05 & 60.359 \\
\hline & 24 & 74 & 38,48 & 54.338 \\
\hline $\mathrm{h}=25 \mathrm{~cm}$ & & 83 & 39,02 & 54.427 \\
\hline BGS & & 00 & 42,11 & 50.045 \\
\hline
\end{tabular}


Observando-se os resultados de módulo de elasticidade do concreto definidos dessa maneira, percebe-se que para as medidas relativas às posições 1 (placa A1) e 6 (placa B2), os valores obtidos são aparentemente irreais. Não existem razões para acreditar que o concreto empregado nas cinco seções da pista experimental USP/FAPESP fossem diferentes, conforme as razões que se expõem ${ }^{1}$ :

- Não houve alteração da dosagem estabelecida para o projeto entre diferentes concretagens;

- Não houve alteração do fornecedor do concreto entre as cinco fases de execução da pista;

- O fornecedor do concreto não alterou agregados ou cimento Portland na formulação dos concretos em cada uma das fases;

- Não houve diferença importante entre condições climáticas e de cura dos concretos em nenhuma das fases;

- As medidas de resistência de amostras moldadas durante todas as fases de execução, bem como as medidas de valores de módulo de elasticidade estático do concreto naquela época, não indicaram alteração ou variação expressiva desses parâmetros entre as fases de construção.

Assim sendo, é inevitável afirmar que houve falha na execução dos testes com FWD nessas seções, mesmo porque os processos de retroanálise foram devidamente checados quanto aos elementos fornecidos para o programa ISLAB2000. A título de especulação sobre essas possíveis falhas não detectadas no momento dos testes, duas hipóteses são tangíveis. A primeira delas, mais provável, é que o aplicador de cargas do FWD apoiou-se de maneira não completa sobre a superfície da placa de concreto nos pontos indicados (posições 1 e 6) devido à presença de grão(s) rígido(s); isto afetaria muito a distribuição da carga aplicada, exercendo pressões não uniformes sob a o carregamento. A segunda hipótese seria algum tipo de falha do operador do microcomputador que registra a aquisição de dados, menos provável pois bastante incomum.

\footnotetext{
${ }^{1}$ Comunicação pessoal de José Tadeu Balbo, dezembro de 2008.
} 
Com base em tais constatações, decidiu-se pela eliminação dessas medidas sobre essas placas de concreto para o prosseguimento dos estudos, pois não havia mais tempo e possibilidade de empréstimo do equipamento FWD para os trabalhos.

Das seções restantes destes resultados, observa-se que o módulo de reação do subleito no centro da placa é em torno de 30 a $50 \mathrm{MPa} / \mathrm{m}$ nas seções $C$, D e E, cuja espessura da placa é a mesma $(250 \mathrm{~mm})$, conforme é apresentado na Tabela 4.11. Os valores de módulo de elasticidade do concreto resultaram em geral dentro de faixas possíveis e toleráveis, sendo o ajuste mais adequado para tais valores obtidos por meio de retroanálises com o programa ISLAB2000, o que se apresenta na sequência.

\begin{tabular}{|c|c|c|c|}
\hline Placa & Posição & $\begin{array}{l}\text { Módulo de Reação do } \\
\text { Subleito (k) } \\
\mathrm{MPa} / \mathrm{m}\end{array}$ & $\begin{array}{c}\text { Módulo de } \\
\text { Elasticidade do } \\
\text { CCP (E) } \\
\mathrm{MPa}\end{array}$ \\
\hline A & 3 & 31 a 34 & 48.000 a 53.000 \\
\hline \multirow{2}{*}{ B } & 4 & 60 a 80 & 45.000 a 66.000 \\
\hline & 18 & 89 a 97 & 23.000 a 29.000 \\
\hline \multirow{3}{*}{ C } & 7 & 51 a 65 & 24.000 a 34.000 \\
\hline & 9 & 55 a 61 & 35.000 a 43.000 \\
\hline & 20 & 50 a 65 & 20.000 a 27.000 \\
\hline \multirow{3}{*}{ D } & 10 & 47 a 55 & 21.000 a 24.000 \\
\hline & 12 & 43 a 100 & 9.000 a 31.000 \\
\hline & 22 & 40 a 47 & 27.000 a 32.000 \\
\hline \multirow{3}{*}{ E } & 13 & 42 a 52 & 28.000 a 36.000 \\
\hline & 15 & 33 a 51 & 14.000 a 23.000 \\
\hline & 24 & 35 a 42 & 50.000 a 60.000 \\
\hline
\end{tabular}

\subsection{Retroanálises do Módulo de Elasticidade do Concreto (E) e do Módulo de Reação do Subleito (k) no Centro da Placa}

Na Tabela 4.12 são apresentados os valores de módulo de elasticidade do concreto e de módulo de reação do subleito retroanalisados a partir das cargas aplicadas no centro de cada placa das seções experimentais. Recorda-se que as deflexões medidas no período da manhã do dia 28 de julho de 2006 (inverno) foram empregadas para esta finalidade. 
Tabela 4.12 Resumo dos valores de E e k retroanalisados.

\begin{tabular}{|c|c|c|c|c|}
\hline \multirow{2}{*}{ Seção } & \multirow{2}{*}{ Posição } & \multicolumn{2}{|c|}{ Módulo de Elasticidade (MPa/m) } & \multirow{2}{*}{$\begin{array}{c}\begin{array}{c}\text { Módulo de Reação do } \\
\text { Subleito }(\mathrm{MPa} / \mathrm{m})\end{array} \\
\text { Centro da Placa }\end{array}$} \\
\hline & & Placa CCP & Base CCR & \\
\hline \multirow{6}{*}{ A } & \multirow{3}{*}{1} & 55.150 & - & 55 \\
\hline & & 74.150 & - & 50 \\
\hline & & 73.800 & - & 50 \\
\hline & \multirow{3}{*}{3} & 57.050 & - & 45 \\
\hline & & 57.250 & - & 45 \\
\hline & & 51.350 & - & 50 \\
\hline \multirow{9}{*}{ B } & \multirow{3}{*}{4} & 45.850 & 22.100 & 75 \\
\hline & & - & - & - \\
\hline & & 59.550 & 20.450 & 80 \\
\hline & \multirow{3}{*}{6} & - & - & - \\
\hline & & 27.700 & 26.900 & 125 \\
\hline & & 87.200 & 27.900 & 90 \\
\hline & \multirow{3}{*}{18} & 21.000 & 22.450 & 90 \\
\hline & & 35.000 & 20.500 & 90 \\
\hline & & 40.050 & 19.900 & 90 \\
\hline \multirow{9}{*}{ C } & \multirow{3}{*}{7} & 51.800 & 21.850 & 60 \\
\hline & & 53.900 & 19.800 & 60 \\
\hline & & 54.500 & 18.400 & 60 \\
\hline & \multirow{3}{*}{9} & 72.350 & 22.450 & 65 \\
\hline & & 60.000 & 19.600 & 70 \\
\hline & & 62.300 & 22.500 & 70 \\
\hline & \multirow{3}{*}{20} & 41.000 & 21.550 & 60 \\
\hline & & 37.000 & 20.000 & 65 \\
\hline & & 34.200 & 19.800 & 70 \\
\hline \multirow{9}{*}{$\mathrm{D}$} & \multirow{3}{*}{10} & 52.300 & - & 45 \\
\hline & & 39.850 & - & 55 \\
\hline & & 39.950 & - & 55 \\
\hline & & - & - & - \\
\hline & & - & - & - \\
\hline & & - & - & - \\
\hline & \multirow{3}{*}{22} & 33.400 & - & 60 \\
\hline & & 61.100 & - & 40 \\
\hline & & 45.250 & - & 55 \\
\hline \multirow{9}{*}{$E$} & \multirow{3}{*}{13} & 37.500 & - & 65 \\
\hline & & 33.850 & - & 70 \\
\hline & & 29.750 & - & 75 \\
\hline & \multirow{3}{*}{15} & 26.550 & - & 50 \\
\hline & & 34.950 & - & 45 \\
\hline & & 30.150 & - & 50 \\
\hline & \multirow{3}{*}{24} & 58.850 & - & 60 \\
\hline & & 57.550 & - & 60 \\
\hline & & 65.400 & - & 60 \\
\hline
\end{tabular}

Observa-se dos resultados obtidos que, novamente, os módulos de elasticidade das placas A1 e B6 resultaram em geral elevados, com valores inesperados para o 
concreto empregado, visto que valores acima de $70.000 \mathrm{MPa}$ estão presentes. Também ocorreram valores inesperados na placa $\mathrm{C} 9$, com todos os resultados superiores a $60.000 \mathrm{MPa}$. Considera-se que tais resultados, como retroanálises insatisfatórias devido a erro de procedimento em campo na operação do FWD (ver item 4.2) ou falta de refinamento na retroanálise para estes casos, não sendo posteriormente consideradas nas análises.

O módulo de elasticidade do concreto retroanalisado variou na faixa entre 26.500 e 58.850 MPa desconsiderando-se valores acima mencionados. Essa variação deve ser considerada normal mesmo porque reflete um valor paramétrico médio representativo para a placa de concreto como um todo e não valores de corpos-deprova homogêneos estudados em laboratório. Em pista, durante a construção, em diferentes áreas de concretagem ocorrem de maneiras diferenciadas, fenômenos como a segregação e a exsudação do concreto fresco, o que também é dependente da forma de lançamento e da vibração do material, que certamente não é homogênea em pista. Esses valores de módulo de elasticidade do concreto serão adiante confrontados com os valores de amostras coletadas durante a construção da pista e ensaiadas em laboratório.

Os valores de módulo de elasticidade do CCR nas seções B e C resultaram variando entre 19.600 e 27.900 MPa. Tais valores são típicos de CCR's empregados em pavimentação, como por exemplo encontrados nos estudos de Ricci (2007), para os quais o módulo de elasticidade tangente resultou entre 21.000 e $23.000 \mathrm{MPa}$, e por Trichês (1993, apud Ricci, 2007), neste caso variando entre 16.000 e $19.000 \mathrm{MPa}$, ambos para consumo de cimento em torno de $120 \mathrm{~kg} / \mathrm{m}^{3}$. Observe-se que o CCR empregado na pista experimental apresentava consumo de cimento de $150 \mathrm{~kg} / \mathrm{m}^{3}$.

O módulo de reação do subleito apresentou dois comportamentos distintos. Para as seções $A, D$ e $E$, cujas bases são em BGS, os valores de k variaram entre 40 e 60 $\mathrm{MPa} / \mathrm{m}$. Esta variação, segundo Rodolfo e Balbo (2002), praticamente não possui interferência alguma no comportamento das placas, não se tratando do principal agente no mecanismo de tensões no concreto. Valores de $\mathrm{k}$ em torno de $50 \mathrm{MPa} / \mathrm{m}$ revelam subleitos de boa qualidade quanto à deformabilidade elástica, como é o 
caso do subleito da pista experimental constituído por aterro de solo laterítico argiloso.

O método de projeto de pavimentos de concreto simples da PCA (1966) considera como valor máximo de $\mathrm{k}$ para solos de subleito (com $\mathrm{CBR}=20 \%$ ) em $65 \mathrm{MPa} / \mathrm{m}$. O método da AASHTO (1986) considera que um solo argiloso com grau de saturação não superior a $50 \%$ possui $k=50 \mathrm{MPa} / \mathrm{m}$. Ainda a AASHTO (1998) fornece o valor máximo de $\mathrm{k}=80 \mathrm{MPa} / \mathrm{m}$ para um solo com $\mathrm{CBR}=20 \%$. De acordo com Hall et al. (1997), um solo argiloso do tipo A-7-6, o valor de k varia entre 10 e 60 MPa/m. Considerando que argila do subleito da pista experimental apresenta CBR não superior a $8 \%$, os valores de $\mathrm{k}$ entre 40 e $60 \mathrm{MPa} / \mathrm{m}$ encontrados são perfeitamente adequados.

Nas seções $B$ e $C$ os valores de módulo de reação do subleito variaram em faixa mais ampla e superior ao primeiro caso: entre 60 e $125 \mathrm{MPa} / \mathrm{m}$. Tais valores são encontrados para subleitos sob uma base em CCR, dando uma primeira indicação que tal tipo de base interfere na resposta do subleito, o que ficará melhor esclarecido após a apresentação dos resultados de módulo de reação do subleito retroanalisados para cargas de borda transversal $\left(k_{b}\right)$. As distintas faixas de variação mencionadas ficam bastante evidenciadas na Figura 4.8.

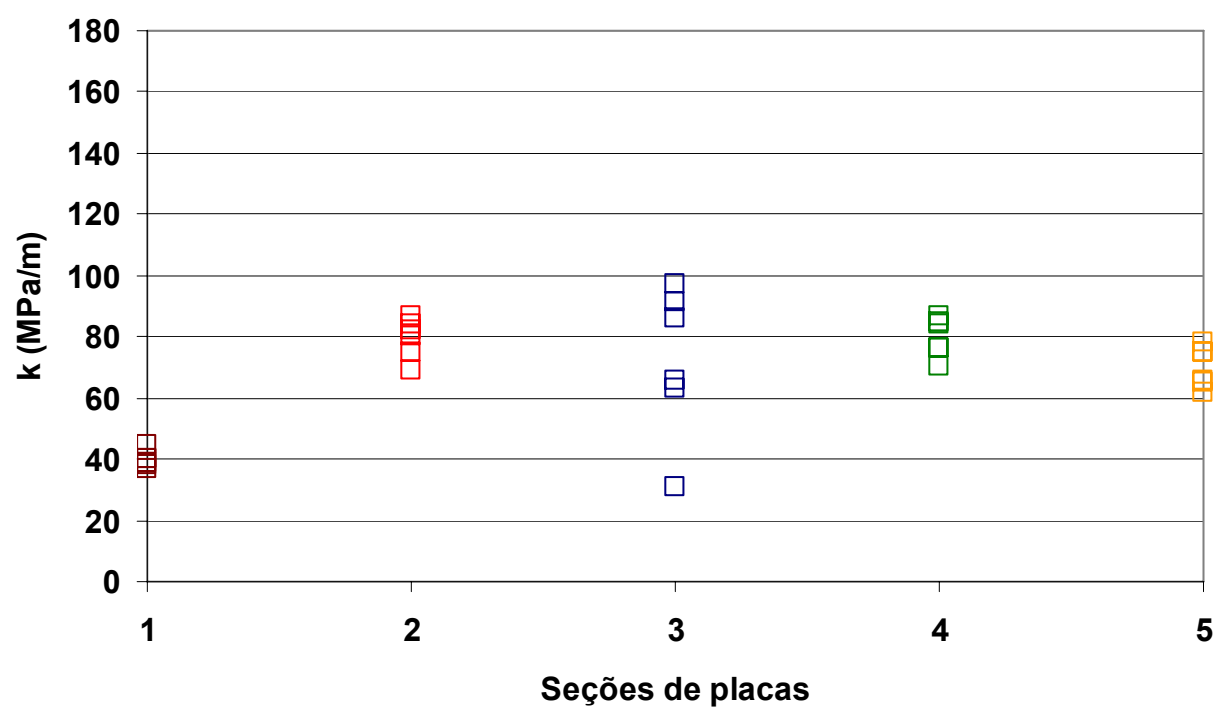

$\square$ Seção A (1) $\square$ Seção B (2) $\square$ Seção C (3) $\square$ Seção D (4) $\square$ Seção E (5)

Figura 4.8 Valores de módulo de reação retroanalisados (centro das placas). 


\subsection{Retroanálises dos Valores de Eficiência de Transferência de Carga (LTE) e de Módulo de Reação do Subleito na Borda da Placa}

Nas Tabelas 4.13 e 4.14, da página seguinte, são indicados valores de módulo de reação do subleito na borda da placa de concreto e valores de eficiência de transferência de carga, tanto nos testes realizados em julho de 2006 (inverno) quanto em março de 2007 (verão).

Tabela 4.13 Valores de LTE e $k_{b}$ (de borda) nos testes realizados em julho/2006.

\begin{tabular}{|c|c|c|c|c|c|c|}
\hline \multirow[t]{2}{*}{ Seção } & \multirow[t]{2}{*}{ Posição } & \multirow{2}{*}{$\begin{array}{c}\text { Carga } \\
(k N)\end{array}$} & \multicolumn{2}{|c|}{$\begin{array}{c}\text { Módulo de Reação do } \\
\text { Subleito na borda }(\mathrm{MPa} / \mathrm{m})\end{array}$} & \multicolumn{2}{|c|}{ LTE (\%) } \\
\hline & & & Manhã & Tarde & Manhã & Tarde \\
\hline \multirow{6}{*}{$A$} & \multirow{4}{*}{2} & 47 & 45 & 54 & 99 & 96 \\
\hline & & 74 & 40 & 51 & 99 & 99 \\
\hline & & 83 & 40 & 52 & 99 & 97 \\
\hline & & 47 & 38 & 41 & 96 & 96 \\
\hline & \multirow[t]{2}{*}{16} & 74 & 37 & 39 & 92 & 95 \\
\hline & & 83 & 39 & 39 & 94 & 94 \\
\hline \multirow{6}{*}{ B } & \multirow{4}{*}{5} & 47 & 75 & 104 & 96 & 89 \\
\hline & & 74 & 80 & 107 & 96 & 94 \\
\hline & & 83 & 84 & 110 & 98 & 94 \\
\hline & & 47 & 69 & 170 & 99 & 96 \\
\hline & \multirow[t]{2}{*}{17} & 74 & 82 & 159 & 99 & 91 \\
\hline & & 83 & 87 & 165 & 99 & 91 \\
\hline \multirow{6}{*}{$\mathrm{C}$} & \multirow{4}{*}{8} & 47 & 66 & 83 & 95 & 95 \\
\hline & & 74 & 63 & 80 & 98 & 94 \\
\hline & & 83 & 31 & 79 & 97 & 94 \\
\hline & & 47 & 86 & 107 & 91 & 95 \\
\hline & \multirow[t]{2}{*}{19} & 74 & 91 & 123 & 91 & 91 \\
\hline & & 83 & 97 & 135 & 90 & 89 \\
\hline \multirow{6}{*}{ D } & \multirow{4}{*}{11} & 47 & 70 & 64 & 94 & 93 \\
\hline & & 74 & 76 & 63 & 94 & 95 \\
\hline & & 83 & 76 & 76 & 95 & 94 \\
\hline & & 47 & 84 & 76 & 95 & 94 \\
\hline & \multirow[t]{2}{*}{21} & 74 & 85 & 78 & 93 & 92 \\
\hline & & 83 & 87 & 69 & 91 & 90 \\
\hline \multirow{6}{*}{$E$} & \multirow{4}{*}{14} & 47 & 78 & 78 & 97 & 97 \\
\hline & & 74 & 75 & 76 & 97 & 97 \\
\hline & & 83 & 75 & 77 & 99 & 97 \\
\hline & & 47 & 62 & 62 & 55 & 74 \\
\hline & \multirow[t]{2}{*}{23} & 74 & 65 & 65 & 53 & 71 \\
\hline & & 83 & 66 & 67 & 49 & 70 \\
\hline
\end{tabular}

Observa-se que em ambos os casos, verão e inverno, os módulos de reação do subleito nas placas das seções B e C aumentam bruscamente no período da tarde se comparados a períodos mais frios como manhã ou anoitecer. Este fato está 
diretamente ligado ao tipo de base utilizado nestas seções: o CCR. No período da tarde, as placas estão mais próximas, e suas juntas mais fechadas, ocasionando um sistema de apoio mais rígido na junta ou na borda, aumentando assim o módulo de reação do subleito.

Os valores de $\mathrm{k}$ nas bordas de placas apoiadas sobre bases granulares ou se mantém praticamente constantes ou apresentam alguma elevação nos horários mais quentes. Isto pode ser assim entendido também para o caso da seção $E$ nas medidas de verão entre tarde e noite, porque entre tais medidas a radiação solar e o calor, ainda persistentes antes do anoitecer, podem ter causado pequeno acréscimo de temperatura no concreto, o que justificaria maiores valores para $k_{b}$.

Tabela 4.14 Valores de LTE e $k_{b}$ (de borda) nos testes realizados em março/2007.

\begin{tabular}{|c|c|c|c|c|c|c|}
\hline \multirow[t]{2}{*}{ Seção } & \multirow[t]{2}{*}{ Posição } & \multirow{2}{*}{$\begin{array}{c}\text { Carga } \\
(k N)\end{array}$} & \multicolumn{2}{|c|}{$\begin{array}{c}\text { Módulo de Reação do } \\
\text { Subleito na borda }(\mathrm{MPa} / \mathrm{m})\end{array}$} & \multicolumn{2}{|c|}{ LTE (\%) } \\
\hline & & & Tarde & Noite & Tarde & Noite \\
\hline \multirow{6}{*}{$A$} & \multirow{3}{*}{2} & 47,18 & 37 & 33 & 95 & 94 \\
\hline & & 74,36 & 31 & 29 & 95 & 94 \\
\hline & & 83,92 & 32 & 37 & 95 & 95 \\
\hline & \multirow{3}{*}{16} & 47,18 & 39 & 40 & 96 & 97 \\
\hline & & 74,36 & 39 & 40 & 98 & 96 \\
\hline & & 83,92 & 42 & 43 & 92 & 93 \\
\hline \multirow{6}{*}{ B } & \multirow{3}{*}{5} & 47,18 & 140 & 129 & 93 & 93 \\
\hline & & 74,36 & 144 & 129 & 94 & 93 \\
\hline & & 83,92 & 137 & 127 & 93 & 93 \\
\hline & \multirow{3}{*}{17} & 47,18 & 152 & 111 & 94 & 96 \\
\hline & & 74,36 & 141 & 115 & 91 & 98 \\
\hline & & 83,92 & 160 & 124 & 89 & 93 \\
\hline \multirow{6}{*}{ C } & \multirow{3}{*}{8} & 47,18 & 101 & 81 & 95 & 93 \\
\hline & & 74,36 & 93 & 92 & 95 & 96 \\
\hline & & 83,92 & 89 & 74 & 95 & 94 \\
\hline & \multirow{3}{*}{19} & 47,18 & 127 & 86 & 87 & 88 \\
\hline & & 74,36 & 124 & 90 & 86 & 88 \\
\hline & & 83,92 & - & 96 & - & 87 \\
\hline \multirow{6}{*}{$\mathrm{D}$} & \multirow{3}{*}{11} & 47,18 & 71 & 77 & 93 & 90 \\
\hline & & 74,36 & 81 & 84 & 92 & 91 \\
\hline & & 83,92 & 82 & 84 & 94 & 92 \\
\hline & \multirow{3}{*}{21} & 47,18 & 88 & 96 & 94 & 90 \\
\hline & & 74,36 & 61 & 70 & 94 & 90 \\
\hline & & 83,92 & 75 & 86 & 88 & 87 \\
\hline \multirow{6}{*}{$E$} & \multirow{3}{*}{14} & 47,18 & 68 & 94 & 95 & 97 \\
\hline & & 74,36 & 67 & 92 & 92 & 99 \\
\hline & & 83,92 & 72 & 90 & 94 & 98 \\
\hline & \multirow{3}{*}{23} & 47,18 & 60 & 72 & 64 & 58 \\
\hline & & 74,36 & 61 & 70 & 62 & 60 \\
\hline & & 83,92 & 68 & 74 & 71 & 58 \\
\hline
\end{tabular}


Os valores de LTE retroanalisados em juntas com BT para as medidas de inverno variaram entre 90 e 99\%, não sendo possível distinguir efeitos claros do tipo de base e de espessura da placa de concreto. Durante o verão tais valores variaram entre 86 e $99 \%$ novamente não sendo possível estabelecer padrões de comportamento. Todos esses valores são típicos de pavimentos novos, o que se justifica pela não ocorrência de tráfego comercial nas seções experimentais, que são um estacionamento de automóveis.

Já no caso da junta sem barra de transferência de carga, no inverno, no período da manhã, o LTE foi sensivelmente inferior que no período da tarde (em torno de $50 \%$ contra $70 \%$ ). No verão não foram verificadas variações tão importantes entre tarde e noite, mesmo porque nesta época do ano a variação da temperatura ambiente é menor que no inverno.

Nas Figuras 4.9 e 4.10 apresentadas a seguir observa-se um evidente aumento nos valores do módulo de reação do subleito com cargas aplicadas nas bordas (juntas transversais) das placas para os casos das seções $B$ e $C$ que possuem base em CCR.

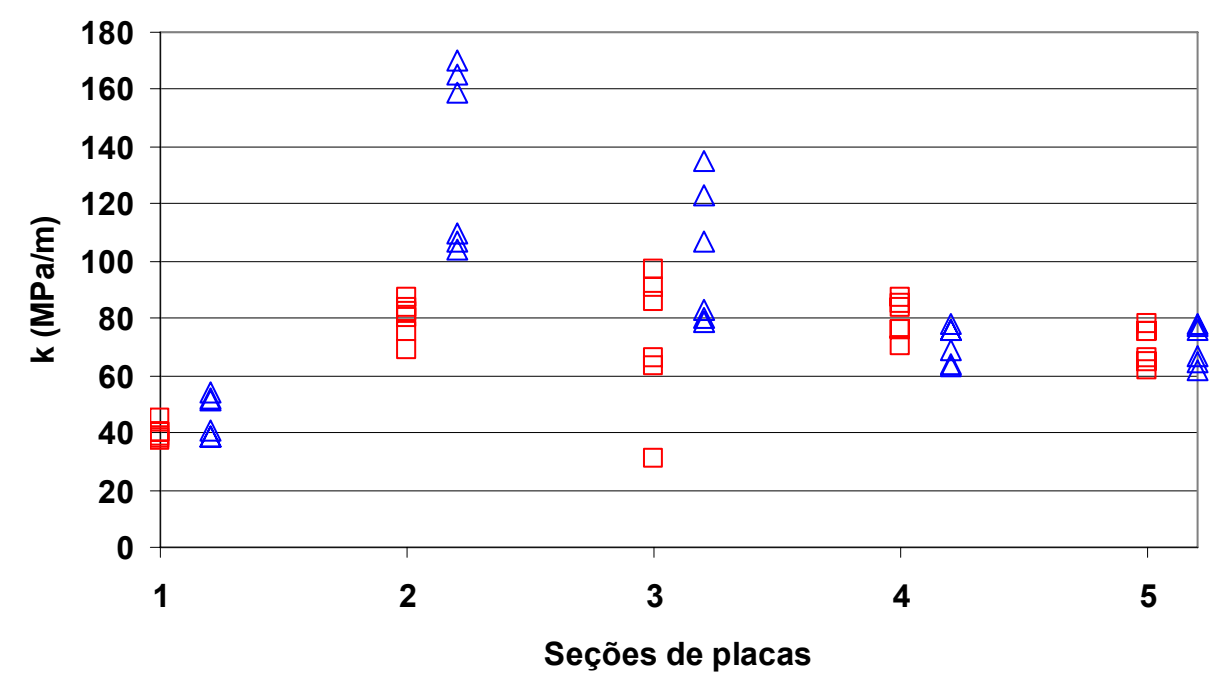

$\square A(1)$ - Manhã $\square B(2)$ - Manhã $\square C(3)$ - Manhã $\square D(4)$ - Manhã $\square E(5)$ - Manhã

$\triangle$ Tarde A $\triangle$ Tarde B $\triangle$ Tarde C $\triangle$ Tarde D $\triangle$ Tarde E

Figura 4.9 Valores de $k_{b}$ nos testes realizados em julho/2006. 
Tal como no caso de cargas centrais, os valores de $\mathrm{k}$ aumentam bastante para as estruturas com bases em CCR denotando que tal parâmetro (módulo de reação do subleito) é dependente da estrutura como um todo. Inclusive, nos casos de bases em CCR os valores aumentam muito para os períodos mais quentes, o que denota uma interferência conjunta no comportamento da estrutura de pavimento da temperatura do concreto e do tipo de base.

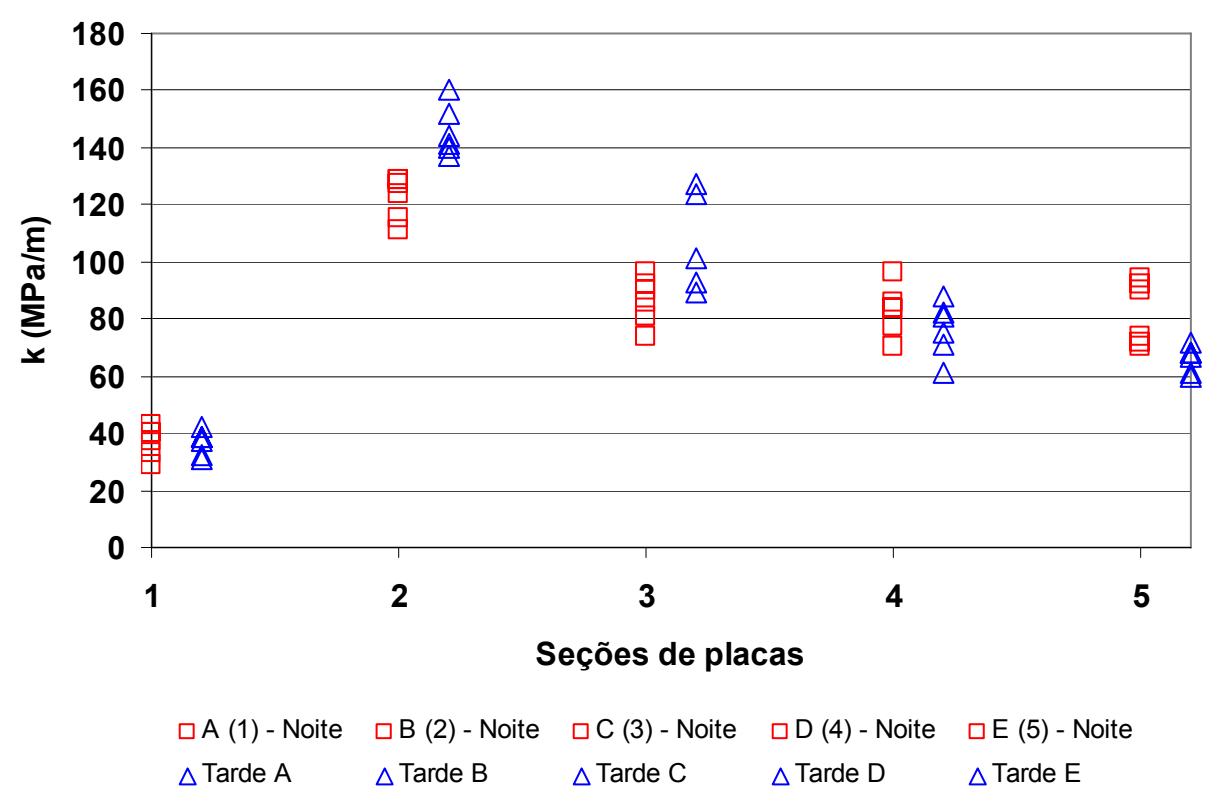

Figura 4.10 Valores de $k_{b}$ nos testes realizados em janeiro/2007.

\subsection{Transferência de Carga em Juntas por Medidas Diretas}

Os valores de LTE foram calculados conforme a Equação 2.4, sendo os mesmos apresentados individualmente para cada carregamento na Tabela 4.15. De tais valores individuais se extrai claramente que a presença de BT nas juntas transversais resulta em acréscimo expressivo no valor do LTE em comparação ao caso de juntas sem BT quando a transferência de carga se faz exclusivamente pelo intertravamento entre faces ou agregados (comparar posições quaisquer com a posição E3). Isto ressalta o fato, conforme descrito por Khazanovich (2007), de pavimentos de concreto com BT apresentarem melhor desempenho, o que se explica pelos estados de tensões mais aliviados decorrentes da presença de BT em juntas quando a carga solicita o pavimento nessa posição. 
Tabela 4.15 Resultados de LTE (em \%) a partir dos testes com diferentes níveis de carga.

\begin{tabular}{|c|c|c|c|c|c|c|c|c|c|c|c|c|c|}
\hline \multirow{4}{*}{ Posição } & \multirow{4}{*}{ Placa } & \multicolumn{6}{|c|}{ Inverno de 2006} & \multicolumn{6}{|c|}{ Verão de 2007} \\
\hline & & \multicolumn{3}{|c|}{ Manhã } & \multicolumn{3}{|c|}{ Tarde } & \multirow{2}{*}{\multicolumn{3}{|c|}{$\begin{array}{c}\text { Tarde } \\
\text { Carga do FWD (kN) }\end{array}$}} & \multirow{2}{*}{\multicolumn{3}{|c|}{$\begin{array}{c}\text { Noite } \\
\text { Carga do FWD (kN) }\end{array}$}} \\
\hline & & Cars & do FV & $(k N)$ & Car & Io Fl & $k N)$ & & & & & & \\
\hline & & 47 & 74 & 84 & 47 & 74 & 84 & 47 & 74 & 84 & 47 & 74 & 84 \\
\hline \multirow{2}{*}{2} & $\mathrm{~A} 1$ & 95 & 96 & 96 & 93 & 93 & 93 & 95 & 94 & 94 & 93 & 92 & 92 \\
\hline & $\mathrm{A} 1$ & 96 & 95 & 96 & 93 & 93 & 92 & 94 & 94 & 94 & 93 & 93 & 92 \\
\hline \multirow{2}{*}{5} & B1 & 95 & 93 & 92 & 90 & 87 & 87 & 88 & 87 & 87 & 87 & 86 & 85 \\
\hline & B1 & 93 & 94 & 92 & 87 & 87 & 87 & 86 & 86 & 87 & 86 & 86 & 86 \\
\hline \multirow{2}{*}{8} & $\mathrm{C} 1$ & 94 & 94 & 94 & 91 & 89 & 89 & 95 & 94 & 94 & 94 & 94 & 94 \\
\hline & C1 & 94 & 100 & 94 & 91 & 90 & 91 & 93 & 96 & 93 & 94 & 94 & 94 \\
\hline \multirow{2}{*}{11} & $\mathrm{D} 1$ & 94 & 92 & 90 & 89 & 88 & 88 & 91 & 92 & 91 & 88 & 89 & 89 \\
\hline & D1 & 94 & 91 & 91 & 89 & 88 & 90 & 89 & 90 & 91 & 90 & 89 & 90 \\
\hline \multirow{2}{*}{14} & E1 & 95 & 94 & 95 & 92 & 94 & 92 & 93 & 93 & 93 & 97 & 98 & 97 \\
\hline & $\mathrm{E} 1$ & 95 & 94 & 95 & 92 & 91 & 93 & 93 & 93 & 93 & 97 & 96 & 97 \\
\hline \multirow{2}{*}{16} & A3 & 93 & 94 & 94 & 91 & 92 & 92 & 93 & 97 & 96 & 96 & 96 & 96 \\
\hline & A3 & 93 & 92 & 93 & 92 & 92 & 92 & 94 & 95 & 96 & 96 & 96 & 97 \\
\hline \multirow{2}{*}{17} & B3 & 100 & 100 & 100 & 92 & 90 & 90 & 87 & 88 & 88 & 96 & 96 & 96 \\
\hline & B3 & 100 & 98 & 98 & 90 & 89 & 88 & 87 & 87 & 87 & 96 & 96 & 95 \\
\hline \multirow{2}{*}{19} & C3 & 91 & 91 & 91 & 93 & 92 & 88 & 84 & 85 & 87 & 88 & 90 & 89 \\
\hline & C3 & 92 & 90 & 90 & 92 & 89 & 88 & 84 & 85 & 87 & 88 & 89 & 88 \\
\hline \multirow{2}{*}{21} & D3 & 92 & 91 & 91 & 91 & 89 & 90 & 95 & 94 & 91 & 89 & 90 & 89 \\
\hline & D3 & 92 & 91 & 91 & 91 & 89 & 90 & 95 & 95 & 93 & 91 & 91 & 90 \\
\hline \multirow{2}{*}{23} & E3 & 62 & 63 & 63 & 77 & 74 & 72 & 63 & 67 & 82 & 62 & 65 & 68 \\
\hline & E3 & 58 & 62 & 62 & 70 & 73 & 73 & 66 & 75 & 82 & 57 & 62 & 67 \\
\hline
\end{tabular}

Um aspecto importante a ser extraído dos resultados apresentados na Tabela 4.15 é que existe um acréscimo para valores de LTE calculados em placas sem BT (placa E3) em função do incremento de carga, para o verão. Já em placas com BT, não existe diferença significativa para esses valores de LTE em diferentes níveis de carregamento, tanto no inverno quanto no verão. Isto não significa que as deflexões não se alterem com o incremento de carga.

Com base em tal constatação, as análises que se seguem são realizadas a partir dos valores médios de todas as medidas para as cargas aplicadas, conforme apresentados na Tabela 4.16 . 
Tabela 4.16 - Resultados do LTE em 2006 e 2007.

\begin{tabular}{c|cccccccc}
\hline Placa & $\begin{array}{c}\text { LTE } \\
\text { Inverno } \\
\text { Manhã/2006 }\end{array}$ & $\begin{array}{c}\text { LTE } \\
\text { Inverno } \\
\text { Tarde/2006 }\end{array}$ & $\begin{array}{c}\text { LTE } \\
\text { Verão } \\
\text { Tarde/2007 }\end{array}$ & $\begin{array}{c}\text { LTE } \\
\text { Verão } \\
\text { Noite/2007 }\end{array}$ & $\begin{array}{c}\text { Espessura da } \\
\text { Placa }(\boldsymbol{m m})\end{array}$ & $\begin{array}{c}\text { Tipo de } \\
\text { Base }\end{array}$ & $\begin{array}{c}\text { Comprimento } \\
\text { ( } \boldsymbol{m})\end{array}$ & $\begin{array}{c}\text { Presença } \\
\text { de B.T. }\end{array}$ \\
\hline A1 & 95,8 & 92,8 & 94,3 & 92,6 & 150 & BGS & 4,0 & Sim \\
B1 & 93,0 & 87,5 & 86,9 & 86,1 & 150 & CCR & 4,0 & Sim \\
C1 & 94,9 & 90,0 & 94,2 & 94,0 & 250 & CCR & 4,0 & Sim \\
D1 & 92,1 & 88,8 & 90,7 & 89,2 & 250 & BGS & 4,0 & Sim \\
E1 & 94,6 & 92,4 & 92,9 & 97,1 & 250 & BGS & 5,5 & Sim \\
A3 & 93,2 & 91,9 & 95,2 & 96,0 & 150 & BGS & 7,5 & Sim \\
B3 & 99,3 & 89,7 & 87,7 & 95,9 & 150 & CCR & 7,5 & Sim \\
C3 & 90,6 & 90,4 & 85,2 & 88,5 & 250 & CCR & 7,5 & Sim \\
D3 & 91,4 & 90,1 & 94,4 & 90,1 & 250 & BGS & 7,5 & Sim \\
E3 & 61,6 & 73,5 & 72,3 & 63,6 & 250 & BGS & 5,5 & Não \\
\hline
\end{tabular}

Em todas as juntas das placas, com exceção da junta E3 que não possui BT, a transferência de carga varia muito pouco da manhã para a tarde, no inverno. Quando não existe a BT o valor de LTE aumenta durante a tarde, conforme fica claro para a placa E3 (de 61,6 para $73,5 \%$ ). Estes valores são intermediários àqueles indicados por Vandenbossche (2007), que seriam de 50\% pela manhã e de $90 \%$ no período da tarde.

As variações entre manhã e tarde e tarde e noite em geral encontram-se abaixo de \pm 5 pontos porcentuais, exceção feita à placa B3 onde esta variação atinge de 9 a 10 pontos porcentuais. Porém uma variação de 10 pontos sobre um valor básico de $90 \%$ significa uma variação de cerca de $10 \%$ no LTE. Já no caso da placa E3, encontra-se uma variação de 12 pontos porcentuais sobre um LTE de $62 \%$, o que representa um acréscimo de cerca de $20 \%$ no valor. Este resultado coincide com aqueles apresentados por Shahin (1985), que afirmava que em estudos realizados para placas sem BT, valores de LTE no período da tarde em relação ao período da manhã variavam em $20 \%$ (variação positiva).

Apenas para o caso de medidas de inverno fica evidente que, nas juntas com barras de transferência de carga, os valores de LTE diminuem da manhã para a tarde, sem exceções. Essa assertiva de modo geral é prejudicada, pois, nas medidas de verão, isso não foi verificado. 
Tais fatos estão bem elucidados na representação gráfica da Figura 4.11 para o inverno de 2006. Na maioria dos casos de placas com BT a LTE não varia ou pouco diminui no período da tarde, e quando diminui não há quedas que conduzam a valores inferiores a $90 \%$ em média. Toma-se $90 \%$ como um excelente valor de LTE posto que o sistema construtivo possa apresentar deficiência de apoio na base nas proximidades da junta, por exemplo, reduzindo o LTE. Observa-se, contudo, queda apreciável no valor do LTE quando não há transferência de carga com BT, que no caso foi de cerca de $95 \%$ (com BT) para 65\% (sem BT).

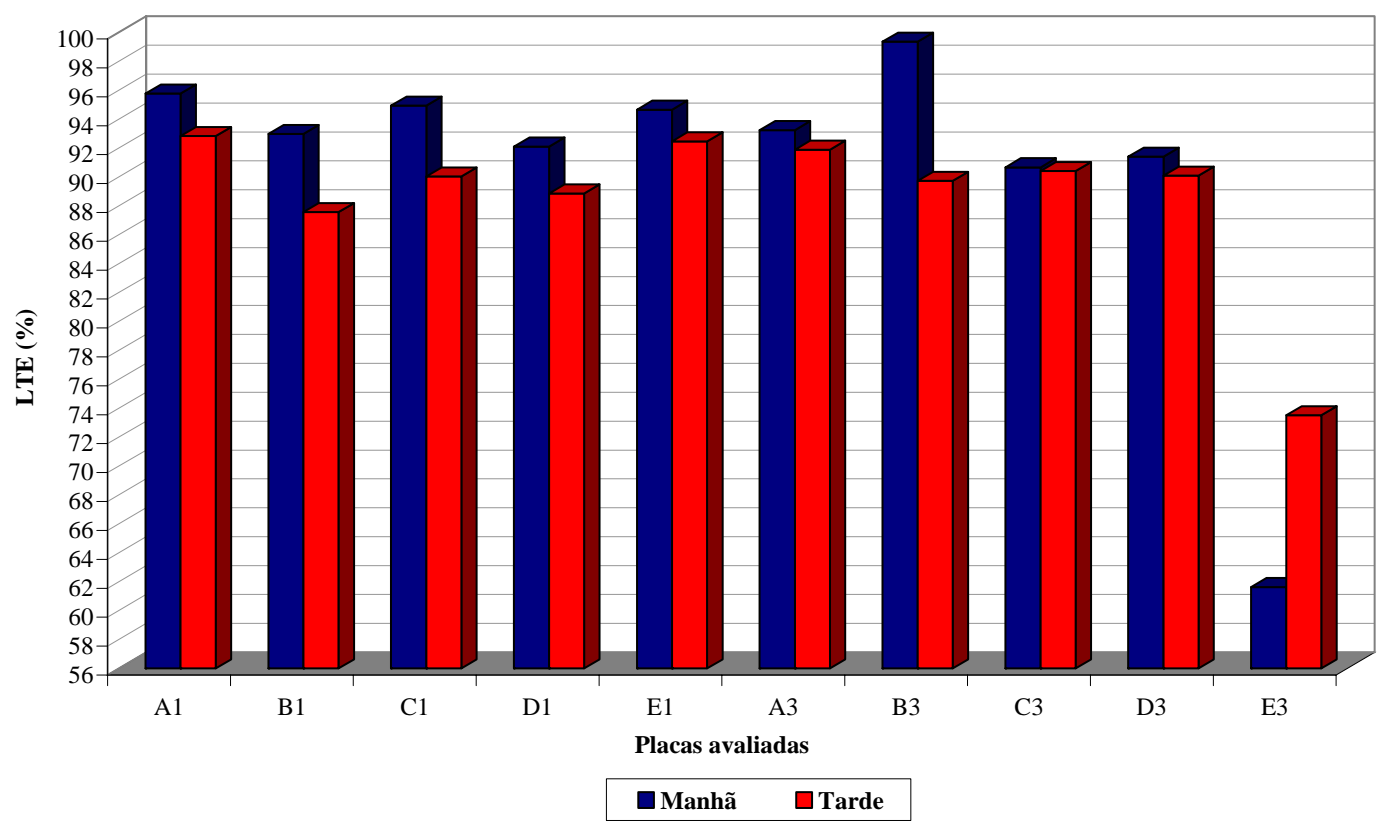

Figura 4.11 Valores de LTE nas juntas, durante o inverno de 2006.

Há ainda uma importante transferência de carga no caso da placa E3 devida ao entrosamento na face, mesmo na ausência da BT. Além disso, a resposta das medidas é bastante coerente, pois com o aumento da temperatura de topo de cerca de $10^{\circ} \mathrm{C}$ (ver Tabela 3.3) entre a medida da manhã (11 h) para aquela da tarde (14 h), na placa E3, o LTE aumentou; isto significa que a placa teria expandido e a abertura da junta, em conseqüência, diminuído, o que causaria maior entrosamento entre ambas, melhorando a transferência de carga, como na prática se observou; em outras palavras, há incremento no valor do módulo em cisalhamento da interface de agregados. 
Conclui-se, portanto, que durante os períodos sem insolação, quando o concreto retoma seu volume original (de construção) ou se contrai, o LTE deverá ser menor ainda que aquele valor observado para $11 \mathrm{~h}$, no caso de ausência de BT nas juntas. Na Figura 4.12 são apresentados graficamente os valores de LTE medidos no dia de verão que resultaram em valores também elevados para juntas com BT e reduzidos para juntas sem BT, sem alterações importantes para o verão em relação ao inverno.

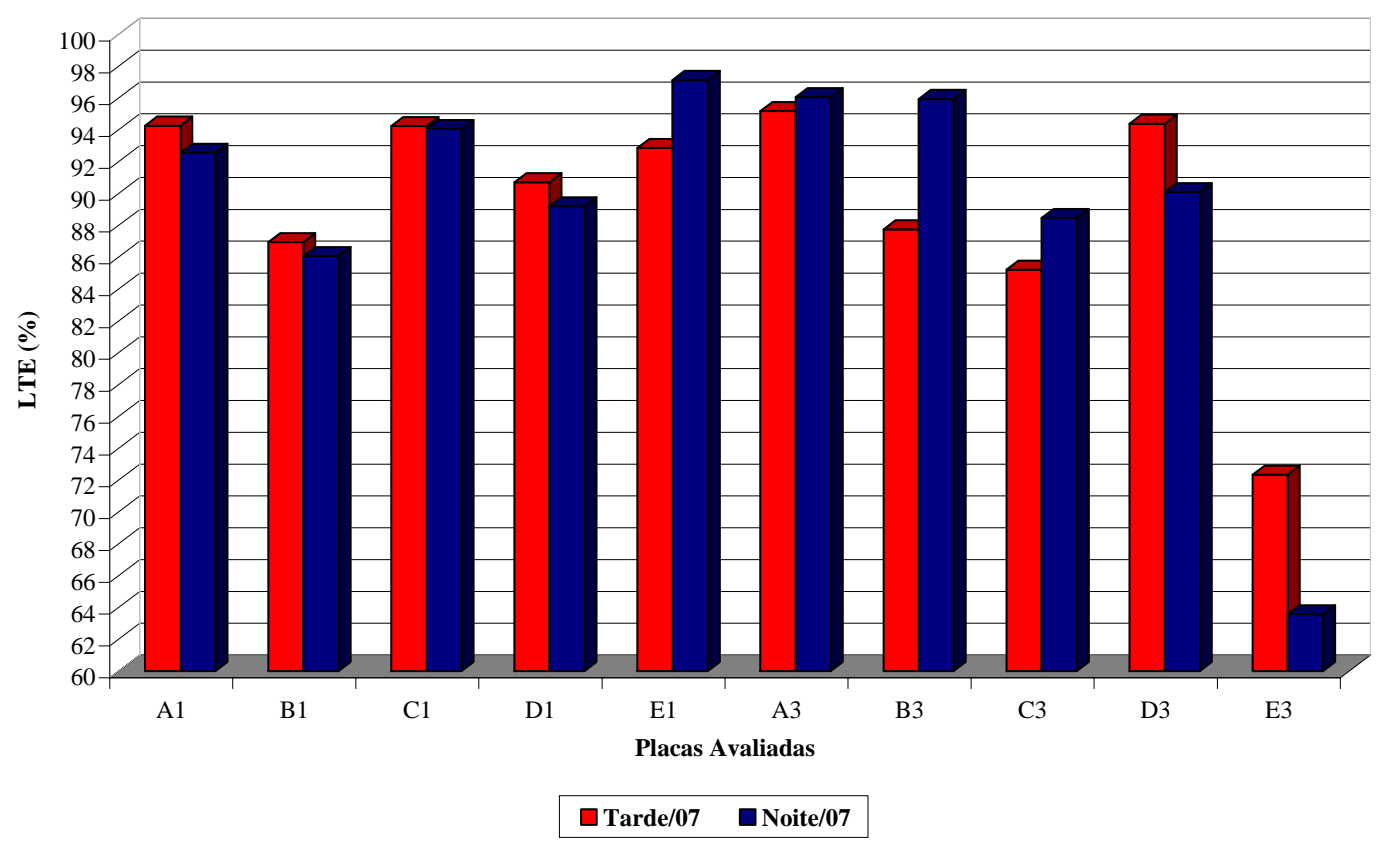

Figura 4.12 Valores de LTE nas juntas, durante o verão de 2007.

Embora seja difícil a comparação entre dados para as placas com BT uma vez que como regra geral, a transferência de carga se dá de modo satisfatório, com mais de $90 \%$, há que se recordar que as bases representam ainda um elemento estrutural que possui reflexos nessa transferência de cargas. Note bem que, ao sofrer deformação, a base sofrerá um deslocamento vertical e que a placa sucessiva àquela onde a carga é aplicada nas proximidades da junta transversal, por exemplo, deverá também acompanhar esse deslocamento vertical sofrido no topo da base que lhe serve de apoio. Isto significa que alguma deflexão sofre a placa sucessiva sem que haja uma transferência direta de carga de uma placa para outra por meio de um elemento como a BT. 
Assim, parcela da transferência, que é medida como uma relação entre deflexões totais nas proximidades da junta, poderá ser decorrente da deformação elástica da superfície da base. Nem sempre é uma tarefa fácil, com medidas de valores de deflexão na superfície das placas, individualizar o que é contribuição de cada camada. Todavia, os resultados obtidos permitiriam ainda algumas especulações sobre os efeitos de transferência de cargas em situações diferenciadas quanto ao tipo de base, espessura de placa, etc., conforme se faz na seqüência.

Nos resultados nesse experimento, embora possa ser discutida a precisão das medidas de deflexões bem como compará-las individualmente (margem de erro de cada medida ou média de medidas), os valores de inverno permitem entender que em placas de concreto delgadas $(150 \mathrm{~mm})$ com BT a transferência de carga é ligeiramente maior quando estão sobre base de BGS; já em placas espessas com BT, a transferência de carga é maior em placas sobre base de CCR do que sobre bases em BGS, conforme se verifica na Figura 4.13. No primeiro caso, dada a baixa rigidez da base, o mecanismo pode ser conseqüência de uma maior concentração de esforços na própria placa a serem transferidos. Já no caso do CCR, a combinação de rígida camada de concreto (placa) e de base também em concreto resulta em mecanismos de transferência, medidos pela deflexão avaliada na junta da placa de concreto, ligeiramente melhores.
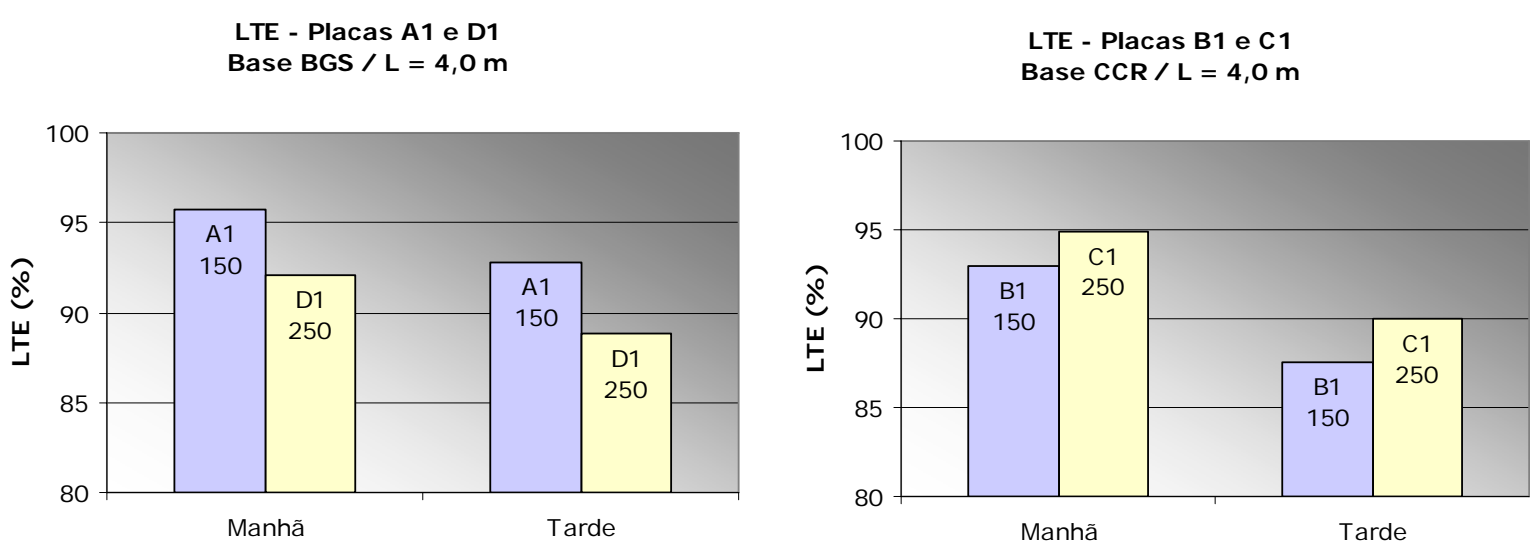

Figura 4.13 Transferência de carga de manhã e à tarde no inverno de 2006 em placas com tipos de bases diferentes. 
Bodocsi et al. (1993) afirmam que o tipo de base não afeta a abertura da junta e como a abertura da junta está ligada diretamente com a transferência de carga, então este parâmetro não afeta a LTE; porém isto ocorre em juntas sem BT. No presente estudo não havia possibilidades de verificar esse comportamento pois contava-se apenas com uma junta sem BT sobre base granular. Os resultados obtidos permitem afirmar apenas que, sobre base granular o LTE aumentou com a redução da espessura; sobre base de CCR, o LTE diminuiu com a redução da espessura da placa. Contudo, são alterações de pequena monta que não permitem uma afirmação mais contundente sobre o assunto.

Na Figura 4.14 é apresentado um conjunto de curvas, conforme equação 2.10 (BUCH, 1989), relacionando o grau de transferência de carga (LTE) com o valor de AGG, para um valor fixo de $\ell=0,164336 \mathrm{~m}$ e $\mathrm{k}$ variando entre 40 e $90 \mathrm{MPa} / \mathrm{m}$; esses valores foram escolhidos com base em valores de módulo de elasticidade encontrados, bem como módulos de reação de subleito, ambos retroanalisados, a partir de provas de carga na pista experimental na USP, com FWD.

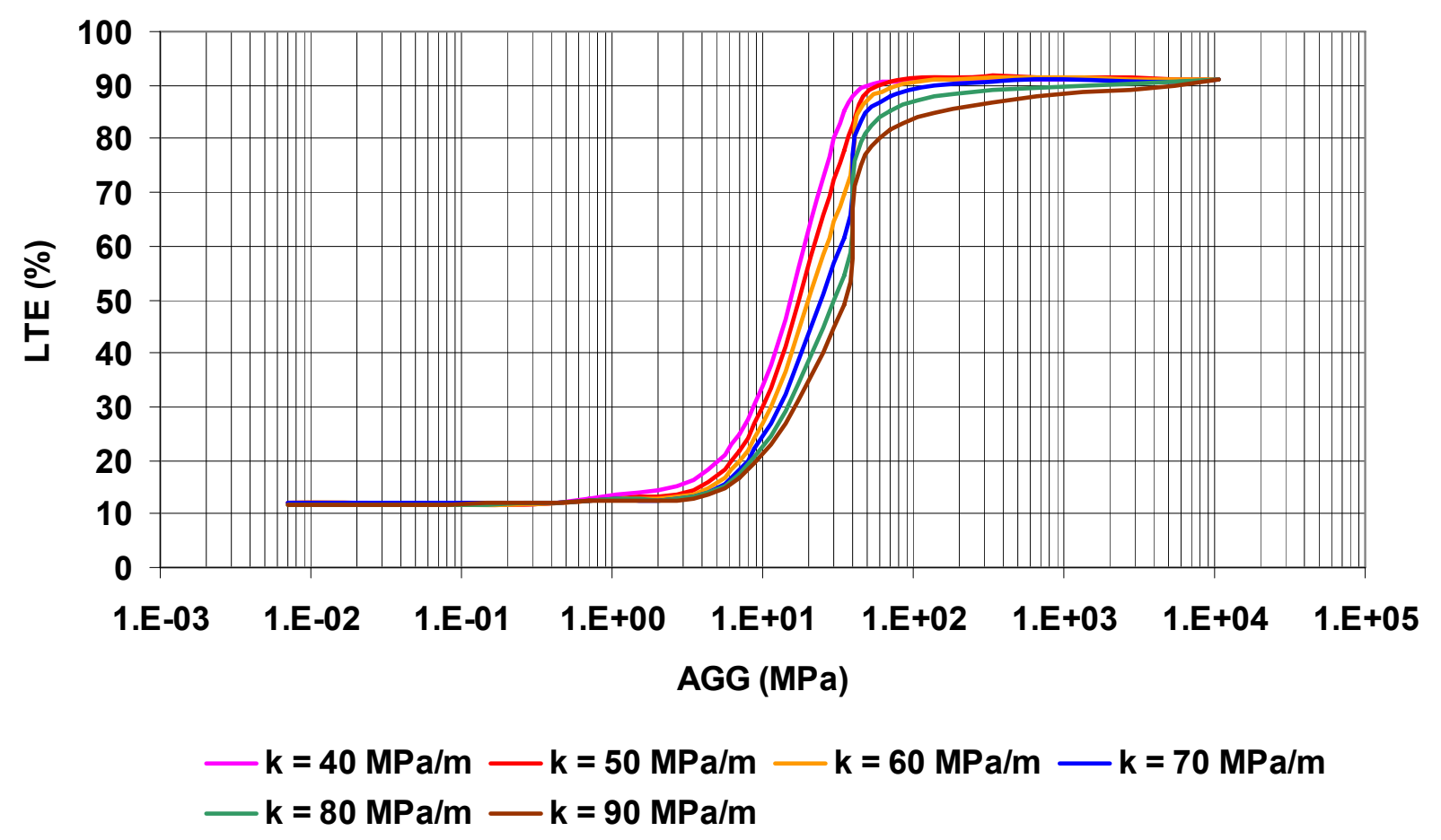

Figura 4.14 Curvas extraídas da equação de Buch relacionando o grau de transferência de carga com o valor de AGG. 
Observa-se que os valores de LTE encontram-se sempre entre 10 e 90\%. Quanto menor o valor de $k$ a taxa de variação do LTE em função de AGG é maior. Os valores encontrados mostram sensibilidade nos resultados para valores de AGG entre $1 \mathrm{MPa}$ e 100 a $1000 \mathrm{MPa}$ (limite superior) em função de k. Buch (1989) indica valores de AGG entre 2.100 e $10.500 \mathrm{MPa}$ aproximadamente em seus experimentos.

Na Tabela 4.17 são apresentados valores retroanalisados para o módulo de reação do subleito e o módulo de elasticidade do concreto, permitindo assim o cálculo dos demais parâmetros necessários para a determinação do valor de LTE. Apenas os valores de AGG foram arbitrados, tentativamente, de maneira a se chegar a valores de LTE calculados pela equação $2.10 \mathrm{com}$ aqueles observados em pista. Como visto por meio da Figura 4.10, os valores teóricos de LTE não ultrapassam $91 \%$, sendo que isso levaria a valores de $A G G=10.546 \mathrm{MPa}$ como limite superior.

Tabela 4.17 - Valores retroanalisados e medidos de LTE.

\begin{tabular}{c|cccccccc}
\hline Seção & $\begin{array}{c}\mathbf{k} \\
(\mathbf{M P a} / \mathbf{m})\end{array}$ & $\begin{array}{c}\mathbf{E} \\
(\mathbf{M P a})\end{array}$ & $\begin{array}{c}\text { Esp. } \\
(\mathbf{m})\end{array}$ & $\begin{array}{c}\text { AGG } \\
(\mathbf{M P a})\end{array}$ & $\boldsymbol{\ell}(\mathbf{m})$ & $\begin{array}{c}\text { LTE (\%) } \\
\text { equação 2.10 }\end{array}$ & $\begin{array}{c}\text { LTE (\%) } \\
\text { MANHÃ }\end{array}$ & $\begin{array}{c}\text { LTE (\%) } \\
\text { TARDE }\end{array}$ \\
\hline A1 & 40 & 73.800 & 0,15 & 10.546 & 0,853 & 91 & 99 & 97 \\
A3 & 38 & 57.050 & 0,15 & 10.546 & 0,811 & 91 & 96 & 96 \\
B1 & 75 & 45.850 & 0,15 & 10.546 & 0,648 & 91 & 96 & 89 \\
B3 & 82 & 35.000 & 0,15 & 10.546 & 0,592 & 91 & 99 & 91 \\
C1 & 63 & 53.900 & 0,25 & 10.546 & 1,033 & 91 & 98 & 94 \\
C3 & 91 & 37.000 & 0,25 & 10.546 & 0,858 & 91 & 91 & 91 \\
D1 & 76 & 39.850 & 0,25 & 10.546 & 0,914 & 91 & 94 & 95 \\
D3 & 87 & 45.250 & 0,25 & 10.546 & 0,912 & 91 & 91 & 90 \\
E1 & 75 & 33.850 & 0,25 & 10.546 & 0,880 & 91 & 97 & 97 \\
E3 & 62 & 58.850 & 0,25 & 177 ou 257 & 1,060 & 55 ou 74 & 55 & 74 \\
\hline
\end{tabular}

Para a Placa E3 onde não há BT observa-se que o efeito da temperatura foi marcante, como já comentado, e que o valor de AGG retroanalisado deve ser alterado de $177 \mathrm{MPa}$ para $257 \mathrm{MPa}$ para se obter o LTE de campo. Isso aponta a necessidade de melhoria do modelo de Buch (1989) para se considerar o efeito do diferencial térmico no LTE. Note que a variação do diferencial térmico entre ambas as medidas foi de apenas $5^{\circ} \mathrm{C}$, reforçando o importante efeito da temperatura do conjunto da placa em sua resposta mecânica. 
$\mathrm{Na}$ Figura 4.15 são apresentados resultados de LTE em relação ao nível de carrgegamento aplicado nas proximidades das juntas das placas. Observa-se que em juntas sem BT quanto maior a carga aplicada maior a eficiencia de transferencia de carga na junta. No caso de placas com BT nas juntas não existem diferenças marcantes entre os niveis de carga aplicadas e o LTE.

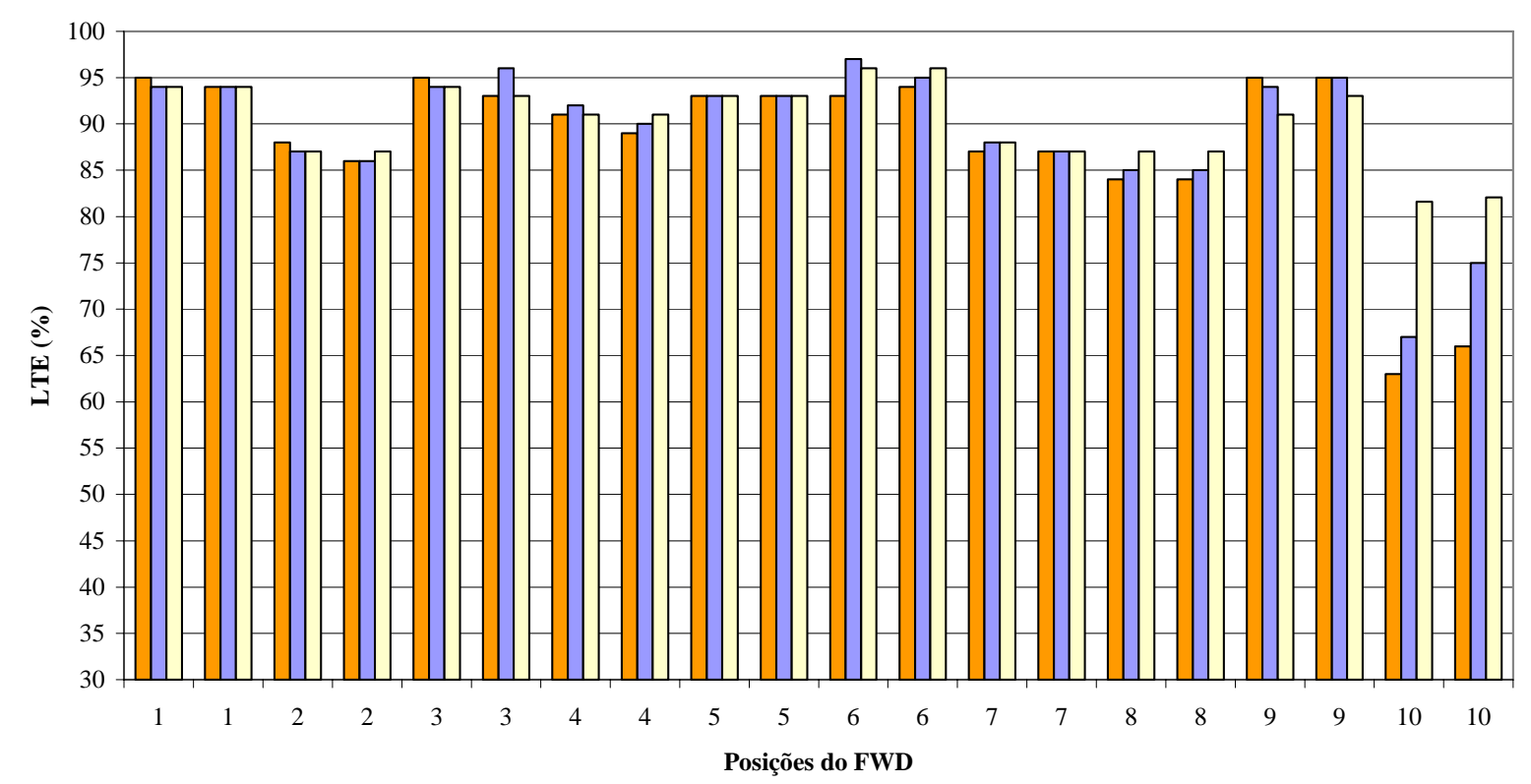

$\square$ Carga $1 \quad \square$ Carga $2 \square$ Carga 3

Figura 4.15 Comparações entre LTE, com os três diferentes níveis de carga.

Do ponto de vista de desempenho estrutural dos pavimentos da pista experimental USP/FAPESP em São Paulo, considerando os limites tomados pelo FHWA (1990), as placas de concreto encontram-se todas em boas condições, exceto no que tange à junta E3 no período da manhã. Dado que não existe tráfego de veículos comerciais no local, nem mesmo são observados escalonamentos após quase dez anos de construção das placas de concreto simples, as condições observadas no presente estudo refletem, com segurança, as condições construtivas. Portanto, entende-se que juntas sem barras de transferência de carga, nos períodos matutinos e noturnos, não apresentam condições estruturais adequadas para rodovias, devendo ser evitadas a qualquer custo dessa forma. 


\subsection{LTE medido versus LTE retroanalisado}

Na Tabela 4.18 são apresentados valores de LTE retroanalisados e os medidos em campo, tanto no inverno quanto no verão.

Tabela 4.18 - Resumo de valores de LTE retroanalisados e medidos em campo.

\begin{tabular}{|c|c|c|c|c|c|c|c|c|c|c|}
\hline \multirow{3}{*}{ Seção } & \multirow{3}{*}{ Posição } & \multirow{3}{*}{$\begin{array}{c}\text { Carga } \\
(\mathrm{kN})\end{array}$} & \multicolumn{4}{|c|}{ LTE RETROANALISADOS (\%) } & \multicolumn{4}{|c|}{ LTE MEDIDOS EM CAMPO (\%) } \\
\hline & & & \multicolumn{2}{|c|}{ Inverno } & \multicolumn{2}{|c|}{ Verão } & \multicolumn{2}{|c|}{ Inverno } & \multicolumn{2}{|c|}{ Verão } \\
\hline & & & Manhã & Tarde & Tarde & Noite & Manhã & Tarde & Tarde & Noite \\
\hline \multirow{6}{*}{ A } & \multirow{4}{*}{2} & 47 & 99 & 96 & 95 & 94 & 95,5 & 93,0 & 95,5 & 93,0 \\
\hline & & 74 & 99 & 99 & 95 & 94 & 95,5 & 93,0 & 95,5 & 92,5 \\
\hline & & 83 & 99 & 97 & 95 & 95 & 96,0 & 92,5 & 96,0 & 92,0 \\
\hline & & 47 & 96 & 96 & 96 & 97 & 93,0 & 91,5 & 93,0 & 91,5 \\
\hline & \multirow[t]{3}{*}{16} & 74 & 92 & 95 & 98 & 96 & 93,0 & 92,0 & 93,0 & 92,0 \\
\hline & & 83 & 94 & 94 & 92 & 93 & 93,5 & 92,0 & 93,5 & 92,0 \\
\hline \multirow{6}{*}{ B } & & 47 & 96 & 89 & 93 & 93 & 94,0 & 88,5 & 94,0 & 88,5 \\
\hline & \multirow[t]{3}{*}{5} & 74 & 96 & 94 & 94 & 93 & 93,5 & 87,0 & 93,5 & 87,0 \\
\hline & & 83 & 98 & 94 & 93 & 93 & 92,0 & 87,0 & 92,0 & 87,0 \\
\hline & & 47 & 99 & 96 & 94 & 96 & 100,0 & 91,0 & 100,0 & 91,0 \\
\hline & \multirow[t]{3}{*}{17} & 74 & 99 & 91 & 91 & 98 & 99,0 & 89,5 & 99,0 & 89,5 \\
\hline & & 83 & 99 & 91 & 89 & 93 & 99,0 & 89,0 & 99,0 & 89,0 \\
\hline \multirow{6}{*}{ C } & & 47 & 95 & 95 & 95 & 93 & 94,0 & 91,0 & 94,0 & 91,0 \\
\hline & \multirow[t]{3}{*}{8} & 74 & 98 & 94 & 95 & 96 & 97,0 & 89,5 & 97,0 & 89,5 \\
\hline & & 83 & 97 & 94 & 95 & 94 & 94,0 & 90,0 & 94,0 & 90,0 \\
\hline & & 47 & 91 & 95 & 87 & 88 & 91,5 & 92,5 & 91,5 & 92,5 \\
\hline & \multirow[t]{3}{*}{19} & 74 & 91 & 91 & 86 & 88 & 90,5 & 90,5 & 90,5 & 90,5 \\
\hline & & 83 & 90 & 89 & - & 87 & 90,5 & 88,0 & 90,5 & 88,0 \\
\hline \multirow{6}{*}{ D } & & 47 & 94 & 93 & 93 & 90 & 94,0 & 89,0 & 94,0 & 89,0 \\
\hline & \multirow[t]{3}{*}{11} & 74 & 94 & 95 & 92 & 91 & 91,5 & 88,0 & 91,5 & 88,0 \\
\hline & & 83 & 95 & 94 & 94 & 92 & 90,5 & 89,0 & 90,5 & 89,0 \\
\hline & & 47 & 95 & 94 & 94 & 90 & 92,0 & 91,0 & 92,0 & 91,0 \\
\hline & \multirow[t]{3}{*}{21} & 74 & 93 & 92 & 94 & 90 & 91,0 & 89,0 & 91,0 & 89,0 \\
\hline & & 83 & 91 & 90 & 88 & 87 & 91,0 & 90,0 & 91,0 & 90,0 \\
\hline \multirow{6}{*}{$E$} & & 47 & 97 & 97 & 95 & 97 & 95,0 & 92,0 & 95,0 & 92,0 \\
\hline & \multirow[t]{3}{*}{14} & 74 & 97 & 97 & 92 & 99 & 94,0 & 92,5 & 94,0 & 92,5 \\
\hline & & 83 & 99 & 97 & 94 & 98 & 95,0 & 92,5 & 95,0 & 92,5 \\
\hline & & 47 & 55 & 74 & 64 & 58 & 60,0 & 76,5 & 60,0 & 76,5 \\
\hline & \multirow[t]{2}{*}{23} & 74 & 53 & 71 & 62 & 60 & 62,5 & 74,0 & 62,5 & 74,0 \\
\hline & & 83 & 49 & 70 & 71 & 58 & 62,5 & 72,5 & 62,5 & 72,5 \\
\hline
\end{tabular}

Observa-se dos resultados que os valores de LTE em juntas com BT variaram de 88 a $100 \%$, enquanto que os obtidos em juntas sem BT variaram de 60 a $75 \%$. Na Figura 4.16 tais dados são lançados um em função do outro, o que permite comparar qualitativamente as discrepâncias entre valores de LTE medidos e retroanalisados. Verifica-se que, para valores baixos de LTE $(<80 \%)$, casos sem BT, os valores de 
LTE medidos são em geral superiores àqueles calculados. De forma diferente, no caso de LTE em juntas com BT, os valores retroanalisados são em sua maioria superiores àqueles calculados.

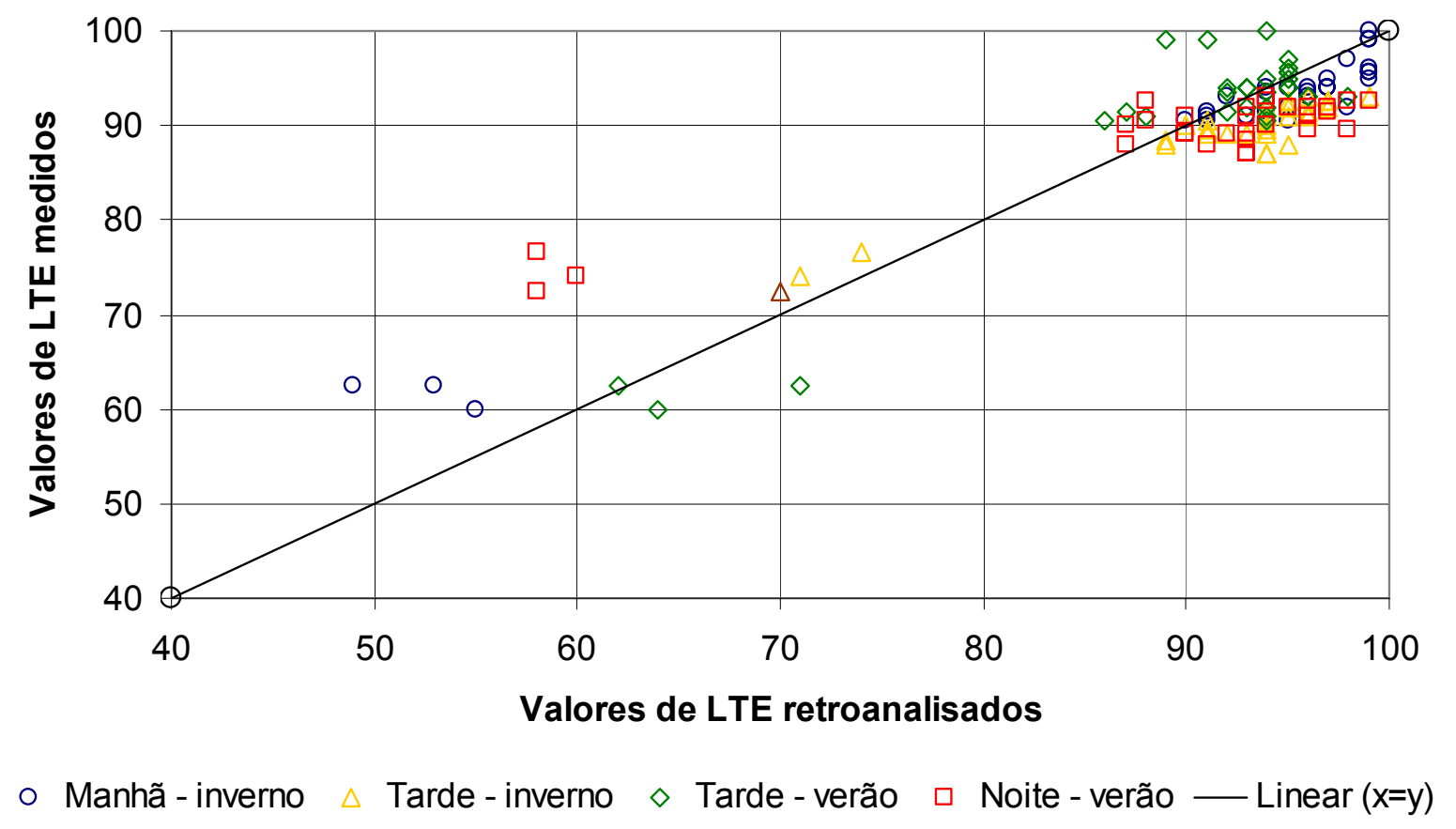

Figura 4.16 Comparação entre LTE medido e retroanalisado em juntas com BT.

Com base nas médias de valores de LTE retroanalisado e medido em campo em juntas com BT, conforme apresenta a Tabela 4.19 e ilustra a Figura 4.17, verifica-se claramente que os valores de LTE retroanalisados são em geral mais altos do que os valores medidos em campo, em juntas com BT.

Tabela 4.19 - Média dos valores de LTE retroanalisados e medidos em campo, em juntas com BT.

\begin{tabular}{c|cccccccc}
\hline & \multicolumn{3}{|c}{ LTE RETROANALISADOS (\%) } & \multicolumn{2}{c}{ LTE MEDIDOS EM CAMPO (\%) } \\
\hline \multirow{3}{*}{ Média } & \multicolumn{2}{|c}{ Inverno } & \multicolumn{2}{c}{ Verão } & \multicolumn{2}{c}{ Inverno } & \multicolumn{2}{c}{ Verão } \\
Sanhã & Tarde & Tarde & Noite & Manhã & Tarde & Tarde & Noite \\
cv & 95,7 & 94,0 & 93,0 & 93,1 & 93,9 & 90,4 & 93,9 & 90,4 \\
& 2,9 & 2,6 & 2,8 & 3,4 & 2,7 & 1,9 & 2,7 & 1,8 \\
& 3,1 & 2,8 & 3,0 & 3,7 & 2,8 & 2,0 & 2,8 & 2,0 \\
\hline
\end{tabular}




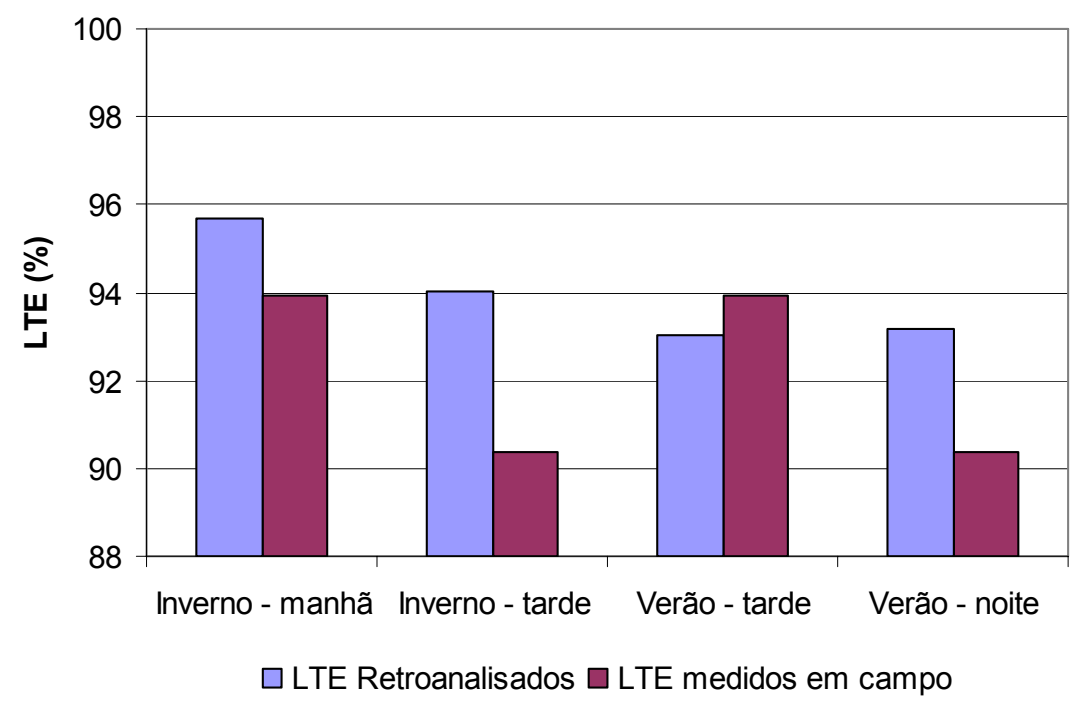

Figura 4.17 Comparação entre LTE medido e retroanalisado em juntas com BT.

Calculando-se a média, desvio padrão e coeficiente de variação de dados de LTE retroanalisado e medido em campo em juntas sem BT, de acordo com a Tabela 4.20, e ilustrando-os na Figura 4.15, verifica-se o contrário: valores de LTE medidos em campo são em geral maiores do que os retroanalisados pelo ISLAB2000. Notase também que a discrepância entre os valores de LTE retroanalisados e medidos aumenta nos períodos em que a abertura da junta era maior: na manhã e na noite. Assim, o programa ISLAB2000 simula condições mais críticas de transferência de carga (mais baixos valores de LTE) para mesmas medidas de deflexões em campo e teoricamente definidas. Este resultado corrobora com resultados apresentados por Rodolfo (2001) que indicaram maiores tensões calculadas pelo programa que aquelas determinadas com medidas de deformações em pista; ou seja, o modelo numérico do ILSAB2000, nessas condições, apresenta resultados a favor da segurança para fins de projeto.

Tabela 4.20 - Média dos valores de LTE retroanalisados e medidos em campo em juntas sem BT.

\begin{tabular}{|c|c|c|c|c|c|c|c|c|}
\hline & \multicolumn{4}{|c|}{ LTE RETROANALISADOS (\%) } & \multicolumn{4}{|c|}{ LTE MEDIDOS EM CAMPO (\%) } \\
\hline & \multicolumn{2}{|c|}{ Inverno } & \multicolumn{2}{|c|}{ Verão } & \multicolumn{2}{|c|}{ Inverno } & \multicolumn{2}{|c|}{ Verão } \\
\hline & Manhã & Tarde & Tarde & Noite & Manhã & Tarde & Tarde & Noite \\
\hline Média & 52,3 & 71,7 & 65,7 & 58,7 & 61,7 & 74,3 & 61,7 & 74,3 \\
\hline $\mathrm{s}$ & 3,1 & 2,1 & 4,7 & 1,2 & 1,4 & 2,0 & 1,4 & 2,0 \\
\hline $\mathrm{cv}$ & 5,8 & 2,9 & 7,2 & 2,0 & 2,3 & 2,7 & 2,3 & 2,7 \\
\hline
\end{tabular}




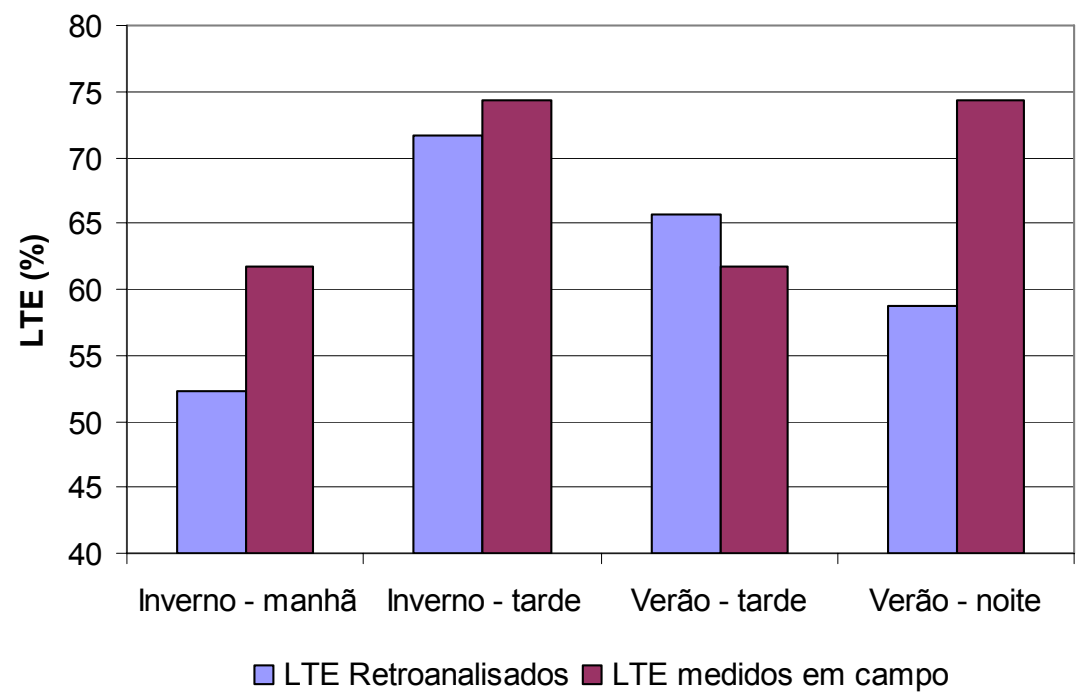

Figura 4.18 Comparação entre LTE medido e retroanalisado em juntas sem BT.

As médias de valores de LTE retroanalisados e medidos em campo são muito próximas, o que não permite uma diferenciação dos resultados. Inclusive os resultados apresentam valores de desvio padrão e de coeficiente de variação muito baixos, em especial para as juntas com BT (o desvio padrão máximo observado foi de $3,4 \%$, bastante positivo para medidas efetuadas em campo), o que permite boa confiabilidade nos resultados obtidos por meio da metodologia de pesquisa empregada. Tais resultados estão provavelmente atrelados à grande homogeneidade de construção da pista experimental. Os valores aqui obtidos são inferiores àqueles sugeridos por Khazanovich e Gotlif (2003) - coeficiente de variação em torno de $10 \%$ para juntas com BT e de $40 \%$ para juntas sem BT -; pesese aqui o fato de que aquela pesquisa foi muito mais ampla e contemplou pavimentos de diferentes idades, estruturas e condições dos concretos em geral.

Como evidenciaram Colley e Humphrey (1966) a transferência de cargas em juntas sem BT são extremamente dependentes da abertura da junta; esta abertura depende essencialmente da temperatura média do concreto. Em períodos mais frios, com a contração do concreto, as juntas se abrem, causando a queda no valor de LTE, o que foi visível no presente estudo. 


\subsection{Análise dos Valores de Módulo de Elasticidade do Concreto}

Segundo Severi (2002), o concreto empregado na construção das placas da Pista Experimental EPUSP foi dosado para atingir um módulo de ruptura à flexão de 4,5 $\mathrm{MPa}$ aos 28 dias. As proporções de materiais empregados para a confecção dos concretos pela empresa fornecedora na época da construção da pista experimental são apresentadas na Tabela 4.21, de onde se extrai que não ocorreram, de fato, alterações nas misturas que pudessem interferir com clareza diferenciando suas propriedades após endurecimento. No caso do CCR empregado nas seções B e D, executado em uma mesma data, as proporções de materiais são apresentadas na Tabela 4.22.

Tabela 4.21 Dosagem do concreto de cimento Portland da pista experimental.

\begin{tabular}{|c|c|c|c|c|c|c|c|}
\hline Seção & $\begin{array}{c}\text { Data de } \\
\text { execução }\end{array}$ & $\begin{array}{c}\text { Cimento } \\
\left(\mathrm{kg} / \mathrm{m}^{3}\right)\end{array}$ & $\begin{array}{c}\text { Areia } \\
\left(\mathrm{kg} / \mathrm{m}^{3}\right)\end{array}$ & $\begin{array}{l}\text { Brita } 1 \\
\left(\mathrm{~kg} / \mathrm{m}^{3}\right)\end{array}$ & $\begin{array}{l}\text { Brita } 2 \\
\left(\mathrm{~kg} / \mathrm{m}^{3}\right)\end{array}$ & $\begin{array}{l}\text { Água } \\
\left(I / m^{3}\right)\end{array}$ & $\begin{array}{c}\text { Plastificante } \\
\left(1 / \mathrm{m}^{3}\right)\end{array}$ \\
\hline$E$ & 21/07/1999 & 383 & 638 & 486 & 729 & 174 & 1,341 \\
\hline$A$ & 30/07/1999 & 383 & 638 & 486 & 729 & 174 & 1,341 \\
\hline$B$ & 17/09/1999 & 396 & 620 & 483 & 724 & 180 & 1,388 \\
\hline C & 29/09/1999 & 396 & 620 & 483 & 724 & 180 & 1,388 \\
\hline$D$ & 12/08/1999 & 396 & 620 & 483 & 724 & 180 & 1,388 \\
\hline
\end{tabular}

Tabela 4.22 Dosagem do CCR da pista experimental.

\begin{tabular}{cccccc}
\hline $\begin{array}{c}\text { Cimento } \\
\left(\mathrm{kg} / \mathrm{m}^{3}\right)\end{array}$ & $\begin{array}{c}\text { Areia } \\
\left(\mathrm{kg} / \mathrm{m}^{3}\right)\end{array}$ & $\begin{array}{c}\text { Pedrisco Misto } \\
\left(\mathrm{kg} / \mathrm{m}^{3}\right)\end{array}$ & $\begin{array}{c}\text { Brita 1 } \\
\left(\mathrm{kg} / \mathrm{m}^{3}\right)\end{array}$ & $\begin{array}{c}\text { Brita 2 } \\
\left(\mathrm{kg} / \mathrm{m}^{3}\right)\end{array}$ & $\begin{array}{c}\text { Água } \\
\left(\mathbf{l} / \mathrm{m}^{3}\right)\end{array}$ \\
\hline 150 & 484 & 486 & 390 & 586 & 138 \\
\hline
\end{tabular}

Foram realizados diversos ensaios, dentre eles, testes para determinação do módulo de elasticidade secante em tração e em compressão; tais ensaios individuais são importantes para análise dos valores obtidos no presente estudo para módulos de elasticidade retroanalisados. Os resultados de ensaios de módulo de elasticidade em tração na flexão do CCP estão apresentados na Tabela 4.23. Na Tabela 4.24 são apresentados valores de módulo de elasticidade do CCR empregado na base das seções $B$ e $C$ da pista experimental. 
Tabela 4.23 Módulo de elasticidade em tração na flexão do CCP na pista experimental.

\begin{tabular}{|c|c|c|}
\hline Seção & Corpos de Prova & $\mathrm{E}(\mathrm{MPa})$ \\
\hline \multirow{8}{*}{$\frac{\text { A }}{\text { (ensaios aos } 27 \text { dias) }}$} & CP A1a & 24.997 \\
\hline & CP A1b & 23.381 \\
\hline & $\mathrm{CP} A 2 \mathrm{a}$ & 17.510 \\
\hline & $\mathrm{CP} A 2 \mathrm{~b}$ & 20.720 \\
\hline & Média (MPa) & 23.033 \\
\hline & Desvio Padrão (MPa) & 2.160 \\
\hline & Coeficiente de Variação (\%) & $10,66 \%$ \\
\hline & CP B1 & 41.750 \\
\hline \multirow{5}{*}{$\begin{array}{c}\text { B } \\
\text { (ensaios aos } 68 \text { dias) }\end{array}$} & CP B2 & 57.473 \\
\hline & CP B3 & 43.331 \\
\hline & Média (MPa) & 42.541 \\
\hline & Desvio Padrão (MPa) & 791 \\
\hline & Coeficiente de Variação (\%) & $53,81 \%$ \\
\hline \multirow{7}{*}{$\begin{array}{c}\text { C } \\
\text { (ensaios aos } 55 \text { dias) }\end{array}$} & $\mathrm{CP} \mathrm{C} 1$ & 28.536 \\
\hline & $\mathrm{CP}$ C2 & 23.239 \\
\hline & CP C3 & 44.221 \\
\hline & CP C4 & 58.346 \\
\hline & Média (MPa) & 31.999 \\
\hline & Desvio Padrão (MPa) & 10.911 \\
\hline & Coeficiente de Variação (\%) & $2,93 \%$ \\
\hline \multirow{9}{*}{$\begin{array}{c}\text { D } \\
\text { (ensaios aos } 27 \text { dias) }\end{array}$} & CP D1a & 17.095 \\
\hline & CP D1b & 16.264 \\
\hline & CP D2a & 19.799 \\
\hline & CP D2b & 17.164 \\
\hline & CP D3a & 24.192 \\
\hline & CP D3b & 14.618 \\
\hline & Média (MPa) & 18.903 \\
\hline & Desvio Padrão (MPa) & 3.242 \\
\hline & Coeficiente de Variação (\%) & $5,83 \%$ \\
\hline \multirow{9}{*}{$\frac{\text { E }}{\text { (ensaios aos } 28 \text { dias) }}$} & $\mathrm{CP} \mathrm{E} 1 \mathrm{a}$ & 24.538 \\
\hline & CP E1b & 25.460 \\
\hline & CP E2a & 34.439 \\
\hline & CP E2b & 25.029 \\
\hline & CP E3a & 26.957 \\
\hline & CP E3b & 26.821 \\
\hline & Média (MPa) & 25.761 \\
\hline & Desvio Padrão (MPa) & 1.081 \\
\hline & Coeficiente de Variação (\%) & $23,83 \%$ \\
\hline
\end{tabular}

Tabela 4.24 Módulo de elasticidade em compressão de amostras aos 28 dias do CCR empregado na pista experimental.

\begin{tabular}{cc}
\hline Corpos de Prova & Módulo Secante (MPa) \\
\hline CP 1 & 25.650 \\
CP 2 & 26.410 \\
CP 3 & 25.000 \\
Média (MPa) & 25.687 \\
Desvio Padrão (MPa) & 706 \\
Coeficiente de Variação (\%) & 2,75 \\
\hline
\end{tabular}


$\mathrm{Na}$ Tabela 4.25 são apresentados os valores individuais obtidos em laboratório (à época da construção da pista experimental) para módulos de elasticidade bem como aqueles valores obtidos por retroanálises no presente estudo.

Tabela 4.25 Valores de módulos de elasticidade obtidos em laboratório.

\begin{tabular}{|c|c|c|}
\hline Seção & E laboratório (MPa) & E retroanalisado (MPa) \\
\hline \multirow{6}{*}{ A } & 24.997 & 55.150 \\
\hline & 23.381 & 74.150 \\
\hline & 17.510 & 73.800 \\
\hline & 20.720 & 57.050 \\
\hline & - & 57.250 \\
\hline & - & 51.350 \\
\hline \multirow{7}{*}{ B } & 41.750 & 45.850 \\
\hline & 57.473 & 59.550 \\
\hline & 43.331 & 27.700 \\
\hline & - & 87.200 \\
\hline & - & 21.000 \\
\hline & - & 35.000 \\
\hline & - & 40.050 \\
\hline \multirow{9}{*}{ C } & 28.536 & 51.800 \\
\hline & 23.239 & 53.900 \\
\hline & 44.221 & 54.500 \\
\hline & 58.346 & 72.350 \\
\hline & - & 60.000 \\
\hline & - & 62.300 \\
\hline & - & 41.000 \\
\hline & - & 37.000 \\
\hline & - & 34.200 \\
\hline \multirow{6}{*}{ D } & 17.095 & 52.300 \\
\hline & 16.264 & 39.850 \\
\hline & 19.799 & 39.950 \\
\hline & 17.164 & 33.400 \\
\hline & 24.192 & 61.100 \\
\hline & 14.618 & 45.250 \\
\hline \multirow{9}{*}{$\mathbf{E}$} & 24.538 & 37.500 \\
\hline & 25.460 & 33.850 \\
\hline & 34.439 & 29.750 \\
\hline & 25.029 & 26.550 \\
\hline & 26.957 & 34.950 \\
\hline & 26.821 & 30.150 \\
\hline & - & 58.850 \\
\hline & - & 57.550 \\
\hline & - & 65.400 \\
\hline
\end{tabular}


Em laboratório os valores resultaram por vezes baixos como, por exemplo, em torno de 17.000 MPa ou elevados, como em torno de 58.000 MPa. Em geral, os valores atualmente retroanalisados apresentam-se superiores aos valores medidos em laboratório de um a dois meses após a construção da pista experimental. Como os valores de módulo de elasticidade em concretos convencionais guardam relação com a resistência do concreto, e considerando o elevado consumo de cimento de cerca de $400 \mathrm{~kg} / \mathrm{m}^{3}$, é bastante palpável que sete anos após a construção das placas a resistência do concreto seja superior à resistência medida em laboratório aos 28 dias que estava entre 4,5 e 5,5 MPa (em tração na flexão). Esta pode ser uma das razões pela quais os valores de módulo de elasticidade do concreto atuais sejam superiores àqueles medidos em 1999.

$\mathrm{Na}$ Tabela 4.26 são apresentados os valores de módulos de elasticidade retroanalisados do CCR, encontrados no presente estudo. O valor médio para o módulo de elasticidade do CCR avaliado com apenas três amostras do material em 1999 resultou em 25.687 MPa, enquanto que o valor médio do módulo de elasticidade retroanalisado do CCR, adicionado de seu desvio padrão, foi de 24.203 $\mathrm{MPa}$. Isto demonstra uma boa aproximação entre os valores de laboratório e de campo.

Tabela 4.26 Módulos de elasticidade retroanalisados para o CCR.

\begin{tabular}{c|cc}
\hline Seção & Carga & $E(M P a)$ \\
B1 - 5 & 1 & 22.100 \\
& 3 & 20.450 \\
\hline \multirow{2}{*}{ B2 - 8} & 2 & 26.900 \\
& 3 & 27.900 \\
\hline \multirow{2}{*}{ B3 - 24 } & 1 & 22.450 \\
& 2 & 20.500 \\
\hline \multirow{2}{*}{ C1 - 9 } & 3 & 19.900 \\
\hline \multirow{2}{*}{ C2 - 12 } & 1 & 21.850 \\
& 3 & 19.800 \\
& 2 & 18.400 \\
\hline \multirow{2}{*}{ C3 - 27 } & 3 & 22.450 \\
& 2 & 19.600 \\
\multicolumn{2}{c}{ Média (MPa) } & 22.500 \\
\hline \multicolumn{2}{c}{ Desvio Padrão (MPa) } & 21.550 \\
Coeficiente de Variação (\%) & 20.000 \\
\hline
\end{tabular}




\subsection{Análise dos Valores de Módulo de Reação de Subleito $\left(k_{b}\right)$ na Borda e no Centro da Placa (k)}

$\mathrm{Na}$ Tabela 4.27 são apresentados conjuntamente os resultados de módulo de reação do subleito para cargas aplicadas no centro e na borda transversal das placas de concreto. A partir desses valores bem como das constatações já discutidas no item 4.3, foi consolidada a Tabela 4.28 onde são apresentados os limites mínimos e máximos arredondados para valores de k de centro e de borda.

Tabela 4.27 Resultados de retroanálises de módulo de reação do subleito no centro da placa e na borda, em todos os testes realizados.

\begin{tabular}{|c|c|c|c|c|c|c|}
\hline \multirow{3}{*}{ Seção } & \multirow{3}{*}{ Posição } & \multirow{3}{*}{$\begin{array}{l}\text { Módulo de Reação do } \\
\text { Subleito no Centro da } \\
\text { Placa (MPa/m) }\end{array}$} & \multicolumn{4}{|c|}{ Módulo de Reação do Subleito na borda (MPa/m) } \\
\hline & & & \multicolumn{2}{|c|}{ Inverno / 2006} & \multicolumn{2}{|c|}{ Verão / 2007} \\
\hline & & & Manhã & Tarde & Tarde & Noite \\
\hline \multirow{6}{*}{$A$} & \multirow{4}{*}{2} & 55 & 45 & 54 & 37 & 33 \\
\hline & & 50 & 40 & 51 & 31 & 29 \\
\hline & & 50 & 40 & 52 & 32 & 37 \\
\hline & & 45 & 38 & 41 & 39 & 40 \\
\hline & \multirow[t]{3}{*}{16} & 45 & 37 & 39 & 39 & 40 \\
\hline & & 50 & 39 & 39 & 42 & 43 \\
\hline \multirow{6}{*}{ B } & & 75 & 75 & 104 & 140 & 129 \\
\hline & \multirow[t]{3}{*}{5} & - & 80 & 107 & 144 & 129 \\
\hline & & 80 & 84 & 110 & 137 & 127 \\
\hline & & 90 & 69 & 170 & 152 & 111 \\
\hline & \multirow[t]{3}{*}{17} & 90 & 82 & 159 & 141 & 115 \\
\hline & & 90 & 87 & 165 & 160 & 124 \\
\hline \multirow{7}{*}{ C } & & 60 & 66 & 83 & 101 & 81 \\
\hline & \multirow[t]{3}{*}{8} & 60 & 63 & 80 & 93 & 92 \\
\hline & & 60 & 31 & 79 & 89 & 74 \\
\hline & & 60 & 86 & 107 & 127 & 86 \\
\hline & \multirow[t]{3}{*}{19} & 65 & 91 & 123 & 124 & 90 \\
\hline & & 70 & 97 & 135 & - & 96 \\
\hline & & 45 & 70 & 64 & 71 & 77 \\
\hline \multirow{5}{*}{ D } & \multirow[t]{3}{*}{11} & 55 & 76 & 63 & 81 & 84 \\
\hline & & 55 & 76 & 76 & 82 & 84 \\
\hline & & 60 & 84 & 76 & 88 & 96 \\
\hline & \multirow[t]{3}{*}{21} & 40 & 85 & 78 & 61 & 70 \\
\hline & & 55 & 87 & 69 & 75 & 86 \\
\hline \multirow{6}{*}{$E$} & & 65 & 78 & 78 & 68 & 94 \\
\hline & \multirow[t]{3}{*}{14} & 70 & 75 & 76 & 67 & 92 \\
\hline & & 75 & 75 & 77 & 72 & 90 \\
\hline & & 60 & 62 & 62 & 60 & 72 \\
\hline & \multirow[t]{2}{*}{23} & 60 & 65 & 65 & 61 & 70 \\
\hline & & 60 & 66 & 67 & 68 & 74 \\
\hline
\end{tabular}


Muitos estudos no passado revelaram que o valor do módulo de reação do subleito em juntas de placas de concreto simples é maior que o valor do módulo de reação do subleito no centro da placa. Por exemplo, o primeiro deles (SPANGLER, 1942) indicou resultado de $180 \mathrm{MPa} / \mathrm{m}$ para borda contra $14 \mathrm{MPa} / \mathrm{m}$ para o centro de uma mesma placa. No presente estudo, os valores retroanalisados, comparadas suas faixas de variação, indicam valores superiores de módulo de reação do subleito nas bordas em comparação com os centros de placas.

Tabela 4.28 Limites mínimos e máximos arredondados de $\mathrm{k}$ de centro e de borda

\begin{tabular}{c|cc}
\hline Seção & $\begin{array}{c}\text { Faixa de Variação do Módulo de Reação do } \\
\text { Subleito na Borda da Placa (MPa/m) }\end{array}$ & $\begin{array}{c}\text { Faixa de Variação do Módulo de Reação } \\
\text { do Subleito no Centro da Placa (MPa/m) }\end{array}$ \\
\hline A & de 30 a 55 & de 40 a 50 \\
B & de 80 a 170 & de 60 a 125 \\
C & de 60 a 90 & de 40 a 60 \\
D & de 70 a 90 & de 60 a 75 \\
E c/ BT & De 60 a 75 & E s/ BT
\end{tabular}

As medidas de $\mathrm{k}_{\mathrm{b}}$ também indicam que no caso de pavimentos sobre bases rígidas (CCR) ocorre maior reação nas juntas que nas juntas de placas sobre bases granulares. Isto novamente vem a reforçar a idéia de que o módulo de reação do subleito não se trata de uma propriedade intrínseca do subleito, e sim um parâmetro relacionado à capacidade estrutural total do pavimento de concreto.

Comparando-se valores retroanalisados de $k_{b}$ com a eficiência de transferência de carga nas juntas com BT, obtida pela eq. 2.5, e lançados estes dados na Figura 4.16, observa-se que, no inverno, os valores de $k_{b}$ retroanalisados para o período da manhã são mais agrupados e menores do que aqueles para o período da tarde, onde há maior dispersão dos pontos. De acordo com Zollinger (2007), quanto menor a valor de $k_{b}$ maior a abertura da junta, e este fenômeno é também explicado na literatura: a abertura das juntas é maior no período mais frio.

Ainda na Figura 4.19, para as medidas de verão, confrontando os dados para medidas efetuadas à tarde e na noite, nota-se um decréscimo nos valores de $k_{b}$ durante a noite, por comparação, pois de fato a temperatura do pavimento está caindo e as juntas estão se abrindo, diminuindo assim a reação da fundação a 
forças aplicadas no pavimento de concreto simples. Assim, tem-se em cascata pelos resultados obtidos:

- Valores de k de borda são maiores nos períodos mais quentes;

- Nos períodos mais quentes as juntas estão mais fechadas devido à expansão do concreto;

- Nesses períodos mais quentes o k de borda aumentou pois, estando as faces das placas (nas juntas) mais encostadas e comprimidas entre si, a reação da estrutura como um todo à ação da carga aumentou;

- Conforme mencionado anteriormente, valores de $\mathrm{k}$ de centro de placa e de borda não podem ser considerados idênticos, com base em resultados experimentais em pista (SPANGLER, 1942; além dos resultados no presente estudo);

- O módulo de reação do subleito, nessas condições, não parece ser um parâmetro relacionado exclusivamente à reação da fundação, pois, na pista experimental da USP, ela é muito homogênea.

De tal forma, que no presente trabalho, os resultados aderiram bastante à seguinte afirmação de loannides (1999): "O módulo de reação do subleito não é uma propriedade intrínseca do solo."

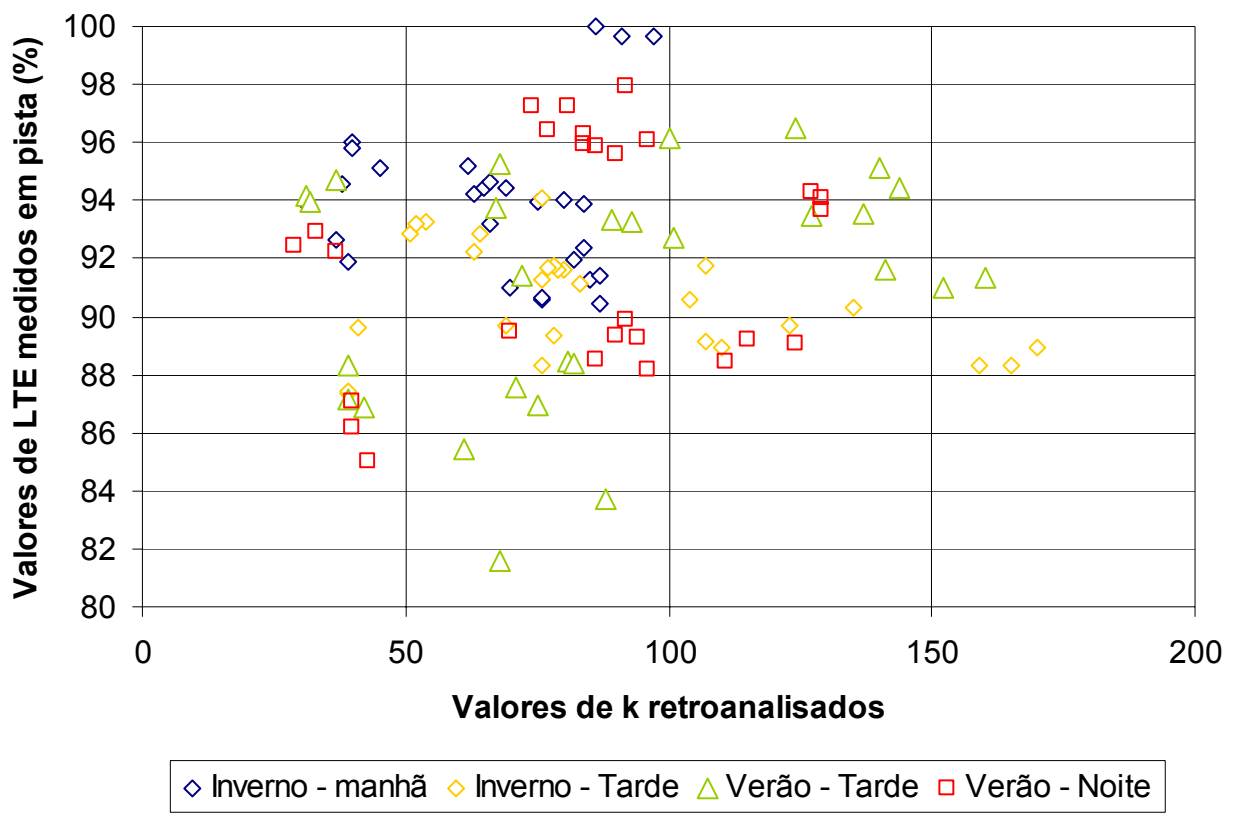

Figura 4.19 Valores de $\mathrm{k}_{\text {borda }}$ retroanalisado versus $\mathrm{LTE}_{\text {medido. }}$ 
Na Figura 4.10 são apresentados os valores confrontados, para as seções C, D e E, quando não se suspeitou de nenhuma operação falha com FWD, de módulos de reação do sistema de apoio para cargas de centro e cargas de borda. Na seção $\mathrm{C}$ o aumento de $\mathrm{k}$ de borda em relação ao $\mathrm{k}$ de centro foi de 17 a 30\%; na seção $\mathrm{D}$ de 38 a 56\%; na seção $\mathrm{E}$ de 0 a $44 \%$. Tal fato leva a crer que o emprego de um valor de $\mathrm{k}$ apenas para toda a fundação sob a placa, para a posição mais central de carga sobre a placa, é um procedimento de segurança de projeto; ao contrário, para cargas de canto ou borda em placas sem barras de transferência poderia ser empregado valor de $\mathrm{k}$ de borda, cujo conceito não é apreciado nos métodos de projeto vigentes.

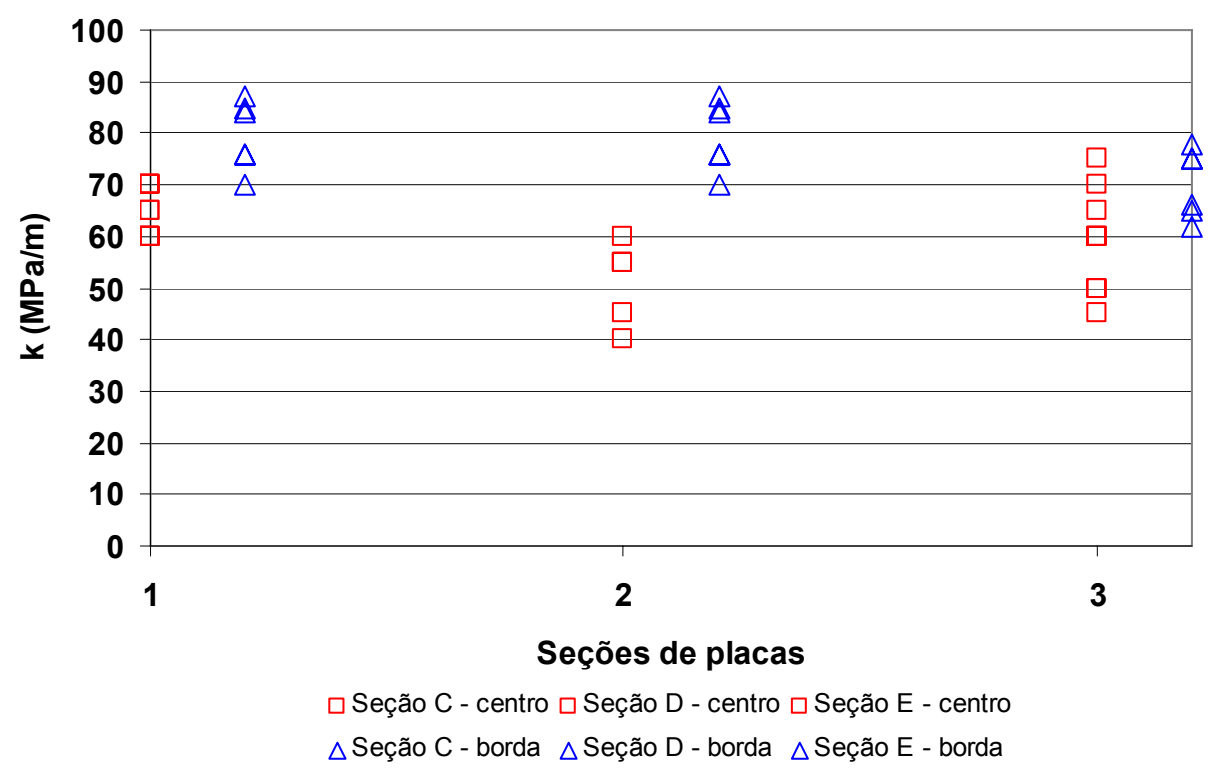

Figura 4.17 Valores de $k_{\text {borda }}$ versus $k_{\text {centro. }}$ 


\section{CONCLUSÕES E RECOMENDAÇÕES}

A transferência de cargas em juntas de pavimentos de concreto simples é um fenômeno complexo e envolve diversos fatores condicionantes como as características geométricas e estruturais das placas de concreto, os tipos de dispositivos de transferência de cargas e da temperatura do concreto que o faz expandir ou contrair, diminuindo ou aumentando a abertura das juntas serradas.

No presente estudo buscou-se avaliar a eficiência de transferência de carga nas juntas de pavimentos de concreto simples da Pista Experimental da USP/FAPESP, localizada em São Paulo no campus da USP na Cidade Universitária, que possui juntas com barras de transferência de cargas e sem esse dispositivo. As placas possuem subleito muito homogêneo e estão assentes sobre bases granulares ou de concreto compactado com rolo.

As determinações de parâmetros de transferência de carga (LTE - load transfer efficiency) foram possíveis com base em medidas de deflexões obtidas com falling weight deflectometer bem como por retroanálise de bacias de deformações empregando-se o programa computacional ISLAB2000.

Os estudos permitiram ainda parametrizar os pavimentos existentes no que tange 0 módulo de elasticidade de suas camadas rígidas e o módulo de reação do subleito na área do experimento. Com base nos resultados obtidos e análises realizadas, os estudos permitiram concluir que:

Quanto às respostas estruturais das placas de concreto da Pista Experimental

- Os valores de módulo de reação do subleito medidos nas bordas (juntas transversais) de placas são maiores que aqueles medidos nos centros das placas;

- O módulo de reação do subleito retroanalisado encontrado no centro das placas de concreto variou entre 30 e $60 \mathrm{MPa} / \mathrm{m}$ para pavimentos com bases granulares (BGS); 
- Para placas sobre bases de CCR, esta camada interferiu na resposta da fundação, alterando para maiores valores de módulo de reação do subleito. Isto deixa claro que o módulo de reação do subleito não se trata de uma propriedade exclusiva do solo de fundação, recebendo interferências das camadas de base;

- Nas retroanálises, os valores de módulo de reação do subleito no centro da placa nas seções $\mathrm{B}$ e $\mathrm{C}$, cuja base é concreto compactado com rolo, variaram entre 60 e $125 \mathrm{MPa} / \mathrm{m}$; isto esclarece como tal parâmetro depende não apenas da fundação (que é homogênea) mas da esrutura dos pavimentos como um todo;

- Nas seções das placas B e C, onde a base é concreto compactado com rolo, os valores retroanalisados de módulo de reação do subleito na borda aumentaram expressivamente nos períodos mais quentes quando comparados a períodos mais frios;

- Os valores de módulo de elasticidade do concreto em geral variaram entre 26.500 e $58.850 \mathrm{MPa}$; houve casos em que as retroanálises não levaram a resultados reais possivelmente por falhas nos testes em pista com FWD;

- Os valores de módulo de elasticidade do CCR em geral variaram entre 19.600 e 27.900 MPa, resultados estes muito semelhantes com aqueles verificados em laboratório anteriormente para a pista experimental.

\section{Quanto ao LTE especificamente}

- Quando se aplica a carga próxima à junta, as deflexões são menores no período mais quente se comparadas àquelas medidas em um período mais fresco; isso é devido à expansão e à contração do concreto ao longo das horas. A expansão causa o fechamento das juntas, reduzindo as deflexões medidas.

- Os valores retroanalisados de LTE em juntas com BT variaram em geral entre 86 e 99\%; tais valores são considerados bastante satisfatórios com base na literatura técnica estudada;

- Já em juntas sem BT, os valores retroanalisados de LTE variaram entre 50 e $75 \%$, sendo os menores valores encontrados para testes realizados no 
período mais frio; a razão desse fato é a contração do concreto e a abertura das juntas em tais condições;

- Em medidas diretas de LTE realizadas no verão, no caso de juntas sem BT, com o incremento de carga, aumenta-se a transferência de carga na junta;

- Ainda em medidas diretas realizadas no inverno em juntas com BT, não houve variações significativas entre medidas de manhã e à tarde; já em juntas sem BT, o LTE aumentou em cerca de $20 \%$ com o aumento da temperatura;

- Em valores de LTE medidos no inverno em juntas com BT, nota-se um acréscimo destes em função do tipo de base e sua espessura: em placas delgadas, a LTE é maior sobre base granular; em placas espessas, a LTE é maior sobre base rígida; contudo, as alterações devem ser consideradas de pequena monta nesses casos;

Dentre os fatores objetivamente avaliados nesse estudo, encontrou-se uma grande dependência dos valores de LTE em relação às deflexões, à presença de dispositivos de transferência de carga, à temperatura do concreto, e, em última estância, dos valores de reação do suporte, no que seriam inclusos o subleito e as bases empregadas nas pistas experimentais. Bases em CCR, como parece ocorrer, são muito favoráveis à estrutura do pavimento como um todo, do ponto de vista de carregamentos do tráfego: melhoram a reação de apoio além de dividir estruturalmente esforços com as placas de concreto.

Todavia, com o aumento significativo do módulo de reação do sistema de apoio observado para as estruturas de pavimentos com bases em CCR, a tendência de maiores tensões por empenamento se agrava.

O estudo pode claramente permitir o entendimento do conceito de que módulo de reação do subleito é uma propriedade da estrutura como um todo e não simplesmente, como muitas vezes se faz crer, dos solos de fundação.

Futuros estudos com avaliação de abertura de juntas e temperaturas no interior do concreto, correlacionados com provas de carga em juntas, com e sem barras de transferência de carga, poderão permitir a modelagem matemática de LTE em 
função dos diversos parâmetros, para emprego em projetos e análises estruturais de pavimentos de concreto simples. 


\section{REFERÊNCIAS BIBLIOGRÁFICAS}

AMERICAN CONCRETE INSTITUTE. Sprayed concrete technology. New York. 1996.

AMERICAN ASSOCIATION OF STATE HIGHWAY AND OFFICIALS. Guide for design of pavement structures. ISBN 1-56051-055-2, Washington, D.C., 1986.

Supplement to the AASHTO guide for design of pavement structures - part II - Rigid pavement design \& rigid pavement joint design. ISBN 1-56051-078-1, Washington D.C., 1998.

AMERICAN CONCRETE PAVEMENT ASSOCIATION. Effect of pavement surface type on fuel consumption. Skokie, 1989.

BALBO, J. T. Aplicação do método dos elementos finitos na avaliação estrutural de pavimentos rígidos rodoviários. Dissertação (Mestrado). Escola Politécnica da Universidade de São Paulo, São Paulo,1989.

BALBO, J.T.; SEVERI, A.A.; RODOLFO, M.P.; PEREIRA, D. da S. Pesquisa dos efeitos do clima sobre pavimentos de concreto - instrumentação da pista experimental na USP. In: Panorama Nacional da Pesquisa em Transportes 2000, Cd-rom, Associação Nacional de Ensino e Pesquisa em Transportes, Gramado. 2000.

BALBO, J. T.; SEVERI, A. A. Thermal gradients in concrete pavements in tropical environment: an experimental appraisal. In: Transportation Research Record no 1809, TRB, pp.12-22, Washington, D.C., 2002.

BALBO, J. T. Pavimentação asfáltica: materiais, projeto e restauração. Oficina de Textos, São Paulo, 2007. 
BIAN, Y., KOHLER, E., HARVEY, J. T. Laboratory Evaluation of Fiber Reinforced Polymer Dowel Bars for Jointed Concrete Pavements. TRB, $86^{\text {th }}$ Annual Meeting Compendium of Papers (CD-ROM), 2007.

BODOCSI, A.; MINKARAH, I. A.; ARUDI, R. S. Analysis of Horizontal Movements of Joints and Cracks in Portland Cement Concrete Pavements. In: Transportation Research Record $\mathrm{n}^{\circ}$ 1392, pp. 43-52. TRB, National Research Council, Washington, D.C., 1993a.

BODOCSI, A.; MINKARAH, I. A.; YOUNG, C.C.; MILLER, R.A.; ARUDI, R. S. Comparison of Four Different Methods for Measuring Deflection in Jointed Reinforced Concrete Pavements. In: Transportation Research Record n⿳ 1388, pp. 29-34, TRB, National Research Council, Washington, D.C., 1993b.

BRADBURY, R. D. Reinforced Concrete Pavements. Wire reinforced Institute, Washington, D.C., 1938.

BUCH, N. Factors Affecting Load Transfer Across Transverse Joints in Jointed Concrete Pavements. American Concrete Institute (Recent Developments in the Design and Specification of Concrete Pavement Systems), SP 181-3, Michigan, 1989.

BUCH, N. Factors Affecting Load Transfer Across Transverse Joints in Jointed Concrete Pavements. In: Recent Developments in the Design and Specification of Concrete Pavement Systems, American Concrete Institute, SP-181, pp.43-64, Farmington Hills, 1999.

BUCH, N.; VONGCHUSIRI, K.; GILLILAND, D.; DAM, T. V. A preliminary mechanistic evaluation of pcc cross-sections using islab2000 - a parametric study. Michigan Department of Transportation, Research Report RC-1441, Final Report, Lansing, 2004. 
COLLEY, B. E.; HUMPHREY, H. A. Entrosagem de Agregados em Juntas de Pavimentação de Concreto de Cimento Portland. $2^{\circ}$ Simpósio sobre Pesquisas Rodoviárias, Rio de Janeiro, Brasil, 1966.

CROVETTI, J.A. Design and Evaluation of Jointed Concrete Pavement Systems Incorporating Open-Graded Permeable Bases. Ph.D. Dissertation, University of Illinois at Urbana-Champaign, 1994.

CROVETTI, J. A. Deflection-Based Analysis Techniques for Jointed Concrete Pavements Systems. In: Transportation Research Record no 1809, TRB, pp. 3-11, Washington, D.C., 1997.

DARTER, M. Design of Zero-maintenance Plain Jointed Concrete Pavement Development of design procedures. U. S. Department of Transportation, FHWA - 77 - 11, vol. I, Washington, D.C. 1977.

EDDIE, D..; SHALABY, A.; RIZKALLA, S. Glass Fiber-Reinforced Polymer Dowels for Concrete Pavements. ACI Structural Journal, vol. 98, n.2, p. 201-206, 2001.

FEDERAL HIGHWAY ADMINISTRATION. Pavement rehabilitation manual. FHWA-ED-88-025, Washington, D.C., 1990.

FLEURY, R. H. C. G. O.; GUIMARÃES, G. N. Estudo experimental de mecanismos de transferência de esforços em juntas de pavimento rígido. In: Anais (Cd-rom) da 37a . Reunião Anual de Pavimentação, Associação Brasileira de Pavimentação, Goiânia, 2006.

FRIBERG, B. F. Load and deflection characteristics of dowels in transverse joints of concrete pavements. Transactions of the American Society of Civil Engineers, vol. 105, pp. 140-161, 1938. 
FURNAS CENTRAIS ELÉTRICAS S.A. Programa Intelaboratorial de Ensaios de Concreto 2000. DCT.T.1.153.2000 - RO - VI, Goiânia, 2000.

HALL, K.; DARTER, M.I.; HOERNER, T.E.; KHAZANOVICH, L. LTPP data analysis: Phase I: Validation of guidelines for $\mathbf{k}$-value selection and concrete pavement performance prediction. U.S. Department of Transportation, FHWA-RD-96-198, Washington, D.C., 1997.

HALL, K. T. Performance, Evaluation, and Rehabilitation of asphalt-overlaid concrete pavements. Ph.D. thesis. University of Illinois at Urbana-Champaign, 1991.

HOUBEN, L. J. M. Finite-elements analysis of plain concrete pavements subjected to temperature gradients and traffic loadings. In: International Workshop on the Design and Evaluation of Concrete Pavements, $3^{\text {rd }}$ Proceedings. CROW, pp. 141-173, Krumbach, 1994.

HUANG, Y. H. Pavement analysis and design. Prentice Hall, Inc. New Jersey, 1993.

IOANNIDES, A.M. CEE 607-Pavement Design: Supplementary Class Notes, University of Cincinnati, 1999.

IOANNIDES, A. M.; KOROVESIS, G. T. Aggregate interlock: a pure-shear load transfer mechanism. Transportation Research Board, TRR no 1286, pp. 14-24, Washington, DC, 1990.

IOANNIDES, A.M.; KOROVESIS, G.T. Analysis and design of doweled slab-ongrade pavement systems. American Society of Civil Engineers, Journal of Transportation Engineering, Vol. 118, No. 6, pp. 745-768, New York, 1992. 
JEONG; JIN-HOON; LEE, J-H; SUH, Y-G; ZOLLINGER, D. Effect of slab curling on movement and load transfer capacity of saw-cut joints. In: Transportation Research Record no 1947, TRB, pp. 69-78 National Research Council, Washington DC, 2006.

KHAZANOVICH, L. Structural analysis of multi-layered concrete pavement systems. Ph.D. Thesis, University of Illinois, Urbana, IL. 1994.

KHAZANOVICH, L.; BUCH, N.; GOTLIF A. Mechanistic evaluation of vertical misalignment of dowel bars and their effect on joint performance. In: Proceedings, $7^{\text {th }}$ International Conference on Concrete Pavement, International Society for Concrete Pavements, pp. 525-538, Lake Buena Vista, 2001.

KHAZANOVICH, L.; GOTLIF, A. Evaluation Of joint and crack load transfer. Final Report, Federal Highway Administration, FHWA-RD-02-088, Washington, D.C., 2003.

KHAZANOVICH, L. Execução de juntas e transferência de cargas em pisos de concreto: controvérsias e fatos reais. Tradução: José Tadeu Balbo. Revista Concreto \& Construções, Instituto Brasileiro do Concreto, $n^{0}$. 45, ISSN 1809-7197, pp.15-18, São Paulo. 2007.

KHAZANOVICH, L.; YU, H.T.; RAO, S.; GALASOVA K.; SHATS E; JONES R. ISLAB2000 - Finite element analysis program for rigid and composite pavements. User's Guide. Champaign, IL: ERES Consultants. 2000.

LEE, S. W.; STOFFELS, S. M. Analysis of in situ horizontal joint movements in rigid pavements. In: Transportation Research Record no 1778, TRB, pp. 09-16, Washington, D.C., 2001.

MALISCH, W. R. Move over, round dowels. Concrete Construction, Publication CO0L034, 2000. Disponível em: www.pna-inc.com/articles/move overrd.pdf. Acesso em 23-10.2008. 
NISHIZAWA, T.; SHIMENO, S; KOMATSUBARA, A.; KOYANAGAWA, M. Study on thermal stresses in continuously reinforced concrete pavement. In: Transportation Research Record $n^{\circ}$ 1629, TRB, pp. 99-107, Washington, D.C., 1989.

OLIVEIRA, P. L. Projeto estrutural de pavimentos rodoviários e pisos industriais de concreto. Dissertação (Mestrado). Escola de Engenharia de São Carlos, Universidade de São Paulo, São Carlos, 2000.

PEREIRA, D. S.; BALBO, J.T.; KHAZANOVICH, L. Theoretical and field evaluation of interaction between ultra-thin whitetopping and existing asphalt pavement. International Journal of Pavement Engineering, vol.7, no. 4, pp. 251-260, 2006.

PITTMAN, D. W. Load transfer characteristics of roller-compacted concrete pavement joints and cracks. In: Transportation Research Record $\mathrm{n}^{\circ}$ 1525, TRB, pp.01-09 Washington, D.C., 1996.

PREFEITURA DO MUNICÍPIO DE SÃO PAULO. Dimensionamento de pavimentos de concreto. IP-07/2004, São Paulo, 2004.

POBLETE, M., VALENZUELA, R.; SALSILLI R. Load transfer in undoweled transverse joints of PCC pavements. Transportation Research Record 1207, Washington, D. C, 1988.

PORTLAND CEMENT ASSOCIATION. Pavements. Disponível em: http://www.cement.org/pavements/pv_cp_general.asp. Acesso em: 13/11/08.

PORTLAND CEMENT ASSOCIATION. Thickness design for concrete pavements. Chicago, 1966.

PORTLAND CEMENT ASSOCIATION. Thickness design for concrete hightway and street pavements. EB109P, Skokie, 1984. 
RICCI, G. Estudo das características mecânicas do concreto compactado com rolo com agregados reciclados de construção e de demolição para pavimentação. Dissertação (Mestrado), Escola Politécnica da Universidade de São Paulo, São Paulo, 2007.

RODOLFO, M. P. Análise de tensões em pavimentos de concreto com base cimentada e sujeitos a gradientes térmicos. Dissertação (Mestrado), Escola Politécnica da Universidade de São Paulo, São Paulo, 2001.

RODOLFO, M.P.; BALBO, J.T. Modelagem de tensões em pavimentos de concreto submetidos a gradientes térmicos e cargas rodoviárias. In: Transporte em Transformação V, Makron Books e Confederação Nacional do Transporte, Cap.7, pp.101-117, São Paulo, 2002.

RODRIGUES, L. F. Juntas em pavimentos de concreto. Caderno de Engenharia de Estruturas, São Carlos, vol. 8, pp. 37-40, 2006.

RODRIGUES, L. F. Juntas em pavimentos de concreto: dispositivos de transferência de carga. Tese (Doutorado), Escola de Engenharia de São Carlos, Universidade de São Paulo, São Carlos. 2008.

RODRIGUES, L. F.; PINHEIRO, L. M.; GUINAMÃES, G. N. Joints in plain concrete pavements: an experimental study of load transfer mechanisms. Proceedings of the International Workshop on Best Practices for Concrete Pavements (Cd-rom), Brazilian Concrete Institute, Recife, 2007.

RODRIGUES, P. P. F., BOTACINI, S. M., GASPARETTO, W.E. Manual gerdau de pisos industriais. Editora PINI Ltda., 1ª edição, São Paulo, 2006.

RODRIGUES, P. P. F.; CASSARO, C. F. Pisos industriais de concreto armado. Instituto Brasileiro de Telas Soldadas, 1998. 
SEVERI, A. A. Estudos de gradientes térmicos em pavimentos de concreto de cimento portland em ambiente tropical. Tese (Doutorado), Escola Politécnica da Universidade de São Paulo, São Paulo, 2002.

SHAHIN, M. Y. Use of the falling weight deflectometer for the non-destructive deflection testing of jointed concrete airfield pavements. In: Proceedings, $3^{\text {rd }}$ International Conference on Concrete Pavement Design and Rehabilitation, Purdue University, pp. 549-556, 1985.

SNYDER, M. B. Best practices for concrete pavement construction. In: Proceedings of the International Workshop on Best Practices for Concrete Pavements (Cd-rom), Brazilian Concrete Institute, Recife, 2007.

SPANGLER, M.G. Stresses in corner region of concrete pavements. Bulletin 157, Engineering Experiment Station, lowa State College, Ames, 1942.

TELLER, L. W.,; CASHELL H. D. Performance of doweled joints under. Repetitive Loading. Public Roads, Vol. 30, pp. 1-24. 1958.

TERTULIANO, G. Avaliação experimental de mecanismos de transferência de esforços cisalhantes em juntas de pavimentos rígidos. Dissertação (Mestrado) Universidade Federal de Goiás. 2005.

VANDENBOSSCHE, J. M. Effects of slab temperature profiles on the use of falling weight deflectometer data to monitor joint performance and detect Voids. In: Transportation Research Board Annual Meeting, Compendium of papers (Cd-rom), Washington, D. C., 2007.

WALKER, W. W.; HOLLAND, J. A. Plate dowels for slabs on ground. $\mathrm{ACl}$ Structural Journal. $\mathrm{n}^{\circ}$ 7, vol. 20, p 32-38, 1998. 
WESTERGAARD, H. M. Analysis of stresses in concrete pavements due to variations of temperature. In: Proceedings of the 6th Annual Meeting of the Highway Research Board, pp. 201-215, Washington, D.C., 1926.

WU, C.L.; TIA, M. Development of a rational thickness design method for rigid pavements. Transportation Research Record 1227, pp,205-218 Washington, D.C. 1989.

YODER, N. C.; WITZACK, M. W. Principles of pavement design. 2 ed., John Wiley and Songs. New York, 1975.

ZOLLINGER, D.G. Curing and finishing concrete pavements. Proceedings of the International Workshop on Best Practices for Concrete Pavements. Brazilian Concrete Institute and International Society for Concrete Pavements, Recife, (Cdrom), 2007.

ZOLLINGER, D.G.; SOARES, J. Performance of continuously reinforced concrete pavements: volume vii: summary. Final Report, Federal Highway Administration, PCS Law Engineering, FHWA-RD-98-102, Washington, D.C., 1999.

ZOLLINGER, D. G.; BARENBERG, E. J. A Mechanistic based design procedure for jointed concrete pavements. In: Proceedings, $4^{\text {th }}$ International Conference on Concrete Pavement Design and Rehabilitation, Purdue University, pp. 75-97, 1989. 


\section{VITA}

Glenda Maria Colim, natural de Brasília (14.02.1981), Distrito Federal, é engenheira civil (2005) pela Universidade Estadual de Goiás.

Iniciou seu programa de mestrado em 2006 sob orientação do Prof. Dr. José Tadeu Balbo, tendo tido a colaboração durante o mês de julho de 2006 do Prof. Dr. Lev Khazanovich, da Universidade de Minnesota, no aprendizado de retroanálises com o programa ISLAB2000.

Entre 2006 e 2007 prestou assistência na organização do International Workshop on Best Practices for Concrete Pavements, realizado pela EPUSP, pelo IBRACON e pela ISCP em Recife. De julho de 2007 a dezembro de 2008 participou da equipe da EPUSP que realizou um plano de gerência de pavimentos urbanos para o município de Suzano (SP).

Atualmente atua no ramo da construção civil como engenheira do setor comercial de empresa de edificações na cidade de Goiânia (GO). 